MARGARETE Misselwitz, KLAUS SCHLichte ( HG.)

Politik der Unentschiedenheit

Die internationale Politik und ihr Umgang mit Kriegsflüchtlingen

[transcript] 
Margarete Misselwitz, Klaus Schlichte (Hg.)

Politik der Unentschiedenheit 

Margarete Misselwitz, Klaus Schlichte (Hg.)

\section{Politik der Unentschiedenheit}

Die internationale Politik

und ihr Umgang mit Kriegsflüchtlingen

[transcript] 


\section{(9) $(1) \Theta$}

Dieses Werk ist lizenziert unter der Creative Commons AttributionNonCommercial-NoDerivs 4.0 Lizenz (BY-NC-ND). Diese Lizenz erlaubt die private Nutzung, gestattet aber keine Bearbeitung und keine kommerzielle Nutzung. Weitere Informationen finden Sie unter https://creativecommons.org/licenses/by-nc-nd/4.o/deed.de/. Um Genehmigungen für Adaptionen, Übersetzungen, Derivate oder Wiederverwendung zu kommerziellen Zwecken einzuholen, wenden Sie sich bitte an rights@transcript-verlag.de

\section{(C) 2010 transcript Verlag, Bielefeld}

Die Verwertung der Texte und Bilder ist ohne Zustimmung des Verlages urheberrechtswidrig und strafbar. Das gilt auch für Vervielfältigungen, Übersetzungen, Mikroverfilmungen und für die Verarbeitung mit elektronischen Systemen.

\section{Bibliografische Information der Deutschen Nationalbibliothek}

Die Deutsche Nationalbibliothek verzeichnet diese Publikation in der Deutschen Nationalbibliografie; detaillierte bibliografische Daten sind im Internet über http://dnb.d-nb.de abrufbar.

Umschlagkonzept: Kordula Röckenhaus, Bielefeld Lektorat \& Satz: Margarete Misselwitz, Klaus Schlichte Druck: Majuskel Medienproduktion $\mathrm{GmbH}$, Wetzlar Print-ISBN 978-3-8376-1310-0 PDF-ISBN 978-3-8394-1310-4

Gedruckt auf alterungsbeständigem Papier mit chlorfrei gebleichtem Zellstoff.

Besuchen Sie uns im Internet: $h t t p: / / w w w . t r a n s c r i p t-v e r l a g . d e$ Bitte fordern Sie unser Gesamtverzeichnis und andere Broschüren an unter: info@transcript-verlag.de 


\section{INHALT}

Kriegsflucht: Neue Blicke auf ein altes Thema

MARGARETE MisSELWITZ/KLAUS SCHLICHTE

POLITIK DES BESCHRÄNKTEN ZUGANGS

Flucht und Asyl - zur Genealogie eines Feldes 23

KLAUS SCHLICHTE

Sicherheit und Immigration:

$\mathrm{Zu}$ einer Kritik der Gouvernementalität des Unbehagens

DIDIER BIGO

Möglichkeiten und Grenzen des internationalen Flüchtlingsschutzes für kolumbianische Flüchtlinge in Ecuador 77

KATJA BALTZER/KRISTOFER LENGERT

Afrikanische Staaten, Staatsbürgerschaft und Krieg:

Die Region der Großen Seen

MAHMOOD MAMDANI

\section{EXIL: ZWISCHENLEBEN}

Die Militarisierung liberianischer Flüchtlinge in Guinea $\quad 135$

FELIX GERDES

Schuld und Sühne: Mechanismen der Finanzierung von

Bürgerkriegen aus der Diaspora

KATRIN RADTKE 
Palästinensische Flüchtlingslager neu denken:

Von Abhängigkeit zu ziviler Selbstverwaltung

PHILIPP MISSELWITZ

\section{RÜCKKEHR IN DIE FREMDE}

Palästinenser im Exil und nach ihrer Rückkehr

PÉNÉLOPE LARZILLIÈRE

Nach der Abschiebung:

Abgeschobene Jugendliche aus Deutschland im Kosovo 263

MARGARETE MISSELWITZ

Autorinnen und Autoren 


\title{
Kriegsflucht: Neue Blicke auf ein altes Thema
}

\author{
MARGARETE MisSELWITZ/KLAUS SCHLICHTE
}

Mit der Europäisierung der Asylpolitik, den Skandalen um die Abschiebung von Flüchtlingen und ihren Angehörigen aus verschiedenen europäischen Ländern und der Persistenz der Lager als Form der Kasernierung von juristisch nicht eindeutig kategorisierbaren Menschen hat das Thema der Flucht in den vergangenen Jahren publizistisch und politisch wieder an Beachtung gewonnen. Im Vordergrund der Diskussionen stehen dabei vor allem Themen wie die "gerechte" Verteilung von Flüchtlingen in Europa, der Integration und der Kampf gegen illegale Migration. Fast durchgängig wird das Thema der Kriegsflucht als ein »Problem « für die Aufnahmegesellschaften, das internationale Recht oder für die Kooperation zwischen Staaten thematisiert.

Mit dem vorliegenden Band möchten wir das Forschungsfeld der Kriegsflucht auf eine andere Weise markieren. Statt von vornherein aus einer nationalstaatlich gerahmten Perspektive zu interpretieren, sollen in diesem Band die Zustände der Flüchtlinge selbst, ihre Erfahrungen und Problemlagen im Mittelpunkt stehen. Beide Perspektiven, die dem staatlichen Denken nahe, und damit klassische Politikwissenschaft, wie die Perspektive der »Politik von unten« (vgl. Bayart et al. 1992) sind 
notwendig komplementär, um diesen Gegenstand in den Blick zu nehmen.

Das Phänomen der Kriegsflucht erschöpft sich zwar nicht in den einzelnen Erfahrungen der Betroffenen, in ihren Strategien des Umgangs und den unvollständigen Lösungen, die sie für die Disruptionen ihrer Biographien entwickeln. Doch diese Erfahrungen von Macht und Herrschaft sind das eigentlich Politische der Kriegsflucht, so dass eine Beschäftigung, die sich nur auf Regularien und staatliche Politiken beschränkt, am eigentlichen Gegenstand vorbeilaufen würde.

Die Perspektive der »Politik von unten « hat es in der sozialwissenschaftlichen Auseinandersetzung mit dem Thema Kriegsflucht bisher nicht gegeben. Vor der erneuten Aufmerksamkeit der vergangenen Jahre hat das Themengebiet in der politikwissenschaftlichen wie in der soziologischen Debatte der letzten zwanzig Jahre zumal in Deutschland überhaupt wenig Beachtung erfahren. In der alten Bundesrepublik hatte sich mit dem Schlagwort der "Asylantenflut « die Diskussion auf asylrechtliche Fragen zugespitzt (vgl. Kimminich 1983). Die politikwissenschaftliche Forschung in Deutschland setzte sich in den Folgejahren mit dem Thema entweder nur in Überblicken (Opitz 1988) oder in der Form von Einführungen (Nuscheler 1995) auseinander.

Große Aufmerksamkeit hat das Thema der Kriegsflucht und damit zusammenhängenden Asylpolitik vor allem als Teil der Europa-Forschung erfahren, besonders unter der Frage der Möglichkeiten und Grenzen der Vergemeinschaftung von Politikfeldern (vgl. Angenendt 2004). Das Flüchtlings-»problem《 wird dabei vor allem als Herausforderung unter den Aspekten der Sicherheit und der Integration thematisiert (vgl. Münz u.a. 1999). In jüngerer Zeit wurde das Thema der Flucht- und Asylpolitik dann unter dem Eindruck der dramatischen Entwicklungen um das Mittelmeer diskutiert: Die Externalisierung der EU-Grenzen und das massive Vorgehen einzelner EU-Staaten auch außerhalb ihrer Territorien scheinen neue Formen koordinierter internationaler Politik anzunehmen, die sich nur euphemistisch als "global governance» bezeichnen ließen (vgl. Huysmans 2006).

Eine Beschäftigung mit Kriegsflüchtlingen aus der Perspektive der Flüchtlinge selbst ist dagegen vor allem durch die in 
diesem Feld engagierten Nichtregierungsorganisationen geschehen, genügt aber kaum wissenschaftlichen Ansprüchen. Eine soziologische Auseinandersetzung mit den Institutionen und Politiken der Kriegsflucht hat in den vergangenen Jahren gerade erst begonnen (vgl. z.B. Inhetveen 2006, Bernardot 2008).

Eine phänomenologisch orientierte Forschung, die wir mit diesem Band anstoßen wollen, existiert zur Frage der Kriegsflucht und $\mathrm{zu}$ ihren mikrosozialen und mikropolitischen Dimensionen bisher nicht. Dazu soll dieser Band ein erster Beitrag sein. Er kann dieses Forschungsfeld noch nicht abdecken, sondern nur anregen, sich aus dieser Perspektive näher mit dem Phänomen der Kriegsflucht und ihren politischen Implikationen auseinanderzusetzen.

Die Mehrzahl der hier versammelten Beiträge befasst sich mit Flüchtlingsfragen außerhalb der OECD-Welt, in der zum einen im Vergleich zur westlichen Welt die weltweit größten Flüchtlingsbewegungen stattfinden. Zum andern ist über die dortigen Mechanismen, Bedingungen und Dynamiken von Kriegsflucht und Flüchtlingspolitik am wenigsten bekannt. Sowohl theoretisch unterschiedlich orientierte wie auch historische Zugänge sollen Bedingungen und Dynamiken von Flüchtlingspolitik aufdecken und aus der Perspektive der Betroffenen einen neuen Blick auf die Formen, Praktiken und Grenzen des Flüchtlingsschutzes und der Politik von Staaten und internationalen Organisationen freigeben. Zur Systematisierung der verschiedenen Facetten des Themas haben wir für unseren Sammelband die thematische Aufteilung in »Politik des beschränkten Zugangs", "Exil: Zwischenleben" und "Rückkehr in die Fremde« vorgenommen.

Das Thema Kriegsflucht ist bei weitem noch nicht mit der Bearbeitung von Fluchtursachen im Herkunftsland erschöpft. Oft stellt die Flucht vor Gewalt lediglich den Beginn einer manchmal Generationen anhaltenden Problematik dar. Die meisten Kriegsflüchtlinge stehen nach ihrer Flucht aus dem Herkunftsland vor ganz neuen Problemen. Sie scheinen, aber dies wäre in empirischen Forschungen genauer zu untersuchen, teils aus "Lösungen « zu resultieren, die vom Aufnahmeland oder auch internationalen Organisationen in ihrem Bedürfnis nach Regulierung entworfen wurden. 
Staaten tun sich in der Regel schwer im Umgang mit Flüchtlingen und der Frage, welche Rechte sie ihnen zugestehen sollen. Sie halten sie meist in einem Zustand der Unentschiedenheit. Größtenteils weigern sie sich, den Flüchtlingen die notwendigen Grundvoraussetzungen für eine Integration bereitzustellen und beschränken Zugangsrechte zum Arbeitsmarkt, zur Politik und Land oder versuchen prinzipiell die Grenzen vor Einwanderung zu verschließen. Die Zustände der Unentschiedenheit, das Leben im »Dazwischen «, die blockierte Biographie, das scheinen kontextübergreifend Merkmale der Existenz von Flüchtlingen zu sein.

\section{Die Inhalte der Beiträge}

Im Teil »Politik des beschränkten Zugangs« dieses Bandes entsteht der Eindruck, als habe die Asylpolitik in den vergangenen Jahrhunderten eine Art Umkehrung erlebt. Der ursprüngliche Wortsinn bezeichnete ein Verbot des Zugriffs auf die sonst Entrechteten, während sich in der heutigen Debatte eine Art Verbot des Zugangs als das "Asylproblem « darstellt. Die Verstaatlichung der Welt scheint es Kriegsflüchtlingen zunehmend schwerer zu machen, sich über die Grenzen von Staaten hinweg in Sicherheit zu bringen.

Die Politik mit Flüchtlingen ist selbst ein historisches Phänomen. Im Beitrag von Klaus Schlichte wird der Frage nachgegangen, was sich gegenwärtig über die Genealogie des Asyls als Rechtsform und Praxis sagen lässt. Die vorstaatlichen Formen des Asyls deuten daraufhin, dass sich hier, wie in vielen anderen sozialen Feldern, im Verlauf des 19. und 20. Jahrhunderts ein Prozess der staatlichen Aneignung dieses Rechts ereignet hat, die eng mit der Entstehung und Ausbreitung der neuzeitlichen Gouvernementalität verbunden zu sein scheint. Jedenfalls hat die Trias aus Souveränität, Territorium und Bevölkerung, die von Michel Foucault als Leitvorstellungen der neuzeitlichen Gouvernementalität herausgestellt wurden, sich global verbreitet. Die Frage, die sich aus den im Text versammelten Beobachtungen ableiten ließe, wäre darauf gerichtet, zu prüfen, ob sich im Gefolge dieser Bewegung eigentlich ein $\mathrm{Zu}-$ wachs oder ein Verlust von Freizügigkeit in der Weltgesellschaft beobachten lässt. Gegenwärtig deutet die Entwicklung 
wohl eher auf eine Einschränkung der Möglichkeiten hin, bei innerstaatlicher Verfolgung Schutz zu finden.

Mit dem Beitrag von Didier Bigo stellen wir einen der avanciertesten Versuche vor, die Gründe für eine Tendenz zu erfassen, Asylbewerber und Migranten überhaupt zu einem Sicherheitsproblem zu machen. Seine Interpretation, die sich wesentlich auf Konzepte und Theoreme Michel Foucaults und Pierre Bourdieus stützt, stellt dabei nicht nur die diskursive Produktion des "gefährlichen Migranten" in den Mittelpunkt (vgl. Schiffauer 2008; Eckert 2009), sondern sie begreift die »Politik des Unbehagens « als Ergebnis einer Konvergenz: Die institutionellen Interessen von Sicherheitsagenturen wie Militär, Polizei und Geheimdiensten mit privatwirtschaftlichen Interessen und einer alarmistischen Publizistik hat zur Herausbildung eines - mit Bourdieu gesprochen - Feldes der Sicherheit geführt, das sich unpolitisch präsentiert und weitgehend losgelöst von öffentlicher und wissenschaftlicher Kontrolle »Risiken" diskursiv produziert, von deren Bearbeitung dann diese Produzenten leben. Die sozialwissenschaftliche Forschung zu diesem Thema, so Bigo, sollte jedoch nicht vergessen, auch die Praktiken dieser Politik, die Technologien der Überwachung und der Bürokratie, der Verwaltung und der Kontrolle in den Blick zu nehmen, weil sich erst aus beidem, aus Diskursen und aus den Praktiken, ein angemessenes Bild dieser Politik entwickeln lasse.

An Bigos Text wird deutlich, dass das Thema der Kriegsflucht in vielfältiger Weise auch mit den politischen Diskussionen in Deutschland und Europa verbunden ist. Nicht nur wirkliche oder mögliche Bewegungen von Flüchtlingen innerhalb Europas oder über Europas Grenzen hinweg machen das Thema für die politische und politikwissenschaftliche Diskussion relevant. Seine Bedeutung liegt auch darin, dass hier wie in anderen Weltgegenden die Wirklichkeit von internationaler Politik noch einmal auf ganz andere Weise deutlich wird, als dies in der staatszentrierten Fassung der »Internationalen Beziehungen « als Subdisziplin der Politikwissenschaft der Fall ist. Kriegsflucht ist ein politisches Phänomen, das auf enge Weise mit den konstituierenden Grundprinzipien internationaler Politik verbunden ist. An ihr wird, folgt man Bigo, deutlich, wie die Mechanismen der Produktion von Bedeutung und »Gefahren« 
funktioniert und wie sich, oft losgelöst von empirisch tatsächlich vorfindlichen Gegebenheiten, Diskurse entwickeln, die in der Öffentlichkeit unhinterfragt bleiben, zugleich aber leitend für politisches Handeln werden. Ähnliche Beobachtungen lassen sich in den Diskursen über »internationalen Terrorismus «, das »Scheitern von Staaten « oder die »organisierte Kriminalität« ausmachen (vgl. Schlichte 2006).

Für die Flüchtlinge bedeutet die Erfahrung der Flucht und die abweisende staatliche Politik vor allem ein Warten auf endgültige Entscheidungen, ohne die eine Normalisierung ihres Lebens nicht möglich ist und deren Ausbleiben sie als Fremde von allgemeinen Rechten ausschließt. Wer daran aus welchen Gründen Interesse hat, was das für die Flüchtlinge heißt, wie man sich einrichtet in einem Leben der Ungewissheit, das sind zentrale Gegenstände in den nachfolgenden Beiträgen dieses Bandes.

Der Beitrag von Katja Baltzer und Kristofer Lengert zu kolumbianischen Flüchtlingen in Ecuador zeigt, wie internationale Organisationen über die selektive Vergabe des Flüchtlingstitels Zugangsrechte zum Aufnahmeland auch beschränken. Auf der Grundlage eines Forschungsaufenthaltes in Ecuador beschreiben die AutorInnen Praktiken und Probleme bei der Vergabe des Flüchtlingsstatus durch den UNHCR und gehen auf die Schwierigkeiten von illegalisierten Kolumbianern in Ecuador ein. Gerade in diesem Beitrag wird deutlich, dass die Politik internationaler Organisationen noch einmal bereichernd aus einer phänomenologischen Perspektive betrachtet werden kann. Die teilnehmende Beobachtung der Arbeit des UNHCR, die diesem Beitrag zugrunde liegt, macht über die beobachtbaren Praktiken klar, dass es eine regelrechte bürokratische Produktion von Flüchtlingen gibt, deren Mechanismen hier erst in Umrissen erkennbar werden.

Der übersetzte Zeitschriftenbeitrag von Mahmood Mamdani beschreibt die Situation in der Region der »Großen Seen «, wo die politischen Ereignisse der Staaten Ruanda, Burundi, Uganda und DR Kongo über die kriegsbedingten Migrationen eng miteinander verflochten sind. Dabei arbeitet Mamdani heraus, wie die durch den Kolonialismus eingeführte Institutionalisierung von "Einheimischen « und »Einwanderern" in den Rechtssystemen der postkolonialen Staaten fortwirken und hinsicht- 
lich dieser Trennung Staatsbürgerschaftsrechte vorenthalten werden, was für die Konfliktivität der Region mitursächlich ist. Diese Perspektive ermöglicht es auch zu erkennen, wie über die Frage von Kriegsflucht und - zumeist verweigerter Staatsbürgerschaft - eine Verkettung der Bürgerkriege in der Region eingesetzt hat. Der Beitrag zeigt damit sehr eindringlich, wie konfliktiv die mangelhafte politische Bearbeitung der Kriegsflucht wirken kann - bis hin zur Verursachung weiterer Kriege.

Im zweiten Teil des Bandes mit dem Titel »Exil: Zwischenleben " wird das interimistische der Flüchtlingsexistenz an ganz unterschiedlichen Phänomenen deutlich. Ein Kennzeichen dieses Zustandes ist schon seine unbekannte Dauer. Nicht nur die oft peripheren Orte, in denen Flüchtlinge untergebracht werden, sondern auch die zeitliche Unbestimmtheit ihres Zustandes und die Anwesenheit unter Fremden charakterisieren also dieses »Zwischen «.

Im Beitrag von Felix Gerdes wird erneut eine Verkettung von Fluchtbewegungen und kriegerischen Ereignissen erkennbar, in diesem Fall in Westafrika. Liberianische Mandingo, die im Zuge des Bürgerkrieges in Liberia nach Guinea flohen, waren teils gezwungen, in Flüchtlingslager zu leben, die dann zu Rekrutierungszonen für liberianische Kriegsparteien wurden. Aber auch jene Mandingo, die nach dem Ende des ersten liberianischen Bürgerkrieges nach Liberia zurückkehrten, hatten Schwierigkeiten, ihre verlassenen Besitztümer wieder zu erhalten. Die Rückkehr, wie in diesem Beitrag erkennbar wird, ist keine einfache Herstellung des status quo ante. Die Wechselfälle der aus Liberia geflohenen Mandingo zeigen aber auch, dass diese nicht bloß negative Sanktionen gewärtigten, sondern dass sie selbst auch Teil der legitimationsheischenden Politik der Kriegsakteure wurden, die teils auf ihre Unterstützung angewiesen waren. Wie im Beitrag von Katrin Radtke wird deutlich, dass sich die Beziehungen zwischen Geflohenen und Kriegsakteuren ständig auf einem Kontinuum zwischen Zwang und Werbung bewegen. Trotz ihrer Marginalisierung blieben die geflohenen Mandingo Teil der Muster patrimonialer Herrschaft in beiden westafrikanischen Staaten.

An der ambivalenten Haltung der guineischen Regierung und Bevölkerung wird der »Zwischen«-Status, der verlängerte 
Zustand der Flucht, besonders deutlich. Während sich auf dem afrikanischen Kontinent noch recht häufig beobachten lässt, dass große Zahlen von Flüchtlingen ohne starke politische Verwerfungen integriert werden, hat die globale Ausbreitung des Modells der Staatsbürgerschaft und die damit einhergehende Codierung in »Staatsbürger « und »Fremde« die in früheren Jahrhunderten gängige einfache Integration erheblich kompliziert. Gegenwärtig lässt sich auch auf dem afrikanischen Kontinent beobachten, dass der Diskurs der Autochtonie, der einen Unterschied zwischen Einheimischen und Fremden einführt, enorm an Fahrt gewinnt (Cutolo 2008).

Aber nicht nur der Umgang von Staaten mit Kriegsflüchtlingen ist geprägt durch eine Politik der Unentschiedenheit. Flüchtlingsgemeinschaften entwickeln im Exil oft eine Eigendynamik, die von einer Verbundenheit zum Herkunftsland bestimmt ist und als ein transnationales »Zwischenleben « zwischen Exil und »Heimat « bezeichnet werden kann. Ihre Position als »Fremde« aber auch die Sehnsucht nach der Heimat, insbesondere vor dem Hintergrund schlechter Integrationsmöglichkeiten im Exil und ein Pflichtgefühl gegenüber den Zurückgebliebenen beeinflussen das Leben und Handeln im Exil. Gerade dieser Umstand ist nicht zuletzt auch für politische Akteure von Interesse, die dies zu ihrem eigenen Nutzen einsetzen.

Katrin Radtke beschreibt in ihrem Beitrag vergleichend die Situation von Kriegsflüchtlingen aus Sri Lanka und Eritrea im Exil und ihre Bindungen an die Herkunftsländer, die von einem Gefühl der Verpflichtung und durch Unterstützungsleistungen geprägt sind. Sie zeigt, wie in beiden Fällen die sich im Exil herausgebildete »moralische Ökonomie« der Flüchtlinge später zum Gegenstand der Politik der Kriegsakteure wurde, die mit Erfolg die in der Diaspora generierten Ressourcen für ihre politischen Zwecke nutzten. Der Beitrag stellt die Strategien und Konflikte in den Exilgemeinden dar und beleuchtet die politischen Implikationen dieser Verkettungen.

Philipp Misselwitz beleuchtet in seinem Beitrag »Palästinensische Flüchtlingslager neu denken« aus der Perspektive der Stadtentwicklung die räumliche Entwicklung von palästinensischen Flüchtlingslagern, an der sich interne Machtverhältnisse und soziale Entwicklungen innerhalb der Flüchtlingslager aber auch äußere politische Ereignisse ablesen lassen. Trotz der Kon- 
troll- und Reglementierungsversuche der zuständigen UNFlüchtlingsorganisation entwickelten die Flüchtlingslager gegenüber diesen zunehmend ein städtisches Eigenleben. Der Autor beschreibt das spannungsreiche Verhältnis zwischen dem politischen Recht auf Rückkehr und dem Recht auf ein Leben in Würde. Die Furcht vor dem Verlust des Rückkehrrechts machte jahrzehntelang eine dringend notwendige städtebauliche Verbesserung der hochverdichteten und verarmten Flüchtlingslager unmöglich. Ein von dem Autor entworfenes Programm für partizipative Entwicklungsplanung zur Verbesserung der Flüchtlingslager arbeitet die spezifischen Bedingungen, Potentiale und Notwendigkeiten in drei Lagern heraus, für die der paternalistische Ansatz der UN-Flüchtlingsorganisation weitestgehend blind war.

Der dritte Teil des Bandes beleuchtet unter dem Titel »Rückkehr in die Fremde« die Effekte der Wandlungen, die sich im Verlauf der Zwischenzustände ergeben. Denn während der Abwesenheit der Flüchtlinge geht der soziale Wandel in ihren Heimatgebieten fort, während sie sich zugleich in anderen Kontexten verändern. Die Rückkehr ist deshalb nie eine Rückkehr in alte Zustände, sondern eine neue Herausforderung mit neuen Unbekannten. Beide Beiträge dieses Teils zeigen, dass diese "Lösung « besonders für im Exil Geborene eine traumatische Erfahrung sein kann.

Die Rückkehr in das Herkunftsland wird von vielen Staaten aber auch vom UNHCR als die langfristig bestmögliche Lösung für das Flüchtlingsproblem angesehen. Der UNHCR stellt dafür im Vergleich zu den anderen beiden Optionen, »Integration « und "Weiterwanderung", die meisten Mittel zur Verfügung. Gleichzeitig erklären sich immer mehr Staaten nur noch bereit, Kriegsflüchtlinge lediglich temporär aufzunehmen. Mit der Ankunft der Flüchtlinge wird zugleich ihre Rückkehr erwartet. Das Leben im Exil - ob kurzfristig oder länger geplant - folgt aber eigenen Regeln und sozialisiert insbesondere die jüngere Generation in einer eigenen Weise, so dass speziell für sie die Rückkehr in die Heimat oftmals eine »Rückkehr in die Fremde« bedeutet.

Der auf eine französischsprachige Dissertation zurückgehende Beitrag von Pénélope Larzillière, »Junge Palästinenser im 
Exil und nach ihrer Rückkehr «, beschäftigt sich mit den Strategien und Lebensplänen junger Palästinenser, die nach einem längeren Auslandsaufenthalt nach Palästina zurückkehrten. Im Vordergrund steht ihre Haltung zum »nationalen Kampf« der Palästinenser, die durch den Auslandsaufenthalt Wandlungen erfährt. Der Beitrag macht zugleich noch einmal deutlich, wie eng das Phänomen der Kriegsflucht mit der Produktion von Staatenlosigkeit verbunden ist (vgl. a. Gousseff 2008; Vetters 2007), das im Zeitalter der Verstaatlichung der Welt nicht nur für die Betroffenen enorme Schwierigkeiten aufwirft, sondern auch von einer zunehmend bürokratisierten politischen Logik zum Problem erhoben wird.

Der letzte Beitrag von Margarete Misselwitz beschäftigt sich auf der Grundlage von im Kosovo geführten Interviews mit der Situation von aus Deutschland abgeschobenen Jugendlichen, die den kosovarischen Minderheiten der Aschkali und »Ägypter « angehören. Sie geht den Fragen nach, was eine erzwungene Rückkehr für die Betroffenen bedeutet, wie sie vor Ort damit umgehen und vor welchen Schwierigkeiten sie gegenüber der Mehrheits- aber auch gegenüber der Minderheitsgesellschaft stehen.

\section{Fragen der Forschung}

Die in diesem Band versammelten Beiträge sind in der Regel nicht Resultate von längeren Forschungsprojekten, sondern sie sind entweder Übersetzungen oder aber Originalbeiträge, die gleichsam als Nebenertrag aus Forschungen für Qualifikationsarbeiten entstanden sind. Den neuen Blick auf das Thema der Kriegsflucht, den wir mit diesem Band anregen wollen, können sie noch nicht vollständig entfalten. Dies bleibt die Aufgabe der theoriegeleiteten, systematischen Forschung, die sich gleichwohl phänomenologische Offenheit bewahren muss, will sie nicht in Perspektiven zurückfallen, die sich nur an Regierungsinteressen ausrichten.

Abschließend seien deshalb ein paar leitende Fragen formuliert, die den Herausgebern für dieses Forschungsfeld wesentlich erscheinen. Weniger in den Details der hier vorgestellten Beiträge als in den daraus abzuleitenden Perspektiven auf das 
Forschungsfeld scheint uns deshalb der Ertrag dieses Bandes zu bestehen.

Zunächst ist aus politikwissenschaftlicher Sicht interessant, wie stark sich in diesem Feld lokale, nationale, regionale und globale Dynamiken verbinden. Nicht nur dann, wenn Kriegsflucht über territoriale Grenzen von Staaten hinweg erfolgt, wird sie zu einem Gegenstand transnationaler Politik: Internationale Organisationen, regionale Verbände und entfernte lokale Gemeinschaften werden über sie zu einem politischen Bedingungsgefüge verbunden. Ohne euphemistische Absichten lässt sich die Kriegsflucht daher auch als ein Teil der Globalisierung verstehen, denn sie stellt Interdependenzen zwischen Akteuren und Arenen her, die zuvor nicht existierten. Welche Interdependenzen dies sind, scheint uns eine wichtige Frage der Forschung zu sein, die sich mit Globalisierungsprozessen beschäftigt. Dabei sind besonders solche Veränderungen interessant, die sich im Vergleich mit den auch schon immer hochgradig internationalisierten kausalen Prozessen von innerstaatlichen Kriegen ergeben (vgl. Schlichte 2009).

Ein zweiter Fragenkomplex für die sozialwissenschaftliche Forschung ergibt sich aus der hier beobachtbaren Transnationalisierung der Politik. Während die politikwissenschaftliche Diskussion noch zwischen Modellen des »Empire" oder der "global governance " schwankt, um solche Formen von Politik zu begreifen, deuten die hier versammelten Beobachtungen auf eine dritte, vielleicht eher an Pierre Bourdieu oder Michel Foucault orientierte Perspektive hin, die sich für die Analyse solcher Zusammenhänge entwickeln ließe. Damit erhält das hier behandelte Forschungsfeld auch einen direkten Bezug zur sozial- und politiktheoretischen Diskussion. Denn nicht allein die Frage von sozialer Gleichheit und auch nicht nur die Frage des geschickten Regierens in »Mehrebenen«-Systemen würde dann gestellt werden können, sondern auch die Frage, welche Subjekttypen in transnationalen Räumen produziert werden und wie sich diese Dispositionen zu Institutionalisierungen verhalten, die gegenwärtig als Formen von Macht und Herrschaft das internationale System charakterisieren. Die Forschung zur Kriegsflucht könnte damit Teil einer neuen politischen Soziologie der Weltgesellschaft werden. 


\section{Literatur}

Angenendt, Steffen (2004): »Die europäische Migrations- und Asylpolitik «. In: Werner Weidenfeld (Hg.), Die Europäische Union. Politisches System und Politikbereiche, Berlin: Bundeszentrale für Politische Bildung, S. 359-379.

Bayart, Jean-François/Mbembe, Achille/Toulabor, Comi (2007):

Le politique par le bas en Afrique noire: contribution à une problématique de la démocratie, Paris: Karthala.

Bernardot, Marc (2008): Camps d'étrangers, Bellecome-enBauges: Editions due Croquant.

Cutolo, Armando (2008): »Populations, citoyennetés et territoires: autochthonie et gouvernementalité en Afrique«. In: Politique africaine, 112, S. 5-17.

Eckert, Julia (Hg.) (2009): The Social Life of Anti-Terrorism Laws. The war on terror and the classification of the »dangerous other «, Bielefeldt: Transcript.

Gousseff, Catherine (2008): L'exil russe. La fabrique due réfugié apatride, Paris: CNRS éditions.

Huysmans, Jef (2006): The Politics of Insecurity - Fear, Migration, and Asylum in the EU, Abingdon: Routledge.

Inhetveen, Katharina (Hg.) (2006): Flucht als Politik. Berichte von fünf Kontinenten, Köln: Köppe-Verlag.

Kimminich, Otto (1983): Grundprobleme des Asylrechts, Darmstadt: Wiss. Buchges.

Münz, Rainer/Seifert, Wolfgang/Ulrich, Ralf (1999): Zuwanderung nach Deutschland. Strukturen, Wirkungen, Perspektiven, Frankfurt a.M.: Campus.

Nuscheler, Franz (1995): Internationale Migration. Flucht und Asyl, Opladen: Leske u. Budrich.

Opitz, Peter J. (1988): Das Weltflüchtlingsproblem. Ursachen und Folgen, München: Beck.

Schiffauer, Werner (2008): Parallelgesellschaften. Wie viel Wertekonsens braucht unsere Gesellschaft? Für eine kluge Politik der Differenz, Bielefeldt: Transcript.

Schlichte, Klaus (2006): »Neue Kriege - alte Thesen. Wirklichkeit und Repräsentation kriegerischer Gewalt in Publizistik und Wissenschaft«. In: Anna Geiss (Hg.) Den Krieg überdenken. Kriegsbegriffe und Kriegstheorien in der Kontroverse, Baden-Baden: Nomos, S. 111-132. 
Schlichte, Klaus (2009): In the Shadow of Violence. The politics of armed groups, Frankfurt a.M.: Campus.

Vetters, Larissa (2007): »The Power of Administrative Categories: Emerging Notions of Citizenship in the Divided City of Mostar«. In: Ethnopolitics, 6, 2, S. 187-209. 



\section{POLITIK DES}

\section{BESCHRÄNKTEN ZUGANGS}





\section{Flucht und Asyl - \\ zur Genealogie eines Feldes}

KLAUS SCHLICHTE

Wie bei vielen anderen politischen Themen besteht auch bei Flucht und Asyl eine Schwierigkeit darin, zu sprechen, ohne dabei die Sprache des Staates zu benutzen. Offenbar ist auch in diesem Bereich die Emanzipation der Sozialwissenschaften von ihrem Gegenstand noch nicht sehr weit fortgeschritten. Die gegenwärtige Debatte um die Regelungen der Grenzen der Europäischen Union wie die um die Regulierung der Flüchtlingsbewegungen oder des »Flüchtlingsproblems«, das wie so viel andere als »globales Problem« thematisiert wird, macht dies deutlich.

In diesem Beitrag soll versucht werden, die hintergründigen Vorstellungen von Politik und Regierung näher zu bestimmen, die dem gegenwärtigen »Flüchtlingsproblem« vorausgehen und die sich in der verwaltenden Sprache der Politik nicht formulieren lassen.

Dazu wird der Weg einer genealogischen Skizze eingeschlagen. Durch einen Blick, oder besser ein paar Schlaglichter auf unterschiedliche historische Momente und Phasen, soll es möglich werden, den kausalen Zusammenhängen der Debatten um Flucht und Asyl einige neue Aspekte hinzuzufügen und die Kontingenz der gegenwärtigen Flüchtlingspolitik ebenso sicht- 
bar zu machen, wie die historischen Voraussetzungen offen zu legen, aus denen sich diese Politiken entwickelt haben.

Wie sich die Genese von Fluchtpolitiken erklären lässt, ist ein weithin unbearbeitetes Feld. ${ }^{1}$ Diese Aufgabe steht vor der Herausforderung, das Vokabular der Rekonstruktion von gesetzlichen Bestimmungen, Verwaltungspraktiken und öffentlichen Diskursen zu umgehen, das die Genese der Asylpolitik als Ensemble von Praktiken und Herrschaftszusammenhängen eher verdeckt.

In diesem Beitrag soll also versucht werden, die Produktionen des Staates, staatliche Politik auf eine Weise aufzufassen, die sich von den dem Staat eigenen Interpretationen distanziert. Drei zentrale Thesen des Beitrags lassen sich vorweg angeben:

Erstens: Es gibt keine durchgehende Genealogie des Asyls. Das Ensemble von Regelungen rechtlicher und praktischer Art, das heute im internationalen und nationalen Recht Asylpolitik genannt wird, ist keine Tradition aus antiken Zeiten, wie sich dies vielleicht für andere Rechtsfiguren und die mit ihnen zusammenhängenden Praktiken sagen lässt. Die Genealogie des Asyls setzt erst im 19. Jahrhundert ein. Sie fällt so zusammen mit anderen Prozessen der Verstaatlichung gesellschaftlicher Bereiche wie dem Geldwesen oder der Bildung.

Zweitens: Das Asyl ist eine politische Einrichtung. In der Moderne ist das Asyl vor allen Dingen eine aus politischen Gründen stattfindende Praxis. Es ist kein universelles Recht, vor allem nicht in dem Sinne, dass es universell garantiert wäre. Sondern als Recht ist es abhängig von politischen Entscheidungen. Deshalb ist die Praxis des Asyls den Wechselfällen des politischen Geschehens untergeordnet.

Drittens: Das Asyl ist ein Indikator der Strukturen des internationalen Systems. Daran kann man erkennen, wie das internationale System wirklich funktioniert. An der Praxis des Asyls lassen sich die politischen Strukturierungen der Weltgesellschaft als sozialem Raum erkennen. Denn das Recht und die Praxis des Asyls bezeichnen im Weberschen Sinne Schließungen sozialer Beziehungen. ${ }^{2}$ Die Genealogie des Asyls in der

1 Vgl. jedoch die Beiträge von Noiriel (1994) und Marrus (1999).

2 Mit dem Begriff der sozialen Schließung stellt Weber auf den Mechanismus $a b$, dass insbesondere Interessenverbände die 
modernen Politik legt wesentliche Grundstrukturen von Herrschaftsorganisation im internationalen System frei: Die Trias von Souveränität, Territorium und Bevölkerung formt sich als globales System von Staatsbürgerrechten aus, aber die versteckte Seite dieser Kodifizierung ist der Ausschluss von Nichtinhabern der Staatsbürgerschaft. Die Praktiken und Rechtsfiguren des Asyls sind Teil dieser Schließungen, über die politisch entschieden wird, deren modus operandi aber heute vor allem bürokratisch ist.

\section{Die religiöse Genese des Asylgedankens}

In der griechischen Antike ist das Asyl eine Praxis, mit der sich Rechtlose oder solche, die nicht mehr auf eine rechtsgemäße Behandlung hoffen konnten, sich selbst vorübergehend in einen gesonderten Status versetzen konnten. Dieser Status untersagt Praktiken, die anderenfalls erlaubt sind. Die Etymologie des griechischen Wortes Asyl zeigt das an: Das Wort bezieht sich auf »sylan« - der vorstaatlichen Praxis der Entführung von Personen oder Dingen - das »a-syl « ist das Aussetzen dieser Praxis, das Verbot des Zugriffs auf Dinge oder Personen (Gödde 2003). Noch vor der Polis existiert diese Praxis, die zunächst einen sakralen Bezug hat: Es ist die Praxis der Hikesie. Die Schutzerflehenden lassen sich am Altar eines Heiligtums nieder und wollen auf diese Weise die Aura des Sakralen eintauchen, die ihnen Schutz vor der »eigenmächtigen Rechtsdurchsetzung « (Thür 2003: 24) von einzelnen gewähren soll. In dieser Situation die Schutzflehenden zu verletzen, hätte wohl geheißen, das Sakrale zu verletzen.

In diesem Sinne ist das Asyl also kein Schutz vor der Gewalt des Staates, sondern eher Teil der Formierung einer Gesamtrechtsordnung. Das Asyl schützt vor der - immer im Grenzfall willkürlichen - Rechtsverfolgung durch einzelne. Erst ab dem

Tendenz haben, sich gegenüber Nicht-Mitgliedern abzuschliessen (Weber 1985: 23). Für den Fall der »Schließung « von Nationalstaaten über die Definition von Staatsbürgerschaft müsste freilich dieser Mechanismus modifiziert werden, weil sich die Gemeinschaft von Staatsbürgern nicht durchweg als Interessenverband definieren lässt. 
5. Jahrhundert wird dieses Recht auch von Menschen bzw. von Institutionen zugesprochen, etwa in dem Sinne, dass eine Polis einer Personengruppe während eines temporären Aufenthalts Personenschutz zuspricht (Gödde 2003: 89).

Über das Tempelasyl des antiken Rom entwickelt sich diese Praxis bis zum mittelalterlichen Kirchenasyl, das schon in der Spätantike entsteht. Auch Synagogen haben diese Funktion, Schutzsuchenden einen vorübergehenden Aufenthalt zur Klärung der Rechtsfrage zu geben, und sie dem unmittelbar drohenden gewaltsamen Zugriff zu entziehen. Für das Kirchenasyl im europäischen Mittelalter gilt etwa, dass im Umkreis von 30 oder 50 Schritt um die Kirche Schutz vor weltlich-politischen Eingriffen gilt. Allerdings müssen die Schutzsuchenden unbewaffnet sein und wenn sie Schulden haben, so müssen sie diese vorher begleichen (Siems 2003: 267). Auch hier gibt es also schon eine Indienstnahme der kirchlichen Praxis durch die Interessen der Gläubiger. Seit der christlichen Spätantike sind durch die Justitianischen Novellen Ehebrecher, Frauenräuber, Mörder und Häretiker vom Asylschutz ausgeschlossen (Siems 2003: 267). Allerdings wird auch Asylbruch, also das gewaltsame Entfernen von Asylsuchenden aus der Kirche - jedenfalls de jure - mit Exkommunikation geahndet. Das Kirchenasyl schützt aber nur vor der weltlichen Macht, nicht vor kirchlichen Richtern (Siems 2003: 285).

Diese an religiöse Institutionen gebundenen Asylformen werden im Verlauf der Neuzeit mehr und mehr staatlichen Instanzen untergeordnet. Die Frühe Neuzeit mündet in die $\mathrm{Zu}-$ rücknahme kirchlicher Autorität vor den Machtansprüchen des Staates: Im 16. Jahrhundert werden etwa Deserteure und Militärstraftäter vom Asyl ausgenommen (Siems 2003: 287). Am Ende des 19. Jahrhundert ist das Kirchenasyl schließlich überall in Europa dem staatlichen Recht untergeordnet (Morgenstern 2003: 83).

Es wäre deshalb vermutlich ein Missverständnis, wenn man das Kirchenasyl als einen Ausnahmeraum eines sonst sanktionierenden Rechtssystems begreifen wollte. Was sich stattdessen beobachten lässt, ist eher das in das jeweilige Rechtssystem hineinragende kirchliche Selbstverständnis als »heilsgüterspendende " Organisation, die wenigstens im Innenraum von Sakralbauten eine Art Gottesfrieden herstellen musste. Zugleich 
ist aber deutlich erkennbar, dass sich dieser Anspruch in zunehmender Konkurrenz mit weltlichen Autoritäten durch die Verstaatlichung auflöst bzw. zurückgedrängt wird.

Mit der Verstaatlichung des Asylrechts ist die Frage verbunden, inwiefern hier überhaupt von einer Kontinuität gesprochen werden kann. Ist das heutige Asylrecht in seinen nationalen Ausformungen und internationalem Status überhaupt noch in einer Linie mit den antiken und mittelalterlichen Asylregeln und -praktiken zu sehen? Historiker bezweifeln, dass eine solche Linie gezogen werden könnte. ${ }^{3}$

\section{Die Verstaatlichung des Asyls}

Mit dem modernen Asylrecht, wie es sich im 19. Jahrhundert verbreitet, entsteht offenbar etwas Neues, das sich nicht als bloße Fortführung der antiken und dann kirchlich überformten Praxis begreifen lässt, auch wenn die Semantik des Schutzsuchens und -gewährens dies nahe legt. Die Schlüsselperiode für die Entstehung des modernen politischen Asylgedankens ist deshalb die europäische Neuzeit: Bis 1793 gibt es eigentlich kein staatliches Asylrecht in Europa. Doch die Staaten nehmen sich das Recht, einzelne oder ganze Gruppen in ihren Ländern aufzunehmen. Einer der Gründerväter des modernen Völkerrechts, Hugo Grotius, ist ein solcher Fall. In der Regel aber geht es um ganze, teilweise sehr große Gruppen, die aber nicht als vorübergehend Aufenthaltsberechtigte aufgefasst werden, sondern von denen von Beginn an klar ist, dass sie in die neue Gesellschaft aufgenommen werden (Härter 2003: 302), wie dies etwa mit den sephardischen Juden und den Hugenotten nach der Aufhebung des Edikts von Nantes geschieht.

Diese pauschale, auf ganze Gruppen bezogene Form des Asyls lässt sich einerseits als humanitäre Maßnahme interpretieren. Sie ist aber in einem herrschaftssoziologischen Sinne noch plausibler als Praxis in einer bestimmten politischen Konstellation interpretierbar, die diese Maßnahme des Asylgewährens noch einmal in einem anderen Licht erscheinen lässt, näm-

3 »Doch es gibt keine direkte Verbindung von antiken Vorstellungen zum modernen Asylbegriff« (Näf 2003: 348). 
lich als Teil der Gouvernementalité des frühneuzeitlichen Staates. Die Gruppen, denen Asyl gewährt wird, werden als Teil der Bevölkerung des Territoriums aufgefasst, »als einer der Faktoren, als eines der Machtelemente eines Souveräns « (Foucault 2004: 105). Für die Vorstellung einer "Bevölkerung « eines Landes ist die Auffassung grundlegend, dass Menschen sedentär leben, sesshaft werden. Nicht bloß die Zeit der Völkerwanderungen zwischen Spätantike und Frühmittelalter ist eine historische Epoche, in der die soziale Realität dieser statischen Vorstellung der "Bevölkerung « entgegensteht. Auch außerhalb der europäischen Geschichte ist die weiträumige Wanderung von unterschiedlich großen Gruppen der historische Normalfall. Diese Tatsache wird - auch in der rückblickenden Betrachtung - davon verdeckt, dass die Konzeption von Staatlichkeit als Einheit von Bevölkerung, Territorium und Souveränität sich heute global verallgemeinert hat (vgl. Migdal/Schlichte 2005). Auch in Europa musste sich diese Vorstellung eines räumlich abgegrenzten Staatsgebiets und einer durch Mitgliedschaft definierten, sesshaften Bevölkerung indes erst gegen eine soziale Wirklichkeit durchsetzen, die den Kategorisierungen staatlicher Herrschaft nicht einfach gehorchte. Das Asyl wird zur Ausweichbewegung vor den Zudringlichkeiten des Staates.

Die wachsende Gültigkeit der staatlichen Vorstellungen kann man daran erkennen, dass es die »mobilen Randgruppen « sind, denen in der Frühen Neuzeit, meist gegen Gebühr, Asyl gewährt wird. »Betteljuden", »Zigeuner « und anderes »fahrendes Volk " gehören in diese Gruppe (Härter 2003: 322). Das Paradoxe an den Effekten des Asylgewährens ist, dass der Ausweg zum gleichen Resultat führt: Das Asyl für diese Gruppen wird ein Vektor ihrer Sedentarisierung.

Mit den Formen und Vorstellungen moderner Staatlichkeit entsteht in der Geschichte des Asyls der entscheidende Bruch: Für die Entstehung des politischen Asyls in der Bedeutung, wie wir sie heute unterstellen, ist offenbar die Formierung der Repräsentationen von Staatlichkeit in den Formen von Souveränität, Territorialität und Bevölkerung entscheidend (vgl. Foucault 2004a,b). Diese Formierung bezeichnet den wesentlichen Bruch mit den antiken und mittelalterlichen Vorstellungen. Und doch überlebt der Begriff: Als eigentlicher institutioneller Ursprung des modernen Asyls gilt das diplomatische Asyl, also die Zu- 
fluchtsuche in einer diplomatischen Vertretung eines anderen Staates. Immunität und die Zugeordnetheit zu einem externen Gerichtsstand haften zuerst dem anderen Herrscher an, dann auch seiner Unterkunft, also dem Hotel der Gesandtschaft, die zum exterritorialen Gebiet wird.

Die Gewährung von Asyl wird dabei selbst zum Ausdruck von staatlicher Souveränität: Anderen Asyl zu gewähren setzt voraus, dass man in der Lage ist, diesen Anspruch auch durchzusetzen. Wer Asyl gewähren kann, ist ein Souverän (Härter 2003: 330). Das diplomatische Asyl wird zugleich in der frühen Neuzeit zentral über den Aspekt der Territorialität definiert. Die Praxis, das Aufsuchen eines Ortes und die geäußerte Bitte um Schutz sind offenbar identisch mit der Asylie/Hikesie des antiken Griechenlands. Doch nun ist diese Praxis ihres religiösen Bezugs beraubt und vollständig säkularisiert. Was als Praxis entsteht, formt sich erst mit der französischen Verfassung als eine schriftlich kodifizierte Institution aus.

Als Praxis von Staaten entwickelt sich das Asyl dann aber offenbar als Ergebnis von mindestens zwei weiteren Prozessen. Mit der »Verstaatlichung der Strafjustiz « (Härter 2003: 327) im 19. Jahrhundert entsteht zum einen eine verschärfte Aufmerksamkeit und eine bessere Erfassung der Bevölkerung. Diese Erfassung ist auch das Resultat des bürokratischen Herrschaftswissens der Staaten über ihre Bevölkerung. Denn erst mit dem frühneuzeitlichen Staat entsteht das Projekt der Regierenden, ihre Bevölkerung zu individualisieren und bürokratisch zu erfassen, nicht zuletzt, um sie für Abgaben und Wehrdienst einsetzen zu können (vgl. Spittler 1980). Im 19. Jahrhundert entsteht daraus die Praxis des Ausweises und des Passes, die fortan das Überschreiten von Staatsgrenzen zum kontrollierbaren bürokratischen Akt machen. Mit der »Bertillonage«, dem nach einem Kriminalisten benannten Ensemble von anthropometrischen Techniken zur Personenkontrolle, entsteht das moderne Regime der Kontrolle von Grenzen und von Personen.

Zudem formalisieren sich die Beziehungen zwischen Staaten. Das Asylrecht wird zum Ausnahmerecht zwischen Staaten, die sonst allgemein ein umfassendes Auslieferungsrecht vereinbaren (Härter 2003: 330). Die Techniken der Kontrolle erlauben es ihnen, auch den Austausch von Daten zu betreiben, so dass das Kontrollregime in der Tendenz international wird. 
Die zweite Bewegung, die dem Asyl vorausgeht und es zugleich mit konstituiert, ist die Erfindung der Staatsbürgerschaft. Diese ist historisch ein Projekt der Emanzipation gegen imperiale oder fürstliche Gewalt. Die Schaffung der Rechtsfigur der »citizenship" ist eigentlich eine Emanzipation (Shafir 1998). Diese juristische Form der Teilhabe, die mit dem auf Gleichberechtigung zielenden Begriff des Bürgers verkoppelt ist, ist eben zugleich auch immer ein Ausschluss. In Europa setzt sich diese Form im 19. Jahrhundert als Anspruch durch, auch wenn es bis ins 20. Jahrhundert dauert, bis dieser Anspruch insofern Realität wird, dass so gut wie alle auf dem Gebiet eines Staates lebenden Menschen in dem Sinne bürokratisch bekannt sind, dass sie persönlich und individuell erfasst sind. Diese SchlieBung von Nationalstaaten ist jedoch selbst ein Prozess, der sich global ausbreitet und eine Unzahl von Migrations- und Fluchtbewegungen auslöst (vgl. Gallagher 1989).

Aus der Arbeit von Gérard Noiriel (1994) kann man diese Bewegungen sehr klar erkennen. Sie haben noch eine weitere Konsequenz: Während es im 19. Jahrhundert noch möglich ist, als polnischer Flüchtling eine pauschale Anerkennung in Frankreich zu erlangen, ganz einfach dadurch, dass man der Gruppe angehört, der pauschal Asyl gewährt wird, lässt die entstehende bürokratische Maschinerie ein solches Verfahren nicht mehr zu. Der Staat des 19. Jahrhunderts war noch nicht in der Lage, jede einzelne Bewegung nachzuvollziehen und die Schicksale $\mathrm{zu}$ individualisieren. Im 20. Jahrhundert wird das möglich, und diese Bürokratisierung ist die dritte Stufe in der Geschichte des Asyls, die hier abschließend betrachtet werden soll.

\section{Asylpolitik als bürokratische Politik}

Territorialität und Souveränität sind die wirksamen leitenden Prinzipien internationaler Politik seit dem Beginn des 20. Jahrhunderts. Zusammen mit der Idee der Staatsbürgerschaft ergeben sie die Grundvorstellungen der politischen Ordnung der Welt, die bis heute tragend sind, auch für jene Gebiete, die im Zuge der Dekolonisierung die Begriffe und Institutionen moderner Staatlichkeit übernahmen. $\mathrm{Ob}$ in Schweden, Uganda 
oder Bolivien: Jeder ist heute de jure Bürgerin oder Bürger eines Staates, niemand ist staatenlos, und die Welt besteht aus Staaten, deren Bevölkerungen aus Bürgern bestehen, die auf einem Territorium leben.

Wie einige andere Regeln ist das Asyl eine Ausnahme von dieser allgemeinen Vorstellung. Und wenn es auch mit der Menschenrechtscharta der Vereinten Nationen von 1948 als völkerrechtliche Norm universalisiert worden ist, so wird das Asylrecht in der Praxis überall auf der Welt vor allem aus politischen Zweckmäßigkeitserwägungen gewährt. Die humanitäre Idee ist dabei nie ganz abwesend, aber leitend für die großen Entscheidungen und die großen Zahlen von Asylgewährungen ist das politische Signal, das mit der Anerkennung von Asylberechtigungen verbunden ist. Die Liste der Länder, die als »sicher« oder als "gefährlich « gelten, wird nicht rein von instrumentellen politischen Erwägungen bestimmt. Aber diese Kategorisierungen spiegeln wider, wie Regierungen jeweils andere Staaten codieren.

Die Verteilung von Anerkennungen ist deshalb auch immer eine Aussage darüber, wie politische Systeme sich gegenseitig wahrnehmen: Der politische Charakter dieser Politik ist vielleicht am klarsten am Fall der beiden deutschen Staaten BRD und DDR erkennbar gewesen: Während aus der DDR in die BRD übersiedelnde Personen keinen Asylantrag stellen mussten, denn sie waren automatisch Bürger der BRD, genossen die ca. 300.000 Übersiedler aus der BRD in die DDR dort de jure $\gg$ Asyl«.

Zugleich ist die Formulierung und Praxis des Asyls auch immer Aussage einer Gesellschaft über sich selbst: Der »Asylkompromiss «, den die großen Parteien in Deutschland 1992 verabschiedeten, veränderte die Anerkennungsquote maßgeblich - so wurden nach Angaben des Bundesamts für Flüchtlinge in 2007 nur 1,1 Prozent der Anträge positiv beschieden. Seit 1992 gilt das Prinzip der »sicheren Drittstaaten«, der »sicheren Herkunftsstaaten « und die so genannte "Flughafenregelung", also die Entscheidung im Flughafen auf Grundlage »eingeschränkter materieller Prüfung «, denn die Einreise als Asylbewerber nach Deutschland ist seit 1992 nur noch per Flugzeug möglich, da Deutschland seitdem von »sicheren Drittstaaten" umgeben ist. 
Diese Codierung ist politisch, insofern sie ganz explizit eine Bewertung der politischen Strukturen und Realitäten in anderen Staaten enthält. Sie ist aber auch politisch, weil sich in diesen Regelungen allgemeinere politische Haltungen ausprägen. ${ }^{4}$ Laut »Spiegel« vom 17. Februar 1992 waren damals 74 Prozent der deutschen Bevölkerung für eine Einschränkung des Asylrechts, Hintergrund, so die Presseberichte, war die Angst vor »Überfremdung ", die Betonung des Selbstverständnisses, kein Einwanderungsland $\mathrm{zu}$ sein. Eine genauere Analyse der Geschichte des Asyls muss also auch immer die Historizität der einzelnen Politiken, ihre Vermittlung mit dominanten gesellschaftlichen Einstellungen untersuchen. In diesen Einstellungen prägen sich auch in westlichen Staaten historische Erfahrungen und politische Ideen aus, die keineswegs allein dem Kanon der liberalen bürgerlichen Politikauffassung entstammen. Für den Fall Deutschland wäre sicher zu prüfen, ob darin nicht ein postfaschistisches Syndrom zum Ausdruck kommt.

Während das Asyl in dieser Hinsicht ein grundlegend politisches Phänomen ist, ist der Modus seiner Praxis vor allem bürokratisch und erscheint deshalb zunächst apolitisch. ${ }^{5}$ Wiederum Gérard Noiriel hat herausgearbeitet, wie diese bürokratische Praxis auch eine neue Form der Subjektivierung bedeutet. Während die Asyl-»Bewerber « in einer liminalen Position leben, zwischen Erinnerung und Hoffnung (Malkki 1995), zwingt die bürokratische Bearbeitung ihrer Lebenslagen sie dazu, ihr Leben als eine persönliche Geschichte dazustellen, die mit Dokumenten belegbar sein muss und zugleich in Übereinstimmung mit den gängigen Codierungen stehen soll. Wo dies nicht gelingt, ist die Sache verloren, es sei denn, es handelt sich um die Gewährung pauschaler Sonderrechte, wie sie aus politischen Erwägungen gelegentlich eingeräumt wurden, etwa im

4 Oder, in der Sprache der Politikwissenscahaft formuliert: »Foreign policy, domestic pressure and fiscal concerns shape state selections « (Hein 1993: 48).

5 Die Bedeutung der Bürokratie reicht indes weit über diesen Zusammenhang hinaus. Zu untersuchen wäre, inwieweit nicht das bürokratische Feld der eigentlich Quell der Semantik ist, in der über politische Fragen gesprochen wird. Selbst das Phänomen der Migration - als Name - ist ein Produkt der bürokratischen Nationalstaaten (vgl. Dowty 1987). 
Fall der »boat people« aus Vietnam oder den Opfern der Repression der chilenischen Militärdiktatur in den 1970er Jahren. Mit den Techniken der Personenidentifizierung, die Teil dieses bürokratischen Prozesses sind, wird internationale Politik schließlich über die Aufenthaltserlaubnis eine Praxis der Regierung von Körpern (vgl. Noiriel 1994: 140ff., 162).

Auch in dieser Hinsicht, in der Bedeutung bürokratischer Praktiken, könnte die internationale Fluchtpolitik als Index weltpolitischer Verhältnisse gelten. Denn während die Frage von Staatsbürgerschaft und Immigration in vielen verschiedenen Kontexten gegenwärtig politisiert wird - in Europa, in afrikanischen Staaten (Geschiere 2009) genauso wie in Südasien (Appadurai 2006) oder in den zentralasiatischen Nachfolgestaaten der Sowjetunion (Reeves 2005) - bedeutet die Figur des Flüchtlings stets eine Provokation gegenüber der binären Logik von Zugehörigkeit und Nicht-Zugehörigkeit. Die bürokratischen Maschinen, die Max Weber zufolge der Alltagsfall von Herrschaft sind, versuchen überall auf der Welt, Eindeutigkeiten herzustellen. Das »Flüchtlingsproblem « könnte in dieser Lesart auch aufgefasst werden als ein Problem eben dieser bürokratisierten Politik.

\section{Schlussbemerkung}

Die Genealogie des Asyls in der modernen Politik legt wesentliche Grundstrukturen von Herrschaftsorganisation im internationalen System frei: die Trias von Souveränität, Territorium und Bevölkerung formt sich als globales System von Staatsbürgerrechten aus, aber die versteckte Seite dieser Kodifizierung ist die Schließung sozialer und politischer Beziehungen. Die Praktiken und Rechtsfiguren des Asyls sind Teil dieser Schließungen, über die politisch entschieden wird, deren modus operandi aber bürokratisch ist.

Wie eingangs betont, kann man am Asylregime erkennen, wie das internationale System wirklich funktioniert. Das Recht und die Praxis des Asyls lassen sich als Ausnahmen von im Weberschen Sinne Schließungen sozialer Beziehungen auffassen. Wie jede Ausnahme bedeutet das Asyl zugleich eine Bestätigung der Regel. Die Asylpolitik operiert mit der Logik natio- 
naler Zugehörigkeiten, und noch in der leitenden Idee des »resettlement« im Umgang mit Kriegsflüchtlingen bleibt die Dominanz der Vorstellung von Bevölkerung, Territorialität und Souveränität in der verstaatlichten Welt erkennbar.

Die Maßnahmen der Asylpolitik kennzeichnen aber auch Grenzen des internationalen Systems, die nicht mehr rein territorial sind, sondern als Machträume unterschiedliche Lebensläufe und Optionen ausschließen oder wahrscheinlicher machen. Das Asylregime ist vielleicht ein geeigneter Punkt, um das offen zu legen, denn hier zeigt sich an Biographien von Menschen, wie sich diese Schließungen der internationalen Politik tatsächlich auswirken.

Für das Asyl gilt wohl auch, was Emma Haddad für die Flucht herausgestellt hat: Ohne internationales System würde es auch keine Flüchtlinge geben, und deshalb wird die Existenz des internationalen Systems auch kontinuierlich die Produktion von Flüchtlingen garantieren (Haddad 2008: 2). Der Flüchtling, der ein Asylant werden kann, ist ein Produkt der internationalen politischen Ordnung, der Globalisierung der Vorstellung von Souveränität, Territorium und Staatsbürgerschaft (vgl. Foucault 2004), die sich eben als ein globales Ordnungsmodell verallgemeinert hat (Haddad 2003, 2008). Diese juristisch kodifizierte Ordnung ist der symbolische Bezugspunkt von bürokratischen Praktiken und politischen Diskursen, die das Feld des Asyls kennzeichnen, die aber für grenzüberschreitende Migration insgesamt typisch sind.

Gilt das auch umgekehrt: Würde es ohne Flüchtlinge und ohne Asyl auch kein internationales System geben? Man kann argumentieren, dass das Vorhandensein von Flüchtlingen und die Praxis des Asyls auch ihrerseits konstitutiv für das internationale System, für Weltpolitik in ihrer gegenwärtigen Fassung sind (vgl. Haddad 2003: 298). Flüchtlinge und Asylanten haben auch eine symbolische Funktion im politischen Diskurs: Als Ausnahmen machen sie den Regelfall klar - Territorialität und Staatsbürgerschaft, die Existenz von Grenzen.

Ob die territoriale Ordnung des Westfälischen Systems noch eine angemessene Lösung für eine Welt ist, in der sich mehr und mehr soziale Beziehungen über die Grenzen dieser Territorien hinweg spannen, wird gegenwärtig in unterschiedlichen Disziplinen diskutiert. Dass die europäische Integration eine 
Antwort für dieses Problem darstellt, kann wohl mit guten Gründen bezweifelt werden: Die Konstruktion Europas als »hegemoniales Projekt der Liberalisierung (Münch 2008: 372) konnte einen ihrer zentralen Widersprüche nämlich bisher nicht auflösen: Der moralische Anspruch kosmopolitischer Gerechtigkeit und universeller Rechte gilt für den Innenraum der EU, aber in ihrem Außenverhalten ist eine Logik erkennbar, die an den leitenden Ideen des Westfälischen Systems orientiert ist (vgl. Benhabib 2005: 675).

Mit den transnationalen Beziehungen, die sich nicht erst seit der Entdeckung der »Globalisierung « über Staatengrenzen und Kontinente hinwegspannen, ${ }^{6}$ erscheint die nationalstaatliche Strukturierung der Welt aber immer weniger angemessen. Denn die Fragmentierung der Welt in durch Visaregime abgetrennte Rechtsräume steht den Bedürfnissen entgegen, die im transnationalen Raum entstehen. Die Geschichte des Asyls und der Möglichkeiten der Flucht lässt sich in diesem Zusammenhang als Indexierung der Freiheitsgrade lesen, die die Politik in der Weltgesellschaft erlaubt oder hervorgebracht hat. Die nationalstaatliche Schließung der Möglichkeiten, die mit der Verstaatlichung der Welt einhergegangen ist, steht auch im Widerspruch zur Behauptung der Freiheit, die sich mit dem liberalen Zeitalter verbindet.

\section{Literatur}

Appadurai, Arjun (2006): Fear of Small Numbers. An essay on the geography of anger, Durham, NC: Duke UP.

Bayart, Jean-François (2004): Le gouvernement du monde. Une critique politique de la globalisation, Paris: Fayard.

Benhabib, Sheila (2005): »Borders, Boundaries, and Citizenship«. Political Science and Politics, 37, 4, S. 673-679.

Dowty, A. (1987): Closed Borders: the contemporary assault on the freedom of movement, New York: Yale UP.

6 Zur historischen Tiefe der Interdependenzen und Bewegungen, die seit den 1990er Jahren als »Globalisierung " thematisiert werden vgl. grundlegend Bayart (2004), sowie zu den Formierungen im 19. Jahrhundert nun auch Osterhammel (2009). 
Foucault, Michel (2004a): Geschichte der Gouvernementalität I: Sicherheit, Territorium, Bevölkerung, Frankfurt a.M: Suhrkamp.

Foucault, Michel (2004b): Geschichte der Gouvernementalität II: Die Geburt der Biopolitik, Frankfurt a.M: Suhrkamp.

Gallagher, Dennis (1989): »The Evolution of the International Refugee System«. International Migration Review, 23, 3, S. 579-598.

Geschiere, Peter (2009): The Perils of Belonging. Autochthony, Citizenship, and Exclusion in Africa and Europe, Chicago, Ill.: Chicago UP.

Gödde, Susanne (2003): »Poetisches Recht: Asyl und Ehe in den Hiketiden des Aischylos«. In: Martin Dreher (Hg.), Das antike Asyl. Akten der Gesellschaft für griechische und hellenistische Rechtsgeschichte, Köln u.a.: Böhlau, S. 85-106.

Haddad, Emma (2003): The Refugee. The individual between sovereigns, in: Global Society, 17, 3, 297-322.

Haddad, Emma (2008): The Refugee in International Society. Between Sovereigns, Cambridge UP.

Härter, Karl (2003): »Vom Kirchenasyl zum politischen Asyl: Asylrecht und Asylpolitik im frühneuzeitlichen Alten Reich «. In: Martin Dreher (Hg.), Das antike Asyl. Akten der Gesellschaft für griechische und hellenistische Rechtsgeschichte, Köln u.a.: Böhlau, S. 301-336.

Hein, Jeremy (1993): Refugees, Immigration, and the State, in: Annual Review of Sociology, 19, 43-59.

Malkki, Liisa H. (1995): Purity and Exile: Violence, Memory and National Cosmology among Hutu Refugees in Tanzania, Chicago: Chicago UP.

Marrus, Michael R. (1999): Die Unerwünschten - the unwanted. Europäische Flüchtlinge im 20. Jahrhundert, Berlin: Schwarze Risse.

Migdal, Joel S./Schlichte, Klaus (2005): »Rethinking the State«. In: Klaus Schlichte (Hg.): The Dynamics of States. The formation and crisis of state domination outside the OECD, Aldershot: Ashgate, S. 1-40.

Morgenstern, Matthias (2003): Kirchenasyl in der Bundesrepublik Deutschland: Historische Entwicklung - aktuelle Situation - internationaler Vergleich, Wiesbaden: VS. 
Münch, Richard (2008): Die Konstruktion der europäischen Gesellschaft. Zur Dialektik von transnationaler Intergration und nationaler Desintegration, Frankfurt a.M.: Campus.

Näf, Beat (2003): »Asyl - humanitäres Erbe des Altertums? Ein Rückblick auf die Tagung «. In: Martin Dreher (Hg.), Das antike Asyl. Akten der Gesellschaft für griechische und hellenistische Rechtsgeschichte, Köln u.a.: Böhlau, S. 337-348.

Noiriel, Gérard (1994): Die Tyrannei des Nationalen. Sozialgeschichte des Asylrechts in Europa, Lüneburg: zu Klampen.

Osterhammel, Jürgen (2009): Die Verwandlung der Welt. Eine Geschichte des 19. Jahrhunderts, München: Beck.

Reeves, Madeleine (2005): »Locating danger: konfliktologiya and the search for fixity in the Fergana Valley borderlands", Central Asian Survey 24, 1, S. 67-81.

Siems, Harald (2003): »Asyl in der Kirche? Wechsellagen des Kirchenasyls im Mittelalter«. In: Martin Dreher (Hg.), Das antike Asyl. Akten der Gesellschaft für griechische und hellenistische Rechtsgeschichte, Köln u.a.: Böhlau, S. 263-300.

Spittler, Gerd (1980): »Abstraktes Wissen als Herrschaftsbasis. Zur Entstehungsgeschichte bürokratischer Herrschaft im Bauernstaat Preußen«. Kölner Zeitschrift für Soziologie und Sozialpsychologie 32, 4, S. 574-604.

Shafir, Gershon (1998): »Introduction: The Evolving Tradition of Citizenship«. In: Ders. (Hg.), The Citizenship Debates, Minneapolis: University of Minnesota Press, S. 1-28.

Thür, Gerhard (2003): „Gerichtliche Kontrolle des Asylanspruchs«. In: Martin Dreher (Hg.), Das antike Asyl. Akten der Gesellschaft für griechische und hellenistische Rechtsgeschichte, Köln u.a.: Böhlau, S. 23-36.

Weber, Max 1985: Wirtschaft und Gesellschaft. Grundriss der verstehenden Soziologie, 5. Aufl., Tübingen: Mohr. 



\section{Sicherheit und Immigration: \\ Zu einer Kritik der Gouvernementalität}

\section{des Unbehagens ${ }^{1}$}

\section{DIDIER BIGO}

Migration wird zunehmend als Sicherheitsproblem interpretiert. Das Prisma der Sicherheitsanalyse wird besonders wichtig für Politiker, für nationale und lokale Polizeiorganisationen, für die Militärpolizei, Zollbeamte, Grenzbeamte, Geheimdienst, Armeen, Richter, soziale Einrichtungen wie Schulen, Krankenhäuser, private Unternehmen wie Bankanalysten, Wachdienste, für Journalisten der Boulevardpresse und für jene Bevölkerungsteile, die dem »law and order«-Denken zuneigen. Die Popularität dieses Denkens ist aber kein Ausdruck hergebrachter Antworten auf gestiegene Risiken der Unsicherheit, von Verbrechen oder Terrorismus oder neuen Gefahren der Globalisierung. Sondern sie resultiert aus der Schaffung eines Kontinuums von Gefahren und des Unbehagens. Darin tauschen viele Akteure ihre Ängste und Befürchtungen aus, und schaffen so eine "gefährdete und riskante« Gesellschaft. Es sind gerade die

1 Dieser Artikel erschien zuerst unter dem Titel »Security and Immigration: Toward a Critique of the Governmentality of Unease « in: Alternatives, 2002, 27. Jg, Special Issue, S. 63-92. Copyright von Centre d'Etudes sur les Conflits. Übersetzung von Klaus Schlichte und Margarete Misselwitz. 
Berufskreise, die mit dem Management von Risiken und Ängsten befasst sind, die die Legitimität, die sie im Kampf gegen den Terrorismus, Kriminalität und Spionage erzielen, gegen andere Ziele richten, besonders gegen transnationale politische Aktivisten, gegen Menschen, die Grenzen überqueren oder Staatsbürgern, deren Eltern anderer Nationalität waren.

Diese Expansion dessen, was als sicherheitsrelevant betrachtet wird, führt zu einer Verschmelzung von internationaler und interner Sicherheit. Gerade für das Thema Migration ist diese Verschmelzung besonders wichtig, und insbesondere hinsichtlich der Frage, wer überhaupt als Immigrant gilt. Die Sicherheitsexperten selbst, und mit ihnen einige Akademiker, geben vor, nur auf Bedrohungen zu reagieren, die Maßnahmen jenseits der üblichen Politik notwendig machen würden. Doch in der Praxis sind die Transformation von Sicherheit und die Betonung der Immigration eng mit ihren Interessen verbunden. Denn es geht dabei um Budgets und Aufträge und um die Erneuerung der Technologien, die sie benutzen, wie computergestützte Datenbanken, Profiling und elektronische Überwachungstechnologien. So werden die Europäisierung und die Verwestlichung der Überwachungs- und Kontroll-Logiken jenseits nationaler Politiken durch die Schaffung eines transnationalen Feldes von Professionellen angetrieben, die das »Management des Unbehagens « betreiben. Dieses Feld geht weit über die Polizeiorganisationen hinaus, denn es umfasst auf der eine Seite Privatunternehmen und Organisationen, die um den Sozialstaat herum gelagert sind, und auf der anderen Seite Geheimdienste und militärische Abteilungen, die nach dem Ende des Ost-West-Konflikts auf der Suche nach einer neuen Rolle sind. Doch diese Manager des Unbehagens sind nur ein Knoten in einem Netzwerk, das bestimmte Gruppen als Risiko oder Ursache von Unbehangen einstuft. ${ }^{2}$

Dieser Prozess der Versicherheitlichung ist mittlerweile wohlbekannt. Aber obwohl eine Reihe von kritischen Beiträgen

2 Diese Zusammenhänge sind der politischen Soziologie seit langem bekannt, (vgl. Bigo 1992; Anderson/Den Boer 1994; Anderson/Den Boer/Cullen/Gilmore/Walker 1996; Bigo 1996a; Palidda 1999; Ericson 1999). Aber in der Politikwissenschaft scheinen diese Einsichten immer noch unbekannt zu sein. 
auf diese Definierung von Migration als Sicherheitsproblem aufmerksam gemacht hat, dauert die Praxis an. Warum? Warum wird Migration weiterhin mit Terrorismus, Kriminalität, religiösem Eiferertum und Arbeitslosigkeit in einen Zusammenhang gestellt und warum wird Migration nicht als Chance für die europäischen Gesellschaften, als Teil der Freiheit, auf der ganzen Welt zu reisen oder als neue Form von Staatsbürgerschaft begriffen (vgl. Bauman 1999)? Das ist die Frage, die ich in diesem Beitrag behandeln möchte.

Einige »kritische" Diskurse von Nichtregierungsorganisationen und manchen Wissenschaftlern nehmen an, dass eine Veränderung eintreten würde, wenn Politiker, Journalisten, Regierungen und Bürokratien »aufgeklärt« würden, und dadurch ihre Ansichten und Praktiken änderten. Das Problem sei deshalb, so ihre Position, ein Problem der Ideologie oder des Diskurses, insofern die Versicherheitlichung der Migranten vor allem auf Sprechakten beruhe. Von diesen Autoren wird der Ausdruck "Sprechakt« nicht im technischen Sinne wie bei Austin verwendet, sondern metaphorisch, um normative Positionen von Sprechern zu rechtfertigen und um zugleich einen kritischen Diskurs gegen die Redeweisen der Sicherheitsexperten zu ermöglichen. Dieses Verständnis verstärkt die Auffassung, dass es um einen Wettbewerb von Ideen und Normen geht, in dem Akademiker eine tragende Rolle spielen könnten. ${ }^{3}$

Dieser Beitrag soll auf eine andere Weise kritisch sein. Es soll hier vermieden werden, die Auseinandersetzung als eine ideologische zwischen Konservativen und Liberalen oder gar als einen »intertextuellen Wettbewerb « zu präsentieren, der zwischen Institutionen ausgetragen wird und in dem Akademiker eine Schlüsselrolle spielen. In diesem Beitrag wird untersucht, wieso der Diskurs über Immigranten als Sicherheitsproblem fortwirkt, obwohl doch die Kritik daran wohlbekannt ist, und warum die akademischen und alternativen Diskurse sowohl in der Politik als auch im Alltagsleben so unbedeutend geblieben sind. Dabei wird hier die Arbeit der Politisierung betont, der Mobilisierung von Gruppen und Technologien, die es

3 Man könnte leicht erklären, warum diese Position unter Akademikern so beliebt ist. Über die »illusio « der Akademiker über ihre eigene Rolle vgl. Bourdieu (1984). 
einigen Berufsgruppen und Agenturen, vor allem aber politischen Akteuren, Medien, dem Sicherheitssektor und einigen Teilen der Bevölkerung erlauben, eine »Wahrheit« zu etablieren, die Migration mit Kriminalität und Arbeitslosigkeit in $\mathrm{Zu}-$ sammenhang bringt, obwohl viele Akademiker, die Kirchen und Nichtregierungsorganisationen seit vielen Jahren dagegen argumentieren.

Meine These ist, dass die Versicherheitlichung der Immigration nicht das Resultat der Propaganda der politischen Rechten ist, und dass sie auch nicht bloß auf »Sprechakten« von Regierungsvertretern oder gesellschaftlichen Gruppen besteht (vgl. auch Buzan 1993). Die Versicherheitlichung des Migranten als Risiko hat, so die These, etwas mit unserer Vorstellung vom Staat als ein Körper oder als ein Gefäß für politische Gemeinschaften zu tun. Sie ist in der Vorstellung von Politikern verankert, die Angst davor haben, die symbolische Kontrolle über territoriale Grenzen zu verlieren. ${ }^{4}$ Der Diskurs der Versicherheitlichung wird durch den Habitus ${ }^{5}$ der Sicherheitsbeamten und ihren Interessen an Fremden und Immigranten strukturiert. ${ }^{6}$ Diese Interessen korrelieren mit der Globalisierung neuer Technologien der Kontrolle und Überwachung (Bigo 2000a; Mathiesen 2000). Der Diskurs basiert auch auf dem Gefühl des »Unbehagens«, das einige Bürger verspüren, weil sie sich an den Rand gedrängt fühlen und mit den neuen Ungewissheiten des alltäglichen Lebens nicht umgehen können.7 Dieses Unbehagen ist nicht psychologisch. Es ist ein strukturelles Unbehagen in einer "Risikogesellschaft«, die durch den neoliberalen Diskurs erzeugt wird und in der Freiheit immer gleichbedeutend mit Gefahr und Unsicherheit ist.

4 Vgl. Anderson 1996; Anderson/Den Boer 1994; Ganster 1997; Bigo 2001a; Guild 2001.

5 Mit dem Begriff des »sozialen Habitus « ist in der Soziologie Pierre Bourdieus die mentale Struktur gemeint, die die Akteure dazu neigen lässt, Strukturen und Institutionen $\mathrm{zu}$ reproduzieren. Er wird bei Bourdieu als Ensemble von Wahrnehmungsund Bewertungsschemata definiert (Anm. d. Übers.).

$6 \mathrm{Zu}$ Bourdieus Verständnis von Habitus siehe Pierre Bourdieu (1990).

7 Vgl. Beck 1992; Beck 1996; Bauman 1992; Bourdieu 1993; Bigo 1998a; Ericson 1999. 
Die Versicherheitlichung der Migration ist also eine transversale politische Technologie, die als Modus einer Gouvernementalität ${ }^{8}$ von verschiedenen Institutionen genutzt wird, um mit dem Unbehagen zu spielen, oder um es zu wecken, wo es noch nicht existiert. Damit wollen diese Institutionen ihre Nützlichkeit als Sicherheitsagenturen beweisen und zugleich ihr Versagen kaschieren (vgl. Delumeau 1989). Die Politik der Versicherheitlichung der Immigration entsteht also aus einer Korrelation zwischen erfolgreichen Sprechakten von politischen Führern, der Mobilisierung, die sie für oder gegen bestimmte Gruppen erzeugen, und dem spezifischen Feld des Sicherheitspersonals, das in der westlichen Welt trotz vieler nationaler Unterschiede nun Polizisten, Gendarmerien, Geheimdienste, Militärs, Sicherheitsunternehmen und Experten des RiskAssess-ment vereint. Aber diese Politik geht auch hervor aus einer Vielzahl von administrativen Praktiken, wie dem "profiling « der Bevölkerung, der Risikoabschätzung, der statistischen Berechnung, der Schaffung von Kategorien und der Prävention sowie aus dem, was als der spezifische Habitus des Sicherheitspersonals bezeichnet werden kann, mit seinem Ethos des Geheimnisses und der Verwaltung von Angst und Unbehagen (vgl. Buzan/Waever/de Wilde 1998).

\section{Der Erfolg der Versicherheitlichung der Immigration im politischen Raum}

Der Großteil der antirassistischen Bewegung und der Menschenrechtsorganisationen wie auch der Wissenschaftler, die mit diesen Organisationen verbunden sind, erklärt die Macht des Sicherheitsdiskurses über Migration mit einer "spontanen" Ausbreitung von Intoleranz und rassistischen Vorurteilen in großen Bevölkerungsteilen. Die Bevölkerung sei »kontaminiert « durch »law and order «-Visionen über Fremde und würde diese Vorstellungen akzeptieren. Das Nichtwissen über die größeren

8 Unter Gouvernementalität werden in diesen Beitrag nach Foucaults Definition alle Praktiken verstanden, die Strategien festlegen, definieren, organisieren und instrumentalisieren, die Individuen in ihrer grundlegenden Freiheit in Beziehungen mit anderen haben. 
Zusammenhänge und der Populismus, der frustrierte Bevölkerungsgruppen gefallen soll, seien begünstigende Hintergründe für solche fremdenfeindlichen Haltungen. ${ }^{9}$ Das mag in einigen Hinsichten zutreffen. Doch die Ineffizienz der Kritik an diesen Haltungen kann nicht einfach mit der Blindheit von Politikern, Medien und Wählern begründet werden. ${ }^{10}$ Erfolg kommt nicht durch endlose Wiederholung der Aussage zustande, wie nützlich Fremde für eine Gesellschaft sind. Die Weigerung, kritische Diskurse zu berücksichtigen muss daher statt als eine Wissenslücke vielmehr als ein politisches Vergessen, als eine Negierung dessen verstanden werden (vgl. Foucault 1994).

Die Behauptung, dass zunehmende Unsicherheit auf stärkere Immigration zurückgeführt werden kann, wurde schon oft von Kritikern widerlegt, aber ohne großen Effekt. Analytische Genauigkeit hat den Konsens zwischen Politikern und Bürokraten nicht zerstören können. Der kritische Diskurs kann die Situation nicht dadurch verändern, dass er sich für Migranten und gegen »securitization « einsetzt. Das Detailwissen über die negativen Effekte von Regierungspolitik und der Politik von internationalen Organisationen wird die Situation der Migranten nicht verändern. Sie werden weiterhin Gegenstand von $\mathrm{Zu}-$ rückweisungen und Integration sein. Eine wirklich effektive Herausforderung kann nur indirekt geschehen, nämlich durch die Analyse der Bedingungen, unter denen ein Diskurs als »wahr « anerkannt wird, der hier Immigranten zu »outsidern" innerhalb von Staaten macht (vgl. Abdelmalek 1999).

9 Einige vermeintlich kritische Diskurse setzen im Grunde eine fremdenfeindliche Öffentlichkeit voraus. Sie glorifizieren auf der anderen Seite eine aufgeklärte Schicht, die aus guten Bürgern, sie selbst eingeschlossen, bestünde. Damit teilen sie die Bevölkerung in Massen und Eliten auf (vgl. Wievorka 1992 und Taguieff 1991). Natürlich spielt Fremdenfeindlichkeit für den Sicherheitsdiskurs eine Rolle, aber diese Fremdenfeindlichkeit ist vor allem auch ein Produkt dieses Diskurses.

10 Vgl. Favell 1998; Geddes 1996; Rea 1998; Lessana 1998; Bonelli 2000. 


\section{Sicherheit und Einwanderung: „Seeing like a state ${ }^{11}$}

Die Politik der Verweigerung, des aktiven Vergessens der Bedeutung von Migration zieht ihre Stärke aus der Art und Weise, wie der Staat von den Hauptakteuren des Sicherheitsdiskurses imaginiert wird. Journalisten, Politiker, Bürokraten, aber auch viele Politikwissenschaftler verwechseln den Staat mit dem Staatsapparat und den Regierenden. Die Regierenden in repräsentativen Demokratien, so argumentieren sie, würden ihre Legitimität von den Bürgern erhalten, wodurch sie Staat mit Demokratie assoziieren, ohne die Grenzen und Widersprüche zwischen diesen beiden Konzepten zu bemerken. Bürger werden als Inländer verstanden, im Unterschied zu Ausländern, und Ausländer werden als Bürger anderer Staaten aufgefasst, die sich von den Inländern durch andere Werte und Normen unterscheiden. Immigration wird so immer verstanden in den Kategorien von Staat und Nation, als eine Gefahr für die »Homogenität des Volkes«. Schon die Aktivierung des Migranten zum »Im«-Migranten wird als etwas Zerstörerisches aufgefasst. Die Metapher der »body politic«, die in dem Mythos der Souveränität eingebettet ist, - nötig, um die Grenzen zu überwachen, um die Integrität dessen zu gewährleisten, was sich im Innern befindet, in der Praxis der territorialen Kontrolle, in den Technologien der Überwachung - schafft eine Imagination des Immigranten als jemanden, der von Außen hereinkommt, als eine Gefahr für die Homogenität des Staates, der Gesellschaft und des politischen Körpers (vgl. Bigo/Hanon/Bonelli/ Tsoukala 2000; Andreas 2001).

Die Genealogie des westlichen Staates, gerade bezogen auf seine stärksten Mythen und seine Institutionalisierung, ist vielfach untersucht worden, unter anderem von Antony Giddens (1984) und Pierre Bourdieu (1994). Sie haben gezeigt, um es mit Bourdieu zu sagen, dass »der Staat uns stärker begreift, als wir den Staat begreifen «. Die Studien in den Theorien internationaler Beziehungen von John Ruggie, Thomas Biersteker, Richard Ashley und R.J.B. Walker haben ebenso gezeigt, wie stark Staa-

11 Diese Überschrift bezieht sich auf den gleichnamigen Buchtitel von James Scott "Seeing Like A State: How Certain Schemes to Improve the Human Conditions Have Failed« (1999). 
ten sich als Bewusstseinsformen entwickelt haben.12 Das hat Theoretiker der Internationalen Beziehungen dazu gebracht, die territoriale Dimension des Westfälischen Staates zu analysieren, wie dies Bertrand Badie (1996), Richard Mansbach (1989) und Martin Heisler (2001) getan haben. Ich will dies hier nicht weiterentwickeln, sondern nur darauf hinweisen, dass all diese Begriffe Waffen und Munition in symbolischen und politischen Auseinandersetzungen zwischen sozialen Gruppen gewesen sind. Begriffe wie Souveränität, Sicherheit und Grenzen strukturieren unser Denken in dem Sinne, als dass sie einen »Körper«, einen »Behälter", einen »Container" schaffen, dessen Inhalt von dem zu unterscheiden sei, was ihn umgibt. Der Staat rechtfertigt sich dann als die einzig akzeptable Ordnungsform, sobald akzeptiert ist, dass Souveränität, Gesetz und Ordnung und ein einheitlicher »Körper « die Voraussetzungen für Frieden und Homogenität sind. Er rechtfertigt die »nationale« Identität, die der Staat durch seine Territorialisierung seiner Ordnung erreicht, durch die Setzung von Grenzen.

Die Stärke dieser symbolischen Ordnung ist so oft analysiert worden, dass dies hier nicht noch einmal geschehen muss. Aber es muss doch daran erinnert werden, weil so viele Ökonomen und Soziologen, die zum Thema Migration arbeiten, dies »vergessen « haben. Sie wirken aktiv daran mit, die »Illusion« der Macht als Körper zu vergessen, wobei durch die Betonung auf Homogenität, Souveränität und die Gesetze das Verständnis über die globalen sozialen Transformationen hinsichtlich der Bewegungen von Menschen und Identitätspolitik verhindert wird. Viele Politiker, Juristen und auch einige Sozialwissenschaftler können kaum zugeben, dass man die Macht nicht über legitime und stabile Formen verstehen kann, dass sie nicht »von oben « kommt, das sie, um es mit Michel Foucault zu sagen, "nicht in ihren Intentionen analysiert werden kann, sondern, im Gegenteil da, wo sie mit ihren Zielobjekten interagiert, wo sie sich bewegt, wo sie im Extremfall die Grenzen des Rechts überschreitet, dort können die Techniken und Taktiken der Herrschaft beobachtet werden" (vgl. Foucault 1996). Foucault hat schon vor langer Zeit eine Alternative zur Beschreibung der

12 Vgl. Ruggie 1998; Walker/Mendlovitz 1990; Ashley/Walker 1990; Biersteker/Weber1996. 
Machtbeziehungen in den Begriffen der Souveränität vorgeschlagen, die das Verständnis des "politischen Körpers" herausforderte. Aber dieser Vorschlag ist marginal geblieben. Selbst in akademischen Kreisen wird sich bis heute geweigert, Souveränität und Sicherheit zu analysieren und stattdessen beharren sie darauf, dass diese Begriffe lediglich Werkzeuge wären, um die Beziehungen zwischen Staat und Gesellschaft zu verstehen (vgl. Hysmans 1995).

Aber Souveränität und Sicherheit sind keine analytischen Begriffe, sondern sie müssen einer genealogischen Analyse unterzogen werden, um ihre Beziehung zu den Ideen des Regierens offen zu legen, der Idee des so genannten Westfälischen Staates in seinen modernen - Hegelschen oder Weberschen Variationen. Das aktuelle Revival der Souveränität in der politischen Debatte kann daher als der Einsatz eines Narrativs verstanden werden, der die Absicht verfolgt, mit Positionen der symbolischen Autorität zu spielen, um soziale Praktiken in die benötigte Richtung zu lenken. Souveränität bedeutet, diese Positionen anzuerkennen, doch wenn sie angezweifelt werden, kann der Autoritäts-Effekt nicht lange bestehen. Denn diese Autorität lebt nicht aus sich selbst heraus, sondern sie entsteht intersubjektiv. Das gleiche gilt für das Sicherheitsargument. Die Praktiken der Sicherheit sind nicht naturgegeben, sondern sie sind das Ergebnis von politischen Handlungen von Politikern und der Spezialisten des Bedrohungsmanagements.

\section{Sicherheit und Einwanderung: Seeing like a Politician}

Die Vorstellung eines Staates als ein Körper, der von Migranten bedroht wird, ist eine politische Erzählung, die von Politikern genutzt wird, um sich von anderen Politikern abzugrenzen, allerdings innerhalb desselben Spiels. Diese Erzählung ist eine nützliche Konstruktion für die Politisierung von Migration. Von Murray Edelman (1991) haben wir gelernt, wie die Konstruktion eines politischen Spektakels funktioniert. Er hat gezeigt, warum es für Politiker nützlich ist, aus Situationen Probleme zu machen: die Politiker können sich dann als »Manager « präsentieren und so ihre Autorität rechtfertigen. Es erlaubt ihnen, andere Probleme nicht $\mathrm{zu}$ behandeln und strukturelle Schwierigkeiten in einfache Formeln zu transformieren. All die- 
se Elemente und Praktiken sind wichtig, um die Versicherheitlichung von Immigration zu erklären. Michel Rogin, um nur ein Beispiel zu erwähnen, hat die Idee entwickelt, dass in verschiedenen Ländern unter anderem in den USA, politische Rhetorik als politische Dämonologie wirkt, mit der eine »law-and-order «Politik begründet werden kann (vgl. Rogin 1998).

Doch weder Edelman noch Rogin haben eine weitergehende Dynamik richtig analysiert, die Paul Veyne in einem anderen Kontext entwickelt hat, nämlich wenn Politiker an ihre eigenen Mythen glauben, auch wenn sie sie zynisch und bewusst selbst aktivieren. Sie sind nicht einfach Irreführer oder Schauspieler. Trotz der Differenzen in politischen Auseinandersetzungen, nationalen Traditionen, professionellen Interessen und trotz des offensichtlichen Zynismus in den Führungen von Polizei und Militär, leben Politiker in den Mythen über den politischen Körper, die Souveränität und den Staat. Sie nehmen teil an diesen Illusionen des politischen Feldes. Die Mythen strukturieren ihren Raum, ihre Denk- und Handlungsweise bei "politischen Problemen«. Und das erklärt zu einem gewissen Grad die Homogenität ihrer Reaktionen auf das »Immigrationsproblem « in den verschiedenen westlichen Staaten.

Das heißt nun nicht, dass Politiker notwendig an die Mythen glauben würden, die sie über Immigranten oder Islamisten und über Grenzüberschreitungen in Umlauf bringen: Sie kennen die Grenzen ihrer Fabeln genauso wie die alten Griechen wussten, dass ihre Götter Teil ihrer mythischen Märchen waren (vgl. Veyne 1983). Dennoch können sie nicht die Mythen über den Staat und die Integrität des Volkes in Frage stellen, denn in diesen Mythen erklären sie ihre alltägliche Welt und innerhalb dieser Mythen sind auch ihre eigene Werte und Auseinandersetzungen angesiedelt. Deshalb ist die Metapher des Eindringens von etwas Fremden in einen Körper so mächtig, auch wenn die nationalen Fassungen jeweils etwas anders ausfallen: als »Flutwelle« in Großbritannien, als »Deichbruch « in den Niederlanden oder als »Barbareninvasion « in Frankreich (vgl. Leveau 1998).

Diese Diskursfiguren über Immigration als »Eindringen " werden von Berufsgruppen und Politikern geschaffen, und sie beruhen auf einer zentralen Unterstellung, die die Politiker über ihre eigenen Fähigkeiten gegenüber dem Staat haben: die 
Behauptung, dass es möglich sei, den Strom von Menschen an den Grenzen zu kontrollieren (vgl. Bigo 1996b). Sie gehen davon aus, dass Berufspolitiker eine Kontrollmacht haben, die sie nicht verlieren wollen, nämlich das Recht, Ausländern Zugang zu gewähren oder nicht. Dieses Recht wird ihnen umso wichtiger, als sie erfahren, dass sie in anderen Bereichen, etwa bei Geld und Kredit, immer weniger Entscheidungsfähigkeiten besitzen (vgl. Strange 1994). Dieses Recht bedeutet aus der Sicht der Politiker, dass sie in der Lage sind, durch Gesetze und ihre Implementierung, die Zirkulation von Menschen über die Grenzen zu kontrollieren, wozu sie sich so berechtigt fühlen (vgl. Torpey 1998). Wenn diese Diskurse und Mythen der politischen Professionellen aber auf die sozialen Praktiken der Grenze treffen und die Unmöglichkeit offensichtlich wird, das Verhalten von Millionen von Menschen zu steuern, dann geraten sie in Konflikt mit den Professionellen der Sicherheit, die den Auftrag haben, die Grenze zu kontrollieren, aber von der praktischen Unmöglichkeit wissen, die Grenze tatsächlich zu versiegeln.

Dieser »Wille zu beherrschen « der Politiker hat nur einen Effekt, der aber sehr wichtig ist. Sie verändern den Status von Personen, indem sie die Bedingungen ändern, die Reise- und Bleibemöglichkeiten eröffnen oder beschränken. Indem sie etwa die Ankunft oder den Aufenthalt als legal oder illegal erklären. Aber sie wissen, dass jeder, der wirklich kommen will, dies auch tun kann. Als Illegaler wird der Migrant so zum Feind des Politikers, besonders für Lokalpolitiker, die Bürgermeister, die in direktem Kontakt mit Migranten kommen und diese zurückweisen wollen. Politiker fühlen sich beleidigt durch ihre offensichtliche Unfähigkeit, die Integrität des »nationalen Körpers « zu sichern, den sie ja repräsentieren.

Doch auch wenn Politiker frustriert sind vom Kontrast, der zwischen ihren Selbstbildern, ihrer effektiven Macht und den tatsächlichen Praktiken existiert, so ist ihre Macht doch keine gewöhnliche. Sie ist nämlich die Fähigkeit zu definieren, wer ein Migrant ist und was es bedeutet ein Migrant zu sein. Ihre symbolische Macht ist nicht Abwesenheit von Macht (vgl. Edelman 1991). In jedem Land wird die Figur des Migranten durch die Umkehrung des Bildes vom "guten Staatsbürger" geschaffen. In Frankreich erzeugen Laizismus und Zentralismus 
das Bild des Migranten als religiöser Fanatiker, der Mitglied einer Gemeinschaft ist, die die Fundamente des Republikanismus zerstören will. In Deutschland erzeugen Sozialkontrolle und Sozialpartnerschaft ein Bild eines revolutionären und sozial auffälligen Migranten. In Großbritannien lassen traditionelle und Gemeinschaftsregeln den Migranten als einen Unruhestifter erscheinen, der keinen Respekt für Anstand und gutes Benehmen hat.

Die Inkarnationen dieser Figur mögen wechseln, aber das Muster wird stärker. In der Mitte der 1920er Jahre kamen die Migranten in Frankreich aus Polen oder Italien, heute kommen sie aus Algerien oder sie sind in Frankreich geboren. Der Begriff des Migranten ist eine Methode, um jemanden als Feind der Kernwerte eines Landes, eines Staates zu definieren, und er hat nichts zu tun mit der rechtlichen Kategorie des Ausländers. Das Wort Immigrant ist ein Schibboleth (vgl. Bourdieu 1998).

Zugleich gibt es ein offensichtliches Paradox: Wenn jedes Land eine unterschiedliche Vorstellung vom Migranten hat, wie können dann nationale Sicherheitsagenturen, etwa auf europäischer Ebene wirksam zusammenarbeiten? Hier ist die Plastizität der Terminologie wichtig. Wenn die Franzosen den Ausdruck »Algerier« benutzen, um ihren namenlosen Feind zu benennen, dann wird das gegenüber Briten zum Problem, weil es dort eine andere Politik gegenüber dem Islam gibt. Ähnlich wäre es, wenn die deutsche Regierung gegenüber der französischen von Kurden als »Terroristen« spräche. Sie könnten auf Widerspruch treffen. Doch wenn die Sicherheitsdienste das Wort Immigrant als Symbol von Gefahr verwenden, dann ist Konsens möglich, denn dieses Wort kann der Fremde als Algerier sein, also jemand der als Mitglied einer ethnischen Minderheit schon die Staatsbürgerschaft besitzt, oder aber auch andere Formen von Fremden. Jedes Land kann dann den anderen gegenüber seine Ängste plausibel machen, so dass Algerier in Großbritannien und Deutschland überwacht werden wie auch Kurden in Frankreich und Großbritannien. Das kommt einem Börsenhandel der Sicherheit gleich, und dies ist in der Tat die Rolle von Europol in seiner Konkurrenz zu Interpol und nun einigen vertraulichen Kreisen innerhalb der NATO.

Das Herzstück der politischen Arbeit von Berufspolitikern ist deshalb die Beziehungen zwischen Sicherheit und Migration. 
Keins der beiden Wörter ist an sich aussagefähig, keines beschreibt genaue Phänomene. Sie entstammen nicht klar erkennbaren sozialen Problemlagen, auf die Politiker aufmerksam machen. Die Beziehung zwischen Sicherheit und Migration ist voll und ganz politisch. Die Bezeichnungen sind niemals unschuldig. Beides sind umstrittene Begriffe, und sie werden genutzt, um zu mobilisieren, nicht um etwas zu erklären. Einwanderung wird in westlichen Gesellschaften zur Zeit auf eine Art und Weise problematisiert, die ganz anders ist als die alte Unterscheidung von Staatsbürgern und Ausländern. Hier geht es nicht um einen legalen Status, sondern um ein soziales Image, es geht um »die soziale Verteilung des Bösen«.

Migration wird als politisches Problem gesehen, denn sie wird als etwas in die politische Arena eingeführt, dass das politische Gemeinwesen und den Staat bedroht. Einwanderung wird seitdem als etwas Problematisches angesehen, als etwas, das durch Gesetzgebung nicht gelöst werden kann. Manche meinen, das »Problem « könne durch Kompromisse gelöst werden, mit dem Fokus auf nationale Interessen, indem etwa Immigranten als ökonomischer Vorteil gesehen werden. Aber für andere, besonders für Vertreter der Sicherheitsbehörden, ist Immigration keine politische Frage, sondern ein Sicherheitsproblem. Für sie sind Migranten ein Problem in der Vergangenheit gewesen, und sie bleiben auch heute eine heimtückische Gefahr: Der Ausdruck Immigrant ist nur im Kontext des Kampfes "gegen illegale Einwanderung" politisch bedeutsam oder in Zusammenhang mit der »Regulierung «, immer jedoch mit dem Effekt, durch eine Rhetorik des kulturellen Nationalismus einen Unterschied zwischen den Staatsbürgern und den Außenseitern im Innern der Staaten zu schaffen (vgl. Bigo 1996a).

Oft beruht der Diskurs, der sich "gegen « die Versicherheitlichung richtet, indem etwa die »Festung Europa« kritisiert wird, auf genau den gleichen Voraussetzungen wie der Diskurs, den er kritisiert, etwa im Bezug auf Souveränität, Staat oder politischen Körper. Dann wird der Inhalt kritisiert, nicht aber die Regeln der Formierung dieses Diskurses. Dabei sind sie es, aus denen der Sicherheitsdiskurs seine Kraft bezieht (vgl. Rea 1998; Rattansi/Westwood 1994).

Die Europäisierung der Politik hat neue Foren hervorgebracht, in denen Politiker, ob von rechts oder links, ihr »law 
and order«-Programm zur Kontrolle der Migrationsflüsse vertreten, um so ihre eigene Macht zu sichern. Diese Politiker fordern, häufig mit Erfolg bei ihrer Wählerschaft, mehr Kontrollen, mehr Monitoring, mehr private Beteiligung der Unternehmen und der Bürger, um die Sicherheit der Grenzen zu konsolidieren. Sie mobilisieren Sicherheitsagenturen, fragen nach der Hilfe von Bürgern und versteigen sich in Phantasien eines internen Sicherheitsstaates, dessen überwachende Kapazitäten noch nie so stark waren wie seitdem allgemein die Schwäche des Staates beklagt wird (vgl. Weil 1998). Und doch sind die Staaten völlig unfähig, die Dinge umzusetzen, die in ihren Programmen vorgeschlagen werden.

Sicherheit wird hier von traditionellen Gruppen als die Spitze eines politischen Problems betrachtet, bei dem es gerechtfertigt sei, »außergewöhnliche Maßnahmen" und »Maßnahmen jenseits des Gesetzes « zu ergreifen. Sicherheitspolitik ist somit ein Prozess, der aus der Mobilisierung durch politische Diskurse und der Praktiken von Sicherheitsagenturen resultiert, und der auf dem Argument von Gefahr und Notständen beruht. Viele Studien vergessen den primären Effekt, dass politische Mobilisierung zur Versicherheitlichung führt. Damit reproduzieren sie auf analytischer Ebene den Diskurs der »hard-liner« oder der berufsmäßigen Sicherheitsexperten.

Sie betrachten Sicherheit als einen von der Politik zu unterscheidenden Bereich, als einen »besonderen Typ von Politik, der auf unterschiedliche Bereiche angewandt werden kann" (vgl. Buzan/Waever/de Wilde 1998). Sie verstehen Sicherheit als eine "Sphäre«, die der Armee und anderen Sicherheitsexperten zugerechnet werden kann, eine Sphäre der existentiellen Bedrohungen des Überlebens, die aus anderen Bereichen kommen würden (Buzan 1983). Damit unterstützen sie die Sichtweise der Professionellen, dass Sicherheit eine "Erklärung «, eine Lösung ist, statt diesen Diskurs selbst zu kritisieren.

Weil sie dies vernachlässigt, führt die kritische Sicht auf Sicherheitspolitik, wie sie Barry Buzan, Ole Waever und Jaap de Wilde entwickelt haben, dazu, dass militärische Diskurse ins akademische Feld über soziale und innere Sicherheit eingeführt werden. Sie wiederholen die Diskurse, die von einem Teil des Militärs geführt werden, die sich zu »Kleinen Kriegen« äußern. Diskurse, die, nach dem Ende des Kalten Krieges, erklären 
wollten, dass Immigration eine existentielle Bedrohung für die nationale Identität darstellt, selbst wenn die Migranten den Staat selbst gar nicht bedrohen. Diese Theoretiker akzeptieren die »Wahrheit « darüber, was Sicherheit ist, nicht indem sie mit dem Militär übereinstimmen, sondern indem sie den Bereich der Sicherheit als einen jenseits des Politischen liegenden definieren, als einen, der mit Ausnahmezuständen und Ausnahme zu tun hat (vgl. Terriff/Croft/James/Morgan 1999; David 2000). Auf diese Weise tragen sie zu der Idee des Ausnahmecharakters dieser Politik bei. Weil sie die Illusionen des Feldes teilen, das sie analysieren, verstehen sie nicht wirklich den Effekt des Kampfes zwischen den Managern des Unbehagens, und sie teilen mit den Professionellen die Visionen über die »Wahrheit « und ihren Zwangsmaßnahmen als »Lösung«.

Einige Akteure im akademischen Feld und die Professionellen der Sicherheit nehmen an einer aktiven Strategie der Legitimierung ihrer Rolle im Feld der Migration über das politische Spiel der Integrität eines Volkskörpers und des Staates teil. ${ }^{13}$ Sie weisen die Heterogenität des Lebens zurück und versuchen es ständig auf Homogenität und Hierarchie zwischen verschiedenen Kategorien zu reduzieren (vgl. Veyne 1971).

Die Unterscheidung zwischen der Sicherheit des Staates und sozialer Sicherheit ist aber analytisch nicht hilfreich. Sie reproduziert lediglich den Diskurs der Professionellen der Sicherheit in ihrem Bemühen darum, eine Hierarchie von Gefahren herzustellen, die ihre Ansprüche auf Ressourcen legitimieren soll. Versicherheitlichung lässt sich nicht sinnvoll nur als diskursive Praxis bezeichnen, die um den Begriff der Ausnahme kreist, auch wenn sie darin ihren Ursprung haben mag. Versicherheitlichung funktioniert durch Alltagspraktiken, durch Machteffekte, die eher kontinuierlich als außergewöhnlich sind, durch politische Kämpfe und besonders durch Wettbewerb zwischen Institutionen im Feld der Sicherheit, in dem es um triviale Interessen geht (vgl. auch Williams 1999; Bigo 2001b)

13 Um einige Panikmacher zu nennen, die seit Anfang der 1990er Jahre zur (Un-)Sicherheit geschrieben haben: Richard Clutterbuck (1990); J. Lodge (1992); Paul Wilkinson (1990); R. Latter (1990); A. Jamieson (1992); F.J. Horchem (1995); P. Migaux (1993); Raufer (1993). Die zunehmend expandierende Liste lässt sich nach 1995 weiter fortführen. 
Die Versicherheitlichung der Einwanderung ist das Resultat, und nicht die Ursache, der Entwicklung von Technologien der Kontrolle und Überwachung. Sie ist verbunden mit der Computerisierung, mit Risikoprofilen, Visapolitik, der Distanzkontrolle von Grenzen, der Schaffung von internationalen und nicht-territorialen Zonen in Flughäfen, usw. (vgl. Mathiesen 1999; Bigo 1996b; Marx 1972).

Die Analyse der Versicherheitlichung eines Referenzobjektes in einem Feld oder Sektor (Umwelt, Wirtschaft, Gesellschaft) ist nicht bloß als Sprechakt interessant, sondern auch weil diese Sprechakte mit strukturellen Positionen der Sprechakte korrelieren (vgl. Waever 1997). Aus dieser Perspektive resultiert die Versicherheitlichung aus Machtpositionen und nicht aus den Handlungen irgendwelcher Individuen, die Interpretationsrahmen herstellen (vgl. Deleuze/Guattari 1972; Butler 1996); sie resultiert aus Auseinandersetzungen im Innern von Institutionen und zwischen Institutionen darüber, was als legitime Wahrheit gelten darf. Wenn man sich nur auf die Rolle politischer Diskurse im Prozess der Versicherheitlichung bezieht, dann unterschätzt man die Rolle der bürokratischen Professionalisierung im Management der Angst.

\section{Sicherheit und Einwanderung: Sicht eines professionellen Managers des Unbehagens}

Die dialektische Beziehung zwischen Politikern und den professionellen Managern der Angst impliziert, dass die Institutionen der Angst nicht nur auf Bedrohung antworten, sondern dass sie auch bestimmen, was als Risiko und Bedrohung gilt und was nicht. Sie tun das als »Professionelle«. Ihre Mitarbeiter sind damit beschäftigt, Bedrohungen zu definieren und Prioritäten herzustellen. Sie klassifizieren Ereignisse nach ihren eigenen Kategorien. Während Autounfälle gegenwärtig eher als "Ungeschick", denn als Bedrohung betrachtet werden, geraten andere Ereignisse in den Beurteilungen der »Professionellen « in den Status einer Gefahr oder zum Risiko, das sie kontrollieren müssen. Natürlich können »Amateure" im Sicherheitsprozess (Verbände, Kirchen, Oppositionsparteien, engagierte Bürger) in diesem Spiel intervenieren und die Beurteilung des Immigranten als »Risiko« in Frage stellen. Aber die Professionellen haben 
den Vorteil, dass sie öffentliche Gewalt ausüben. ${ }^{14}$ Sie verfügen über das institutionelle Wissen zu Bedrohungen, und sie haben die Technologien, die man braucht, um auf diese »Bedrohungen « zu antworten. Sie profitieren, von dem Glauben, dass sie etwas wissen, dass »wir " (Nicht-Professionelle, Amateure) nicht wissen, und dass sie über spezifische Handlungsformen verfügen, die wir nicht kennen.

Ein besonderes Charakteristikum dieses Diskurses ist der Mangel an Präzision, mit dem Bedrohungen von den Professionellen konstatiert werden, zu denen sie "geheimes Wissen « haben. Amateure müssen ihre Behauptungen immer belegen, während die Professionellen, egal ob öffentliche oder private, nationale oder internationale Dinge behaupten können, ohne sie zu beweisen. Sie generalisieren oft von einem einzigen Fall, um das Publikum dazu zu veranlassen, zu glauben, dass die Bedrohung weiter verbreitet ist als erwartet. Das Ethos dieses geteilten Wissens zwischen den Professionellen, ein Wissen, das jenseits der Kenntnisse von Menschen liegt, die das »Knowhow « der Risiko-Einschätzung nicht kennen, ist also das Ethos des Geheimnisses und der Vertraulichkeit. Es schafft eine Gemeinschaft der gegenseitigen Anerkennung und es regiert eine Logik der impliziten Akzeptanz von Behauptungen, die von Professionellen gemacht werden, nicht nur im Hinblick auf den Inhalt dieser Behauptungen, sondern auch bezogen auf die Form und die Technologien, mit denen dieses Wissen erworben wird. Die Technologie, wie etwa die Satelliteninformationen, die Echelon bereitstellt, oder die Datenbanken, die Europol und Interpol bereithalten, soll die Wahrheit der Daten garantieren, die sie aufbewahren. Das Ethos, das dadurch erzeugt wird, impliziert spezifische Weisen von Vertrauen und Misstrauen. Im professionellen »Universum des Bedrohungsmanagements « geht es deshalb immer weniger um den Einsatz von Gewalt gegen ein Individuum und immer mehr um das Geschäft einer Bank, die Kredite über Kundenprofile verwaltet.

Der Begriff des Habitus ist in diesem Zusammenhang sehr hilfreich. Er hilft nämlich zu verstehen, wie die Methode der Antizipation von Ereignissen durch morphologische Technolo-

14 Vgl. dazu die Kritik zu John Austin von Pierre Bourdieu (1982) oder Bourdieu (1991). 
gien als Vorhersage der Bewegungen von Gruppen im Raum wie auch ihres Verhaltens dazu führt, dass ein »Aktienmarkt« von Bedrohungsängsten auf transnationaler Ebene entsteht, dessen Wissen gegenüber Außenstehenden abgeschottet wird. Dieser Habitus vereint die Mitglieder von so unterschiedlichen Diensten wie des Zolls, der Polizei, der Geheimdienste, und der Banken, die an Risikoeinschätzungen arbeiten, sowie der Lieferanten von neuen Technologien der Überwachung. Sie teilen einen spezifischen "Sinn des Spiels«. Sie nehmen an einer gemeinsamen Illusion teil, denn sie glauben und verhalten sich in ähnlicher Weise auch wenn sie zueinander in Wettbewerb stehen. Die Professionellen des Sicherheitsfeldes sind alle »Manager der Angst «. Für dieses Feld, das Management der Angst, haben sie eine beträchtliche Autonomie erreicht. Es ist ihnen gelungen, "Sicherheit« als ihr Feld zu monopolisieren, das nicht mehr das Feld nationaler Politiker ist. Sie haben die Sicherheit zu ihrem legitimen Objekt gemacht, durch ihre Diskurse, aber auch durch den Einsatz von Zeit, statistischer Apparate und anderen Routinen, die politische Bezeichnungen glaubhaft machen.

Dieses Feld der professionellen Sicherheit ist zunehmend transnational organisiert. Es verbindet Bürokratien über bestimmte Bedrohungen, die gemeinsam kontrolliert werden müssen: die Migration, die reguliert werden muss, eine Umwelt, die geschützt werden soll, eine Terrorist, der bekämpft werden muss, und am Ende eine Bevölkerung, die sich Sorgen darüber macht, von Barbaren umgeben zu sein und die von der Idee ihrer untergehenden Zivilisation besessen ist (vgl. Hassner 1996). Diese Internationalisierung ist besonders für die Europäische Union bedeutsam, wo die professionellen Manager der Angst, ihre eigenen Foren und Netzwerke ausgebildet haben, manchmal entgegen den Absichten ihrer nationalen Politiker. In manchen Domänen jedoch haben ihre Netzwerke auch eine transatlantische Dimension.

Die Versicherheitlichung wird also erzeugt durch eine Konfrontation zwischen den Strategien politischer Akteure (oder von Akteuren, die Zugang zur politischen Bühne über die Medien haben) im nationalen politischen Feld, und den Sicherheitsprofessionellen auf transnationaler Ebene (öffentliche und private Bürokratien des Management der Angst) und durch 
den globalen sozialen Wandel, der die Möglichkeiten der Grenzkontrolle verändert. Der Prozess der Sicherheit ist also das Resultat eines Feldeffektes, in dem es keinen zentralen Akteur und keine »Meister des Spiels « mehr gibt, sondern in dem das Wissen aller Beteiligten und technische Ressourcen eine Hierarchie der Bedrohungen erzeugen. Der Prozess umfasst also die Durchsetzung einer Behauptung über Sicherheit, die verstanden wird als die "Wahrheit « von Institutionen und »unabhängigen Experten«. Diese »Wahrheit« wird unterstützt durch das Wissen verschiedener Sicherheitsagenturen, seien sie privat oder staatlich, und durch den vorherrschenden Diskurs in den Medien (vgl. Bigo 2000b).

Versicherheitlichung ist also die Verwandlung eines politischen Diskurses in einen Diskurs der Wahrheit durch die Professionellen des Bedrohungsmanagements, die damit ihre institutionellen Interessen verfolgen.

Im Gegensatz zu manchen Erklärungen über Versicherheitlichung von Migration wurde die Immigration nicht einfach zum Sicherheitsproblem zum Beispiel in den Jahren der ökonomischen Krise um 1974 oder mit dem Ende des Ost-WestKonflikts. Immigration wurde zum Sicherheitsthema, weil es von Professionellen des Sicherheitsmanagements so bezeichnet wurde, damit sie ihre Positionen sichern konnten und um bestimmte Formen ihres institutionellen Wissens (Militär, Polizei, Geheimdienste) in etwas zu verwandeln, das Bedeutung hatte. Migration funktionierte darin als eine Referenz, um die herum ein Netzwerk von Bedeutungen mit Sicherheitsrelevanz entstand, dass es jeder Bürokratie erlaubte, an andere etwas zu verkaufen, um so im engeren Sinne eine Hierarchisierung der Ängste zu erreichen. Immigration ist also mit anderen Worten ein Schlagwort, ein Schibboleth, in dem die institutionellen Aussagen bezogen auf Sicherheitsnormen auf den innenpolitischen und internationalen Ebenen konvergieren. Die »neuen Bedrohungen «, mit denen sich Polizei, Militär, der Zoll und Geheimdienste beschäftigen, konvergieren in diesem Punkt (vgl. Katzenstein 1996).

Die Gegenwart ist in dieser Hinsicht besonders interessant. Innen und Außen haben keine klare Bedeutung mehr für die Professionellen des Bedrohungsmanagements. Das MöbiusBand hat den traditionellen Begriff der Grenze ersetzt. Es de- 
stabilisiert die Figuren von Bedrohungen wie auch die Grenzen der Aktivitäten von Institutionen. Während des Ost-WestKonflikts wurde militärische Bedrohung mit der Sowjetunion identifiziert und die Polizei beschäftigte sich mit Verbrechen. Die Bewegung von großen Menschengruppen, ein Thema schon der zwanziger Jahre, schien während des Kalten Krieges unproblematisch. Ideologie und die Zirkulation von Menschen wurden nicht in einen Zusammenhang gebracht, außer in der Idee der »fünften Kolonne Moskaus", die den Westen infiltrieren sollte. In Europa hat die Schaffung der Europäischen Union, die Implementierung des Schengen-Abkommens und die Abschaffung der Grenzkontrollen die Situation verändert. Mit dem Ende der Bipolarität und der Krise des Militärs musste sich auch die Gestalt des Feindes entwickeln. Militärische Organisationen brauchten andere Feinde als die Sowjetunion. Zur gleichen Zeit erfanden Polizisten auf der EU-Ebene den Begriff der »inneren Sicherheit«, um die Zusammenarbeit zwischen Polizeiorganisationen zu befördern und um die Überwachung auf Menschen auszudehnen, die die Grenzen innerhalb Europas überschritten. In einigen Militärkreisen verband sich diese Idee mit der Vorstellung einer südlichen Bedrohung, so dass die Aufgabe der Überwachung auf Menschen aus dem Ausland ausgedehnt wurde.

Wie Pierre Bourdieu gezeigt hat, können wir die Autonomisierung eines Feldes dadurch erklären, dass innerhalb eines bestehenden Feldes Normen und Ideen verändert werden, weil es in diesem Feld Konflikte gibt. Dann wird Kreativität wichtig, auch wenn Kreativität hier lediglich die Regression eines schon bestehenden Habitus und das Überschreiben von bekannten Geschichten mit alten Grammatiken bedeutet. Diese Analyse der Sicherheit zeigt, dass die Vermischung von interner und externer Sicherheit die Bedingung der Möglichkeit produziert hat, durch die der Migrant von beiden Seiten zum Objekt der Versicherheitlichung wurde. Das »Feld der Sicherheit«, in dem Polizisten nun Geheimdienstmitarbeiter und Militärs treffen, um einen weiteren Begriff der Sicherheit zu formulieren, konzentriert sich jetzt auf den Migranten als eine interne und externe Bedrohung. Nicht der innere und der äußere Raum haben sich verändert, und es ist auch nicht so, dass die internationale Sicherheit sich nun in einem innergesellschaftlichen Bereich äu- 
ßern würde. Sondern in der Figur des Migranten konvergieren zwei Bewegungen der Redefinition von Sicherheit und Gefahr.

Aber was ist der Immigrant für die Professionellen der Sicherheit? Der akademische Begriff als die Bewegung von Menschen, die als Fremde in einem Land ihrer Ankunft bleiben wollen, hat für die Sicherheitsdiskussion keine Bedeutung. Für die Bedrohungsmanager ist Immigration automatisch ein Feld, in dem sie mit ihren Technologien experimentieren können. Erst in zweiter Hinsicht denken sie an Grenzen, die geschützt werden müssen, seien es die einer politischen Gemeinschaft, einer Gruppe oder einer Identität. Die Akteure im Feld der Sicherheit erfinden den Immigranten nach ihren eigenen Fantasien. Es hängt sozusagen von der Kreativität der Akteure ab, welches Bild sie erzeugen. Experten aus Militärkreisen verweisen auf die Existenz von »rogue states «, gescheiterten Staaten und der Beziehung zwischen Diasporas und ihren Herkunftsländern. Geheimdienste vermuten, dass Terrorismus aus dem Ausland von Immigranten unterstützt wird. Polizisten erklären den Anstieg der Gewalt durch die Aktivitäten von Immigranten und ihren Kindern, die nicht hinreichend sozialisiert wären. Journalisten rufen das Gefühl von Unsicherheit bei der Bevölkerung hervor. Ökonomen veranschlagen die Risiken für den Wohlfahrtsstaat durch neue Lasten. Gesundheitsexperten beschuldigen Immigranten, eine Gefahr zu sein, weil sie neue und alte Viren importieren würden. Akademiker schließlich verbinden all diese verschiedenen Ängste in einem Gemälde der »kulturellen Gefahr«, auch wenn sie nicht präzise sagen können, warum die verschiedenen Kategorien so stark variieren.

Im Zentrum des »Wissenschaftlichen Diskurses zur Migration« liegt ein Diskurs über Einwanderung, der Migration als Gefahr und Bedrohung sieht. Und je stärker die Bedrohungen als unsichtbar und diffus betrachtet werden, desto mehr hat es den Anschein, dass sie »von nirgendwo« kommen. Darauf beruht die Katalyse verschiedener Ängste und die Erzeugung falscher Vorstellung über, zum Beispiel, das transnationale organisierte Verbrechen, eine globale Mafia, und illegale Immigration, die wiederum die Wachsamkeit von Institutionen rechtfertigen. In diesem Kontext ist es besonders bedeutsam, dass das Wort Immigration sehr Unterschiedliches bezeichnet, den Kurzaufenthalt ebenso wie ein längeres Bleiben, aber auch die Kin- 
der von ausländischen Eltern. Weil Immigration ein Schlagwort ist, umfasst es verschiedene Aspekte der »Bedrohung «, die sehr heterogen sind, aber im selben Wort zusammengefasst werden (Bigo 1998b).

Der Kontext ist also wichtig. Unter anderen Umständen wird die Bewegung als eine normale Tatsache des sozialen Lebens betrachtet. In einigen westlichen Staaten wird es zum Beispiel als ungerechtfertigt betrachtet, einen jungen Staatsbürger als Immigrant zu bezeichnen, bloß weil seine Eltern im Ausland geboren wurden, etwa in Frankreich. Aber im Kontext einer moralischen Panik, in der der Wohlfahrtsstaat zum strafenden Staat wird, betrachtet man dies als normal und selbstevident, weil Abweichungen vom normalen Verhalten von den Professionellen als ein Angriff auf die politische Gemeinschaft verstanden werden.

Gefangen in dieser Normwelt erlaubt der Verweis auf die Migration, die Heterogenität der Gesellschaft als eine Folge der Immigration zu erklären. Die Versicherheitlichung der Migration ist deshalb ein Prozess, der ständig Unsicherheit und allgemeine Ängste auf die spezifische Kategorie des Migranten zurückführt (vgl. Foucault 1969; Deleuze 1986).

\section{Sicherheit und Migration: Techniken für das Management des Unbehagens}

Die programmatische Begründung des Unbehagens - um die Unterscheidung von Ewald zwischen programmatischer und diagrammatischer Rationalität zu verwenden - strukturiert die diskursive Entwicklung hinsichtlich der Migration. Aber das Programm ist nicht das Diagramm. Das Diagramm funktioniert über Institutionen, über das Panoptikum moderner Gesellschaften und ihrer Widerstände. Aber zunächst ist es wichtig das Programm zu analysieren, die Begründung, die Versicherheitlichung und Liberalismus miteinander verbindet. Denn dies sind keine Gegensätze, wie man zunächst annehmen kann, sondern derselbe Prozess. Das Programm der Versicherheitlichung integriert die soziale Konstruktion von Bedrohung und verschiedenen Ängsten mit dem Verweis auf Probleme, die den Staat, die Grenzen, Städte, Demokratie und Staatsbürgerschaft betreffen, als ob diese die Folgen von Immigration seien (vgl. Ewald 
1996). Die internen Debatten innerhalb dieses Programms zwischen den Sicherheitsdiskursen (über Blockaden, Ausweisung, Abschreckung und Überwachung) und den humanitären Diskursen (über die Notwenigkeit eines Sozialstaates, niedrige Geburtenrate und Menschenrechte von Asylsuchenden) verdecken diese allgemeinen Voraussetzungen der Versicherheitlichung. Tatsächlich ist der zweite Typ des Diskurses - der humanitäre - selbst ein Nebenprodukt des Prozesses der Versicherheitlichung.

So ist zum Beispiel der Diskurs über Menschenrechte von Asylsuchenden de facto ein Teil des Versicherheitlichungsprozesses, wenn die Unterscheidung zwischen Asylsuchenden und illegalen Migranten übernommen wird, bei der ersteren durch die Verdammung letzterer geholfen wird, was aber die Kontrolle der Grenzen an sich rechtfertigt (vgl. Bigo 1998c). Mit der Rationalität dieses Programms (wofür der Begriff moralische Panik verwendet wird, obwohl man damit nur die repressive Seite beleuchtet) wird das Wort Immigration ein Begriff für die Katalyse von Ängsten und Befürchtungen vor wirtschaftlichen, sozialen und politischen Entwicklungen in den westlichen Ländern. Es wird zum Inbegriff von Schrecken und Konfusion über nationale kulturelle Identitäten wie auch von den Schwächen der Solidaritätsmechanismen. Es ist die Terminologie, durch die eine Artikulierung oder sogar Fusion produziert wird, die einen stark generalisierten Diskurs über globale Sicherheit erlaubt, statt dringende Analysen zu hoch diversifizierten Prozessen wie Globalisierung, Städte, Arbeitslosigkeit und Geburtenrate durchzuführen (vgl. auch Wieviorka 1988). Es ist diese generalisierte »diskursive Formation«, welche die Arbeitslosigkeit auf eine simple Kausalität reduziert: Immigranten würden Einheimischen die Jobs wegnehmen. Diese Aussage benötigt aber die Erfindung der binären Kategorien von Einheimischen und Immigranten (vgl. Le Bras 1998). Dieser Formation ist es auch geschuldet, dass die Zirkulation von Individuen (was den Tourismus einschließt, den Genuss des Reisens, allein die Möglichkeit, dies zu tun und sogar das Gefühl einer europäischen Staatsbürgerschaft, die über die nationalen Grenzen hinaus geht) auf Probleme reduziert wird, wie die Zirkulation von Drittstaatenangehörigen und die Risiken des Terrorismus, Dro- 
genhandels oder des organisierten Verbrechens, Risiken, die von Drittstaatenangehörigen erwartet werden (vgl. Bigo 1992).

Die Techniken zum Management von Angst und die soziale Aufteilung des »Bösen « mobilisieren den Begriff Immigrant für jede Schwäche der politischen Strategie. Durch dieses Label des Immigranten werden zum Beispiel religiöse Traditionen und ihr Platz in der säkularen Moderne reduziert auf das Problem des Aufkommens eines intoleranten und radikalen Islams, indem einige autoritäre Regime in Verbindung gebracht werden mit Individuen, die auf dem Gebiet der EU leben (Césari 1997). In diesem Kontext taucht auch die sehr wichtige Frage der geographischen Segregation auf: Städte sind verbunden mit kapitalistischen Strukturen und Immobilienspekulationen wie auch mit solidarischen Konzeptionen, wie öffentlicher Verkehr, urbane Sicherheit, Umwelt und Wohlfahrt im Allgemeinen. Dies ist mit anderen Themen verbunden, wie »Innenstadt und Kommunitarismus" oder "Unruhen in der Vorstadt«, die sehr schnell als Problem der "Jugend der zweiten Generation « aufgefasst werden (Body-Gendrot 1995; Ceyhan 1997). Das Heraufbeschwören der Figur des Immigranten ist die Konsequenz dessen, dass viele ungelöste strukturelle Fragen in diesen Raum zusammen fließen, wo politische Lösungen fehlen (Arbeitslosigkeit, Stadtplanung, Demographie, das Nord-Süd-Gefälle, usw.). Paradoxerweise ist es auch eine Folge der unscharfen Definition von kollektiven politischen Identitäten in Europa, die zu der Definition der Europäer als homogener Körper nur in Beziehung zu Drittstaatenangehörigen oder Migranten führt und den Europäern erlaubt zu vergessen, dass sie selbst Migranten sind.

Wer kann sich jetzt noch erinnern an die Angst von Großbritannien oder Frankreich vor zehn Jahren vor dem Einströmen griechischer Migranten und den Risiken, die sie mitbringen würden? Die eingeführte Unterscheidung von EU- und NichtEU-Staatsbürgern hat die Beziehung zur Identität verändert, indem eine Assoziation von Immigranten nur mit Drittstaatenangehörigen oder »Schwarzen « erzeugt wurde. Immigrant bezeichnet den Anderen durch den Prozess einer Identitätsgrenze des "Zwischen uns" (Kastoriano 1998). Er oder sie ist der Insider, der der europäischen Gouvernementalität über den Staat hinaus eine Form gibt. Braucht womöglich die Unschärfe der 
umgebenden Zugehörigkeit und die sich verändernde politische Mitgliedschaft $\mathrm{zu}$ Europa notwendigerweise die verschwommene Figur des Immigranten? Die Grenzen der Staatlichkeit stehen auf dem Spiel und unterliegen einer Neukonfiguration gemäß dieser Beziehungen (vgl. Crowley 1998). Wie auch immer, die Komplexität des Sozialen und das Spiel der Grenzen wird vergessen oder verleugnet durch den Diskurs über Versicherheitlichung, der die Benennung eines Schuldigen vorzieht, dessen Unschärfe eine ad hoc Instrumentalisierung ermöglicht.

Ängste, Unruhen, Befürchtungen, die aus den Defiziten der Politik hinsichtlich der Erfüllung ihrer Pflichten auf lokaler, nationaler oder auch europäischer Ebene entstehen, werden wiederum zur Legitimation der Politik genutzt, indem ein Gegner und sogar ein interner Feind definiert wird. Diese Politik ist aber eine sehr extreme Politik, eine degenerierte Version von Carl Schmitt, bei der die Politik die Fortsetzung des Krieges mit anderen Mitteln ist und Diskurse verbreitet werden, die die Behauptung aufstellen »die Gesellschaft muss verteidigt werden« - etwas das Michel Foucault am Fall von Rassismus demonstriert hat. Es ist ein »kriegsbasiertes Gemeinwesen ", die Voraussetzung für eine generalisierte Konfrontation, die nicht mehr fähig ist, zwischen privaten und öffentlichen Feinden zu unterscheiden. Indem behauptet wird, es bestehe die Notwendigkeit des Überlebens um jeden Preis, ein realer und permanenter Kampf, verankert in einer Eschatologie der schlimmsten Art, wird eine Notfallpolitik generiert, eine Angstpolitik, die jeglichen Wandel und jedwedes Risiko in eine intendierte Bedrohung oder einen Feind verwandelt. Das ist die wichtigste Technik der Versicherheitlichung: strukturelle Schwierigkeiten und Transformationen werden in Elemente verwandelt, die es ermöglichen, spezifische Gruppen zu beschuldigen, noch bevor sie irgendetwas getan haben, nur indem sie kategorisiert werden. Risikoprofile werden aus früheren Trends antizipiert und durch die Generalisierung des potentiellen Verhaltens eines jeden Individuums betreffend der Risikokategorie erstellt.

Dieser auf Befürchtungen gegründete Sicherheitsprozess ist eine politische Herrschaftsmethode, die die Angst gegen einen Feind kanalisiert, der immer unscharf bleibt und schwierig zu fassen ist, während gleichzeitig eine Politik des Vergessens (oft 
unbeabsichtigt) gegenüber den Konsequenzen der strukturellöffentlichen Politik betrieben wird, die vor 20 oder 30 Jahren eingeführt wurde. Der auf Angst gegründete Sicherheitsprozess wird den Disziplinarmethoden beigefügt und stärkt die Legitimität der permanenten Überwachung, die angeblich immer für die »Anderen « bestimmt ist, für die schlechten Bürger. Ihre soziale Unsichtbarkeit führt in einigen Fällen (wenn Zeichen des Handelns gezeigt werden müssen) durch Formen der Xenophobie zu einer Strategie der "Sichtbarkeit«, bei denen Kriterien erfunden werden (Hautfarbe, religiöse Praktiken, kulinarische Praktiken), die Sie von Uns trennen. Dem Verbrechen ein Gesicht geben heißt daher dem Migranten ein Gesicht geben.

Diese Herrschaftsmethode spielt mit den innersten Bestandteilen der Angst und Unsicherheit, die in die heutige Risikogesellschaft eingepflanzt sind, um diese wiederum zu festigen, entweder auf der Ebene von Nationen, intermediärer kollektiver Gruppen oder von Individuen. Diese Machtmethode vereint interne und externe, individuelle und kollektive Sicherheit und versucht das Vertrauen in den Staat wieder herzustellen und zwar nicht über austeilende Sicherheiten, sondern indem Menschen beunruhigt werden, darüber was sowohl intern als auch extern passiert. Das daraus resultierende Weltbild ist dominiert von Chaos und urbaner Unsicherheit.

Als Resultat dieser Immigrationshypothese möchte ich - in Erweiterung zur Arbeit von Michel Foucault - behaupten, dass die Versicherheitlichung der Immigration, die Einführung immer restriktiverer Normen, die Ablehnungs- und Internierungspraktiken an der Grenze, die Stärkung eines »internen Sicherheitsstaates « auf Kosten des Wohlfahrtstaates, Zeichen einer generellen Transformation sind, in der die auf Befürchtungen und Unruhe basierende Form der Gouvernementalität eine Macht ablöst, welche vor allem ein Garant für Sicherheit und Schutz sein sollte (Delumeau 1989). Die Gouvernementalitätsform postmoderner Gesellschaften ist kein Panoptikum, bei dem die globale Überwachung jeden einzelnen betrifft, sondern eine Form des ban-opticon, bei der die Überwachungsmethoden ein Auswahl treffen, wer überwacht werden soll und wer aufgrund seines Profils davon ausgenommen wird (vgl. Bigo 2000c). Diese Form des vor- und nach-Hobbesianischen Staates scheint auf die Idee des sozialen Vertrags gänzlich zu verzich- 
ten und transformiert die Angst in einen Herrschaftsmodus. Die Betonung liegt nicht länger auf der Förderung und dem Schutz der individuellen Entwicklung, vielmehr wird mit dem Verweis auf potentiell gefährliche Minderheiten mit Ängsten gespielt. Weder reduzierbar auf Herrschaft und Bestrafung noch auf Bio-Politik und Macht über das Leben stützt sich diese politische Methode auf proaktive, antizipierende und morphologische Techniken, die eine chaotische Zukunft mit einem minimalistischen Management bewältigen sollen, das sich nur noch auf riskante (als solche identifiziert) oder auf gefährdete Gruppen bezieht. ${ }^{15}$

Das heißt nicht, dass das Programm des ban-opticon (das hauptsächlich aber nicht nur ein Programm der dominanten Akteure ist, die miteinander im Wettstreit stehen, Bedrohungen $\mathrm{zu}$ definieren und Maßnahmen dagegen zu entwerfen) einfach implementiert werden kann, ohne dass nicht auch lokaler Widerstand geweckt wird (entweder kollektiv oder individuell). Es gibt eine erhebliche Distanz zwischen dem Mythos der Macht, der das Soziale durchdringt und die Gesellschaft vollständig kontrolliert und den vielfältigen und komplexen Praktiken der »Machteffekte«. Diese Machteffekte sind aufgrund der "Mikrophysik « der Kämpfe zwischen den Dominanten, den Experten usw. schwieriger zu kalkulieren als man glaubt. Das Programm der »sicheren " Immigration mit dem Ziel der absoluten Kontrolle kann unvorhersehbare grenzüberschreitende (im Sinne von Klassen und Nationen) Widerstände hervorbringen - wie dies der Kampf der nicht registrierten Migranten in Frankreich (les sans papiers) und der Kampf gegen Abschiebung auf den internationalen Zonen der Flughäfen zeigen. Diese Zonen, bei denen der Staat sich weigert, sie als Teil seines Territoriums anzuerkennen und dennoch möchte, dass sie unter seine Souveränität fallen, sind heute der zentrale Brennpunkt der Spannung zwischen Globalisierung und des territorialisierten Kontrollapparats. Die Aufrechterhaltung der Souveränität ist aber nur durch transnationales Handeln möglich, was jedoch ein wenig mehr von der Vision des Gemeinwesens als Körper zerstört. Die Konsequenzen gehen über die »lokalen« Kämpfe

$15 \mathrm{Zu}$ dem Phänomen »Proaktivität« empfehle ich als weiterführende Literatur das Journal Deviance et Société 1 (1997). 
hinaus und beinhalten die Bildung eines Netzwerkes, das den sozialen Widerstand auf globaler Ebene organisiert.

Und dennoch, während die Normen und praktischen Bedingungen der Demokratie verändert werden, konzentrierte diese auf Angst beruhende Gouvernementalität die Mittel, das Verhalten anderer Menschen zu lenken, in den Händen derjenigen, die administratives Managementwissen über Angst und Risiken besitzen. Diese Gouvernementalität ergriff zum eigenen quasi-exklusiven Nutzen die Disziplinierungs- und Überwachungsmethoden, die es ermöglichen, »Verhalten zu steuern" und die Struktur des Staates selbst zu verändern. Diese Gouvernementalität entledigte sich einiger Akteure, wie das Parlament, das für lange Zeit von dieser Konzentration profitierte. Es verändert alte liberale Regierungsmethoden und den Diskurs $\mathrm{zu}$ checks and ballance. Heutzutage sind es die Regierungen und ihre Bürokratien (und nicht die territoriale Form der Staaten), die ihre Kontrolle über die Gesellschaft festigen und mehr denn je ausdehnen, wie über die Auslagerung von Herrschaftsaktivitäten in den privaten Sektor (beispielsweise bei der Ausweiskontrolle in semiöffentlichen Orten oder bei der Gepäckund anderen Kontrollen an Grenzen).

In Europa entfaltet sich diese Gouvernementalität auf nationaler wie auch auf europäischer Ebene und hat sogar eine transatlantische Dimension. Sie verstärkt die internationale $\mathrm{Zu}$ sammenarbeit zwischen verschiedenen Bürokratien, hält eine Rhetorik der Angst hinsichtlich jeglicher Schwächung territorialer und souveräner Methoden aufrecht, während sie in der Praxis weniger an der Kontrolle über Territorium als vielmehr an der Kontrolle über Menschen interessiert ist (vgl. Bigo 1996a). Sie transnationalisiert sich selbst in ein »Außerhalb« der Grenzen und strukturiert die Beziehungsrahmen zwischen Verwaltungen, zwischen der »exekutiven Macht« eines jeden Landes. Sie baut die Sicherheitsdienste auf Kosten von sozialen Einrichtungen aus, indem eben jene Einrichtungen in Sicherheitshelfer verwandelt werden. All dies geht nicht ohne neue Konkurrenten und der Kampf zwischen Trägern von staatlichen Verwaltungswissen und internationalen Organisationen wird in der Tat immer stärker, wie dies auch an den verhüllten Kämpfen zwischen der Europäischen Kommission und den Regierungen im Rat der Europäischen Union sichtbar wurde. Aber es ge- 
winnt immer die Verwaltungsmacht und Verfahren der öffentlichen Deliberation werden abgelehnt.

Sogar wenn NGOs intervenieren, können sie das nur tun, wenn sie professionell werden, indem sie diese Art von Wissen produzieren. Die transnationale Mobilisierung von Verwaltungswissen schreitet schneller voran als die Mobilisierung, die aus alternativen Quellen kommt, wie die von Parlamenten oder Vereinigungen. In dieser Hinsicht ist es schwierig von »Herrschaft ohne Regierung « zu sprechen (Holsti 1992), wie dies einige Internationalisten tun. Herrschaft ist eigentlich eine Ausdehnung der Regierungspraktiken und des Verwaltungswissens außerhalb der »Öffentlichkeit«. Es muss als Mechanismus der Dominanz analysiert werden und nicht als ein neues Wort, welches Thesen zur Polyarchie wieder aufleben lässt. Das ist der Grund, warum ich das Wort Herrschaft vermeide und Gouvernementalität vorziehe - womit die Art der Beherrschung als Handlungs- und Verhaltensstrategie in Beziehungen gemeint ist.

Gouvernementalität durch Angst, sei es national oder transnational auf europäischer Ebene, verändert die internen Balancen zwischen Sicherheit und Freiheit und erweitert den Bereich der Kontrollen. Folglich ändern sich die Formen der Beherrschung (domination) aber nicht die beherrschenden (dominating) Akteure, selbst wenn (an den Rändern) die globale Rekonfiguration eines transnationalen Sicherheitsfeldes einige Agenturen benachteiligt (Strategen, konventionelle Soldaten) wie auch einige Orte (Parlamente) und andere befördert (Orte des lobbying, antiterroristische Polizeiagenturen, Geheimdienste, Zölle und Gendarmerien). Wie Hamit Bozarslan gezeigt hat, kann es passieren, dass die Exekutive sich auch durch die Zerstörung von Staatsformen (Rechtsstaatlichkeit) am Leben erhält, was auch zu einigen Widerständen führt (legale und internationale Normen und die Anwendung dessen). ${ }^{16}$

Die Verteidigung des Rechts gegen die Verwaltung (wie z.B. Orte der Deliberation gegen Geschwindigkeit oder $»$ Dromocracy“, oder Maßnahmen des Vertrauens gegen Maßnahmen systematischer Verdächtigung) ist nicht unwichtig. Die Erfindung

16 Hamit Bozarslan, »L'État et la violence au Moyen-Orient « wird in Les Annales veröffentlicht. 
verschiedener Normen der Emanzipation ist ebenfalls bedeutend, wie dies Ken Booth (1991) und R. B. J. Walker (1997) auf verschiedene Weise betont haben. Generell sollte die Gemeinschaftsproduktion von Sicherheit, wichtig im Kampf gegen das Verbrechen, vom Migrationsthema entkoppelt und von der Gemeinschaftsproduktion von Freiheiten und Garantien begleitet werden, so dass die Schwachen und Neuankömmlinge in einem Land nicht zum exklusiven Angriffsziel einer Politik gegen die Kriminalität werden. Sicherheit sollte daher eine andere Bedeutung bekommen, unabhängig von den Interessen der Politiker und den Experten des Unbehagens. Wissenschaftler können sich dabei nicht als passive Zuschauer präsentieren. Ihre Analysen, auch die kritischsten, werden von Akteuren des sozialen und politischen Zusammenspiels genutzt. Sie nehmen nolens volens an der Produktion der Geschichte der Versicherheitlichung der Immigration teil, wenn sie nicht die Veränderung der Verwaltungspraktiken beschreiben. Ein Rückzug in die reine Theorie ist nicht möglich, dennoch sind Akademiker keine Schlüsselakteure im Prozess der (Ent-)Versicherheitlichung.

Daher muss die Struktur des politischen und bürokratischen Zusammenspiels auf einer dialektischen Grundlage analysiert werden, um das »politische Spektakel« zur Versicherheitlichung der Immigration besser verstehen zu können (vgl. Edelman 1991). Die verschiedenen diskursiven Praktiken müssen genauso durchdrungen werden wie die Heterogenität der nicht-diskursiven Praktiken, die zusammen eine Einheit darstellen, (Gesetzeseinrichtungen, politische Rhetorik, Polizeipraktiken, Überwachungstechnologien, Menschenrechtsdiskurse, Widerstand von Akteuren, usw.) um ein Verständnis für die Artikulation von Wissen und Machtbeziehungen entwickeln zu können (vgl. Dreyfus/Rabinow 1984). Die diskursive Transversalität der Figur des Immigranten muss in all ihren Verdrehungen, Wendungen und Bedeutungen erfasst werden, die die Figur mit den verschiedensten strukturellen Problemen und mit der Figur des souveränen Staates selbst verbindet.

Die Gründe für einen Diskurs der »Regulierung « und die Verschiebung von einem bewahrenden Diskurs mit dem Ziel der Entfaltung hin zu einen Diskurs über Anstieg der Unsicherheit mit der Absicht zu stören und zu beunruhigen, bedarf 
der Forschung entlang der Kriterien von Foucault und Ericson, Bourdieu und Wacquant. Dies ist nur möglich mittels einer detaillierten Analyse über die Positionen der Autoritäten, die eine Bedrohungsdefinition in allen Bürokratien befördern, ob öffentlich oder privat. Die Folge dieses quer durchlaufenden und transnationalen Feldes des Managements des Unbehagens auBerhalb des Nationalen, welches die Praktiken und das Wissen der verschiedenen Agenturen in Europa miteinander verbindet, muss ebenso analysiert werden. Und dabei gilt es zu fragen, was diese Gouvernementalität herausbildet und wie sie sich historisch mit der Figur des Staates gleichsetzt. Diese Analyse, gegründet auf einem soziologischen Konstruktivismus, benötigt eine Reflektion über diskursive Interaktion - über die Positionen der dominanten Sprecher, der Vertreter der Institutionen. Sie muss die interne Logik des Feldes der Experten beim Management des Unbehagens analysieren - die Logik, welche das Gesprochene und das Unausgesprochene hinsichtlich der Immigration und die Praktiken der Sicherheitsagenturen strukturiert. Denn, um es mit Alexander Wendt zu beschreiben, »security is what the professionals of unease management make of it« (Wendt 1992). (Übersetzung von Klaus Schlichte und Margarete Misselwitz)

\section{Literatur}

Abdelmalek, Sayad (1999): »Immigration et pensée d’Etat «. In: Actes de la recherche en sciences sociales, S. 5-15.

Anderson, Malcolm (1996): Frontiers: Territory and State Formation in the Modern World, Cambridge: Polity.

Anderson, Malcolm/Den Boer, Monica (1994): Policing across National Boundaries, London: Printer

Anderson, Malcolm/Den Boer, Monica/Cullen, Peter/Gilmore,

R. C./Walker, Neil (1996): Policing the European Union, Oxford: Clarendon.

Andreas, Peter (2001): Border Games: Policing the U.S.-Mexico Divide, Ithaka, New York: Cornell UP.

Ashley, Richard/Walker, R. B. J. (1990): »Reading Dissidence/Writing the Discipline: Crisis and the Question of Sovereignty in International Relations«. International Studies Quarterly 34, no. 3, S. 367-416. 
Badie, Bertrand (1996): La fin de territories, Paris: Seuil.

Bauman, Zygmunt (1992): »Survival as a Social Construct«. Theory, Culture, and Society 9, no.1, S. 1-36.

Bauman, Zygmunt (1999): Le coût humain de la mondialisation, Paris: Hachette.

Beck, Ulrich (1992): Risk Society: Towards a new Modernity, London: Sage.

Beck, Ulrich (1996): »World Risk Society as Cosmopolitan Society?«. Theory, Culture, and Society 13, no. 4, S. 1-32.

Biersteker, Thomas J./Weber, Cynthia (1996): State Sovereignty as Social Construct, Cambridge, Cambridge UP.

Bigo, Didier (1992): L'europe des polices, et de la sécurité intérieure, Bruxelles: Complexe.

Bigo, Didier (1996a): Polices en réseaux: l'expérience européenne, Paris: Presses de Sciences Po.

Bigo, Didier (1996b): »L'illusoire maîtrise des frontières«. Le Monde Diplomatique, October.

Bigo, Didier (1998a): »Sécurité et immigration, vers une gouvernementalité par l'inquiétude?«. Cultures and Conflicts, Nr. 31, 32, S. 13-38.

Bigo, Didier (1998b): »L'immigration au carrefour des sécurités«. Revue Européenne des Migrations Internationales 1.

Bigo, Didier (1998c): »Europe Passoire et Europe Forteresse: La sécurisation/humanitarisation de l'immigration«. In: Andrea Rea (Hg.), Immigration et Racisme en Europe, Bruxelles: Complexe, S. 203-241.

Bigo, Didier (2000a): »Liason Officers in Europe: New Officers in the European Security Field«. In: James Sheptycki (Hg.), Issues in Transnational Policing, London: Routledge

Bigo, Didier (2000b): When Two Become One. In: Morten Kelstrup/Michael C. Williams (Hg.), International Relations Theory and the Politics of European Integration: Power, Security, and Community, London: Routledge.

Bigo, Didier (2000c): Discipline and Punish beyond the borders: The Social Practices of Controls and Their Locus, ISA.

Bigo, Didier/Hanon, Jean Paul/Bonelli, Laurent/Tsoukala, Anastasia (2000): La notion de protection, de la protection du territoire á la protection des individus, Report for CPGN.

Bigo, Didier (2001a): Le champ européen des professionnels de la sécurité et 1'État. Quebec: IPSA.

Bigo, Didier (2001b): »Internal and External Security(ies): The Möbius Ribbon«. In: Albert Mathias/David Jacobson/Lapid 
Yosef (Hg.), Identities, Borders, and Orders, Minneapolis: U in Minnesota Press, S. 91-136.

Body-Gendrot, Brigitte (1995): Villes et violences: L'irruption de noveaux acteurs, Paris: PUF.

Bonelli, Laurent (2000): La machine á punir, L'esprit frappeur.

Booth, Ken (1991): "Security and Emancipation«. Review of International Studies 17, 4, S. 313-326.

Bourdieu, Pierre (1982): Ce que parler veut dire: L'économie des échanges linguistiques, Paris, Fayard.

Bourdieu, Pierre (1984): Homo academicus, Paris: Minuit.

Bourdieu, Pierre (1990): In Other Words: Essays Towards a Reflexive Sociology, Stanford: Stanford UP.

Bourdieu, Pierre (1991): Language and Symbolic Power, Cambridge: Harvard UP.

Bourdieu, Pierre (1993): La misére du monde, Paris: Seuil.

Bourdieu, Pierre (1994): Raisons Pratiques: Sur la théorie de l'action pratique, Paris: Seuil.

Bourdieu, Pierre (1998): Contre feux: Propos pour servir à la résistance conte l'invasion neo-libéral, Paris: Raison d'agir.

Bozarslan, Hamit: L' Ėtat et la violence au Moyen-Orient, Les Annales.

Butler, Judith (1996): Presentation at Seminar with Pierre Bourdieu on »The Future Role of Intellectuals«, University of California, Berkeley.

Buzan, Barry (1983): People, State, and Fears, Brighton: Harvester.

Buzan, Barry et. al. (1993): Identity, Migration, and the new Security Agenda in Europe, New York: St. Martin's.

Buzan, Barry/Weaver, Ole/de Wilde, Jaap (1998): Security: A new Framework of Analysis, Boulder: Lynne Rienner.

Césari, Jocelyne (1997): Faut-it avoir peur de l'Islam?, Paris: Presses de Sciences Po.

Ceyhan, Ayse (1997): Migrants as a Threat, ISA Paper, Toronto: ISA Annual Meeting.

Clutterbuck, Richard (1990): Terrorism, Drugs, and Crime in Europe after 1002, London: Routledge.

Crowley, John (1998): Where the State Actually starts?, ISA Paper, Minneapolis: ISA Annual Meeting.

David, Charles-Phillippe (2000): La guerre et la paix: Approaches contemporaines de la sécurité et de la stratégie, Paris: Presses de Sciences Po. 
Deleuze, Gilles/Guattari, Félix (1972): Capitalisme et schizophrénie: L'anti-oedipe, Paris: Critique.

Deleuze, Gilles (1986): Foucault, Paris: Minuit.

Delumeau, Jean (1989): Rassurer et protéger: Le sentiment de sécurité dans l'Occident d'autrefois, Paris: Fayard.

Dreyfus, Hubert L./Rabinow, Paul (Hg.) (1984): Michel Foucault: Un parcour philosophique, au-delà de l'objectivité et de la subjectivité, Paris: Gallimard.

Edelman, Murray (1991): Piéces et régles du jeu politiques, Paris: Seuil.

Ericson, Richard (1999): Policing the Risk Society, Toronto: University of Toronto.

Ewald, François (1996): Histoire de l'État Providence, Paris: Grasset.

Favell, Adrian (1998): Philosophies of Integration: The Theory and Practise of Ethnic Minorities Policies in France and Britain, New York: Palgrave.

Foucault, Michel (1969): L' archéologie du savoir, Paris: Gallimard.

Foucault, Michel (1994): »La politique de l'oubli et du déni«. In: Dits et Ecrits, vol. 2/3.

Foucault, Michel (1996): Il faut défendre la société. Course au Collége de France 1976, Paris: Seuil.

Ganster, Paul (1997): Borders and Border regions in Europe and North America, San Diego: Institute for Regional Studies of the Californias.

Geddes, Andrew (1996): The Politics of Immigration and race, Manchester: Baseline.

Giddens, Anthony (1984): The Constitution of Society: Outline of the Theory of Structuration, Cambridge: Polity.

Guild, Elspeth (2001): Transnationalization of Movement of Persons and Labour Forces: The Work Permit Delivery and the Changing Relations between Governments and Companies, Quebec: IPSA.

Hassner, Pierre (1996): »Par-delà la guerre et la paix«. Etudes 9.

Heisler, Martin (2001): »Now and Then, Here and There, Migration and the Transformation of Identities, Borders and Orders«. In: Mathias Albert/David Jacobson/Yosef Lapid (Hg.), Identities, Borders and Orders, Minneapolis: University of Minnesota Press. S. 225-248.

Holsti, K. J. (1992): »Governance without Government: Polyarchy in Nineteenth-century European International Politics«. 
In: J. N. Rosenau/E.O. Czempiel (Hg.), Governance without Government: Order and Change in World Politics, Cambridge: Cambridge UP.

Horchem, F. J. (1995): »The new mass Migrations and International Security «. Democracy and Security 1, S. 1-4.

Hysmans, Jeff (1995): »Migrants as Security Problem«. In: Robert Miles/Dietrich Thranhardt (Hg.), Migration and European Integration: The Dynamics of Inclusion and Exclusion, London: Pinter, S. 53-72.

Jamieson, Alison (1992): »Drug Trafficking after 1992«. Conflict Studies 250, April.

Kastoriano, Riva (1998): Quelle identité pour l'Europe: Le multiculturalisme à l'epreuve, Paris: Presses de Sciences Po.

Katzenstein, Peter J. (1996): Cultural Norms and National Security: Police and Military in Postwar Japan, Ithaka, N. J.: Cornell UP.

Latter, R. (1990): Crime and the European Community, Wilton Park.

Le Bras, Hervé (1998): Le demon des origins: Démographie et extrême-droite, Paris: Editions de l'Aube.

Lessana, Charlotte (1998): „Loi Debré: La fabrique de l'immigré«. Cultures et Conflictes, 7.

Leveau, Rèmy (1998): »The Green Peril«. In: Cyril Buffet/Béatrice Hauser (Hg.), Haunted by History: Myths in International Relations, Oxford: Berghan.

Lodge, J. (1992): Internal Security and Judicial Cooperation beyond Maastricht, Hull: University of Hull.

Mansbach, Richard (1989): The State, Conceptual Chaos, and the Future of International Relations Theory, Boulder: Lynne Rienner.

Marx, Gary T. (1972): „Civil Disorders and the Agents of Social Control«. In: Marx, Gary T. (Hg.), Muckraking Sociology: Research as Social Criticism, New Brunswick, N.J.: Transaction Books.

Mathiesen, Thomas (1999): The Globalisation of Controls, Statewatch Bulletin.

Mathiesen, Thomas (2000): Globalization of Surveillance, Statewatch Report.

Migaux, Philippe (1993): „Sécurité intérieure et menaces extérieures«. CASE, 1.

Palidda, Salvatore (1999): Polizia postmoderna, Roma: Feltrinelli. 
Rattansi, Ali/Westwood, Sally (1994): Racism, Modernity, Identity on the Western Front, Cambridge: Polity.

Raufer, Xavier (1993): Les superpuissances du crime, Paris: Plon.

Rea, Andrea (1998): Immigration et Racisme en Europe, Bruxelles: Complexe.

Rogin, Michael P. (1998): Ronald Reagan, the Movie, and other Episodes of Political Demonology, Berkeley: University of California Press.

Ruggie, John Gerard (1998): Constructing the World Polity: Essays on Internationalization, London, Routhledge.

Scott, James C. (1999): Seeing like a state: How certain Schemes to improve the Human Condition Have Failed, Yale, UP.

Strange, Susan (1994): States and Markets, London: Pinter.

Taguieff, André Pierre (1991): Face au racisme 2: Analyses, hypothéses, perspectives. Paris: La Découverte, S.167-178

Terriff, Terry/Croft, Stuart/James, Lucy/Morgan, Patrick M. (1999): Security Studies Today, Cambridge, Polity.

Torpey, John (1998): »Coming and Going: On the State Monopolization of the Legitimate Means of Movement«. Sociological Theory 16, 3, S. 239-259.

Veyne, Paul (1971): Comment on écrit 1'histoire: Essai d'épistemologie, Paris: Seuil.

Veyne, Paul (1983): Les Grecs ont - ils cru à leurs mythes? Essai sur l'imagination constituante, Paris: Seuil.

Wacquant, Loïc (1998): »De 1’Etat social à 1’Etat pénal«. Actes de la Recherche en Sciences Sociales, 9, 1998.

Waever, Ole (1997): Concepts of Security, Kopenhagen: University of Copenhagen.

Walker, R. B. J./Mendlovitz, Saul H. (1990): Contending Sovereignties: redefining Political Community, Boulder: Lynne Rienner.

Walker, R. B. J. (1997): »The Subject of Security«. In: Krauss, Keith/Williams, Michael C.(Hg.): Critical Security Studies, Minneapolis: Minneapolis UP, S. 61-82.

Weil, Patrick (1998): The Transformation of Immigration Policies: Immigration Control and Nationality Laws in Europe, IUE.

Wendt, Alexander (1992): »Anarchy Is What The States Make of It: The Social Construction of Power Politics«. International Organization 46, 2, S. 391-425.

Wieviorka, Michel (1988): Sociétes et terrorismes, Paris: Fayard. 
Wieviorka, Michel (1992): La France raciste, Paris: Seuil.

Wilkinson, Paul (1990): »Terrorist, Target, and Tactics: New

Risks to World Order «. Conflict Studies 236., Washington:

Research Institute fort he Study of Conflict and Terrorism.

Williams, Michael (1999): Institutions of Security, London: Sage. 



\title{
Möglichkeiten und Grenzen \\ des internationalen Flüchtlingsschutzes für kolumbianische Flüchtlinge in Ecuador
}

KATJA BALTZER/KRISTOFER LENGERT

\begin{abstract}
»Migration can be a move away from adversary, but it can also be a move toward a felt sense of possibility and hope.« (Marsella/Ring 2003: 9)
\end{abstract}

»[...] Ich bin nach Ecuador gekommen, weil ich glaube, dass dieses Land friedlich ist. Hier will ich für den Rest meines

Lebens bleiben. Studieren, arbeiten, eine Familie gründen...« (José, 23 Jahre, Interview 02/2004)

In dem seit 1964 andauernden Bürgerkrieg in Kolumbien haben sich Fluchtbewegungen nicht nur innerhalb des Landes ergeben, sondern auch über die Grenzen hinweg. Aber wer kann als Flüchtling gelten und hat Anspruch auf die Hilfe des UNHCR? In diesem Beitrag geht es um den Migrationsverlauf kolumbianischer Flüchtlinge nach Ecuador. Die AutorInnen richten dabei ihren Blick auf beide Seiten der Grenze: Zunächst wird der Krieg in Kolumbien skizziert und die wesentlichen Fluchtursachen beleuchtet. Anschließend wird der Weg beschrieben, den kolumbianische MigrantInnen gehen müssen, um in Ecuador als Flüchtling im Sinne der Genfer Flüchtlingskonvention anerkannt zu werden. Dies geschieht unter besonderer Berücksichtigung der Rolle des UNHCR als internationale Organisation, die für 
den Schutz von Flüchtlingen seit 2000 in Ecuador aktiv ist. Der Beitrag macht auf die Möglichkeiten und Schwierigkeiten aufmerksam, auf die kolumbianische Flüchtlinge in Ecuador treffen.

\section{Kolumbianische Flüchtlinge in Ecuador}

Der jahrzehntelange bewaffnete Konflikt in Kolumbien hat ein humanitäres Desaster produziert. Vier Millionen KolumbianerInnen wurden im Laufe der letzten 20 Jahre zu Vertriebenen. Die meisten von Ihnen blieben als Binnenflüchtlinge im eigenen Land, jedoch hat die Ausweitung des Bürgerkrieges auf einen Großteil des kolumbianischen Staatsgebietes dazu geführt, dass immer mehr Menschen versuchten, über die Grenzen hinweg in die benachbarten Staaten $\mathrm{zu}$ fliehen. Ecuador ist in stärkerem Ausmaß Ziel kolumbianischer Flüchtlinge als die anderen Anrainerstaaten: Das UN-Flüchtlingskommissariat (UNHCR) schätzt, dass sich mittlerweile bis zu einer halben Million kolumbianische Flüchtlinge in dem kleinen Andenstaat befinden, viele von ihnen ohne sich zu registrieren.

In diesem Beitrag richten wir unseren Blick auf beide Seiten der Grenze und fokussieren ihn auf die Situation der Flüchtlinge. Es wird der Weg nachgezeichnet, den kolumbianische Flüchtlinge zurücklegen, um ihr bisheriges Leben in ihrem Land hinter sich zu lassen und nach Ecuador zu gelangen. Migration und Flucht sind durch eine Vielzahl von politischen, gesellschaftlichen sowie immer auch individuellen Faktoren bestimmt. Neben den primären fluchtauslösenden Faktoren im Heimatland: Krieg und Vertreibung, Hunger und Elend, spielten auch von Ecuador ausgehende Faktoren eine begünstigende Rolle für die Migration. Hierzu zählt etwa die Vorstellung, dass es sich bei Ecuador um einen friedlichen Staat handele oder auch die - im Gegensatz zu anderen Staaten in der Region - offenere ecuadorianische Asylpolitik. Auch wirtschaftliche Motive, wie die Hoffnung auf Arbeit und Verdienstmöglichkeiten, vielleicht um eines Tages mit dem erarbeiteten Geld nach Kolumbien zurückkehren zu können, beeinflussen die Entscheidung zur Migration. 
Nach einer Skizzierung von Fluchtursachen und Motiven der Migration, richten wir unseren Blick auf die Mechanismen und Werkzeuge des Flüchtlingsschutzes in Ecuador und den Prozess, den kolumbianische Flüchtlinge durchlaufen müssen, um institutionellen Schutz im Exil gewährt zu bekommen. Dieser Beitrag thematisiert die besonderen Möglichkeiten und Schwierigkeiten mit denen kolumbianische Flüchtlinge auf der Flucht und beim Prozess ihrer Anerkennung in Ecuador konfrontiert sind. Dabei berücksichtigen wir besonders die Funktion des UNHCR, der seit dem Jahr 2000 als internationale Organisation für den Schutz von Flüchtlingen in Ecuador aktiv ist, dessen Mission kontinuierlich ausgebaut wurde, und der bei der Betreuung des Anerkennungsprozesses eine ganz entscheidende Rolle spielt.

\section{Kolumbien - Ursachen der Vertreibung}

Seit über fünfzig Jahren wird in Kolumbien ein innerer bewaffneter Konflikt ausgetragen. Nach Definition der »Arbeitsgemeinschaft Kriegsursachenforschung « der Universität Hamburg (AKUF) handelt es sich hierbei um einen Antiregimekrieg, in welchem mehrere bewaffnete Oppositionsgruppen gegen die traditionellen Herrschaftsformen aufbegehren und gegen staatliche Sicherheitskräfte und private illegale paramilitärische Verbände kämpfen, um eine Veränderung der Gesellschaftsordnung durchzusetzen (Schreiber 2007: S. 10 ff; S.257 ff).

Während nach dem Ende des Ost-West-Konflikts in ganz Lateinamerika innere bewaffnete Konflikte abebbten oder verschwanden, entwickelte sich der kolumbianische Konflikt gegenläufig. Im Schatten der bewaffneten Auseinandersetzungen vollzog sich seit Mitte der 80er Jahre ein humanitäres Desaster, in welchem die legale politische Opposition zum Ziel und Opfer staatlicher Aufstandsbekämpfung wurde und Übergriffe und Vertreibungen an der Zivilbevölkerung der Systematik der Kriegsführung aller Konfliktparteien entsprachen (Hörtner 2006: 107ff). Der Auf- und Ausbau großer paramilitä- 
rischer Verbände unter dem Dach der AUC1, der Abbruch der Friedensverhandlungen zwischen Regierung und FARC ${ }^{2}$ im Jahr 2001, die Wahl der amtierenden rechtspopulistischen Regierung Uribe Veléz (2002-2010) und die Neuausrichtung der kolumbianischen Innen- und Sicherheitspolitik unter den Vorzeichen autoritärer Terrorismusbekämpfung, bedeuteten für Kolumbien einen neuen Höhepunkt der gewalttätigen Auseinandersetzungen. Regionale Konfliktherde hatten sich auf weite Teile des kolumbianischen Territoriums ausgeweitet (Zelik 2007: 9ff). Zwischen Juni 2001 bis Juni 2006 wurden über 15.000 Menschen aus sozio-politischen Motiven getötet (Comisión Colombiana de Juristas 2006). Hinzu kommen ca. 1.500 Entführungen jährlich (CODHES 2006). Während in der Tendenz die Zahl der Opfer politischer Morde und Entführungen rückläufig ist, gibt es diesen Trend bei den gewaltsamen Vertreibungen nicht. Die Zivilbevölkerung ist das erste Opfer im Bürgerkrieg. Ihr Alltag ist seit Jahrzehnten bestimmt von Gewalt, Armut und Angst. Ca. vier Millionen Menschen wurden zwischen 1985 und $2007 \mathrm{zu}$ Vertriebenen, davon allein 2,3 Millionen zwischen 2000 und 2007 (Salamanca 2008: 6). Diese Zahlen jedoch als Folge direkter Kriegshandlungen zwischen den Kriegsakteuren zu lesen, wäre verkürzt und entspräche weder der Logik der Kriegsführung noch der Systematik der Massenvertreibungen. Vertreibungen gehören für alle Konfliktgegner zu einer Strategie mit dem Ziel, die territoriale Kontrolle herzustellen oder zu erhalten: Der Einsatz paramilitärischer Banden und Todesschwadronen ist in Kolumbien zudem ergänzendes Mittel staatlicher Aufstandsbekämpfungsmaßnahmen. Mit dem Ziel, die vermeintliche Unterstützung und den Rückhalt der Rebellengruppen in der Bevölkerung zu vernichten, wird die Zivilbevölkerung zum direkten Ziel von paramilitärischen Terrorakten: Das soziale Netz der von solchen Aktionen betroffenen Gemeinden wird zerstört; Massaker an der Zivilbevölkerung folgen als Antwort auf Angriffe der Guerilla gegen Militärpos-

$1 \quad$ AUC $=$ Autodefensas Unidas de Colombia - Vereinigte Selbstverteidigungskräfte Kolumbiens (paramilitärisch organisierte Gruppen).

2 FARC= Fuerzas Armadas Revolucionarias de Colombia - Revolutionäre Streitkräfte Kolumbiens (Guerillaorganisation). 
ten oder Infrastruktur. Die Politik der so genannten »Demokratischen Sicherheit« der Regierung Uribe Vélez hat in dieser Hinsicht die Lage der Zivilbevölkerung im Konflikt verschlechtert. Mit Drohung und Gewalt einerseits, andererseits mit Werbekampagnen und finanziellen Anreizen wird die Zivilbevölkerung zur Zusammenarbeit mit den Sicherheitsorganen und paramilitärischen Kräften angehalten (Somasundram 2007: 72ff). Doch diese Zusammenarbeit mit dem Staat birgt für die zur Kooperation gedrängte Zivilbevölkerung ein doppeltes Risiko: Als vermeintliche Spitzel (span. Sapos) werden sie auch Opfer der Guerilla, die begonnen haben, ihrerseits durch Übergriffe gegen die Zivilbevölkerung die Dominanz in »ihrem« Territorium zu sichern. Die Aussage, die Zivilbevölkerung sei zwischen die Fronten des Krieges geraten, trifft den Sachverhalt nur teilweise. Richtiger wäre: Die Zivilbevölkerung wurde zum Terrain des Krieges selbst: Sie ist der Gegenstand um den, gegen den und mit dem gekämpft wird. Doch diese komplexe Konfliktdynamik weist längst nicht alle wichtigen Aspekte im Kontext von Flucht und Vertreibung auf: Häufig sind schlichtweg ökonomische Motive, z.B. von Viehzüchtern, Großgrundbesitzern, zweifelhaften Unternehmern und nicht zuletzt von Drogenbaronen, verantwortlich für regelrechte Massenvertreibungen und Entvölkerung ganzer Landstriche. Betroffen von solchen Unternehmungen ist die Landbevölkerung strukturell benachteiligter Regionen, die wirtschaftlich, vor allem wegen dort vorhandener Bodenschätze (z.B. Öl, Gold, Wasser), oder strategisch interessant sind. Das gilt für die Grenzregionen, für Gebiete, in denen Straßen- oder Kanalbauprojekte umgesetzt werden sollen, und für die Korridore des Drogen-, Benzin- oder Waffenschmuggels (Nubia Bello 2004: 26-28).

\section{Auf der Flucht}

Die ländliche Zivilbevölkerung strukturschwacher Gebiete, darunter insbesondere solche Gruppen, die am stärksten von der Teilhabe gesellschaftlicher Ressourcen ausgeschlossen sind und die zudem sozial und gesellschaftlich diskriminiert werden, ist von Zwangsvertreibungen vornehmlich betroffen. Überproportional stark betroffen sind nach Angaben der unabhängigen Be- 
ratungsstelle für Menschenrechte und Vertriebene CODHES ethnische Minderheiten, wie die afrokolumbianischen Gemeinschaften und indigenen Gemeinden (CODHES 2008: 19ff und 81ff).

Eine nicht mehr ausreichende Grundversorgung und ihre fortwährende Traumatisierung durch wiederholte Übergriffe veranlassten die Menschen zur Flucht. Ziel für die meisten sind die nächstgelegenen Städte. Im Jahr 2005 nahmen die 50 größten Städte Kolumbiens 78 Prozent aller Vertriebenen auf (Romero 2006). Flucht durch Vertreibung bedeutet für die Betroffenen die Aufgabe ihrer bisherigen Existenzgrundlage. Als SelbstversorgerInnen waren sie in der Lage, ihren Lebensunterhalt mit einfachsten Mitteln zu bestreiten. In der neuen Situation leben sie in extremen, ökonomisch prekären Verhältnissen. Ihre Ansiedlung am Rande der Städte ist meist illegal. Es gibt keine ausreichende Versorgung mit Gütern des alltäglichen Überlebensbedarfs. Nur ein Zehntel der intern Vertriebenen haben Zugang zu humanitärer Nothilfe. Zugang zu Arbeit, Bildung und Gesundheitsversorgung existiert nicht oder wird verweigert. Zudem ist die Situation in den Flüchtlingslagern bzw. Stadtrandgebieten, in denen sich die Vertriebenen ansiedeln, von neuen Gewaltstrukturen geprägt. Binnenvertriebene leben in einer weitgehend ungeschützten und rechtlosen Situation und sind neuen Zwängen unterworfen, da lokale Herrschaftsstrukturen häufig von kriminellen Banden oder illegalen bewaffneten Gruppen dominiert sind. In ihrer recht- und schutzlosen Situation besteht die besondere Gefahr für Binnenflüchtlinge, erneut zum Opfer zu werden. Sie werden erpresst, $\mathrm{zu}$ Dienstleistungen gezwungen und in die ökonomische Abhängigkeit getrieben. Mädchen werden in die Prostitution und Jungen in die Mitgliedschaft von Banden gedrängt. Ihre gesellschaftliche Stigmatisierung und Exklusion in Kolumbien, Angst vor Gewalt oder tatsächliche neue Gewalterfahrungen sind Gründe der Weiterwanderung. Viele Vertriebene werden im Laufe der Zeit mehrfach zur Flucht gezwungen (Verney 2006, vgl. auch Salamanca 2008: 159ff). 


\section{Zielland Ecuador}

Der UNHCR geht davon aus, dass eine halbe Million KolumbianerInnen in andere lateinamerikanische Länder geflohen sind, um der Gewalt und Verletzung der Menschenrechte in ihrem Land zu entkommen. Die große Mehrheit dieser Flüchtlinge flieht nach Ecuador, Venezuela, Panama oder Costa Rica. Nur etwa 10 Prozent von ihnen werden überhaupt als Flüchtlinge oder Asylsuchende erfasst (UNHCR 2009: 320ff). Nur einer geringen Zahl von Flüchtlingen gelingt die Flucht über Grenzen hinweg. Während einem Bruchteil der politischen Flüchtlinge, darunter vor allem organisierte AktivistInnen aus Gewerkschaften, Menschenrechtsbüros, politischen Parteien oder anderen Organisationen mit internationalen Kontakten, Asyl in einigen europäischen Ländern, USA und Kanada gewährt wird, hat die große Mehrheit keine Möglichkeit auf eine Flucht in den reichen Norden. Es sind vor allem Kriegsflüchtlinge der grenznahen Provinzen, die in die Nachbarländer Kolumbiens fliehen. Erste Wahl ist hierbei Ecuador. Von 2000 bis 2006 wurden von den in den Nachbarländern registrierten Anträgen auf Asyl und Anerkennung des Flüchtlingsstatus 79 Prozent von Ecuador entgegengenommen, während der Anteil von Venezuela 17 Prozent und der von Panama vier Prozent beträgt (CODHES 2006: 15).

Die grenzüberschreitende Migration von KolumbianerInnen nach Ecuador hat mit der Eskalation des kolumbianischen Bürgerkrieges zur Jahrtausendwende stark zugenommen und sich auf dem erreichten Niveau gehalten. Nach einer Studie des UNHCR entstammten ca. 42 Prozent der kolumbianischen Flüchtlinge in Ecuador aus den Grenzprovinzen Putumayo und Narino, weitere 28 Prozent aus den nahen Provinzen Caqueta, Cauca, Huila und Valle de Cauca (Billsborrow/CEPAR 2006: 22).

Obwohl die Eskalation des kolumbianischen Konflikts in den grenznahen Provinzen anhand eines signifikanten Anstiegs der registrierten Flüchtlingszahlen als Fluchtursache zu belegen ist, stellt die Verfolgung und Flucht vor Gewalt und Krieg nur für einen Teil der KolumbianerInnen in Ecuador den einzigen Grund ihrer Migration dar. Die Entscheidung, den eigenen Lebensmittelpunkt von einem Land in ein anderes zu verlagern, 
ist selten monokausal, sondern setzt sich meist aus einem Set von Einzelaspekten zusammen, denen in ihrer Gesamtheit Beachtung geschenkt werden muss. Um den Fluchtverlauf zu begreifen, gilt es auch die Überlegungen einzelner Flüchtlinge mit einzubeziehen, die für die endgültige Entscheidung zur Flucht ebenfalls eine Rolle spielen, aber nicht den Ausschlag geben. Weitere Gründe für die Wahl Ecuadors als Zielland sind wirtschaftliche und soziale Faktoren, die geografische Lage, die Migrations- und Grenzpolitik Ecuadors, persönliche Kontakte und Netzwerkstrukturen, sowie individuelle Motive (Billsborrow/CEPAR 2006: 25-29).

Ein weit verbreitetes Ressentiment gegen kolumbianische Flüchtlinge lautet, diese würden einzig aus ökonomischen Motiven in das Nachbarland immigrieren. Kolumbien gehört nach Definition der Weltbank zu den »lower-middle-incomeeconomies«. Das Bruttoinlandsprodukt Pro-Kopf lag im Jahre 2007 bei 4.264 US-Dollar, die Inflationsrate war moderat, der geschätzte monatliche Durchschnittslohn lag bei 710 US-Dollar und der staatlich festgesetzte Mindestlohn betrug ca. 190 USDollar. In Ecuador hingegen betrug im Jahr 2007 das statistische Bruttoinlandsprodukt pro Einwohner 3.335 US Dollar, während der geschätzte Durchschnittslohn mit 184 US Dollar knapp unter dem kolumbianischen Mindestlohn lag. (Bundesagentur für Außenwirtschaft 2008a und 2008b). Trotz der ökonomischen Notlage der kolumbianischen Flüchtlinge, sind die äußeren wirtschaftlichen Bedingungen in Ecuador demnach nicht besser, sondern schlechter. Diese Statistiken zumindest erklären nicht, weshalb hunderttausende KolumbianerInnen es vorziehen, in Ecuador unter prekären Bedingungen, in einer teilweise recht- und schutzlosen Situation und mit schlechten Zukunftschancen eine Lebensperspektive zu suchen.

In der Studie von Billsborrow/CEPAR (2006: 26) werden die "Gründe Kolumbien zu verlassen", der befragten KolumbianerInnen in Ecuador statistisch zusammengefasst: Hierbei werden für die Gruppe der kolumbianischen Flüchtlinge und AsylbewerberInnen als Grund ihrer Migration nach Ecuador überwiegend Gewalterfahrungen durch bewaffnete Akteure (88.9 Prozent) und Angst vor weiterer Gewalt (61.1 Prozent) genannt. Für 13 Prozent war auch das Fehlen von Arbeit ein ausschlaggebender Grund. Für die befragten kolumbianischen Migran- 
tInnen, die aus anderen Gründen nach Ecuador migrierten, wurde die eigene wirtschaftlich prekäre Lage als ein ausschlaggebender Faktor der Flucht angegeben (Fehlen von Arbeit: 60.2 Prozent). Gewalt (43.8 Prozent) und die Angst vor Gewalt (40 Prozent) werden jedoch in sehr vielen Fällen ebenfalls angeführt. Billsborrow/CEPAR schlussfolgern hieraus: »We conclude that the flow of migrants from Colombia to Ecuador, even of economic migrants, is affected overwhelming by the violence in Colombia and only secondarily by economic factors." (Billsborrow/CEPAR: 26).

\section{Offene Grenzen}

Lange Zeit hatte Ecuador gegenüber dem Nachbarland eine moderate Migrationspolitik angewandt. Die $586 \mathrm{~km}$ lange gemeinsame Grenze zwischen Kolumbien und Ecuador war im Gegensatz zu den Grenzen der anderen Nachbarstaaten Kolumbiens relativ offen und Infrastrukturbedingungen für eine Flucht günstig. Zwischen Panama und Kolumbien liegt ein kaum passierbares Stück Dschungel, während mehrere Verkehrswege von Kolumbien nach Ecuador gut ausgebaut sind, hier verläuft u.a. die Panamericana, der so genannte PanAmerican Highway, die wichtigste Überlandhandelsroute des Kontinents. Im Rahmen der regionalen Integration hatten die Staaten des Andenpaktes $\mathrm{CAN}^{3}$ auch die Möglichkeiten der Freizügigkeit in der Region erleichtert. Statt einem Visum, benötigte man lediglich eine Tarjeta Andina (Andenkarte), um sich frei in der gesamten Region zu bewegen. Die Andenkarte war kostenlos erhältlich und gestattete den BesitzerInnen den freien Grenzübertritt sowie einen Aufenthalt im jeweiligen Staat bis zu 90 Tagen (UNHCR 2002: 1). Damit bestand für kolumbianische Flüchtlinge und MigrantInnen, die im Besitz der Andenkarte waren, kaum die Gefahr, bereits an der Grenze abgewiesen zu werden. Nach kontinuierlich steigenden Flüchtlingszahlen bis 2003, reagierte die ecuadorianische Regierung im Jahre 2004 mit einer deutlichen Verschärfung der Einreise-

$3 \mathrm{CAN}=$ Comunidad Andina de Naciones - Andengemeinschaft. Dazu gehören: Bolivien, Kolumbien, Ecuador und Peru. 
bestimmungen. Um den Zustrom kolumbianischer Flüchtlinge zu verringern, wurde zunächst die Einführung einer Visumspflicht für KolumbianerInnen gefordert. Für Ecuador als Mitglied der Andengemeinschaft war diese Verschärfung des Einwanderungsrechtes aber nicht möglich, stattdessen wurden zusätzliche Voraussetzungen für die Ausstellung der Andenkarte geschaffen: Neben der Vorlage eines gültigen Reisepasses musste fortan ein polizeiliches Führungszeugnis vorgewiesen werden. Für viele Flüchtlinge wurde durch diese Verschärfung eine kaum überwindbare Hürde geschaffen. Zum einen stellt die für das Führungszeugnis erhobene Gebühr für die arme Landbevölkerung bereits eine schwer aufzubringende Summe dar. Da zum anderen die Ausstellung des Führungszeugnisses im registrierten Wohnort beantragt werden muss und eine Wartezeit von mehreren Wochen erfordert, ist die Erfüllung einer solchen Auflage insbesondere für die Opfer von Krieg und Vertreibung, die häufig in aller Eile fliehen mussten und mit ihrem Leben davon gekommen waren, schwer zu erfüllen. Für politische Flüchtlinge, die also per Definition Opfer staatlicher Verfolgung sein konnten, ist die Beantragung eines polizeilichen Führungszeugnisses im Verfolgerstaat in der Regel nicht erfüllbar. Da Ecuador nicht nur die formellen Einreisebedingungen erschwerte, sondern auch die Migrationspolizei an der Grenze mit zusätzlichen Kräften verstärkte, wuchs die Gefahr bereits an der Grenze zurückgewiesen zu werden. Die Folge war eine Zunahme der irregulären Migration, oft unter großen Risiken über nicht vorgesehene Routen (Benavides Llerena 2006: 6f).

Für die Anerkennung als Flüchtling werden eine Dokumentation der Einreise, eine Vorlage eines Identitätsnachweises und das polizeiliche Führungszeugnis verlangt. Diese Unterlagen sind für einen positiven Abschluss des Antrages zwar nicht zwingend notwendig, es muss jedoch den Prüfern glaubhaft gemacht werden, dass man diese Unterlagen nicht besitzt und es nicht möglich war, diese zu beschaffen. Für die Praxis bedeutete die Verschärfung der Rechtslage eine Erschwerung der Aufnahmemöglichkeit eines Asylverfahrens und eine Verschlechterung der rechtlichen Bedingungen kolumbianischer Flüchtlinge in Ecuador, sowie die Gefahr, von der Migrations- 
polizei aufgegriffen und abgeschoben zu werden, bevor ein Antrag gestellt werden konnte (ebd.).

\section{Netzwerke}

Netzwerke beeinflussen in vielen Fällen die Entscheidung zur Migration insgesamt, weshalb der Netzwerktheorie der Migration als Erklärungsansatz für die Beliebtheit Ecuadors als Zielland eine große Bedeutung zukommt. Als eine Form des sozialen Kapitals erhalten Netzwerke den Informationsfluss sowie die praktische Hilfe zwischen Personen im Herkunfts- und im Zielland aufrecht (Lebhart 2002: 20). Netzwerke von Menschen kolumbianischer Abstammung helfen den Neuankömmlingen bei der Orientierung und stellen damit eine effiziente Überlebensstrategie dar. Sie erleichtern einerseits den Flüchtlingen die Ankunft und den Anfang, andererseits entbinden sie Staaten von ihren Pflichten, die sich zur Aufnahme von politischen Flüchtlingen bekannt haben.

Die teilweise bereits seit den 1950er Jahren in Ecuador lebenden KolumbianerInnen 4 haben ein gut funktionierendes Netz geschaffen, das andere neu ankommende kolumbianische MigrantInnen auffängt. Neuankömmlinge werden bei der Orientierung, bei der Suche nach Arbeit und Unterkunft unterstützt und in bereits bestehende Haushalte aufgenommen. Dort bleiben sie für gewöhnlich so lange, bis sie eine eigene Unterkunft, Erwerbsmöglichkeit und Lebensgrundlage gefunden haben (vgl. ACNUR 2002b).

Netzwerke spielen eine große Rolle für die Entwicklung von Perspektiven kolumbianischer Flüchtlinge in Ecuador. Sie setzen ein bestimmtes Maß an Eigeninitiative voraus und machen deutlich, dass der selbstbestimmte Umgang mit einer sicher nicht gänzlich selbst gewählten Situation eine Möglichkeit der eigenen Lebensgestaltung darstellt. Insbesondere im Kontext sinkender Anerkennungsquoten von Flüchtlingen, stellen Netz-

4 Von 1948 bis 1958 herrschte in Kolumbien die so genannte »Violencia«. Der brutale Bürgerkrieg forderte in wenigen Jahren 300.000 Opfer und verursachte eine Massenflucht unter der Landbevölkerung. 
werkstrukturen für illegalisierte Flüchtlinge eine wichtige Voraussetzung, um im Alltag überhaupt bestehen zu können.

\section{Der UNHCR in Ecuador}

Aufgrund der Ausbreitung und Intensivierung des Krieges in Kolumbien, richtete der UNHCR ${ }^{5}$ im Januar 2000 einen permanenten Sitz in Ecuador ein. Der UNHCR besitzt heute neun Büros, die über das Land verteilt sind. Diese Büros befinden sich in Quito, Lago Agrio, Ibarra, Tulcan, San Lorenzo, Esmeraldas, Santo Domingo de las Colorados, Guayaquil und in Cuenca. Außerdem finden regelmäßige Delegationsreisen in weitere Ankunftsorte von Flüchtlingen statt (ACNUR 2009a).

Die meisten Asylanträge kolumbianischer Flüchtlinge bearbeitet das Hauptbüro des UNHCR in Quito. Die beiden wichtigsten Büros befinden sich in der nordecuadorianischen Stadt Ibarra und der im Westen gelegenen Lago Agrio. Die kolumbianischen Flüchtlinge, die den UNHCR in Ibarra aufsuchen im Durchschnitt zehn Personen pro Tag - sind zumeist über die auf der Panamericana gelegene Brücke in Rumichaca ins Land gekommen. Flüchtlinge, die in Lago Agrio ankommen, haben eine der im Regenwald gelegenen Grenzen passiert. Eine weitere Möglichkeit von Kolumbien nach Ecuador zu gelangen, ist der Meerweg. Flüchtlinge, die mit dem Schiff Ecuador erreichen, werden in Esmeraldas von Delegationen des UNHCR aus Ibarra registriert.

Das erklärte Ziel des UNHCR in den an Kolumbien grenzenden Staaten ist in erster Linie die Minderung der Folgen für die Betroffenen des kolumbianischen Konflikts. Das soll durch humanitäre Hilfe und den Schutz der Flüchtlinge vor einer Abschiebung nach Kolumbien erreicht werden. Weiterhin bemüht sich der UNHCR um die Verbreitung von Informationen und Fachwissen, um die ecuadorianischen Behörden bei der Bewältigung von bürokratischen Aufgaben zu unterstützen, er betreibt Lobbyarbeit für faire Asylverfahren und stellt den Flüchtlingen eine Rechtsberatung zur Verfügung. Der UNHCR unter-

5 Im hispanischen Sprachraum: ACNUR = Alto Commissionado de las Naciones Unidas para los Refugiados. 
stützt den Aufbau von Hilfseinrichtungen für die Verteilung von Lebensmitteln und restauriert im Rahmen so genannter PIRs 6 Schulen und Krankenhäuser und hilft bei der Umsetzung von Projekten, die der Interaktion kolumbianischer Flüchtlinge mit der ecuadorianischen Gesellschaft dienen sollen (ACNUR 2003).

Eine Hauptaufgabe des UNHCR in Ecuador ist die juristische Unterstützung der Flüchtlinge und die Durchführung von Interviews mit AsylbewerberInnen, die erst dann den Titel »internationaler Flüchtling " erhalten, wenn sie sowohl vom UNHCR als auch vom ecuadorianischen Staat als Flüchtling anerkannt worden sind.

MitarbeiterInnen des UNHCR führen mit den kolumbianischen AsylbewerberInnen Interviews, in denen sie diese über die genauen Gegebenheiten befragen, die zu ihrer Flucht geführt haben. Anschließend geben sie eine Einschätzung ab, welche die interviewte Person entweder als Flüchtling einstuft oder negativ ausfällt, was bedeutet, dass die Person nach Kolumbien zurückkehren muss. Im Anschluss findet ein zweites Interview mit Vertretern des ecuadorianischen Staates statt. Die Auswahlkommission, welche sich aus zwei Mitgliedern des Außenministeriums und aus einem Repräsentanten des Innenministeriums zusammensetzt, wurde in den vergangenen Jahren durch den UNHCR hinsichtlich der Rechtssituation von Flüchtlingen eingehend geschult (ACNUR 2002a: 2). In einer abschließenden Sitzung wird die endgültige Bewertung der einzelnen Anträge verkündet. Auch hierbei ist der UNHCR anwesend und argumentiert, falls nötig, zugunsten der Flüchtlinge für eine Positiventscheidung. Der ecuadorianische Staat beruft sich bei der Anerkennung der Flüchtlinge auf die Vorgaben der Genfer Flüchtlingskonvention (GFK). Gemäß der Definition der GFK ist ein Flüchtling eine Person, die

»aus der begründeten Furcht vor Verfolgung wegen ihrer Rasse, Religion, Nationalität, Zugehörigkeit zu einer bestimmten sozialen Gruppe oder wegen ihrer politischen Überzeugung sich außerhalb des Landes

6 PIR (span. Proyecto con Impacto Rapido - »Projekte mit schneller Wirkung«. Die PIRs sind Projekte, deren Auswirkungen unmittelbar zur Verbesserung der Situation beitragen sollen. 
befindet, dessen Staatsangehörigkeit sie besitzt und den Schutz dieses Landes nicht in Anspruch nehmen kann oder wegen dieser Befürchtungen nicht in Anspruch nehmen will« (UNHCR 1997: 55).

$\mathrm{Ob}$ jemand als internationaler Flüchtling anerkannt wird, hängt davon $\mathrm{ab}$, welche Faktoren die Person im Interview mit dem UNHCR und mit dem ecuadorianischen Staat als Priorität angibt und inwieweit sie eine »begründete Furcht vor einer individuellen Verfolgung« (GFK) ihrer Person glaubhaft machen kann.

Die Flüchtlingsdefinition der GFK lässt durch einen an einigen Stellen möglichen Interpretationsspielraum Schutzlücken zu. Zum Beispiel wird geschlechtsspezifische Verfolgung häufig nicht als Fluchtgrund anerkannt. Weiterhin haben sich Kriege dahingehend verändert, dass die Akteure nicht immer staatliche oder staatsähnliche Gruppen sind, jedoch trotzdem zu einer massiven Bedrohung für das Leben der Zivilbevölkerung werden können. Darüber hinaus gerät das Prinzip der nationalstaatlichen Aufteilung der Welt im Rahmen der fortschreitenden Globalisierung immer mehr an seine logischen und realen Grenzen. Zusätzlich hat der ecuadorianische Staat die erweiterte Flüchtlingsdefinition nach der Erklärung von Cartagena anerkannt, die aber im Aufnahmeverfahren für die Flüchtlinge keine weitere Bedeutung mehr hat. ${ }^{7}$

\section{Der Prozess der Beantragung des Flüchtlingsschutzes}

Um als internationaler Flüchtling anerkannt $\mathrm{zu}$ werden und damit wenigstens formal eine weitgehende Gleichberechtigung mit der lokalen Bevölkerung zu erlangen, müssen Flüchtlinge

7 Eigentlich verpflichtet die Erklärung von Cartagena dazu, nicht nur Schutz zu gewähren, wenn ein Flüchtling individuelle Fluchtgründe geltend machen kann, sondern definiert auch Menschen als Flüchtling, die dazu gezwungen waren, ihr Heimatland wegen einer Gefährdung des eigenen Lebens, der Sicherheit und Freiheit aufgrund von herrschender Gewalt, internen Konflikten und stetiger schwerer Verletzung der Menschenrechte zu verlassen (ACNUR 1984). 
nach ihrer Ankunft in Ecuador einen Asylantrag stellen. Es liegt in der Verantwortung der Asylsuchenden, sich um ihren Antrag zu bemühen. Dabei deckt sich die nationale Gesetzgebung mit internationalen Bestimmungen (ACNUR 2009b).

Um in Ecuador Asyl zu erhalten, muss eine Person sich zunächst bei der Migrationspolizei in Lago Agrio, Tulcán, Esmeraldas oder Ibarra, im Kanzleramt in Quito oder in einem der über das Land verteilten Büros des UNHCR melden (ACNUR 2009b). Die AntragstellerInnen müssen sich dort registrieren lassen und erhalten daraufhin den Termin für ein Interview, durch welches festgestellt werden soll, ob auf die betreffende Person die Flüchtlingsdefinition der Genfer Flüchtlingskonvention zutrifft und ob ihre/seine Betreuung damit in den Zuständigkeitsbereich des UNHCR fällt. Die Daten der AntragstellerInnen werden in einem Zentralregister gespeichert. AnschlieBend schickt die Migrationspolizei die Liste mit den Namen an das Kanzleramt in Quito, woraufhin dieses ein provisorisches Zertifikat ausgibt, das die Asyl-AntragstellerInnen als solche identifiziert und ausweist. Das provisorische Zertifikat für den Aufenthalt im Land hat eine Gültigkeitsdauer von neunzig Tagen und lässt sich verlängern, bis das definitive Resultat des Antrags bekannt ist. Im Anschluss wird die Person vertraulich interviewt. Dafür zuständig sind neben dem UNHCR entweder die Kirche in San Miguel de Sucumbíos, das Pfarramt in Ibarra, die Diozese in Esmeraldas oder in Tulcán oder die Organisation »Pro Asyl« (Comité Pro Refugiados). Die zweite Runde der Interviews wird im Kanzleramt in Quito durchgeführt. Jeder Fall wird von der Auswahlkommission (Comisión de Elegibilidad) analysiert. Die Kommission ist dafür zuständig, den definitiven Flüchtlingsstatus zu erteilen. Bei den Sitzungen der Auswahlkommission sind immer auch Mitglieder des UNHCR und seiner Partnerorganisationen anwesend, welche ihre Empfehlungen für jeden einzelnen der besprochenen Fälle bekannt geben. In der Regel deckt sich die Empfehlung der AnwältInnen des UNHCR mit der Einschätzung der VertreterInnen der Auswahlkommission. Bei Unstimmigkeiten werden die Fälle solange im Einzelnen diskutiert bis ein Konsens gefunden wurde. Das Recht darüber abzustimmen, bleibt allerdings letztendlich der Auswahlkommission vorenthalten (UNHCR 2002: 6f). Hat die Kommission über einen Fall entschieden, so teilt das 
Außenministerium der betreffenden Person mit, dass sie als Flüchtling akzeptiert wurde. Diese erhält dann ein Visum, welches ihr den Flüchtlingsstatus auf unbestimmte Zeit in Ecuador dokumentiert. Das von der deutschen GTZ finanzierte Dokument schützt die Flüchtlinge vor der Abschiebung nach Kolumbien. Wenn über den Antrag jedoch negativ entschieden wurde, kann der/die AntragstellerIn binnen einer Frist von dreißig Tagen vor dem Außenministerium gegen die Entscheidung Berufung einlegen. Sollte sie das nicht tun, muss die Person das Land verlassen.

Der Prozess, den ein Flüchtling durchläuft, bis er/sie als solcher anerkannt ist und sich somit unter dem Schutz der internationalen Gemeinschaft in Sicherheit weiß, kann ebenso traumatisierend sein, wie die Fluchterfahrung als solche (Marsella/Ring 2003: 13). Beim Stellen eines Asylantrags, insbesondere bei der Durchführung der Interviews, kommt es vor allem darauf an, dass die Antragsteller ihre Fluchtgründe plausibel darstellen. Die überaus hohe Wichtigkeit der Interviewsituation kann dementsprechend zu einem stark empfundenen Druck auf die/den Interviewten führen. ${ }^{8}$

Das Ereignis, welches $\mathrm{zu}$ ihrer Flucht geführt hat beziehungsweise zur Entscheidung, Kolumbien zu verlassen und in Ecuador Asyl zu beantragen, muss subjektiv begründet, aber ebenso auch objektiv nachvollziehbar sein. Aus der Geschichte der Person muss deutlich werden, dass diese individuell verfolgt wird, dass ihre Furcht vor Verfolgung begründet ist und dass es sich bei der Gruppe, die sie verfolgt entweder um staatliche oder aber um staatsähnliche Instanzen handelt, die im ganzen Land präsent sind, so dass es der Person nicht möglich wäre, innerhalb Kolumbiens einen Ort zu finden, an dem sie von dieser Verfolgung nicht betroffen wäre.

Das Gewicht, welches auf den Interviews mit den Flüchtlingen liegt, schafft mehrere Probleme. Ein Großteil der nach Ecuador fliehenden KolumbianerInnen stammt aus der bäuerlichen Unterschicht. Einige Flüchtlinge sind AnalphabetInnen. Das

8 Die Autorin Baltzer begleitete in Ibarra, Ecuador die AnwältInnen des UNHCR bei ihren Interviews mit kolumbianischen Flüchtlingen. Die geschilderte Darstellung der Interviewsituationen beruht im Wesentlichen auf ihren Feldbeobachtungen. 
Bildungsniveau der asylsuchenden Personen ist dementsprechend sehr niedrig, wodurch ihre rhetorischen Fähigkeiten nicht gut ausgebildet sind. Das kann dazu führen, dass ihre Geschichten für den/die InterviewerIn nicht plausibel klingen, weil sie sich widersprechen oder Ereignisse chronologisch inkonsequent geschildert werden. Aber auch eine chronologisch stimmige Version einer Darstellung kann dadurch beeinträchtigt werden, dass Flüchtlinge ihre Zeit in ganz anderen Kategorien einteilen, als die interviewende Person. Zum Beispiel kann es sein, dass die Flüchtlinge keine Uhr und keine Kenntnis über die Monatsabfolge besitzen, sondern ihre Geschichte schildern, indem sie auf Ereignisse in der Natur zurückgreifen, beispielsweise »die Zeit der Ernte« oder »als die Sonne gerade unterging «. Häufig wird von MitarbeiterInnen des UNHCR aber dennoch gefordert - nicht zwingend, sondern aus Mangel an Kenntnis oder Aufmerksamkeit -, das fluchtauslösende Ereignis unter Verwendung von Zeitangaben zu schildern, die den Interviewten eventuell nicht geläufig sind. Es kann davon ausgegangen werden, dass sich die zentralen Stellen des UNHCR über diese Problematik bewusst sind. Im Feld jedoch wird dies nicht deutlich.

Die Gespräche respektive Interviews erfordern in jedem Fall die Sensibilität der InterviewerInnen und weitgehende Kenntnis über solche zuvor geschilderten Besonderheiten. Eine sensible Umgehensweise ist insbesondere auch in Bezug auf geschlechtsspezifische Problemfelder geboten. Eine Frau, die von Männern misshandelt oder vergewaltigt wurde und deshalb nach Ecuador geflohen ist, wird ihre Geschichte eher einer weiblichen Interviewpartnerin erzählen als einem Mann. Zudem muss beispielsweise beachtet werden, dass Frauen sich in Anwesenheit ihres Ehemannes oft über sexuellen Missbrauch nicht äußern können oder wollen. Frauen wird beim UNHCR grundsätzlich die Möglichkeit gegeben, sich von weiblichen Mitarbeiterinnen interviewen zu lassen. Beachtet und umgesetzt wird die gewünschte Präferenz allerdings nicht immer. Wichtig ist zudem, dass der Interviewsituation genügend Zeit und Raum gegeben wird, die es der interviewten Person ermöglichen, sich wohl zu fühlen und damit die Voraussetzung zu schaffen, dass Geschichten in ihrer Gänze und Reichweite erzählt und daraufhin richtig eingeordnet werden. Die Zeitdi- 
mension eines Interviews stellt auch deshalb immer häufiger ein Problem dar, weil ihm mit steigenden Flüchtlingszahlen weniger adäquat begegnet wird. Durch die wachsende Zahl der AntragstellerInnen verringern sich die Zeitkapazitäten für die Interviews. Jemand kann also als internationaler Flüchtling abgelehnt werden, weil es ihm nicht möglich war, in der kurzen Zeitspanne, die ihm zur Darlegung seiner Geschichte gegeben war, die Aspekte zu nennen, die für die Einschätzung, ob es sich um eine Flucht im Sinne der GFK gehandelt hat, wichtig gewesen wären.

Eine weitere Schwierigkeit besteht darin, dass das Misstrauen der Flüchtlinge Autoritäten gegenüber oftmals so groß ist, dass sie dadurch Schwierigkeiten haben, sich den InterviewerInnen gegenüber zu öffnen. Zwar sind die InterviewerInnen beim UNHCR angewiesen, den AntragstellerInnen mitzuteilen, dass alle Informationen streng vertraulich behandelt werden, dennoch kann der/die Interviewte aufgrund schlechter Erfahrungen mit Autoritäten im Herkunftsland misstrauisch bleiben und dadurch wichtige Informationen für sich behalten.

Bereits im Annual Protection Report des UNHCR aus dem Jahr 2002 stellt der UNHCR selbstevaluierend fest, dass das Procedere der Entscheidung über den Status der AsylbewerberInnen Mängel aufweist. Die Wartezeiten für die Interviews sind sehr ausgedehnt, die AsylbewerberInnen warten oft monatelang auf den zweiten Durchgang ihrer Anträge (UNHCR 2002: 3). Angesichts rückläufiger Anerkennungszahlen und steigender Antragszahlen erkennt der UNHCR im Jahr 2007 an, dass gesetzliche Vorgaben und behördliche Handlungsanweisungen im Anerkennungsprozess der Lebensrealität der Flüchtlinge nicht ausreichend gerecht werden:

"Ecuador's legal and administrative framework, although largely in line with the basic principles of the 1951 Convention and 1984 Cartagena Declaration, lacks adequate legal and procedural mechanisms to fairly and efficiently determine an increasing number of refugee claims by Columbian nationals.«

Zudem bemüht sich der UNHCR um eine Reform des Asylrechts mit dem Ziel, die Rechte der Flüchtlinge zu stärken und 
den Behandlungsstandard im Anerkennungsprozess zu verbessern (UNHCR 2008: 2ff).

Nach offiziellen Daten des UNHCR wurden von 2000 bis 2008 insgesamt 56.384 KolumbianerInnen als AsylbewerberInnen registriert. 20.956 von ihnen wurde der Flüchtlingsstatus zuerkannt, was einer Anerkennungsquote von 37 Prozent entspricht (ACNUR 2009a). Neben den hier verhandelten offiziellen Zahlen geht der UNHCR jedoch derzeit davon aus, dass zusätzlich bis zu 250.000 KolumbianerInnen in Ecuador leben, deren Lebensbedingungen denen der Flüchtlinge entsprechen und die auf Hilfe und Schutz angewiesen sind (»others of concern«, UNHCR 2009: 325).

Tabelle 1: Anträge auf Anerkennung des Flüchtlingsschutzes

\begin{tabular}{|l|l|l|l|l|l|l|l|l|l|}
\hline Jahr & $\mathbf{2 0 0 0}$ & $\mathbf{2 0 0 1}$ & $\mathbf{2 0 0 2}$ & $\mathbf{2 0 0 3}$ & $\mathbf{2 0 0 4}$ & $\mathbf{2 0 0 5}$ & $\mathbf{2 0 0 6}$ & $\mathbf{2 0 0 7}$ & $\mathbf{2 0 0 8}$ \\
\hline $\begin{array}{l}\text { Neue } \\
\text { Anträge }\end{array}$ & 475 & 3017 & 6766 & 11146 & 7858 & 7091 & 7784 & 11544 & 10703 \\
\hline $\begin{array}{l}\text { positiv } \\
\text { entschiedene } \\
\text { Anträge }\end{array}$ & 390 & 1406 & 1578 & 3326 & 2496 & 2486 & 1997 & 2654 & 4623 \\
\hline
\end{tabular}

Quelle: ACNUR 2009a: Refugiados en Ecuador Datos basicos sobre la operacion del ACNUR.

\section{Perspektiven anerkannter Flüchtlinge}

Es gibt perspektivisch gesehen drei Möglichkeiten für die Menschen, die in Ecuador von der Regierung und mit Hilfe des UNHCR als Flüchtlinge anerkannt worden sind: Erstens ist das die Freiwillige Rückkehr, zweitens die lokale Integration in die Gesellschaft des Aufnahmelandes und an dritter Stelle die organisierte Weiterwanderung in einen Drittstaat.

Die Option der Freiwilligen Rückkehr ist der vom UNHCR generell präferierte Umgang mit Flüchtlingsbewegungen. Aufgrund der prekären Sicherheitslage, der katastrophalen Menschenrechtssituation und der fortdauernden Eskalation des kolumbianischen Konflikts, sieht jedoch auch der UNHCR derzeit von 
der Möglichkeit einer freiwilligen Rückkehr ab. Ebenso ist für die Flüchtlinge eine absehbare Rückkehr aktuell keine realistische Option. Eher sieht der Großteil von ihnen ihre Zukunft im Aufbau einer neuen Lebensperspektive in Ecuador.

Häufig ist Angst die ausschlaggebende Komponente in der definitiven Entscheidung der Flüchtlinge, nicht wieder nach Kolumbien zurückzukehren. Der Entschluss, sich in Ecuador zu etablieren, ist meistens schon dann gefallen, wenn der Aufbruch aus Kolumbien stattgefunden hat. Mit der Entscheidung zur Flucht geben die meisten KolumbianerInnen ihre Lebensgrundlage in ihrem Herkunftsland bewusst auf. Sie verlassen ihren Wohnsitz, lassen dort ihre Besitztümer und das Land, welches ihnen gehörte oder welches sie bebaut haben, zurück.

Auch die Integration ist nicht ohne Probleme. Anerkannte Flüchtlinge haben alle Rechte und Pflichten, die ihnen auf Grundlage der Verfassung entsprechend ihrem Status als Ausländer im Allgemeinen und zusätzlich auf Grundlage der Genfer Konvention von 1951 gemäß ihrem Status als Flüchtling im Speziellen zuerkannt werden. Ihnen werden demnach alle Bürgerrechte, alle sozialen und ökonomischen Rechte zuteil, welche auch ecuadorianischen Staatsangehörigen zustehen. So haben etwa anerkannte Flüchtlinge das Recht auf freien Zugang zu den Gerichten, Recht auf Versammlung, das Recht auf eine fair bezahlte Arbeit und auf freie Religionsausübung, um nur einige zu nennen. Zudem kann eine Person, die drei Jahre mit einem Flüchtlingsvisum in Ecuador verbracht hat, einen Antrag auf Einbürgerung stellen. Aufgrund der gesetzlichen Lage hätten anerkannte Flüchtlinge dementsprechend das Recht auf volle Integration in Ecuador (UNHCR 2003: 13ff).

In der Praxis ist die Umsetzung der genannten Rechte für Flüchtlinge allerdings nicht gegeben. Wegen der hohen Arbeitslosigkeit, vor allem in der Grenzregion zu Kolumbien, ist es insbesondere für Flüchtlinge schwierig, Arbeit zu finden. Dadurch kommt es zu Spannungen zwischen der Flüchtlingsbevölkerung und der Aufnahmegesellschaft.

Um eine erfolgreiche Integration der kolumbianischen Flüchtlinge in die ecuadorianische Gesellschaft dennoch zu verwirklichen, hat der UNHCR in den letzten Jahren diverse Projekte, die bereits erwähnten PIRs, durchgeführt. Durch sie sollen erste Kontakte und Annäherungen von KolumbianerIn- 
nen und EcuadorianerInnen erleichtert werden. Von diesen Projekten profitieren sowohl die kolumbianischen Flüchtlinge als auch die Aufnahmegesellschaft (ACNUR 2003). Im Jahr 2003 etwa wurden Schulmöbel und Unterrichtsmaterialien an insgesamt 17 Schulen in der Grenzprovinz Carchi gespendet. Ein weiteres Proyecto con Impacto Rapido bestand 2003 in der Verteilung von Samen zum Zweck des Aufbaus von kleinen Obstund Gemüsegärten. Kolumbianische und ecuadorianische Arbeitslose haben die Gärten gemeinsam angelegt und betreut, um die Früchte anschließend auf den lokalen Märkten verkaufen zu können (UNHCR 2003: 13).

Der UNHCR unterstützt kolumbianische Flüchtlinge zudem mit einer materiellen Eingliederungshilfe. In den Anfangsmonaten erhalten die Flüchtlinge bei Bedarf Lebensmittel in Form von monatlich verteilten Essenspaketen und Medizin. Auch in Bezug auf die Beschaffung von Unterkünften und Bildungsmöglichkeiten ist der UNHCR behilflich. In Ibarra gibt es außerdem eine Herberge, in der Flüchtlinge die ersten Tage nach ihrer Ankunft in Ecuador verbringen können und in der sie betreut werden. Flüchtlingslager in Form von abgegrenzten Territorien, in denen ein Großteil der Flüchtlingsbevölkerung nicht nur aufgenommen wird, sondern auch für einen gewissen Zeitraum lebt, gibt es in dem Sinne in Ecuador nicht.

Trotz der Betreuung durch den UNHCR und seiner Partnerorganisationen ist die Lebenssituation für Flüchtlinge in Ecuador sehr unterschiedlich. Einigen gelingt es, sich in bereits existierende und durch andere KolumbianerInnen geschaffene Strukturen schnell einfügen. Andere Flüchtlinge hingegen haben erhebliche Schwierigkeiten damit, in Ecuador zu Recht zu kommen. Sie finden keine Arbeit, ihnen begegnen fremdenfeindliche Ressentiments und sie schaffen es nicht, soziale Kontakte zu etablieren, wodurch sich zusätzliche psychologische Probleme ergeben, die häufig als Folge von Flucht und auch Migration auftreten. Viele fühlen sich auch in Ecuador noch nicht sicher vor der Bedrohung durch die bewaffneten Gruppen, die ihre Aktivitäten über die Grenze ausgeweitet haben.

Ein Vorteil für die kolumbianischen Flüchtlinge ist der, dass Verständigungsprobleme aufgrund der gemeinsamen Sprache nicht existieren. Dennoch wurde vom UNHCR beobachtet, dass sich die schon seit längerem in Ecuador ansässigen Kolumbia- 
nerInnen solidarischer den Neuankömmlingen gegenüber verhalten als es viele EcuadorianerInnen tun. Auch viele EcuadorianerInnen sind den neu ankommenden KolumbianerInnen gegenüber aufgeschlossen und behilflich. Jedoch gibt es trotz der Ähnlichkeit der Lebensweise und der Kultur in Ecuador und Kolumbien kulturelle und dialektbedingte sprachliche Unterschiede. Sie reichen aus, um die Konstruktion von Fremdheit und damit Ausgrenzung zu ermöglichen.

Die dritte Möglichkeit ist die organisierte Weiterwanderung. Eine wachsende Zahl von Flüchtlingen in Ecuador wurde in den vergangenen Jahren Ziel von Bedrohungen, Einschüchterungsversuchen und bewaffneten Angriffen. Einige Personen erhielten Morddrohungen. Verantwortlich für diese Taten waren nach Angaben der betroffenen Flüchtlinge, Mitglieder der bewaffneten kolumbianischen Konfliktparteien. Eine limitierte Anzahl von Flüchtlingen wird in solchen Fällen in Drittstaaten, wie etwa in den letzten Jahren nach Schweden, Norwegen oder in die USA sozusagen umgesiedelt (UNHCR 2003: 17). Diese organisierte Weiterwanderung (Reasentamiento) ${ }^{9}$ von Asylsuchenden von einem Nachbarstaat in einen Staat, der weiter entfernt ist und zudem als sicher definiert wird, ist eine wirksame Methode zum Schutz der Flüchtlinge. Die organisierte Weiterwanderung ist für diejenigen Personen vorgesehen, deren Schutz im Land des ersten Asyls nicht in vollem Maße gewährleistet werden kann. Sie ist außerdem eine Option für diejenigen Flüchtlinge, deren besonderen Bedürfnissen im Erstasylland nicht entsprochen werden kann. Das können zum Beispiel Personen sein, die schwer krank sind und deren Krankheit vor Ort nicht behandelt werden kann. Weiterhin kommt die Weiterwanderung für Personen mit psychischen und körperlichen Behinderungen, schweren Verletzungen und schwerwiegenden Traumata, die häufig durch den Fluchtauslöser und die Flucht selbst entstanden sind, in Frage. Das Gleiche gilt für Personen,

9 Die deutsche Übersetzung »Weiterwanderung « ist keine genaue Entsprechung des Spanischen »reasentamiento«. Dieser Begriff bedeutet soviel wie »Wiederansiedlung«. Es handelt sich dabei um eine Kontingentaufnahme von Flüchtlingen durch einen Drittstaat (A.d.A.). 
die Opfer von Folterungen und Vergewaltigungen geworden sind (UNHCR 1997: 91-93).

Die Weiterwanderung in ein Drittland kann in einigen Fällen der einzige Weg sein, der dem Antragsteller respektive der Antragstellerin - Frauen kommen häufiger für die Wiederansiedlung in Frage als Männer - einen effektiven internationalen Schutz garantiert. Diese Möglichkeit stellt eine Ausnahme dar und wird nur dann in Erwägung gezogen, wenn weder die freiwillige Rückführung ins Herkunftsland noch die Integration in das Land des ersten Asyls realisiert werden können. Sie ist kein individuelles Recht. ${ }^{10}$

\section{Die Situation illegalisierter Flüchtlinge in Ecuador}

Für »irreguläre« MigrantInnen gestaltet sich der Migrationsverlauf weitaus schwieriger als für offizielle und anerkannte internationale Flüchtlinge. Illegalisierte Personen müssen mit Abschiebung rechnen, die der ecuadorianische Staat als Sanktionsmittel durchführen kann. Außerdem existieren keine internationalen Instrumente, die statuslosen Ausländern einen effektiven Schutz bieten könnten. Viele KolumbianerInnen, die in Ecuador Zuflucht suchen, bleiben anonym. Sie tauchen in den offiziellen Flüchtlingsstatistiken nicht auf. Der Großteil der kolumbianischen Flüchtlinge in Ecuador lebt illegalisiert, da sie weder über eine gültige Aufenthaltserlaubnis verfügen, noch als Flüchtlinge registriert sind oder sich im Asylverfahren befinden. Sie ziehen es vor, sich nicht zu melden, entweder weil sie so bald wie möglich nach Kolumbien zurückkehren möchten, oder weil sie zu große Angst haben, ihre Registrierung als Flüchtlinge würde ihnen nur weitere Schwierigkeiten bereiten. Der UNHCR schätzt, dass ca. 450.000 KolumbianerInnen in Ecuador - zum Teil seit Jahrzehnten - leben, und dass von ihnen bis zu 250.000 schutz- und hilfsbedürftig im Sinne der

10 Das Projekt der organisierten Weiterwanderung wird in Ecuador vom US Gouvernement Bureau for Population and Refugee Migration finanziert. Als eigenständiges Projekt mit Sitz in Quito wurde das Reasentamiento-Büro im Januar 2003 gegründet (UNHCR 2003: 18). 
Flüchtlingskonvention sind (UNHCR 2009: 325). Der Forschungszugang auf diesem Gebiet gestaltet sich als äußerst schwierig. Besonders statistische Daten können höchstens Schätzwerte sein, da Menschen, die in der Illegalität leben müssen, in den wenigsten Fällen statistisch erfassbar sind (Vogel 2003: 162, 167).

Menschen halten sich dann illegal in einem Staat auf oder sie werden als illegal bezeichnet, wenn sie durch international sowie national festgelegte Bestimmungen keine Rechtsgrundlage für ihren Aufenthalt in einem Staat, dessen Staatsangehörigkeit sie nicht besitzen, vorweisen können. Irreguläre Migration ergibt sich entweder durch die Einreise in einen Staat ohne Papiere oder über eine unbewachte Grenze. Darüber hinaus gibt es noch die so genannten Visa Overstayers. Visa Overstayers sind Menschen, die nach Ablauf der Zeit, die sie beispielsweise als TouristIn, StudentIn oder SaisonarbeiterIn in einem Land verbracht haben, bleiben, ohne ihren verlängerten Aufenthalt zu melden. Die gleiche Situation ergibt sich aus der Überziehung der durch die Andenkarte legitimierten Zeitspanne in einem Land der Andenregion. Menschen, die nach Ablehnung ihres Asylgesuchs nicht in ihr Herkunftsland zurückkehren, werden außerdem als illegale MigrantInnen bezeichnet.

$\mathrm{Zu}$ irregulärer Migration kommt es im Allgemeinen dann, wenn Staaten Zuwanderung zwar gesetzlich begrenzen, diese Begrenzung allerdings nicht konsequent umsetzen können oder wollen. Die Beschneidung beziehungsweise Reduktion legaler Zuwanderung verstärkt dabei die illegale Migration. Illegalität ist demnach ein Thema, das sich im »Spannungsverhältnis von Globalisierung und Nationalstaat" verorten lässt (Vogel 2003: 163). Oftmals besteht von Seiten der Aufnahmegesellschaft ein wirtschaftliches Interesse daran, »illegalen « Aufenthalt zu tolerieren. Nachteile ergeben sich daraus vor allem für die in der Illegalität, also ohne die von staatlicher Seite erforderlichen Papiere, lebenden Menschen, deren Existenzbedingungen in den meisten Fällen auf einem Niveau weit unter dem der Bevölkerung der Aufnahmegesellschaft liegen. Eine prekäre Rechtslage ist charakteristisch für die Lebensrealität illegalisierter MigrantInnen. Viele MigrantInnen, die aus wirtschaftlichen Gründen eine internationale Grenze überschreiten, versuchen zunächst durch einen Asylantrag ihren Status im Zielland zu 
legalisieren. Ihnen wird vorgeworfen, dass sie den Gedanken des internationalen Schutzes unterhöhlen würden. Dem allerdings kann nur entgegengewirkt werden, indem solchen MigrantInnen oder "Wirtschaftsflüchtlingen " andere Wege eröffnet werden, um beispielsweise temporär einzuwandern. Oftmals vermischen sich erzwungene und freiwillige Migration.

Die Situation kolumbianischer AusländerInnen ohne Aufenthaltsstatus in Ecuador ist aus den genannten Gründen bedenklich. Ein Mensch, dessen Antrag auf internationalen Schutz, abgelehnt wurde, wird vom UNHCR und von den entsprechenden Behörden des ecuadorianischen Staatsapparates dazu aufgefordert, das Land wieder zu verlassen. Es kann allerdings davon ausgegangen werden, dass die meisten Menschen nicht nach Kolumbien zurückkehren. Denn auch wenn sie nicht als internationale Flüchtlinge anerkannt werden, so verändert das im Nachhinein nicht ihre Motivation, Kolumbien $\mathrm{zu}$ verlassen und ihr Leben in einem anderen Land fortzusetzen. In vielen Fällen gibt es für die betroffenen Personen keine andere Möglichkeit mehr als zu bleiben, da sie das Geld, welches sie für ihre Flucht aufbringen konnten, nicht mehr haben und nun in Ecuador oder in einem anderen Land, in das sie geflüchtet sind bleiben und in der Illegalität leben müssen.

Die so genannte Illegalität ist ein Konstrukt, das Menschen in starkem Maße verwundbar macht. Sie sind von Abschiebung bedroht. Viele statuslose KolumbianerInnen müssen sich aufgrund ihrer Bedürftigkeit auf sehr schlechte Arbeits- und Lebensbedingungen einlassen und werden wegen ihres fehlenden legalen Status wirtschaftlich ausgebeutet. Das weist nicht nur auf ihre schlechte ökonomische, sondern auch auf eine verzweifelte humanitäre Lage hin. ${ }^{11}$

Ein weiteres Phänomen, das die Lebenssituation kolumbianischer Flüchtlinge ohne Aufenthaltsstatus in Ecuador bestimmt, ist die Xenophobie großer Teile der Aufnahmebevölkerung. Die Konkurrenzsituation auf dem ecuadorianischen Arbeitsmarkt, die sich durch die Anwesenheit illegalisierter kolumbianischer Flüchtlinge verschärft, äußert sich vor allem in

11 So berichtet El Comercio im Januar 2004, dass illegalisierte kolumbianische Flüchtlinge für einen Tageslohn von einem Dollar bis zu 1,50 Dollar arbeiten (vgl. El Comercio 12.01.2004). 
der besonders armen und vom Staat vernachlässigten Grenzregion im Norden des Landes in sozialen Spannungen. Viele KolumbianerInnen sind aufgrund ihrer existentiellen Not dazu bereit für einen sehr geringen Lohn zu arbeiten. Die sich dadurch bedroht fühlenden EcuadorianerInnen wollen, dass illegaler Aufenthalt schärfer bekämpft wird, da sie die Anwesenheit illegalisierter KolumbianerInnen als Bedrohung für Arbeit und Ressourcen wahrnehmen. Armut und Arbeitslosigkeit wachsen sukzessive an und die Schuld dafür wird bei den KolumbianerInnen gesucht.

Ebenso direkt wie für das Anwachsen der Arbeitslosenrate machen große Teile der ecuadorianischen Bevölkerung die steigende Zahl kolumbianischer Flüchtlinge für das Anwachsen der Kriminalitätsrate verantwortlich. KolumbianerInnen werden, verstärkt und teilweise hervorgerufen durch Berichte der regionalen Zeitungen und durch polarisierende Fernsehreportagen, als besonders brutal und aggressiv wahrgenommen, was die Xenophobie noch wachsen lässt. Im Allgemeinen werden illegale MigrantInnen häufig mit Kriminellen gleichgesetzt. Es ist $\mathrm{zu}$ beobachten, dass mit zunehmender Kriminalisierung und regelrechten medialen Hetzkampagnen gegen KolumbianerInnen, die eine allgemeine Stimmung »Kolumbianer sind Diebe!« transportierten, die Situation für neu ankommende kolumbianische Flüchtlinge wie auch für anerkannte Flüchtlinge schwieriger wurde und vorhandene Netzwerkstrukturen geschwächt wurden.

\section{Fazit und Ausblick}

Kolumbianische Flüchtlinge in Ecuador haben verschiedene Zukunftsperspektiven, abhängig davon, ob der ecuadorianische Staat ihr Asylgesuch als berechtigt anerkennt. Als Flüchtlinge anerkannte KolumbianerInnen können in Ecuador theoretisch ein Leben führen, das sich durch eine größere Bewegungsfreiheit in einer friedlicheren Atmosphäre auszeichnet. Mit Hilfe des UNHCR, der Kirche und anderer sozialer Organisationen sowie einem Netzwerk, das sich aus bereits in Ecuador lebenden Personen kolumbianischer Herkunft zusammensetzt, haben neu ankommende KolumbianerInnen in Ecuador Chancen, 
aufgenommen zu werden und fortan ihr Leben ohne die tägliche Erfahrung von Gewalt fortführen zu können.

Jedoch darf diese Feststellung nicht darüber hinweg täuschen, dass Flüchtlinge auch in Ecuador auf Problemlagen stoßen, die mitunter nicht leicht und nicht ohne fremde Hilfe zu bewältigen sind. Mit der fortschreitenden Regionalisierung des kolumbianischen Konflikts und der Zunahme der Flüchtlingsbevölkerung in Ecuador verschärften sich diese Probleme. Das Leben in Ecuador ist ebenso wie ihr vorheriges Leben in Kolumbien von Armut und sozialer Ungerechtigkeit geprägt. Die innenpolitische Lage ist instabil. Außerdem werden Menschen kolumbianischer Herkunft in zunehmendem Maße fremdenfeindlichen Ressentiments begegnen. Auch die psychischen und physischen Belastungen, die eine Flucht nach sich ziehen kann, sind gravierend. Dennoch ist durch die Anwesenheit des UNHCR und der Unterstützung durch die Kirche und diverser kleinerer NGOs in Ecuador sichergestellt, dass es für einen Teil der Flüchtlinge Anlaufstellen gibt, die ihnen durch humanitäre und juristische Unterstützung einen Neuanfang ermöglichen; in einigen Fällen sogar durch die organisierte Weiterwanderung in ein Land, in dem für ihre Sicherheit oder eine spezielle Behandlung gesorgt werden kann. Durch die Anwesenheit des UNHCR fließt zudem eine große Summe an Hilfsgeldern in die Gegenden, in denen besonders viele Flüchtlinge aufgenommen werden. Damit profitieren zuvor vom Staat vernachlässigte Gebiete in Ecuador von der Anwesenheit kolumbianischer Flüchtlinge.

Allerdings existieren weiterhin auch Schutzlücken, die es zu füllen gilt. Die Arbeit des UNHCR weist Mängel auf, die dazu führen, dass einzelnen Flüchtlingen in ihrer besonderen Situation nicht entsprochen werden kann. Aufgrund von Zeitmangel und fehlenden Kenntnissen über bestimmte Details der Vorgeschichte einzelner Flüchtlinge oder über die Situation in Kolumbien und deren Auswirkungen auf bestimmte Gruppen können falsche Entscheidungen bezüglich der Flüchtlingseigenschaft von Personen getroffen werden. Was die Rolle des UNHCR und einige Bereiche der Arbeit der Organisation in Ecuador betrifft, so können und müssen bestimmte Aspekte kritisiert werden. Die Mission des UNHCR ist es, Flüchtlinge zu schützen, eine Anwaltschaft für sie zu übernehmen und ihnen 
Hilfe zu gewähren. Angesichts der Tatsache, dass die von ihm durchgeführten Interviews bisher in fast zwei Drittel der Fälle negativ ausfielen, ist fraglich, ob der UNHCR dieser Aufgabe in ausreichendem Maße gerecht wurde. In Ecuador wurde in den vergangenen 10 Jahren unter maßgeblicher Regie des UNHCR weniger als 21.000 Menschen das Recht auf Asyl zugesprochen. Nach seinen eigenen Angaben befinden sich aber weitere 250.000 KolumbianerInnen im Land, die auf Hilfe angewiesen wären. Da eine Vielzahl von KolumbianerInnen angesichts eines eskalierten und vielschichtigen bewaffneten Konflikts individuelle Fluchtgründe nicht geltend machen kann, aber auch die Rückkehr in ihr Heimatland unmöglich ist, wird die Frage nach der Umsetzung der Erklärung von Cartagena und der rechtlichen Stärkung der Flüchtlinge im tatsächlichen Handeln des UNHCR und des ecuadorianischen Staates immer drängender. Der UNHCR hat dieses Problem erkannt. Es bleibt zu hoffen, dass die Arbeit an einer Lösung, im Sinne einer Verbesserung der Lebenswirklichkeit der Flüchtlinge Umsetzung findet.

Problematisch ist die Situation illegalisierter Flüchtlinge und MigrantInnen in Ecuador. Ihnen stehen keine legalen Möglichkeiten zur Verbesserung ihres Lebensstandards zur Verfügung. Folglich haben sie auch keine Zukunftsperspektive. Für nicht anerkannte, also statuslose KolumbianerInnen in Ecuador ergibt sich daraus eine äußerst bedenkliche Lebensrealität, sei es in Ecuador durch ein Leben in der Illegalität oder in Kolumbien, wohin sie zurückkehren müssen, obwohl sie das nicht wollen, weil sie teilweise sogar um ihr Leben fürchten müssen. Die Vorstellung, ein Flüchtling sei eine Person, die gezwungenermaßen ihr Land verlasse und stets mit der Hoffnung weiterlebe, dorthin eines Tages wieder zurückkehren zu können, existiert so nicht mehr. Der Großteil der Flüchtlinge ist sich dessen bewusst, dass der bewaffnete Konflikt in absehbarer Zeit nicht gelöst werden kann und dass - auch wenn es in den nächsten Jahren zu einem Friedensschluss käme - die Gewalt, und die mangelnde Teilhabe der Bevölkerung am gesellschaftlichen und politischen Leben fortdauern würden. Es ist in hohem Maße kritikwürdig, dass es keine offizielle Institution und kein Amt gibt, das sich für den Schutz statusloser AusländerInnen in Ecuador engagiert. Die Lebenssituation von illegalisierten Menschen, deren Alltagsrealität nur aus dem Grund prekär ist, dass 
sie nicht das richtige Dokument besitzen, ist gravierend. Die Situation in Ecuador ist in dieser Hinsicht kein Einzelfall.

Eine Möglichkeit dem entgegen zu wirken, wäre etwa die Ausweitung des Flüchtlingsbegriffes, um zu ermöglichen, dass Schutzsuchende den äußerst prekären Zustand der Illegalität verlassen können. Das wäre nicht nur für die betroffenen KolumbianerInnen dringend nötig. Auch die ecuadorianische Aufnahmebevölkerung würde durch eine Verbesserung der sozialen Situation im Allgemeinen von einer Legalisierung der Flüchtlinge profitieren. Parallelstrukturen würden zurückgedrängt. Es wären weniger Menschen darauf angewiesen, unterbezahlte oder zwielichtige Tätigkeiten auszuführen und damit würde sich die Konkurrenzlage auf dem Arbeitsmarkt entschärfen, was wiederum zu einer weniger vorurteilbelasteten Annäherung von ecuadorianischen StaatsbürgerInnen an die Kolumbianischen Flüchtlingen und MigrantInnen beitragen könnte.

Freilich wäre es am sinnvollsten, in erster Linie die Fluchtgründe in Kolumbien zu bekämpfen und vor allem anzuerkennen, dass Menschen auch dann das Recht haben, eine Grenze $\mathrm{zu}$ überqueren und in einem anderen Land zu leben, wenn die Flüchtlingsdefinition der Genfer Konvention nicht auf sie zutrifft. Es ist dringend notwendig, dass von konstruierten Realitäten - wie etwa dem Prinzip der Aufteilung der Erde in Nationalstaaten - abgewichen wird, um auf aktuelle Entwicklungen in sozial verträglicher Weise reagieren zu können. Soziale Realitäten können oftmals nicht schnell genug auf die divers ausgeformten Globalisierungsprozesse abgestimmt werden, da in der Vergangenheit im Zusammenhang der jeweils vorherrschenden weltpolitischen Einbettung entstandene nationale und internationale Regelwerke und Vereinbarungen diesen Prozess unfreiwillig blockieren.

\section{Literatur}

ACNUR (1984): Declaración de Cartagena sobre refugiados, Cartagena, 1984, http:/ / www.acnur.org/biblioteca/pdf/ 0008.pdf, 13.04.2009. 
ACNUR (2002a): Consideraciones sobre la Protección Internacional de los Solicitantes de Asilo y los Refugiados Colombianos, Genf.

ACNUR (2002b): Colombianos que huyen de la guerra encuentran un remanso de paz en Ecuador, 17.10.2002, http://www.acnur.org/paginas/?id_pag=1714, 13.04.2009.

ACNUR (2003): »Huellas de esperanza«. In: Boletín Nº12 sobre refugiados en Ecuador, http://www.acnur.org/index.php? id_pag=1924August 2003. http:/ / www.acnur.org/index. php?id_pag=1924, 13.04.2009.

ACNUR (2009a): Refugiados en Ecuador Datos basicos sobre la operacion del ACNUR. Http://www.acnur.org/biblioteca/ pdf/6923.pdf. 13.04.2009.

ACNUR (2009b): Hoja informativa: el procedemiento de asilo en Ecuador, http:/ / www.acnur.org/index.php?id_pag= 1393, 13.04.2009.

Benavides Llerena, Gina (2006): Demanda colombiana de refugio: contexto y desarrollo. Seminario »relaciones Ecuador Colombia; Sesión IX Los/as refugiados/as colombianos/as en Ecuador «. Ministerio de relaciones exteriores. Republica del Ecuador, Quito, Mai 2006.

Billsborrow, Richard E. /CEPAR (2006): The living conditions of refugees, asylumseekers and other colombians in Ecuador. Millenium development indicators and coping behaviour. Ecuador Country Report. Den Haag, October 2006.

Bundesagentur für Außenwirtschaft (2008a): Wirtschaftsdaten kompakt. Ecuador. Köln, November 2008.

Bundesagentur für Außenwirtschaft (2008b): Wirtschaftsdaten kompakt. Kolumbien. Köln, November 2008.

CODHES (2006): Boletín de la Consultoría para los Derechos Humanos y el Desplazamiento (CODHES), No. 69, Bogotá, 12.09. 2006.

CODHES (2008): Consultoría para los Derechos Humanos y el Desplazamiento CODHES: Desplazamiento Forzado y Enfoques Diferenciales, Documentos 9. Bogotá.

Comisión Colombiana de Juristas (2006): Ejecuciones extrajudiciales, homicidios sociopolíticos y desapariciones forzadas. http://www.coljuristas.org/documentos/documentos_pag /Vida96-06.zip, 30.03.2009. 
FDCL (2007): Autoritärer Staat und paramilitärische Machtnahme in Kolumbien; Die Regierung Uribe und der Krieg gegen die soziale Bewegung, Forschungs- und Dokumentationszentrum Chile- Lateinamerika FDCL e.V. und kolumbienkampagne berlin: Berlin, Dezember 2007.

Hörtner, Werner (2006): Kolumbien verstehen. Geschichte und Gegenwart eines zerrissenen Landes, Zürich: Rotpunktverlag.

Lebhart, Gustav (2002): »Internationale Migration - Hypothesen, Perspektiven und Theorien«. In: Demographie aktuell (Humboldt-Universität zu Berlin, 19.

Marsella, Anthony/Ring, Erin (2003): »Human Migration and Immigration: An Overview«. In: Gielen, Uwe P./Loeb Adler, Leonore (Hg.), Migration: Immigration and emigration in international perspective, Westport, Conneticut, London.

Romero, Marco Alberto (2006): »Von der Verneinung zur Herausforderung der Wiedergutmachung «. In: Arbeitsgruppe Schweiz-Kolumbien ASK (Hg.), Kolumbien-aktuell 431, Luzern, 18.6. 2006.

Nubia Bello, Martha (2004): »Die Zwangsvertreibungen in Kolumbien: Kapitalanhäufung und soziale Ausgrenzung «. In: Missionszentrale der Franziskaner: Vertrieben im eigenen Land. Grüne Schriftenreihe »Berichte - Dokumente - Kommentare«, Nr.95, Bonn.

Salamanca, Luis Jorge Garay (Hg.) (2008): Verificando el cumplimiento de los derechos. Comisión de Seguimiento a la Política Pública sobre Desplazamiento Forzado. Primer Informe de verificación presentado al Corte Constitucional. Bogotá.

Schreiber, Wolfgang (Hg.) (2007): Das Kriegsgeschehen 2006. Daten und Tendenzen der Kriege und bewaffneten Konflikte. Arbeitsgemeinschaft Kriegsursachenforschung, Hamburg: Verlag für Sozialwissenschaften.

UNHCR (1997): Zur Lage der Flüchtlinge in der Welt, UNHCRReport 1997-98 - Erzwungene Migration: Eine humanitäre Herausforderung, Bonn.

UNHCR (2002): Ecuador - Annual Protection Report 2002 (Reporting period January - December), Quito, S. 1-29. 
UNHCR (2003): Gomez, Jose: Refugiados en las Provincias del Norte Centro y Norte Costa del Ecuador. Ibarra, Ecuador 2003, S. 1-22.

UNHCR (2007): Kommunen in Ecuador unterstützen Registrierung.http://www.unhcr.de/aktuell/einzelansicht/article/ 5/kommunen-in-ecuador-unterstuetzenregistrierung/page. Html, 13.04.2009.

UNHCR (2008): Ecuador Project Concept Notes. Convention and Protocol, http://www.unhcr.org/publ/PROTECTION /4889cb8e2.pdf, 14.4.2009.

UNHCR (2009): UNHCR global appeal 2008-2009. http://www.unhcr.org/ga08/launch.html, 13.04.2009.

Somasundram (2007): "Die Akte Petróleo. Der schmutzige Krieg als Instrument der Ressourcenfreilegung «. In: FDCL und kolumbienkampagne berlin: Autoritärer Staat und paramilitärische Machtnahme. Die Regierung Uribe und der Krieg gegen die soziale Bewegung. Berlin, November 2007.

Verney, Marie-Hélène (2006): Kolumbien: Leben in Angst, Zuflucht auf einer Müllhalde, http://www.unhcr.de/aktuell/ einzelansicht/article/5/kolumbien-leben-in-angst-zufluchtauf-einer-muellhalde.html, 13.04.2009.

Vogel, Dita (2003): »Illegaler Aufenthalt. Konzepte, Forschungszugänge, Realitäten, Optionen «. In: Hunger, Uwe/ Thränhardt, Dietrich (Hg.), Migration im Spannungsfeld von Globalisierung und Nationalstaat, LEVIATHAN Sonderheft 22/2003, Wiesbaden, S. 161-179.

Zelik, Raul (2007): »Der Plan Colombia und Uribes Seguridad Democrática«. In: FDCL und kolumbienkampagne berlin: A.a.O. 


\title{
Afrikanische Staaten, Staatsbürgerschaft und Krieg: Die Region der Großen Seen ${ }^{1}$
}

\author{
MAHMOOD MAMDANI
}

Der folgende Beitrag behandelt den Zusammenhang zwischen Migration und Kriegsflüchtlingen und inner- und zwischenstaatlichen Konflikten in der Region der "Großen Seen " (Uganda, Ruanda, Burundi und Kongo/Zaire). Das besondere Augenmerk des Autors gilt dabei der Institutionalisierung von Gruppenzugehörigkeiten durch den Kolonialismus, die in den Rechtssystemen der postkolonialen Staaten fortwirkt und vom Autor insbesondere im Staatsbürgerschaftsrecht als zentrales Problem herausgearbeitet wird. Über diesen Ansatz stellt der Autor einen Zusammenhang zwischen den kriegerischen Ereignissen in der Region her: Von 1981 bis 1986 führte ein Bürgerkrieg in Uganda zu einem Regimewechsel, dessen Resultate für den Krieg der Front Patriotique Rwandais (FPR) in Ruanda von 1990 bis 1994 bedeutsam wurden. Der mit dem Genozid in Ruanda 1994 einhergehen-

1 Dieser Text (englischer Titel: »African States, citizenship and war: a case study«, veröffentlicht in International Affairs 78, 3 (2002), S. 493-506) ist eine ausgebaute Version einer Einführungsrede zum jährlichen Workshop des Parlaments Ungandas mit dem Titel »The great lakes crisis: its historical origins and contemporary significance«, gehalten am 25. August 2000 im Internationalen Konferenzzentrum in Kampala (Uganda). Übersetzung von Margarete Misselwitz. 
de Regimewechsel rief Flüchtlingsbewegungen hervor, die für die Gewaltkonflikte seit 1997 im Innern des damaligen Zaïre, der heutigen Demokratischen Republik Kongo mitursächlich wurden. Anm.d.Ü.

Abbildung 1: Region der Großen Seen

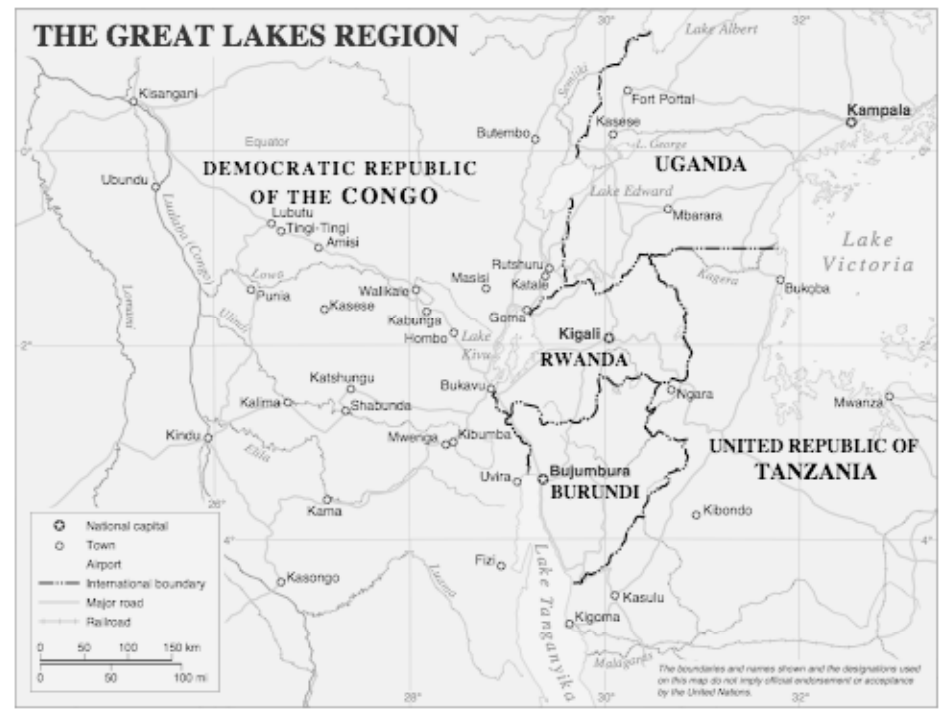

Quelle: Map 4004,1 United Nations, Januar 2004,

Departement of Peacekeeping Operation, Cartographic Section

In den 1970er und 1980er Jahren sprachen wir über Politik in Afrika in der Sprache der politischen Ökonomie. Konfrontiert mit Krisen galt es, deren strukturelle Untermauerung zu reflektieren und der Frage nachzugehen: Welche Art der Beziehungen liegen der Reproduktion von Krisen zugrunde? Heute dagegen neigen wir eher dazu, die Struktur auszublenden und ausschließlich das Handeln der Akteure zu beleuchten. Im Folgenden wird versucht, beide Ansätze zusammenzuführen, indem heutige politische Entwicklungen reflektiert werden, in denen sich Handeln und Struktur verbinden. Wählen nicht Akteure immer aus einem bestimmten Set von Optionen? Und sind diese Optionen nicht immer Produkte der Geschichte? Ist nicht der "gesunde Menschenverstand « nur die Bezeichnung, die wir demjenigen Element unseres historischen Erbes geben, das wir aufgehört haben zu hinterfragen; jenes Element, das wir 
als Teil unserer Tradition mit uns herumtragen? Die Konfrontation mit diesem Erbe bedeutet, es neu »aufzupacken « und das als selbstverständlich hingenommene, allgemeine Verständnis zu hinterfragen.

Dies ist kein Plädoyer für die Rückkehr des Fokus auf die politische Ökonomie, auf die inneren Zwänge unseres Handelns. Vielmehr verstehe ich Handlungen von Akteuren als historisch gewachsen und somit durch strukturelle Zwänge geformt. Statt die uns fehlenden Alternativen $\mathrm{zu}$ beleuchten, möchte ich den Blick auf die von uns getroffene Auswahl lenken und damit auf unsere politischen Institutionen. Drei Formen von Institutionen sind hier von Interesse: die erste ist die Staatsbürgerschaft, bezogen auf die Bürger als Träger von Rechten; die zweite ist die Zivilgesellschaft und die dritte die politische Mehrheit bzw. Minderheit als Ergebnis demokratischer Prozesse. Um zu untersuchen, wie sich unsere Auffassungen von Staatsbürgerschaft, Zivilgesellschaft und politischer Mehrheit/Minderheit in der letzten Dekade verändert haben, werde ich das Dilemma einer bestimmten kulturellen Gruppe in der afrikanischen Region der Großen Seen anführen, das der Banyarwanda.

\section{Die Banyarwanda: Kristallisationspunkt der gegenwärtigen Krise}

Der Begriff Banyarwanda steht zunächst und vor allem für eine kulturelle Identität. Zusammen mit den Kanyarwanda, die dieselbe Sprache sprechen, leben sie in Ruanda und über die Grenzen hinweg in Uganda und Kongo. Insgesamt besteht die Gruppe der Banyarwanda aus etwa 12 bis 14 Millionen Menschen. Sie sind damit die größte ethnische Gruppe in Ostafrika. ${ }^{2}$

Die außerhalb von Ruanda lebenden Banyarwanda können als kulturelle Diaspora aufgefasst werden. Diese kulturelle Diaspora ist in drei Gruppen unterteilt: Staatsbürger, Migranten und Flüchtlinge. Wenn wir in Uganda von BanyarwandaStaatsbürgern sprechen, dann meinen wir diejenigen Banyarwanda, die als indigene Ugander angesehen werden. Als indigen werden Personen aufgefasst, die eine Abstammung von

2 Zur weiterführenden Literatur vgl. Newbury (1995). 
Personen herleiten können, die schon vor der Kolonialisierung Ugandas auf dem Gebiet lebten. Im Gegensatz zu diesen bezeichnen wir diejenigen als nicht-indigene Migranten, die erst während der Kolonialzeit nach Uganda kamen. Anders als Staatsbürger der vor-kolonialen Zeit und Migranten aus der Kolonialzeit sind Flüchtlinge ein weitgehend post-koloniales Phänomen.

Auf welcher Grundlage treffen wir solche Unterscheidungen? Dafür gibt es zwei Ansätze: Der erste besteht in der $A b$ stammung als Grundlage für Staatsbürgerschaft und Rechte. Wenn wir Abstammung definieren benutzen wir in der Regel die zwei Begriffe Rasse und Ethnizität. So offensichtlich uns heute die Unterscheidung auch erscheinen mag, lohnt es sich dennoch diese näher zu beleuchten. In Uganda wurde während der Kolonialzeit und auch danach jedes Individuum vor dem Gesetz einer bestimmten Rasse oder ethnischen Gruppe zugeordnet. Gleiches geschah im 20. Jahrhundert auch in anderen, von westlichen Mächten kolonialisierten, Teilen Afrikas. Auf die Frage, wer nach dem Gesetz zu einer ethnischen Gruppe und wer zu einer Rasse gehört, gibt es keine eindeutige Antwort, jedenfalls keine, die nicht abhängig ist von dem jeweiligen Kontext. Die Antwort hängt von dem jeweiligen Staatstyp ab. In einem Staat mit indirekter Herrschaft, ein Typus, der durch den Britischen Kolonialismus in Uganda eingeführt wurde, wurden nur diejenigen als indigen bezeichnet, die zu einer ethnischen Gruppen gehörten. ${ }^{3}$ Diejenigen, die als nicht-indigen angesehen wurden, galten als Personen ohne Ethnizität, rechtlich wurden sie definiert als zugehörig zu einer Rasse. Die Rechte waren abhängig von der Abstammung, davon, ob jemand als indigen oder nicht-indigen angesehen wurde, bzw. ob man einer ethnischen Gruppe oder einer Rasse angehörte. Während des Kolonialismus besaßen nur Rassen Rechtsstatus, die koloniale Verwaltung unterschied rechtlich nicht zwischen ethnischen Gruppen. Nach der Unabhängigkeit wurden die Verhältnisse in ihr Gegenteil gekehrt: volle Staatsbürgerrechte erhielten nur Personen, die als ethnisch indigen betrachtet wurden.

3 Für eine Analyse der indirekten Herrschaft als eine Form der Kolonialstaaten vgl. Mamdani (1996). 
Meine zweite Beobachtung ergibt sich aus der Frage: Wer ist indigen? 1997 wendete sich CODESRIA - Council for the Development of Social Research in Africa - an einen Kollegen und mich mit einer Forschungsanfrage zur Staatsbürgerschaft in Ki$\mathrm{vu}$, insbesondere hinsichtlich der Banyarwanda in den beiden Kivu-Provinzen im äußersten Osten des Kongo. ${ }^{4}$ Es lassen sich drei Hauptgruppen der Banyarwanda in Kivu unterscheiden. In Nord-Kivu werden die Banyarutshuru als indigen betrachtet, die Banyamasis hingegen als nicht-indigen. Wir gingen der Frage nach, warum dem so sei und erfuhren von den Befragten, dass die Antwort auf der Hand läge: Die Banyarutshuru lebten im Kongo bereits vor der Belgischen Kolonialisierung, wohingegen die Banyamasisi erst während der belgischen Kolonialisierung in den Kongo migrierten. An dieser Stelle empfiehlt es sich, die Bedeutung einer solchen, angeblich allgemein verständlichen Unterscheidung zu untersuchen. Schließlich folgt aus der Aussage, dass der Kolonialismus als Trennungslinie zwischen indigener und nicht-indigener Bevölkerung fungiert. Darüber hinaus bedeutet es, dass der unabhängige Staat Kongo seine eigene Geschichte mit der Entstehung des Kolonialstaates identifiziert. Betrachtet man andere afrikanische Staaten so wird klar, dass in dieser Hinsicht der Kongo keine Ausnahme, sondern vielmehr die Regel darstellt.

Beide Ideen, zum einen, dass die Abstammung die Grundlage für die Rechte sein sollte, zum anderen, dass der Kolonialismus eine Trennungslinie zwischen indigener und nichtindigener Bevölkerung konstituiert, haben ihre Wurzeln in der indirekten Herrschaft des Kolonialismus. Im Gefüge des Nationalstaates drücken sie eine bestimmte Beziehung zwischen Politik und Kultur aus. Generell zeigt die Entwicklung moderner Staaten zwei Arten der Beziehungen zwischen Politik und Kultur auf. Bei der ersten ist der Staat klar identifiziert als ein Staat einer bestimmten Nation und einer bestimmten kulturellen Gruppe. Als solcher unterdrückt er aktiv die kulturelle Diversität und damit die Kulturen anderer Gruppen. Dies ist eine allgemeine europäische Erfahrung, die insbesondere durch zwei Varianten - die französische und die deutsche - verkörpert

4 Bericht der CODESRIA Mission in Kivu von Mahmood Mamdani (1999), »Citizenship crisis in Kivu, Eastern Congo«. 
wird. Der französische Staat definierte seine Staatsbürgerschaft kulturell und hat in seiner Geschichte aktiv eine kulturelle Assimilierung aller Immigranten in den Französischen mainstream betrieben. Der deutsche Staat definierte seine Staatsbürgerschaft biologisch und neigte historisch zu einer Politik der ethnischen Säuberung zur Sicherung der biologischen Reinheit der deutschen Nation.

Die zweite Art der Beziehung zwischen Politik und Kultur lässt sich außerhalb West-Europas finden, sowohl in den ehemals sozialistischen Staaten als auch in den ehemaligen Kolonialstaaten. Während die modernen Staaten in Europa die kulturelle Diversität unterdrückten, gibt es in den modernen Staaten außerhalb Europas die Tendenz, kulturelle Unterschiede zu verfestigen. So war das sowjetische Staatssystem multinational und definierte Gruppenrechte auf der Grundlage der Unterscheidung zwischen Nationen, Nationalitäten und nationalen Gruppen. Ähnlich war der Kolonialstaat angelegt - nämlich als ein multi-ethnisches System. Jede ethnische Gruppe sollte ihre eigene Selbstverwaltung haben, welche die eigene ethnisierte Version der Gewohnheitsrechte durchsetzen sollte. Vom Standpunkt des Kolonialismus des 19. Jahrhunderts - von Historikern als Kolonialismus mit direkter Herrschaft bezeichnet - war es für die Kolonialmächte undenkbar, ein separates Rechtssystem für verschiedene Teile der Bevölkerung zu schaffen - wie etwa Zivilrechte für Mitglieder einer Rasse und separate Gewohnheitsrechte für jede einzelne ethnische Gruppe.

Die jüngeren Generationen könnten unsere Gesetzgeber fragen: In welchem Ausmaß habt ihr versucht, die koloniale Altlast in der Verfassung zu ändern? In diesem Beitrag möchte ich auf drei Versuche hinweisen, das Erbe der Kolonialzeit hinsichtlich der Staatsbürgerschaft zu reformieren. Der erste Versuch wurde in Uganda unternommen, in der Zeit des GuerillaKriegs im Luwero-Dreieck; 5 der zweite in Ruanda während der Zweiten Republik unter Habyarimana und der dritte in Kivu

5 Das Luwero-Dreieck, ein von Sümpfen durchzogenes Gebiet nordwestlich der ugandischen Hauptstadt Kampala, diente in den frühen 1980er Jahren als Operations- und Rückzugsgebiet der National Resistance Army, einer Guerilla, die der heutige Präsident Ugandas, Yoweri Museveni leitete (Anm. d. Ü.). 
durch die Banyamulenge. Alle drei Initiativen wurden für eine Weile umgesetzt, wurden später mit Herausforderungen konfrontiert und schließlich wieder vollständig rückgängig gemacht. Es lohnt sich, alle drei Initiativen zu untersuchen und aus ihren Entwicklungen zu lernen.

\section{Uganda: Das Experiment von Luwero}

Das Luwero-Dreieck in der Buganda-Region in Uganda war geografisch das Zentrum der Guerilla-Kämpfe, die von 1981 bis 1986 von der National Resistance Army (NRA) angeführt wurden. Um die soziale Zusammensetzung des Luwero-Dreiecks in den 1980er Jahren zu verstehen, müssen wir die Volkszählung aus dem Jahr 1959 berücksichtigen, die letzte, welche die Stammeszugehörigkeit der Bevölkerung wiedergibt. Nach dieser Volkszählung waren ca. 45 Prozent der Bevölkerung Bugandas Migranten (vgl. Fortt 1956 und Postan 1956). Die größte Einzelgruppe der Migranten waren die Banyarwanda. Diese Demographie weist auf die wichtigste Herausforderung aller politischen Bewegungen in Buganda hin, nämlich: wie lassen sich diese zwei Gruppen, die Indigenen und die NichtIndigenen, in einer Bewegung zusammenschließen? Die NRA versuchte in den 1980er Jahren eine solche Einheit herzustellen, indem das Konzept der Abstammung durch das Konzept des derzeitigen Wohnsitzes als Grundlage für die Zuweisung individueller Rechte ersetzt wurde: Wann immer die Guerilla ein Dorf eroberte, wurden alle erwachsene Bewohner zu einer Bürgerversammlung zusammengerufen, zwecks Wahl eines neunköpfigen Bürgerrates, der die internen Angelegenheiten verwalten sollte. Die politischen Schlüsselfragen diesbezüglich waren: Wer darf an einer solchen Bürgerversammlung teilnehmen? Wer kann sich für die Posten im Bürgerrat bewerben? Wem wird die Teilnahme an der Wahl gestattet? Es ist entscheidend, dass die NRA nicht nur die indigenen, sondern alle Bewohner des Dorfes dazu ermächtigte. Dadurch erhielt die NRA die Unterstützung sowohl von der indigenen als auch von der nicht-indigenen Bevölkerung im Gebiet des LuweroDreiecks. Dass die NRA bei der Ankunft in Kampala 1986 zu 
mindestens einem Viertel ihrer 16.000 Kämpfer aus Banyarwanda bestand, ist hierfür ein deutlicher Beleg.

Das politische Vermächtnis von Luwero hielt jedoch nicht lange vor. Es wurde faktisch bereits mit der ersten politischen Krise der regierenden National Resistance Movement (NRM) untergraben. Diese Krise kreiste um die Fragen der Rechte und der Indigenität im Luwero-Dreieck und erreichte 1990 ihren Höhepunkt. Ihr Kontext war der Konflikt zwischen Landbesetzern und Farmbesitzern im Masaka Bezirk, insbesondere im Kreis Mawogola. Ein Großteil der Besetzer waren Banyarwanda-Hirten, deren Kinder der NRA beigetreten waren und aus dem Busch mit Erfahrungen im Waffenumgang zurückkehrten. Die Liste der Farmbesitzer wiederum liest sich wie ein »who is who" aller Regime in der ugandischen Geschichte. Die Farmer schlossen sich in einer eigenen Organisation zusammen, die Masaka Livestock Farmers' Association (MALIFA) und beschuldigten Präsident Museveni nicht nur ethnische Begünstigung unter den Ugandern zu betreiben, indem die Banyankole gegenüber den Baganda Farmern bevorzugt würden, sondern zudem, dass er in seiner ethnischen Begünstigung auch die nicht-indigenen Banyarwanda einschließe. ${ }^{6}$

Das Ergebnis war eine größere politische Krise, die zu einer eigens anberaumten drei Tage andauernden Parlamentssitzung Ende August 1990 führte. Darin musste der Präsident öffentlich Stellung nehmen, zum einen gegenüber seinem Verteidigungsminister, der ihn an die Verpflichtungen der NRA gegenüber ihren ehemaligen Kämpfern erinnerte, sowie gegenüber seinem Justizminister, der die öffentlich erklärte Pan-Afrikanische Verpflichtung anmahnte. Dennoch hielten sich Präsident Museveni und die NRM nicht an die Versprechungen von Luwero: Als Voraussetzung für die Staatsbürgerschaft galt erneut die Abstammung und nicht mehr nur ein mindestens 10 Jahre währender Aufenthalt auf dem Territorium Ugandas. Unter der neuen Verfassung wurde die ugandische Staatsbürgerschaft nur zuerkannt, wenn mindestens ein Großelternteil im britisch

6 Für eine detaillierte Analyse zu den Parlamentsdiskussionen, die dem Aufstand der Mawogola 1990 folgten und der Invasion der Front Patriotique Rwandais (FPR) im gleichen Jahr vorausging, vlg: Mamdani 2001: Kap. 6. 
kolonisierten Uganda geboren wurde. Diese Änderung betraf sowohl die Elite als auch gewöhnliche Personen unter den Banyarwanda in Uganda. Während nach dem Guerilla-Sieg der NRA die Banyarwanda-Elite, einschließlich der NRA-Kader, zunehmend weniger befördert wurden, fanden sie sich nun als Objekte einer Art Hexenjagd wieder. Für gewöhnliche Banyarwanda-Hirten bedeutete die nun fehlende Staatsbürgerschaft der Verlust des Rechtsanspruchs auf Weideland.

Dies war der Hintergrund der ersten großen politischen Krise der NRM. Weniger als zwei Monate später, im Oktober 1990, überquerten Kader der Front Patriotique Rwandais (FPR) die Grenze von Uganda nach Ruanda. Die meisten Analysen zu diesem Ereignis konzentrieren sich auf die Unterstützung der FPR durch die NRA zum Zeitpunkt des Grenzübertritts 1990 und in den nachfolgenden Jahren. Mein Argument geht in eine andere Richtung. Egal, wie viel Unterstützung die FPR aus Uganda erhalten haben mag, die unterschwellige Botschaft war für die Banyarwanda eindeutig: Sie sollten nicht zurückkommen. Der Grenzübertritt der FPR bedeutete nicht nur eine bewaffnete Invasion der Ruander aus einer Sektion der NRA, vielmehr bedeutete er eine bewaffnete Repatriierung von Banyarwanda aus Uganda. Mit dieser bewaffneten Repatriierung exportierte die NRA ihr innenpolitisches Problem nach Ruanda.

Zwei Tatsachen müssen hier festgehalten werden. Erstens, noch vor der Parlamentsdebatte im August 1990 gab es eine starke Strömung unter den Banyarwanda in der NRA, die für einen Grenzübertritt plädierten, um Ruanda zu »befreien«. Dies stand im Gegensatz zu den Banyarwanda, die für eine endgültige Niederlassung der Banyarwanda in eben der Region eintraten, in der sie bereits lebten. Vor August 1990 war - insbesondere für gewöhnliche Banyarwanda - die zweite Alternative attraktiver. Mit dem August 1990 wurde diese Alternative faktisch abgeschafft. Zweitens, der Grenzübertritt der FPR bedeutete ein Zusammentreffen von Staatsbürgerschaftskrisen auf beiden Seiten der Grenze, sowohl in Uganda als auch in Ruanda. Später werde ich zeigen, dass in der Zweiten Republik in Ruanda unter Habyarimana zwar den in Ruanda lebenden Tutsi Möglichkeiten zur Anerkennung der Staatsbürgerschaftsrechte eingeräumt wurden, dabei aber versäumt wurde, auch denjenigen Tutsi entsprechende Angebote zu machen, die während 
der Krisen von 1958 bis 1963 und 1973 Ruanda als Flüchtlinge verlassen hatten. Genau aus diesem Grunde neigten Banyarwanda-Flüchtlinge dazu, sich dem Kampf in den Ländern, in denen sie lebten, anzuschließen. Von allen Flüchtlingen hatten die Banyarwanda in Uganda die größte Bindung zu ihrem Aufnahmeland. Ihre Hingabe für das Land, welches sie als ihre Heimat bezeichneten, ging sogar soweit, eigenes Blut dafür zu vergießen. Nach den ständigen Kameradschaftsbeteuerungen während des gemeinsamen Kampfes musste die Aberkennung der Staatsbürgerschaftsrechte den Banyarwanda als ein Betrug der ehemaligen Waffenbrüder erscheinen.

\section{Ruanda: Die Welt der Hutu und Tutsi}

Als die FPR die Grenze zu Ruanda überquerte, verlor sie nicht nur in einer Hinsicht ihre politische Unschuld. Erinnern wir uns an die Berichte der ersten Journalisten, die die von der FPR »befreiten « Gebiete in Ruanda besuchten: Catherine Watson, eine in Kampala lebende amerikanische Journalistin, Charles Onyango-Obbo, ein bekannter Journalist aus Uganda und Gérard Prunier, ein berühmter französischer Afrikawissenschaftler. Alle drei berichteten, dass in den »befreiten « Gebieten so gut wie keine Menschen mehr waren: nur etwa 2.500 waren in einer Region verblieben, in der vorher eine Million Menschen lebten (Watson 1992: 55/Onyango-Obbo 1993/Prunier 1995: 175). Alle drei verwendeten dasselbe Wort zur Charakterisierung der Leere in den »befreiten« Gebieten: Die Stille, sagten sie, war »furchterregend $«$.

Der Grund dafür konnte den FPR-Kadern nicht entgangen sein. Sie stellten fest, dass genau die Bauern, die sie befreien wollten, vor ihnen davon liefen und entdeckten so die Welt der Hutu und Tutsi in Ruanda. Zu diesem Zeitpunkt war aber an eine Rückkehr nach Uganda nicht mehr zu denken. Von nun an bedeutete die Befreiung für die FPR nicht mehr die Befreiung von Menschen, sondern die Befreiung von Territorium. Die Wirkung war unterschiedlich für verschiedene Kader, es gab zwei Extreme: die Machtträger wurden in ihrem Zynismus bekräftigt, die anderen - unvertraut mit den politischen Realitäten 
in Ruanda - entdeckten nun, dass sie letzten Endes als Tutsi galten.

Die Bezeichnung Hutu und Tutsi unterscheiden keine verschiedene Kulturen, nicht mal eine Welt von arm und reich. Es ist vor allem eine politische Konstruktion. Der Beweis dafür, dass Hutu und Tutsi keine Bezeichnung für verschiedene ökonomisch generierte Identitäten sind - ob basierend auf Klassen oder Arbeitsteilung, auf der Unterscheidung zwischen arm und reich oder zwischen Ackerbauern und Viehzüchtern - besteht in den armen Tutsi, die im übrigen auch kein Vieh besaßen. Auch sind Hutu und Tutsi keine Bezeichnungen für unterschiedliche kulturelle Identitäten, da - wie die FPR stolz jedem Besucher in Kigali erzählt - Hutu und Tutsi dieselbe Sprache sprechen und eine gemeinsame Kultur und Religion teilen. Dennoch existieren Hutu und Tutsi - weder als ökonomisch generierte Identitäten noch als kulturelle Identitäten, sondern als politische Identitäten. Der beste Beleg dafür, dass Hutu keine ethnische, sondern eine politische Identität ist, sind die Hutu in Nord-Ruanda: Bevor sie in den Staat Ruanda inkorporiert wurden, galten sie als Bakiga, wie ihre Verwandten in WestUganda. Mit der Inkorporation in den Staat Ruanda wurden sie zu Hutu. Statt einer transhistorischen ethnischen Identität sind Hutu vielmehr eine transethnische subjektive Identität all jener, die von der Tutsi-Macht in Ruanda unterworfen wurden.

Um die historische Bildung von Hutu und Tutsi zu verstehen, muss die historische Gründung des Staates Ruanda betrachtet werden. Die Entwicklungen des Marktes oder der Gemeinschaften können nicht alles erklären. Es ist eine Tatsache, dass Hutu und Tutsi keine ethnischen Identitäten waren. So wie Hutu eine subjektive Identität war, eine Identität all jener, die vor der belgischen Kolonisation von der Macht in Ruanda beherrscht wurden, war Tutsi eine Identität der Macht. Das bedeutet nicht, dass alle Tutsi Macht besaßen, aber alle wurden mit der Macht assoziiert. So wurden auch alle Weißen - auch arme Weiße - während der Kolonialzeit mit der Macht in Verbindung gebracht. Die Assoziation machte nicht alle reich, aber sogar die ärmsten Weißen wurden anders behandelt als alle Nicht-Weißen. Um ein Beispiel zu nennen: König Mwami Rwabugiri führte im späten neunzehnten Jahrhundert die Zwangs- 
arbeit - ubureetwa - in Ruanda ein, im Kolonialstaat jedoch war ubureetwa nur für Hutu reserviert (Newbury 1989: 10-11, 51-2).

Auch die Bezeichnung Tutsi kennzeichnete keine feste Gruppenidentität. Wohlhabende Hutu wurden über Generationen, vor allem durch Mischehen, als Tutsi absorbiert. Obwohl statistisch nicht signifikant, so war ein solcher Prozess von genügend sozialer Bedeutung, als dass ihm ein Name gegeben wurde: Kwihutura. Ähnlich konnten über Generationen durch einen gegenläufigen Prozess arme Tutsi zu Hutu werden, bezeichnet als Gucupira. Hier machte der Kolonialismus einen entscheidenden Unterschied. Die Kolonialverwaltung führte den Begriff der Rasse ein. Hutu wurden als »Bantu « gebrandmarkt als indigen und dumm stereotypisiert - und Tutsi wurden $\mathrm{zu}$ "Hamiten", als zivilisatorisch höher entwickelte Zugewanderte betrachtet. ${ }^{7}$ Der Kolonialismus trennte Hutu von Tutsi vor dem Gesetz und stellte allen einen jeweiligen Ausweis aus. Damit gab es kein Kwihutura und auch kein Gucupira mehr (Haguma 1993). Privilegien wurden an die Rasse gebunden, daran, ob man als indigen oder als Ausländer betrachtet wurde. Wenn wir den Genozid verstehen wollen, dürfen wir diese Tatsache nicht vergessen. Als im Genozid Hutu Tutsi umbrachten, lohnt es sich zu fragen, für wen sich diese Hutu hielten und wen sie zu töten meinten. Sie waren überzeugt, nur sie seien die »Söhne" dieser Region und töteten Fremde, die die Macht an sich reißen wollten. Sie gingen davon aus, sie seien Einheimische, die Eindringlinge töteten. ${ }^{8}$

Wenn ruandische Intellektuelle die Hutu- und Tutsi-Frage diskutieren, sind scharfe Differenzen zwischen zwei Standpunkten festzustellen. Die Hutu betonen, dass Hutu und Tutsi schon immer verschieden waren, während Tutsi behaupten,

$7 \mathrm{Zu}$ dieser, wissenschaftlich nicht haltbaren, »Hamiten-Theorie« vgl. Gérard Prunier: The Rwandan Crisis. 1990-1996, London: Hurst, (Anm. d. Ü.).

8 Zur weiterführenden Diskussion zur Revolution 1959, die im Genozid 1994 sehr >populär< war, zur gleichen perversen Beschäftigung mit der Herkunft in der Ruandischen Geschichtsschreibung, zur Zweiten Republik und dem Wesen des postgenozidalen Staates in Ruanda vgl. insbesondere Kapitel 4, 7, 2 und 5 sowie das Fazit in Mamdani (2001): »When victims become killers «. 
dass sie ein und dasselbe Volk seien, geteilt - wie in jeder »normalen" Gesellschaft - durch andere Lebensumstände, Reichtum oder Beruf. Ihnen gemein ist aber die Beschäftigung mit der Herkunft. Und diese Beschäftigung mit der Herkunft ist das Erbe des Kolonialismus. Sie symbolisiert die nicht mitgedachte Kollaboration zwischen imperialer Ideologie und Geschichtsschreibung in dieser Region. Diese Kollaboration ist in jedes Inhaltsverzeichnis eingeschrieben, das der Geschichtsschreibung der Region vorangeht.

Vor dem Genozid gab es in Ruanda zwei Republiken. Die erste Republik unter Kayibanda behielt die Unterscheidung zwischen Hutu und Tutsi als Klassifikation zwischen arm und reich bei. Es ist richtig, dass die Revolution 1959 die vom Kolonialismus geschaffene Welt auf den Kopf stellte, aber ihre Kategorisierungen wurden nicht ausgetauscht. Lenin schrieb einmal zu Rosa Luxemburg, dass sie so sehr damit beschäftigt sei, den polnischen Nationalismus zu bekämpfen, dass sie, wie die Augen einer Ratte, nichts anderes mehr sehe als Katzen. Die Welt der Hutu und Tutsi wurde zu einer Welt der Ratten und Katzen. Für die Ratte gibt es kein gefährlicheres Tier als die Katze; kein Tiger, kein Elefant, nur Katzen. Und für die Katze gibt es kein köstlicheres Tier als die Ratte. Natürlich können wir nicht die sozialen und politischen Ziele der Revolution von 1959 von der Hand weisen, von der Landreform zur Herrschaftsreform. Aber es lässt sich auch nicht die Begrenztheit der Revolution übersehen: Es wurde versäumt, das politische Erbe des Kolonialismus zu überwinden. Anstatt die vom Kolonialismus geschaffenen politischen Identitäten zu hinterfragen - dass Hutu indigene Bantu und Tutsi ausländische Hamiten seien - wurden sie beibehalten. Es wurde versäumt, den Kolonialismus nicht nur als ökonomisches System zu verstehen, welches die Einheimischen enteignete. Es war ebenso ein politisches System, das durch die Politisierung der Indigenität das politische Leben vergiftete.

Der Putsch von 1973 leitete die Zweite Republik unter Juvenal Habyarimana ein. In Uganda wird Habyarimana als Schurke in der ruandischen Tragödie gesehen. Jedoch unternahm Habyarimana den Versuch, das von Kayibanda installierte politische System zu reformieren. Habyarimana definierte offiziell Tutsi von einer Rasse zu einer ethnischen Gruppe um - von 
einer nicht-indigenen Minderheit ohne politische Rechte in eine indigene Minderheit mit politischen Rechten und mit proportionaler Repräsentation im Parlament, in Botschaften, im Kabinett und sogar in der Armee. Habyarimanas Dilemma war aber, dass er der politischen Tutsi-Diaspora - den in der ganzen Region verstreuten Flüchtlingen von 1959 - keine Zukunft bot. Er machte die post-1959-Flüchtlinge zu den Juden Afrikas. Ich benutze hier die Bezeichnung »Juden« als Metapher für politische Heimatlosigkeit - für diejenigen, die in einer Welt der Nationalstaaten leben, in der alle Nationen einen Staat haben müssen und in einer Welt der ehemaligen Kolonien, in der nach der indirekten Herrschaft, auch alle ethnischen Gruppen eine Heimat haben. Aus dieser Sicht verkörpert der Oktober 1990 ein Zusammentreffen von zwei Versäumnissen auf beiden Seiten der Grenze: das von Habyarimanas Führung in Ruanda und das von Musevenis Führung in Uganda. Die ruandische Invasion vom Oktober 1990 durch die FPR war ein Zeugnis der Staatsbürgerschaftskrise auf beiden Seiten der Grenze.

Die genocidaires, die Praktiker des Völkermords in Ruanda 1994, lehnten Habyarimana ab, wie auch die Idee, dass Tutsi eine ethnische Gruppe seien. Diese Ablehnung kam das erste Mal im Lizide-Putsch von 1978 zu Tage. Die herrschenden Hutu-Propaganda-Organe und die nach der Invasion von 1990 gegründete Coalition pour la Défense de la Republique (CDR) sendeten eine zentrale Botschaft aus: »Tutsi sind keine indigene ethnische Gruppe, sondern eine nicht-indigene Rasse«. Der Genozid an den Tutsi wurde nicht als ein Genozid an den Tutsi sondern als ein Genozid an den Hamiten verübt. Als die vorkolonialen Tutsi Privilegien beanspruchten, taten sie dies nicht auf der Grundlage fremder Abstammung, sondern auf der Grundlage göttlicher Zustimmung (Imana). Im Gegensatz dazu beanspruchten kolonialisierte Tutsi Privilegien als nicht-indigene Hamiten. Genozid wird nicht an Nachbarn verübt, von denen wir annehmen, dass sie legitim auf derselben Erde wohnen, egal welche anderen Unterschiede uns von ihnen trennen. Genozid wird nur an Menschen verübt, deren Präsenz in der politischen Arena als illegitim galt und deren Bemühung um die Herrschaft als fremde Machtergreifung verstanden wurde.

Der Genozid von 1994 schuf einen neuen Staat in Ruanda, ein Staat, der von zwei Grundüberzeugungen geprägt ist. Ers- 
tens, der Post-Genozid-Staat betrachtet sich selbst als moralisch verantwortlich für die Sicherheit und den Schutz aller lebenden Tutsi auf der ganzen Welt, nicht nur in Ruanda. In diesem Sinne ist es ein Diaspora-Staat, wie Israel. Zweitens, dieser Staat glaubt, dass die Herrschaft der Tutsi die Voraussetzung für das Überleben der Tutsi sei: Wenn Tutsi ihre Macht verlieren, verlieren sie ihr Leben. In diesem Sinne ist der Post-Genozid-Staat auch ein nationaler Sicherheitsstaat - ebenfalls wie Israel. Unter Berücksichtigung der Implikationen des ruandischen Staates werden diese Einsichten praktisch relevant. Falls die TutsiHerrschaft tatsächlich die Voraussetzung für das Überleben der Tutsi ist, dann werden Tutsi und Hutu weiter als separate und sogar antagonistische politische Identitäten in Ruanda reproduziert. Unter diesen Voraussetzungen scheint der einzig mögliche Friede zwischen Tutsi und Hutu ein bewaffneter Friede.

Tatsächlich ist dies in dem gegenwärtigen Ruanda zunehmend der Fall. Die Spannungen, die das Post-Genozid-Ruanda charakterisieren, gleichen zunehmend einem Vulkan. Als die FPR das zweite Mal in weniger als einer Dekade die Grenze überschritt - diesmal 1997 von Ruanda in die Kivu-Provinzen des Kongo, damals Zaïre - ähnelte ihr Vormarsch dem von geschmolzener Lava, die alles Lebende unter sich begrub. Die FPR schien entschlossen, nicht nur die Interahamwe in den grenzüberschreitenden Camps auszulöschen, sondern auch andere Hutu als potenzielle Interahamwe und sogar indigene Kongolesen als Komplizen der Interahamwe und Hutu. Während man 1997 noch glauben konnte, dass die Ursache der ruandischen Probleme die bewaffneten Flüchtlingslager hinter der Grenze in Zaïre seien, wäre es heute richtiger zu sagen, dass die Wurzeln der kongolesischen Probleme hinter der Grenze in Ruanda liegen. Im Nachhinein scheint es, dass Ruanda 1997 seine interne Krise in den Kongo exportierte, wie 1990 Uganda seine interne Krise nach Ruanda exportierte. Dies führt uns zu dem letzten und dritten Fokus dieses Beitrags: zum Kongo. 


\section{Kivu und Kongo: \\ Das Recht auf Land und eigene chiefs}

Die Banyarwanda in Kivu sind in drei verschiedene Gruppen geteilt: die Banyarutshuru und die Banyamasisi in Nord-Kivu und die Banyamulenge in Süd-Kivu. Von ihnen wurden die Banyarutshuru, obwohl sie vor dem Kolonialismus Teil des ruandischen Königreichs waren, als Indigene im Kongo betrachtet, die Banyamasisi und die Banyamulenge hingegen als nichtindigen. Um zu verstehen, welch ein enormer Unterschied das für gewöhnliche Bauern in ihrem Alltag macht, müssen wir zunächst das Wesen der Staatsbürgerschaft im postkolonialen Kongo verstehen.

Die Staatsbürgerschaft im heutigen Kongo, wie auch im gegenwärtigen Uganda, hat zwei Dimensionen: eine zivile und eine ethnische. ${ }^{9}$ Wenn wir die Staatsbürgerschaft thematisieren, sprechen wir normalerweise nur von der zivilen Dimension. Die zivile Staatsbürgerschaft bezieht sich auf die individuellen zivilen und politischen Rechte, die für gewöhnlich als solche in der Verfassung festgelegt sind. Im Gegensatz dazu bezieht sich die ethnische Staatsbürgerschaft auf Gruppenrechte. Diese sind soziale und wirtschaftliche Rechte und werden normalerweise als Gewohnheitsrechte bezeichnet. Die ethnische Zugehörigkeit definiert unter anderem das Gewohntheitsrecht auf Land und das Zugangsrecht zu gewohnheitsrechtlichen Gerichten.

Da die Banyarutshuru - als einzige Kinyarwanda-Sprechende - als indigen im Kongo betrachtet wurden, besaßen sie allein eine eigene Verwaltung im kolonialisierten Kongo. Die Banyamasisi kamen als Immigranten während der Kolonialzeit. Im Unterschied zu den Banyarwanda, die nach Uganda migrierten, war die Migration der Banyamasisi eher eine organisierte Transplantation; daher gab man auch ihnen für eine Weile von den späten 1930er Jahren bis 1959 - eine eigene Verwaltung, bezeichnet als Collectivité Gishari. Als diese Collectivité zur Unabhängigkeit abgeschafft und die Banyamasisi unter die so genannten indigenen chiefs gestellt wurden, folgte ein Aufstand

9 Für eine ausführlichere Erörterung der politischen Identität und der Staatsbürgerschaft in der Region der Großen Seen vgl. Mamdani (2001), »When victims become killers«, Kap. 1 und 8. 
gegen diese chiefs, bekannt als La Guerre du Banyarwanda. ${ }^{10}$ Seitdem kämpfen die Banyamasisi um eine eigene Verwaltung, denn ohne sie - das heißt, ohne als indigen anerkannt zu sein fehlen ihnen wichtige Rechte, insbesondere das Gewohnheitsrecht auf Land und das Recht, von eigenen chiefs verwaltet zu werden.

Während die Banyamasisi in Nord-Kivu vor allem Hutu waren, waren die Banyamulenge in Süd-Kivu Tutsi. Wie die Banyamasisi kämpften auch die Banyamulenge um die Anerkennung als Indigene und damit um ihre eigenen Gewohnheitsrechte auf Land und eigene Verwaltung. Als die FPR in den Kongo einrückte, zunächst die Flüchtlingslager einnahm und sich dann weiter in Richtung Kinshasa orientierte, behauptete sie, damit einen neuen Genozid an den Banyamulenge zu verhindern. Aber für Beobachter mit Gespür für die Geschichte dieser Region musste dies unglaubwürdig erscheinen, dass ausgerechtet der ruandische Staat sich als Verteidiger der Rechte der Banyamulenge ausgab. Denn die gesamte Geschichte der Banyamulenge im Kongo war gekennzeichnet durch deren Distanzierung vom ruandischen Staat. Historisch stammten einige der Banyamulenge von aristokratischen Tutsi-Familien ab, die ihre Heimat verlassen hatten aufgrund der Versuche seitens König Rwabugiris, die Aristokratie zu besteuern und das Königreich Ruanda im späten 19. Jahrhundert zu zentralisieren. Andere flohen, als die blutige Sezessionsschlacht nach dem Tod von Rwabugiri verloren war - in der ruandischen Geschichte als Rucuncu bezeichnet. Diese historische Distanzierung von Ruanda wurde bekräftigt durch das Massaker der Hutu in Burundi 1972. Man sagt, die Banyamulenge änderten ihren Namen von Banyarwanda - mit der Betonung auf ihre Herkunft zu Banyamulenge (Banya-mulenge: die, die von den Hügeln von Mulenge kommen). Sie betonten aus einem einzigen Grund ihren damaligen Aufenthaltsort über ihre Herkunft: um sich noch weiter von der unbeständigen Welt der Hutu und Tutsi in Burundi und Ruanda zu entfernen.

Dieser dritte Versuch in der Region der Großen Seen, die Identität auf der Grundlage des Aufenthaltsortes zu definieren,

$10 \mathrm{Zu}$ Collectivité Gishani und La Guerre du Banyarwanda vgl. Bucyalimwe (1990). 
statt wie bisher auf der der Abstammung, scheiterte wie seine Vorgänger in Ruanda und Uganda. Er wurde sabotiert von der kongolesischen Gesellschaft, die demgegenüber feindlicher eingestellt war als der Mobutu-Staat. Im Kongo hatte das MobutuRegime eine widersprüchliche Haltung gegenüber den kongolesischen Banyarwanda. Während 1972 das Dekret von Mobutu den Flüchtlingen von 1959 die Staatsbürgerschaft zuerkannte, setzte das Gesetz von 1981 wieder die Abstammung über den Aufenthaltsort. Als die kongolesische Nationalkonferenz, in der die politische und zivile Opposition gegen Mobutu zusammentraf, 1991 die Staatsbürgerschaftsfrage behandelte, gaben sie ebenfalls ein Gesetz heraus, welches Mobutus Gesetz von 1981 bestätigte und die Abstammung über den Aufenthaltsort als Grundlage für die Staatsbürgerschaft setzte. Es war kein Zufall, dass die Banyamulenge ein Viertel der Kongolesen ausmachten, die sich der FPR 1997 in ihrer grenzüberschreitenden Invasion anschlossen - ungefähr dieselbe Proportion der Banyarwanda innerhalb der NRA, als diese Kampala 1986 erreichte.

Die Banyarwanda-, insbesondere die Tutsi-Minderheit in dieser Region waren schon immer eine Zielscheibe für Vorurteile der Mehrheitsbevölkerung, ob nach der 1959er Revolution in Ruanda, im Guerilla-Krieg in Uganda von 1981 bis 1986 oder während der Nationalkonferenz (CNS) im Kongo von 1990 bis 1991. Es ist wichtig, die Bedeutung dieser Entwicklung zu erfassen. In allen drei Fällen benutzte eine demokratische Mehrheit den demokratischen Prozess, um die Minderheit zu entrechten. In allen Fällen hatte ein demokratischer Prozess ein undemokratisches Resultat. Die Frage der Minderheitenrechte in der Demokratie bedarf besonderer Aufmerksamkeit. Die meisten Artikel zum Genozid 1994 betonen, dass der Genozid das Resultat eines von Seiten des Staates initiiertes Projekt gewesen sein soll. Es herrscht Schweigen darüber, welchen perversen Anteil die Bevölkerung an dem Genozid hatte, darüber, dass das Töten vor allem durch die Beteiligung der Massen möglich war. Letztlich bestand die Rolle der staatlichen Institutionen hauptsächlich darin, gewöhnliche Bahutu zum Töten zu ermutigen. Wir müssen danach fragen, welche Handlungspotentiale $1994 \mathrm{im}$ Genozid, 1991 in der kongolesischen Nationalkonferenz, 1990 im ugandischen Parlament und 1959 in der Revolution in Ruanda freigesetzt wurden. Mein Argument ist, 
dass die Handelnden sich selbst als »einheimisch» sahen und ihr Angriffsziel als »fremd $«$.

\section{Uganda hat die Wahl}

Während Ruanda vorgibt aus Sicherheitsgründen im Kongo zu sein, kann sich die ugandische Regierung nicht entscheiden, warum sie ihre Truppen dorthin entsandte. Das bedeutet, dass Uganda offenbar nicht nur einen Grund hatte. Oft wird das Sicherheitsargument genannt, aber je weiter man sich von der Grenze entfernt, wird ein anderer Grund für ihre Präsenz im Kongo angegeben. Dieser Grund ist ideologisch: »Wir sind hier, um die Revolution zu unterstützen«. Von allen Teilnehmern im Kongo-Konflikt hätte Uganda am besten den Konflikt in einen breiteren historischen Kontext stellen können, seine wachsenden Kosten abschätzen und Alternativen zu dem Konflikt andenken können, denn allein Uganda machte ebenfalls die Erfahrung, von einem Nachbarn »befreit« zu werden. Ich beziehe mich hierbei auf den Krieg von 1979, als Truppen aus Tansania Idi Amin stürzten. Es gibt eine ganz bestimmte Erfahrung, die hier interessant ist. Als die tansanischen Truppen den Diktator Idi Amin angriffen, erhielten sie allgemeine Unterstützung von der ugandischen Bevölkerung. Sobald der Diktator gestürzt war und die tansanischen Truppen dazu übergingen ein neues Parlament zu installieren, schwand diese Unterstützung. Die Konsequenz dieser unangemessenen "guten Nachbarschaft" war ein fünfjähriger Guerilla-Krieg von Seiten der ugandischen Bevölkerung und es bedurfte eines Staatsmannes mit Vision und Mut wie Julius Nyerere, um zu verstehen, dass die tansanischen Truppen nicht nur teilweise, sondern komplett aus Uganda zurückgezogen werden müssen.

Der Kongo hatte 1997 nicht nur einen »Befreier« sondern gleich mehrere. Die regionale Staatenkoalition aus Uganda, Ruanda, Angola, Simbabwe und Namibia erhielt anfangs ebenfalls starke Unterstützung von Seiten des kongolesischen Volkes. Schließlich waren es keine Kongolesen, sondern Teilnehmer der Koalition, - insbesondere Uganda, Ruanda und Angola - die Kabila an die Macht brachten. Als ein Teil der Koalition von Kabila enttäuscht wurde und ihn durch einen anderen Führer 
ersetzen wollte, zerfiel die Koalition. Der bis heute andauernde innerstaatliche Krieg in der Demokratischen Republik Kongo, dem damaligen Zaïre, begann nicht als ein Krieg zwischen Kabila und einer bewaffneten internationalen Opposition, sondern als Krieg zwischen zwei Fraktionen der regionalen Koalition. Dieser Krieg zwischen den Nachbarn von Kongo fand bedauerlicherweise auf dem Boden Kongos statt. Der Kongo-Krieg degenerierte weiter, indem sich Uganda und Ruanda in einer Serie von Scharmützel gegenseitig bekämpften, obwohl beide Staaten bis dahin eine Allianz gebildet hatten.

Dieser kurze Abriss zum Hintergrund ist notwendig, um die Optionen aufzuzeigen, mit der wir in unserer unmittelbaren Zukunft konfrontiert sein werden. Je länger Uganda in dem regionalen Konflikt involviert bleibt, desto mehr wird diese Eingebundenheit auch die internen Entwicklungen beeinflussen. Ugandas unmittelbare Zukunft wird davon geprägt sein, welche der konkurrierenden Dynamiken Oberhand gewinnt: der zivile und potenziell demokratische Trend, der zur internen Öffnung geführt hat, oder der militärische regionale Eingriff. ${ }^{11}$ Diese zwei Dynamiken sind in ihren Auswirkungen gegensätzlich verschieden. Im Zentrum der internen Dynamik stand die Entwicklung des lokalen Gemeindesystems: Das auf der Grundlage des im Guerilla-Krieg geschaffenen Verwaltungssystem sollte von einem Gemeindesystem auf fünf Gemeindesysteme ausdifferenziert werden. Ihre Auswirkung war die Demilitarisierung des Konflikts, indem eine politische Option im Umgang mit Differenzen angeboten wurde. Die Stoßrichtung der regionalen Dynamik ist dem genau entgegengesetzt: Sie tendiert eher dahin, jegliche Differenzen in einen militärischen Konflikt umzuwandeln. Anscheinend fehlt uns entweder eine Führung oder ein Mechanismus, der bzw. die die Region von einem militärischen Umgang zur Lösung von Differenzen hin zu einem politischen Umgang führt. Diejenigen, die sich verpflichtet fühlen, Revolutionen zu unterstützen, sollten sich be-

11 Die Truppen Ugandas, die zwischen 1997 und 1999 am Krieg in der DR Kongo beteiligt waren, sind im Jahr 2002, als dieser Text erstmalig publiziert wurde, offiziell zurückgezogen worden. Dennoch sind ugandische Geschäftsleute und Militärs in vielfältiger Weise in die Dynamiken im Osten der DR Kongo involviert geblieben (Anm. d. Übers.). 
wusst werden, dass Revolutionen nicht durch einen bewaffneten Grenzübertritt exportiert werden können. Ideen können Grenzen überschreiten, Zivilisten und Güter auch. Aber die wichtigste Bedingung für eine friedliche Koexistenz, einschließlich des Rechts eines jeden Volkes auf seine eigene Revolution, ist der Respekt der Staaten und Armeen vor den Landesgrenzen. Der Preis für den Export einer Revolution kann sehr hoch sein: möglicherweise wird es damit enden, dass die internen Reformen als Preis für eine solche Torheit aufgehoben werden.

Derzeit 12 befindet sich die interne Dynamik im Konflikt mit der regionalen Dynamik. Ugandas interne Öffnung ist noch begrenzt, vornehmlich auf lokaler und regionaler Ebene, aber noch schwach im Zentrum. Die Institutionen des Zentrums - in Uganda vornehmlich die Armee und die Kirche - wurden seit dem Inkrafttreten der neuen Verfassung gleichsam unter Quarantäne gestellt. Bei der NRM, der Partei des Präsidenten Museveni, handelt es sich nicht um eine getarnte Einheitspartei. Eine Einheitspartei würde sich darum bemühen, das Monopol zur Organisation zu nutzen, aber die NRM scheint derzeit entschlossen, das Monopol nur zur Verhinderung jeglicher Organisation von anderen, auch in ihrem Innern, zu verwenden. Daher ist es sinnvoll diesen Staat als Kein-Parteien-Staat und nicht als Ein-Parteien-Staat zu bezeichnen. In einer Situation, in der es keine funktionierenden politischen Organisationen im Zentrum gibt, stellt eine regionale militärische Involvierung ein hohes Risiko dar: Der expandierende Krieg kann die Rolle und den Einfluss des Militärs so weit aus den Proportionen zu allen anderen Institutionen herausheben, dass die Konsequenz eine Militarisierung des zivilen Lebens im eigenen Land sein wird, wodurch der politische Reformprozess wieder rückgängig gemacht werden könnte.

Hier müssen wir ebenfalls die Erfahrungen aus der Region im Gedächtnis behalten. Man sollte sich daran erinnern, dass der Zusammenbruch Somalias der Niederlage im OgadenKrieg folgte, als die besiegte Armee gegen die einheimische Opposition vorging, bevor sie zwischen konkurrierenden Warlords zersplitterte. Gleiches gilt für Ruanda, als durch die sich

12 Dieser Text wurde erstmals 2002 veröffentlicht, vgl. Anm. 14 (Anm. d. Übers.). 
abzeichnende Niederlage im Krieg Fraktionen in der Armee anfingen, nach Sündenböcken in der Heimat zu suchen und damit die Voraussetzungen sowohl für den Genozid an den Tutsi wie auch für das Massaker an der Hutu-Opposition schufen. Die derzeitigen Prioritäten Ugandas müssten die Folgenden sein: Erstens, Truppenabzug aus einem regionalen zerstörerischen Konflikt, um seine Energien zur Demilitarisierung der Region einzusetzen; zweitens, Beschleunigung der Öffnung im eigenen Land, indem die Quarantäne für die politischen Organisationen im Zentrum aufgehoben wird.

\section{Fazit}

Dieser Artikel stellte drei scheinbar selbstverständliche Aussagen in Frage. Die erste betrifft die Staatsbürgerschaftskrise in der Region. Diese Krise kreist nicht um knappe Ressourcen, obwohl sie damit verbunden ist. Es geht um die Definition des Zugangs zu Ressourcen. Die Staatsbürgerschaft bedeutet nicht automatisch die Verteilung von Ressourcen, aber sie gibt einem das Recht, in den Kampf um die Ressourcen einzutreten. Auf diese Art sollte generell die Debatte um die Ressourcen auf der Welt verstanden werden. In den USA mussten die Kinder der Sklaven darum kämpfen, als Amerikaner bzw. Afro-Amerikaner anerkannt zu werden. In Großbritannien forderten die Kinder der Immigranten aus den Kolonien ihre Anerkennung als schwarze Briten. Eine andere Dynamik ist in Südafrika unterwegs: Die Kinder privilegierter Immigranten, ehemalige Kolonialisten, realisieren derzeit, dass Afrikaner in den Kampf um Ressourcen eintreten werden und fordern nun, dass auch sie als Afrikaner anerkannt werden. In diesem Sinne bedeutet Demokratie die Ausweitung der Staatsbürgerschaft. Wenn wir Fragen der Staatsbürgerschaft in dieser Region behandeln, ist es wichtig, über das koloniale politische Erbe nachzudenken und uns $\mathrm{zu}$ fragen: Wer ist indigen? Wer ist ein Siedler? Wann werden Siedler Einheimische und wie? Was sollte die Rechtsgrundlage in einer politischen Gemeinschaft sein? Wie reformieren wir den Staat, von einem, der seine Bevölkerung in Siedler und Einheimische einteilt, zu einem, der als Grundlage für seine 
Rechte die Unterscheidungen zwischen Einwohnern und Besuchern trifft?

Zweitens war mein Vorschlag, politisch »heilige Kühe« wie Zivilgesellschaft und Demokratie, zu problematisieren, statt diese heilig zu sprechen. Anstatt Zivilgesellschaft und Demokratie zu idealisieren, müssen wir den undemokratischen Ausgang von mehrheitsgeführten Prozessen reflektieren, wie in der ruandischen Revolution von 1959, im ugandischen Parlament nach dem Guerilla-Sieg in Luwero, in der Nationalkonferenz in Kongo 1991 und insbesondere im ruandischen Genozid von 1994. Anfänglich könnte eine grundsätzliche Frage gestellt werden, bei der zunächst die vom Kolonialismus geerbte Staatsform als selbstverständlich hingenommen wird: Gibt es Grundrechte für Minderheiten - Grundrechte, ohne die wir aufhören würden, einer politischen Gemeinschaft anzugehören - die nicht mal die Mehrheit niederstimmen dürfte? Wir können dann eine tiefer gehende Frage stellen, eine, die institutionell den Kolonialstaat eher in Frage stellt, wie durch die damalige Einführung der Bürgerkomitees und -räte während des Luwero-Kampfes geschehen ist: Wenn wir politische Identitäten von Einheimischen und Siedlern zu Einwohnern und NichtEinwohnern umdefinieren, entfernen wir uns damit nicht von der Definition der Rechte für existierende Minderheiten hin zur Definition, wer überhaupt als Minderheit gelten kann?

Schließlich habe ich die Aufmerksamkeit auf den spezifischen Krieg im Kongo und auf regionale bewaffnete Konflikte im Allgemeinen gelenkt und damit eine Schlüsselerfahrung der Staatskrisen in der Region beleuchtet. Sowohl die positive Lektion aus Julius Nyereres Führung in Tansania als auch die negative Lektion aus Somalia und Ruanda zeigen, dass externe militärische Intervention interne Reformen untergraben und eine nationale Krise herbeiführen können.

\section{Literatur}

Bucyalimwe, Mararo (1990): Land conflicts in Masisi, eastern Zairre: the impact and aftermath of Belgian colonial policy (1920-1989), Dissertation Indiana University. 
Fortt, J.M. (1956): »The distribution of the immigrant and the Ganda population within Buganda«. In: Audrey Richards (Hg.), Economic development and the tribal change: a study of immigrant labor in Buganda, Cambridge: Cambridge University Press. S. 77-118.

Haguma, Captain Eugene M. (1993) »The Rwandese crisis: the political economy of genocide«. Symposiumsbeitrag zu »Interface, Dialogue and Cooperation between Government and NGO's for Popular Participation in National Reconstruction, Conflict and Psycho-Social Trauma Management«, Kigali, 28. Februar 1993.

Mamdani, Mahmood (1996): Citizen and Subject: contemporary Africa and the legacy of late colonialism, Princeton, NJ: Princeton University Press; London: Kames Currey; Kampala: Fountain: Cape Town: David Phillip.

Mamdani, Mahmood (1999): »Citizenship crisis in Kivu, Eastern Congo «. Bericht der CODESRIA Mission in Kivu, Dakar: CODESRIA.

Mamdani, Mahmood (2001): When victims become killers: colonialism, nativism and genocide in Rwanda, Princeton, NJ: Princeton University Press; London: James Currey; Kampala: Fountain: Cape Town: David Phillip.

Newbury, David (1995): »The invention of Rwanda: the alchemy of ethnicity «, mimeo, University of North Carolina, Chapel Hill) n.d., S. 14-17.

Onyango-Obbo, Charles (26 April 1993): »Inside rebelcontrolled Rwanda", Africa News Service.

Postan, Cynthia (1956): „Changes in the immigrant population in Buganda, 1948-59«. In: Audrey Richards (Hg.), Economic development and the tribal change: a study of immigrant labor in Buganda, Cambridge: Cambridge University Press, Appendix F, Tabelle 8.

Prunier, Gérard (1995): The Rwanda crisis: history of a struggle, 1959-1994, London: Hurst \& Co., n.33.

Watson, Catherine (1992): »Rwanda: war and waiting «, Africa Report, Nov./Dez. 
EXIL: ZWISCHENLEBEN 



\title{
Die Militarisierung liberianischer
}

\section{Flüchtlinge in Guinea}

\author{
FELIX GERDES
}

Am Heiligabend 1989 begann mit dem Einmarsch der Rebellenbewegung »National Patriotic Front of Liberia« (NPFL) aus der benachbarten Côte d'Ivoire einer der blutigsten Kriege Afrikas. Der liberianische Krieg hatte umfangreiche Fluchtbewegungen zur Folge, die wiederum auf die Dynamik des Krieges einwirken sollten. Bereits Charles Taylor, Anführer der NPFL, hatte stark unter Flüchtlingen rekrutiert, die vor der brutalen Repression des damaligen Militärdiktators Liberias in die Côte d'Ivoire geflohen waren. Auch eine später auftretende Rebellengruppe, die »United Liberation Movement for Democracy in Liberia« (ULIMO), stützte sich wesentlich auf liberianische Flüchtlinge in Sierra Leone und Guinea. Nachdem sich zwischen 1996 und 1999 ein glaubhaft erscheinender Friedensprozess entwickelt hatte, zeigte sich erneut die Virulenz des Flüchtlingsproblems. Ab 2000 griff die wesentlich aus Flüchtlingen bestehende Rebellengruppe »Liberians United for Reconciliation and Democracy « (LURD) von Sierra Leone und Guinea aus die Regierung Liberias an.

In diesem Beitrag soll den Ursachen der Militarisierung von Flüchtlingen im Rahmen des Fallbeispiels liberianischer Flüchtlinge in Guinea nachgegangen werden. Die Untersuchung ist auf Flüchtlinge der Ethnie der Mandingo fokussiert, und hebt 
die Lebensumstände dieser Gruppe zu unterschiedlichen Perioden der liberianischen Geschichte hervor. Liberianische Mandingo bildeten den Kern der sozialen Basis der LURD und einer Fraktion der ULIMO, der nach ihrem Anführer Alhadji Kromah benannten ULIMO-K. Auch wenn ULIMO-K und LURD keine ethnisch homogenen Verbände waren, so stellten Mandingo den bedeutendsten Teil der Mitglieder, und die Rebellengruppen wurden von einem Großteil ihrer Mitglieder ebenso wie von Gegnern als Mandingo-Kraft wahrgenommen.

Die Analyse wird zwei Dimensionen beleuchten. Im folgenden Kapitel wird zunächst jene der Akteursqualitäten der Flüchtlinge betrachtet. Die Untersuchung ist hier auf die ethnische Gruppe und ihre Position in der liberianischen Gesellschaft fokussiert. Der erste Abschnitt des Kapitels stellt die Rolle der Mandingo in der liberianischen Politik und die Hintergründe ihrer Verwicklung in den internen Krieg dar. Der zweite Abschnitt konzentriert sich auf die Situation liberianischer Mandingo in den Friedensprozessen von 1996-1999 und ab 2003.

Die zweite, im dritten Kapitel analysierte Dimension wird gebildet durch das politisch-gesellschaftliche Umfeld, in dem die ULIMO-K und LURD aktiv werden konnten. Der Staat des Gastlandes ist hier von besonderer Relevanz, da er in der Regel ein Gewaltmonopol beansprucht und Mittel zur Durchsetzung dieses Anspruchs kontrolliert. Flüchtlinge sind dabei tendenziell schwach, da sie fremd und kaum in nationale Machtzirkel eingebunden sind. Darüber hinaus sind bewaffnete Organisationen der Flüchtlinge der gezielten Schwächung durch Kriegsgegner ausgesetzt. Flüchtlingssiedlungen sind insbesondere für solche Rebellenorganisationen von großer strategischer Bedeutung, die zu schwach sind, um Basen im Heimatland aufrecht $\mathrm{zu}$ erhalten. Oftmals entscheidet die Haltung angrenzender Staaten gegenüber Rückzugsbasen auf ihrem Territorium über den Bestand von Rebellengruppen (Rufin 1999). Die Rolle des aufnehmenden Staates muss daher einer genauen Untersuchung unterzogen werden. Wie zu zeigen sein wird, konnten liberianische Rebellen in Guinea nur aktiv werden, solange die guineische Regierung hieran ein Interesse hatte. Es wird argumentiert, dass die Beziehungen zwischen guineischem Präsidenten und LURD als Patronagebeziehungen zu betrachten 
sind, in denen die guineische Regierung den Rebellen Schutz und materielle Unterstützung im Gegenzug für Sicherheitsleistungen und Unterstützung bei der Kontrolle der Flüchtlingsbevölkerung bot. Der erste Abschnitt des dritten Kapitels behandelt eingehend die Beziehungen zwischen guineischer Regierung und LURD, während der zweite Abschnitt sich den Beziehungen zwischen LURD und Zivilisten bzw. Flüchtlingen widmet. Abschließend werden im Schlussteil die herausgearbeiteten Strukturen zusammengefasst und die regionalen Beziehungen mit der Form westafrikanischer Staatlichkeit in $\mathrm{Zu}-$ sammenhang gebracht.

\section{Geschichte und politische Situation der Mandingo in Liberia}

\section{Mandingo und der Krieg in Liberia}

Die vermeintlich traditionellen ethnischen Gruppen Liberias sind in engem Zusammenhang mit der Bildung des modernen Staates entstanden (vgl. allgemein Elwert 1989; zu Liberia: Liebenow 1969). Die Mandingo hatten jedoch eine besondere Geschichte, in deren Folge sie von weiten Teilen der Bevölkerung nicht als Staatsbürger anerkannt werden - dies unabhängig davon, ob sie formell die liberianische Staatsangehörigkeit besitzen. Historisch gilt das Teile der heutigen Staaten Guinea und Mali umfassende obere Niger-Becken als Herkunftsregion der Ethnie. In Folge des kriegerischen Zerfalls des Reiches Mali im 15. Jahrhundert zogen Teile seiner muslimischen Bevölkerung südwärts, und siedelten sich sukzessive in der Waldregion Guineas ${ }^{1}$ und im südlich angrenzenden Liberia an.

1 »Waldregion Guineas« (»Guinée Forestière«) ist ein feststehender Ausdruck für den Südosten Guineas. Dieser konstituiert eine von vier Regionen, in die das Land unter landschaftlichen Gesichtspunkten aufgeteilt wird. Diese landschaftlichen Regionen entsprechen annähernd den Siedlungsgebieten der dominanten Ethnien und sind im Kontext politisierter Ethnizität auch politisch relevant, wenngleich sie nicht der administrativen Grenzziehung entsprechen. 
Liberia wurde in den 1820er Jahren durch die »American Colonization Society « (ACS) mit dem Ziel gegründet, eine Heimstätte für freigelassene Sklaven zu schaffen. Ab der Unabhängigkeit 1847 wurde der Staat von ehemaligen USamerikanischen Sklaven geführt. Die sogenannten AmerikoLiberianer stellten etwa zwei bis fünf Prozent der Bevölkerung Liberias. Diese verband ein äußerst zwiespältiges und wechselhaftes Verhältnis mit den Mandingo, welche zu dieser Zeit weite Teile des Handels zwischen dem afrikanischen Binnenland und der liberianischen Küste kontrollierten. Zum einen wurden sie als Träger des Islam von den christlich geprägten AmerikoLiberianern als religiöse Rivalen aufgefasst, deren Einfluss zu begrenzen war. Jedoch galten sie gegenüber den lokalen Religionen verhafteten Gruppen Liberias als kulturell höher entwickelt und somit als mögliche Bündnispartner. Zum anderen waren sie einerseits Konkurrenten im Kampf um die Kontrolle des liberianischen Handels und gleichzeitig aufgrund ihrer über Liberia hinausreichenden Verbindungen wichtige Geschäftspartner. In Folge dieser verworrenen Motivlage wurden Mandingo »alternately discriminated against and given a favored position relative to the other tribes « (Liebenow 1969: 22). Während die ameriko-liberianischen Siedler fünfzehn weitere, zum Teil willkürlich bestimmte Gruppen zu »tribes of Liberia « erklärten, galten ihnen Mandingo als Einwanderer aus Französisch-Westafrika. Ab den 1950er Jahren wanderten vermehrt Mandingo aus der Waldregion Guineas ein. Diese späte Steigerung des Anteils von Mandingo an der Bevölkerung Liberias wird dort vielfach genutzt, um Mandingo generell als erst kürzlich eingewanderte Ausländer zu qualifizieren.

Im Verlauf der Staatsbildung wurden Posten im Staatsapparat zur Grundlage von Reichtum in der ameriko-liberianischen Gesellschaft. Tätigkeiten in der Geschäftswelt genossen wenig Ansehen unter den Siedlern. Gleichzeitig wurde die Konzentration wirtschaftlicher Macht auf Seiten einheimischer Unternehmer verhindert. »[As] a >rule the government [did] not do business with Liberian businessmen « (»Official«, zitiert in Liebenow 1969: 92). Unter anderem als Folge dieser Politik erlang- 
ten Mandingo im innerafrikanischen Handel und im Zwischenhandel eine herausragende Stellung. ${ }^{2}$

Mandingo integrierten sich im Rahmen traditioneller Praktiken in ihre liberianische Umgebung und erhielten von den ansässigen Gemeinden Grundstücke zur Niederlassung (vgl. Conneh 1996). Im Laufe der Entwicklung des Handels wurden diese oftmals zu kommerziellen Zentren der betreffenden Ortschaften. Der wirtschaftliche Erfolg der Zuwanderer erzeugte Ressentiments, die aber so lange unter der Oberfläche blieben, wie »einheimische" lokale Autoritäten eine unangefochtene Machstellung behielten. Trotz der zum Teil lange zurückreichenden Siedlungsgeschichte der Mandingo in Liberia blieb die Differenz zu »Einheimischen" bestehen. Eine wichtige wirtschaftliche Funktion der Abgrenzung von Seiten der Mandingo war der Schutz von weitgehend auf Vertrauen basierenden, ethnischen Händlernetzwerken. In der Binnenperspektive war die Zugehörigkeit zur und Erhaltung der muslimischen Religion wesentlicher Grund für die Abgrenzung. Dies hatte zur Folge, dass das verbreitete Integrationsmittel der Einheirat nur in eine Richtung wirkte. »Einheimische« Frauen heirateten vielfach Mandingo und traten damit der patriarchalen Struktur folgend dem Islam und der ethnischen Gemeinschaft bei, während Mandingo-Frauen nur endogam verheiratet wurden. Trotz familiärer Beziehungen zu den aufnehmenden Gemeinschaften blieben damit Mandingo in der Selbst- wie der Fremdwahrnehmung eine klar abgegrenzte Gruppierung. Zudem wuchs die Ethnie zahlenmäßig überproportional an, womit auf Seiten der »Einheimischen« Perzeptionen einer drohenden Übermacht der Mandingo gefördert wurden.

Im April 1980 wurde die politische Hegemonie der Ameriko-Liberianer durch einen Militärputsch des »indigenen" Unteroffiziers Samuel K. Doe beendet. Doe entstammte der Minderheitsethnie der Krahn, die etwa fünf Prozent der Bevölkerung des Landes stellte. Im Zuge der Machtkonsolidierung stützte sich Does Patronagesystem zunehmend auf Krahn, die

2 Dieser exponierten Stellung der Mandingo im Binnenhandel entspricht im Bereich des internationalen Handels eine auch im regionalen Vergleich herausragende Position libanesischer Einwanderer. 
zur klar dominierenden Ethnie im Militär wurden. Darüber hinaus integrierte er vermehrt Mandingo, welche wirtschaftlich attraktive Partner waren, aufgrund ihrer Position als Außenseiter aber als politisch wenig bedrohlich erschienen. Die Integration kam symbolisch in der Ernennung der Mandingo zum sechzehnten »tribe of Liberia « zum Ausdruck. ${ }^{3}$ Politisch äußerte sie sich vor allem im Aufstieg des Mandingo Alhadji Kromah, welcher in Does Amtszeit unter anderem den Posten des Informationsminister innehatte. Die Posten gaben Kromah Gelegenheit, Verbindungen zu hohen Stellen guineischer Politik zu knüpfen. Auf lokaler Ebene bedeutete die verbesserte Anbindung an das politische Zentrum eine gestärkte Stellung der Mandingo gegenüber lokalen Autoritäten.

Does Herrschaft war gekennzeichnet durch harte Repression und den Ausschluss breiter Bevölkerungsteile von der Teilhabe an Staatsressourcen. In Folge verlor das Regime drastisch an Legitimität, und gegen die politisch dominanten Ethnien der Krahn und Mandingo entwickelten sich unter anderen Gruppen massive Ressentiments. Am Heiligabend 1989 begann die »National Patriotic Front of Liberia (NPFL) unter Führung des ehemaligen Kabinettsmitglieds Charles Taylor den Krieg gegen die Regierung. Die NPFL erhielt starken Zulauf von der Bevölkerung des nördlichen Nimba County, welche aufgrund der ethnischen Verbundenheit mit zwei wichtigen politischen Rivalen Does besonders unter der Repression zu leiden gehabt hatte. Nimba liegt an der Grenze zu Guinea und hatte einen relativ hohen Anteil an Mandingo unter der Bevölkerung. Taylor beabsichtigte zum einen, von den Ressentiments gegen Mandingo politisch $\mathrm{zu}$ profitieren, indem Spannungen angeheizt wurden, und zum anderen, ihre Geschäfte zu übernehmen. Mandingo, meist Kleinhändler des Hinterlands aber auch Bauern, wurden gezielt zu Opfern der Gewalt durch die Rebellen. Vor der Flucht vor der anrückenden NPFL verkauften viele ihre Geschäfte zu äußerst vorteilhaften Preisen an »Einheimische«. Andere wurden überrascht und flohen unvorbereitet, woraufhin ihre Hinterlassenschaften von Kriegsgewinnlern angeeignet wurden (vgl. Ellis 1999: 89).

3 Diese Entscheidung trifft bis heute in Liberia vielfach auf offene Ablehnung. 
Der größte Teil der liberianischen Mandingo verließ wegen der massiven Gefährdung durch die NPFL das Land. Aufgrund ihrer historischen Verbindungen war Guinea das bei weitem bedeutendste Ziel der Flucht. Die Fluchtumstände schufen ein Bewusstsein, wonach die ethnische Gruppenidentität wesentlicher Grund der Flucht war, und Mandingo selbst unter den zahlreichen Opfern des Krieges eine Sonderstellung einnahmen. Ein Blick in Internetforen der liberianischen Mandingo wie limany.org zeigt deutlich, wie die Selbstwahrnehmung als Opfer die ethnische Identität festigte: »It is a reality that it was only the >Mandingoes <illed unjustifiably with no tangible reason. As they escaped, their properties were confiscated, while some were arrested trying to seek safety. It was the >Mandingoes`slaughtered like cow, sheep and chicken...«(Dolley 2007).

Im Zuge des Krieges wurde also die vorher bereits präsente Abgrenzung zwischen Mandingo und anderen liberianischen Gruppierungen auf den Ebenen der Politik, der Wirtschaft und der kollektiven Identität verstärkt. Auf politischer Ebene, verstanden als Kontrolle der Ausübung von Gewalt, wurde dieser Prozess durch den Entzug physischer Sicherheit repräsentiert. Auf wirtschaftlicher Ebene stellte sich diese Differenz zwischen den Gruppen dar als Abgrenzung zwischen jenen, die ihren Besitz verloren, und jenen, die ihn sich aneigneten. Die kollektive Identität schließlich wurde gestärkt, da Gewalt- und Fluchterfahrung als Gruppenschicksal wahrgenommen und zum Symbol der ethnischen Gemeinschaft wurden. Diese Entwicklungen stellten den Hintergrund für die Herausbildung bewaffneter Organisationen der Mandingo dar. Allerdings änderte sich die Lebenssituation mit Überschreitung der Grenze nach Guinea. Diese veränderten Lebensumstände wiederum waren nicht ohne Auswirkungen auf die Bildung der Rebellengruppe.

Die Lebensumstände unterschiedlicher Gruppen der liberianischen Mandingo in Guinea differierten stark. Diese Lebensumstände lassen sich grob gemäß dem Siedlungsmuster im Aufnahmeland unterscheiden. Ein verhältnismäßig großer Teil der Mandingo war urbanen Hintergrunds. Diese ließen sich auch nach ihrer Flucht überwiegend in Städten der Waldregion, insbesondere im stark von Mandingo besiedelten Macenta und in N'zérékoré, nieder (Damme 1999: 39). Sie fanden meist bei entfernten Verwandten Unterschlupf. Selbst wenn sie mit deren 
Unterstützung wieder im Handel tätig werden konnten, hatten sie in der Regel deutliche Einkommens- und Statusverluste hinzunehmen. Humanitäre Hilfe war eine wichtige Quelle zur Sicherung des Grundbedarfs. ${ }^{4}$

Des Weiteren fanden Mandingo auch in der Waldregion Guineas ein tendenziell feindliches Umfeld vor. Die ethnische Zusammensetzung der Region ähnelt der auf der liberianischen Seite der Grenze, und auch hier gelten Mandingo als eingewanderte Fremde mit ungebührlichem wirtschaftlichen Erfolg (Richards 1995: 154f). Im Kontext lokaler Wahlen fanden in N'zérékore und Umgebung Mitte 1991 Pogrome statt, bei denen etwa 200 Mandingo getötet wurden. ${ }^{5}$ Materielle und teilweise physische Unsicherheit trafen Mandingo also ebenso im Exil.

Für junge Mandingo war in dieser Situation die Teilnahme an bewaffneten Kämpfen sowohl eine Möglichkeit, wirtschaftlicher Not zu entfliehen als auch das Gefühl der Wehrlosigkeit $\mathrm{zu}$ überkommen. Insbesondere unter urbanen Mandingo in N'zérékoré rekrutierte Alhadji Kromah unter Rückgriff auf sein Beziehungsgeflecht Kombattanten für die von ihm gegründete "Movement for the Redemption of Liberian Muslims « (MRLM) (Milner/Christoffersen-Deb 2006: 81). Diese vereinigte sich 1991 mit in Sierra Leone stationierten Soldaten des Regimes Samuel Doe zur Rebellenorganisation »United Liberation Movement for Democracy in Liberia (ULIMO). Die Militärs des alten Regimes verfügten über wertvolle militärische Expertise, die Kromah für seine Rebellenorganisation benötigte. Die ULIMO zerfiel 1994 offiziell in eine Krahn-dominierte und Sierra Leonebasierte ULIMO-J (nach dem Anführer Roosevelt Johnson) und

4 Der UNHCR beabsichtigte Anfang der 1990er Jahre, Mandingo nicht als Flüchtlinge, sondern als Rückkehrer guineischer Nationalität zu klassifizieren, und vom Zugang zu Hilfsgütern auszuschließen. Aufgrund von Protesten der guineischen Regierung wurden diese Pläne jedoch nicht weiter verfolgt. Der Zugang zu Hilfsgütern war für die Flüchtlinge der ersten Kriegsjahre nicht an den Aufenthalt in regulären Flüchtlingssiedlungen gebunden.

5 Interviews in Conakry 17.04.2002 und N'zérékoré 08.06.2002. Vergleiche auch Hemstedt (1992) und Damme (1999). Die Zahl von 200 getöteten Mandingo mag zu hoch gegriffen sein, spiegelt aber die Wahrnehmung der lokalen Mandingo-Gemeinschaft wieder. 
eine Mandingo-dominierte und Guinea-basierte ULIMO-K (nach Kromah). Ethnische Krahn nahmen allerdings weiterhin wichtige militärische Funktionen in der ULIMO-K war.

Eine substanzielle Anzahl ländlicher liberianischer Mandingo siedelte sich in oder nahe guineischen Dörfern an, zu deren Bewohnern verwandtschaftliche oder ethnische Bindungen bestanden. In den ersten Monaten waren sie meist vollständig auf Unterstützung durch die ebenfalls in materiell schwierigen Verhältnissen lebenden Gastgeber angewiesen. Die Waldregion war Anfang der 1990er Jahre kaum erschlossen und schwer zugänglich, weshalb nur mit größerer Zeitverzögerung ein System der humanitären Versorgung etabliert werden konnte. Der UNHCR richtete dann im ländlichen Raum Verteilungszentren ein, in denen bedürftige Flüchtlinge Unterstützung erhalten konnten. Die überwiegende Zahl der ländlichen Flüchtlinge erhielt auf Grundlage traditioneller Regelungen Nutzungsrechte für Land, und wurde innerhalb relativ kurzer Zeit selbstversorgend (Damme 1999). Auch nahmen ländliche Lohnarbeitsverhältnisse mit Flüchtlingen als Feldarbeitern stark zu. Reisfelder und meist durch Kleinbauern betriebene Kaffeeplantagen expandierten stark (Black/Sessay 1997; Grovogui 1996). Die wirtschaftliche Entwicklung der Region wurde durch die Flüchtlinge stimuliert, wovon Guineer jedoch deutlich stärker profitierten als Flüchtlinge (Gerdes 2006: 100-106). Konfliktrelevant waren die Veränderungen vor allem, weil guineische Mandingo von weiten Teilen der Einwohner der Waldregion Guineas als Fremde betrachtet wurden. Mit der Wertsteigerung der Böden wurde der Anspruch seit Generationen ansässiger guineischer Mandingo auf ihre Grundstücke von anderen Gruppen vermehrt in Frage gestellt. Aufgrund ethnischer bzw. verwandtschaftlicher Beziehungen und von liberianischen wie guineischen Mandingo geteilten Wahrnehmungen einer Bedrohung wurde eine Reihe dieser Dörfer zu Basen der ULIMO-K und später der LURD (vgl. Lynx 17.01.2000 u. 17.01.2000a; vgl. Républicain 18.01.2000).

Insgesamt lebte lediglich ein Viertel der liberianischen Flüchtlinge in Guinea in regulären Flüchtlingssiedlungen. Vielfach war dies der verwundbarste Teil der Flüchtlingspopulation; Menschen ohne Verbindungen zu Einheimischen, die sie hätten unterstützen können und geringen Kapazitäten, selb- 
ständig die Krise zu meistern. Für Flüchtlinge, die ab 1994 in Guinea ankamen, waren Registrierung und Erhalt humanitärer Unterstützung auf die offiziellen Flüchtlingssiedlungen beschränkt, so dass Anreize bestanden, zumindest einen Teil der Familie dort leben zu lassen. Flüchtlingssiedlungen waren vergleichsweise unbeliebte Unterkünfte, da geringe Möglichkeiten zur Verbesserung der eigenen Situation vorlagen und humanitäre Unterstützung oft nur unregelmäßig eintraf (Damme 1999). Insbesondere Daro in der Nähe Macentas, mit etwa 12.000 Bewohnern eine der größeren Flüchtlingssiedlungen, wies einen hohen Anteil an Mandingo auf. Daro galt als einziges militarisiertes Flüchtlingslager in Guinea während des ersten liberianischen Krieges. Die hinsichtlich der Militarisierung besondere Rolle der Flüchtlingssiedlung Daro erklärt sich primär aus dessen Nähe zu Macenta. Viele der Kombattanten in Macenta hatten Verwandte in Daro und hielten sich dort zeitweilig auf. In Folge entwickelten sich enge Beziehungen zwischen der vermeintlich zivilen und den militärischen Anlagen der Flüchtlinge.

\section{Mandingo in den Friedensprozessen}

Der erste liberianische Krieg galt mit den Wahlen 1997, die Charles Taylor mit 75 Prozent der Stimmen gewann, als beendet. Für die Flüchtlinge bedeutete dies - zeitlich verzögert eine Beendigung der humanitären Unterstützung und die Schließung der regulären Flüchtlingssiedlungen. Ein Teil der Mandingo kehrte zurück, um ihre Felder zu bestellen oder ihre Geschäftshäuser zurückzufordern. Ländereien hatten im Krieg lange brachgelegen und Boden war gut verfügbar. Da die Konkurrenz in diesem Bereich wenig ausgeprägt war, konnten Mandingo-Bauern sich im Vergleich zu den Händlern relativ gut wirtschaftlich reintegrieren.

Forderungen nach Kompensationszahlungen oder Rückgabe für den Handel genutzter Besitztümer waren jedoch generell erfolglos. Vor allem in Nimba waren die neuen lokalen Autoritäten eng mit Taylors NPFL verbunden gewesen, profitierten zum Teil persönlich von angeeigneten Besitztümern, und machten häufig keinen Hehl aus ihrer Abneigung gegen Mandingo. Mandingo waren darüber hinaus ein bevorzugtes Ziel der ins- 
besondere im ländlichen Raum ohnehin willkürlich die Zivilbevölkerung drangsalierenden Paramilitärs Taylors. Auch auf zentralstaatlicher Ebene hatten Mandingo keine Unterstützung. Zwar hatte Alhadji Kromah von Charles Taylor den Posten des Vorsitzenden der Nationalen Versöhnungskommission angeboten bekommen, diesen aber aufgrund nicht unberechtigter Befürchtungen, hintergangen und umgebracht $\mathrm{zu}$ werden, nicht angenommen. "[Additionally,] ULIMO's fighters and political cadres claimed harassment, betrayal and assassination at the hands of Charles Taylor's [...] forces" (Brabazon 2003: 2). Auch während Taylors Amtszeit verblieb eine substanzielle Anzahl an Mandingo-Flüchtlingen in Guinea, weitere kehrten nach einem kurzen Zwischenaufenthalt in Liberia dorthin zurück. Unter den in Guinea verbliebenen Flüchtlingen befanden sich geschätzte 2.800 ehemalige ULIMO-Kombattanten (Brabazon 2003: 7).

Ehemalige ULIMO-Kommandanten reorganisierten die militärischen Strukturen in Guinea und gründeten die Rebellenorganisation "Liberians United for Reconciliation and Democracy« (LURD). Die LURD führten ab 2000 wieder regelmäßige Angriffe auf Ziele in Liberia durch. Im August 2003 schließlich zwangen sie Charles Taylor ins Exil. An einer nachfolgend für zwei Jahre eingesetzten Übergangsregierung waren die Regierung Charles Taylors, zwei Rebellenorganisationen ${ }^{6}$ und ein ziviler Block beteiligt. Während die LURD-Eliten damit an der Macht und ihren finanziellen Privilegien beteiligt wurden, wurden viele Kombattanten über die klientelistische Vergabe von Anstellungen für die Zeit der Übergangsregierung in den Staatsapparat eingebunden. ${ }^{7}$ Der größte Teil der Rebellen wurde jedoch nur für acht Monate im Rahmen international finanzierter Demobilisierungsprogramme materiell abgesichert.

Nach Ende der Übergangsperiode entschieden 2005 Wahlen über die neue Regierung. Ein gewichtiger Teil der LURD und

6 Anfang 2003, etwa ein halbes Jahr vor Ende des Krieges, tauchte eine weitere Rebellenbewegung auf, die »Movement for Democracy in Liberia« (MODEL). Die MODEL stützte sich auf ethnische Krahn und kooperierte mit den LURD.

7 So stieg bspw. in der von den LURD kontrollierten Hafenbehörde die Zahl der Angestellten um mehr als das dreifache (Ernst \& Young 2005). 
die größte zivilgesellschaftliche Organisation der Mandingo, der »National Mandingo Caucus « (NMC), unterstützten im Wahlkampf die spätere Präsidentin, Ellen Johnson Sirleaf. Mandingo, zum Teil mit Hintergrund in LURD oder ULIMO, wurden anschließend in hohe Staatsämter der neuen Regierung berufen. Der "Minister of National Security « und der »Minister of Public Works«, ein Richter des »Supreme Court« sowie mehrere »Deputy« und »Assistant Minister« gehörten der Ethnie an. Auch im Parlament waren Mandingo vertreten, und der Vorsitzende des NMC machte einen eindrucksvollen, offensichtlich politisch geförderten Aufstieg in der Planwirtschaft (vgl. Panel of Experts 2006: 29). Unter Mandingo war dennoch die Ansicht weit verbreitet, nicht angemessen für die Wahlkampfunterstützung entlohnt worden zu sein (vgl. Dolley 2007). ${ }^{8}$ Auch die unter dem Gesichtspunkt der Etablierung einer ansatzweise professionellen, finanzierbaren staatlichen Verwaltung notwendige Verschlankung des unter der Übergangsregierung massiv angewachsenen öffentlichen Sektors wurde vielfach als Bruch impliziter Übereinkünfte wahrgenommen. Dennoch hatte sich die politische Situation für Mandingo deutlich verbessert.

Bis Mitte 2007 hatte es jedoch in Nimba weder Fortschritte im Konflikt um Besitztümer geflüchteter Mandingo gegeben noch zeichneten sich solche ab. ${ }^{9}$ Mandingo in Nimba schliefen zum Teil auf den Terrassen ihrer von »Einheimischen « bewohnten Häuser. ${ }^{10}$ Neben den LURD hatten auch signifikante Teile des Netzwerkes Charles Taylors den Wahlkampf Johnson Sirleafs unterstützt, darunter "General Peanut Butter « Adolphus Dolo. Dolo gewann einen der zwei Senatorensitze für Nimba County. Im Wahlkampf warb er unter anderem mit dem Argument für Johnson Sirleaf, dass diese den aktuellen Besitzstatus von Geschäftshäusern garantieren würde. Viele amtierende,

8 Interviews in Monrovia, Januar 2006.

9 Auch in Lofa County war die Konfliktlösung von Rückschlägen begleitet, unter anderem aufgrund geringer Vermittlungskapazitäten der häufig nicht unparteiischen lokalen staatlichen Autoritäten. Der Konflikt war dort jedoch weniger zugespitzt, und Lösungsansätze schienen Erfolg versprechender (vgl. Resolution 2005).

10 Eigene Beobachtungen in Saclepea, Nimba County, März 2007. 
zum Teil aus der Regierungszeit Taylors übernommene lokale Autoritäten Nimbas profitierten darüber hinaus persönlich von den vorhergegangenen Besitztransfers. Eine eingesetzte Untersuchungskommission hat zwar umstrittene Besitztümer erstmals umfassend registriert, ansonsten aber keine nennenswerten Ergebnisse erbracht (vgl. Ad Hoc Presidential Commission 2006). .11 $^{1}$

Während einfache Mandingo oft weiterhin marginalisiert wurden, hat die Regierung Johnson Sirleaf ihre Bereitschaft zur Integration von Mandingo-Eliten demonstriert. ${ }^{12}$ Hierdurch unterschied sich ihre Haltung klar von jener der Regierung Taylor (1997-2003). Hiermit wurde zunächst die Beschränkung des Konfliktes zwischen Mandingo und »Einheimischen« auf die lokale Ebene wahrscheinlich. Im Zuge der Konsolidierung von Patronagebeziehungen zwischen neuen politischen MandingoEliten und ihrer ethnischen Basis bestanden mittelfristig Chancen auf eine verbesserte politische und wirtschaftliche Integration der einfachen Mandingo.

\section{Die LURD als patrimonialer Intermediär}

\section{Der guineische Staat, ULIMO und LURD}

Für in den 1990er Jahren geflüchtete Mandingo bestanden damals klare Anreize für den Eintritt in eine Rebellenarmee. Nachdem sie Status und Besitz verloren hatten, offerierte die Existenz als Kombattant Macht sowie Chancen zum sozialen

11 Interviews in Nimba County, Februar/März 2007.

12 Dennoch könnten Entwicklungen während der Amtszeit Johnson Sirleafs auf eine zukünftig weniger prominente Rolle von Mandingo hinweisen. So wurden der »Minister of National Security« und der »Minister of Public Works « ihrer Posten enthoben. Ersterer wurde ausgerechnet durch einen ehemaligen Kommandanten der NPFL und Justizminister Taylors ersetzt. Den zwei Entlassungen stand lediglich eine Neubesetzung eines hochrangigen Postens mit einem Mandingo gegenüber. Der neue "Minister of Planning and Economic Affairs « begann seine Karriere interessanter Weise als »Refugee Education Coordinator « des »International Rescue Committee« in Guinea. 
Aufstieg und zu Reichtum durch Plünderungen. Dies reicht jedoch nicht aus, um das Agieren von ULIMO bzw. LURD auf guineischem Territorium zu erklären. Zu keiner Zeit ist der guineische Staat ernsthaft gegen die Präsenz der ausländischen Rebellen vorgegangen. Trotz regelmäßiger Dementis der guineischen Behörden war die Unterstützung der ULIMO-K bzw. LURD offensichtlich. ${ }^{13}$ Die Hintergründe dieser Haltung sollen in diesem Abschnitt beleuchtet werden.

Charles Taylors NPFL war 1990 durch eine militärische Intervention der Regionalorganisation Economic Community of West African States" (ECOWAS) an der Eroberung der Hauptstadt Liberias gehindert worden. Guinea war das einzige durchgehend an der Intervention beteiligte frankophone Land, und seine Haltung gegenüber den Rebellen kann nicht unabhängig von seiner eigenen Rolle im liberianischen Krieg betrachtet werden.

Die Intervention war direkt gegen eine Machtübernahme Charles Taylors gerichtet gewesen. Guineas Interessenlage war dabei eine besondere, und ging auf die Beziehungen Frankreichs zu Taylor einerseits und Guinea andererseits zurück. Guinea hatte sich als einzige Kolonie 1958 der Eingliederung in die Communauté Française widersetzt und die sofortige Unabhängigkeit gefordert. Die abziehenden Franzosen zerstörten daraufhin weite Teile der administrativen Infrastruktur. Seit Machtübernahme des ersten Präsidenten Sékou Touré galt eine neokoloniale Intervention Frankreichs als primäre Sicherheitsbedrohung, womit Antikolonialismus eine wesentliche ideologische Grundlage des Regimes blieb. Taylor verfügte mittelbar über die Frankreich-freundlichen Regierungen der Côte d'Ivoire und Burkina Fasos über Verbindungen nach Frankreich. Die Rebellion der NPFL wurde in Guinea als Versuch wahrgenommen, gewaltsam in Liberia ein pro-französisches Regime $\mathrm{zu}$ installieren. Die guineische Regierung wiederum definierte

13 Die Anwesenheit der Rebellen wurde regelmäßig geleugnet (siehe z.B. die Regierungszeitung Horoya 24.-26.04.1999). Gelegentlich, insbesondere nach Plünderungen in Guinea, wurden ULIMO- und LURD-Rebellen festgenommen bzw. kam es zu Auseinandersetzungen mit Sicherheitskräften, wodurch die Allianz von guineischer Regierung und liberianischen Rebellen jedoch nicht in Frage gestellt wird (vgl. Gerdes 2006: 83). 
es als zentrales Sicherheitsinteresse, solche Versuche scheitern zu lassen (Inegbedion 1994: 222-225/ Körner 1996: 100104+112f/ International Crisis Group 2002: 2). In diesem Zusammenhang galt Taylor auch als direkte Sicherheitsbedrohung Guineas. Seit Beginn des Krieges kursierten Gerüchte, Taylor plane einen Angriff auf das Land. ${ }^{14}$ Zum anderen bedrohten Taylors regionale Verbindungen wirtschaftliche Interessen Guineas. Guinea war ein wichtiges Transitland für geschmuggelte Güter aus Sierra Leone und Liberia, insbesondere Diamanten (Davies 2000: 360f). Taylors Kontrolle über das ländliche Liberia bedeutete eine Neuausrichtung der Wirtschaftsbeziehungen auf die Côte d'Ivoire und Frankreich. »French and Ivoirian-based Lebanese commercial interests have been important in supplying the NPFL [...] with credit and access to equipment, in return for business concessions in minerals and tropical forest products « (Richards 1995: 143).

Guinea verfolgte mit seinem Engagement in Liberia sicherheitspolitische und wirtschaftliche Interessen, stützte sich hierbei aber nicht nur auf das eigene, staatliche Militär. Zunächst übernahm die ULIMO im Kern eine Entlastungsfunktion, indem sie das guineische Kontingent in Liberia unterstützte. Sie stärkte das guineische Militär aber auch in Fragen der Grenzsicherung. Die Regierung Guineas hatte sowohl einen direkten Einmarsch der NPFL als auch eine vorbereitende Infiltration unter dem Deckmantel des Flüchtlingszustroms befürchtet. ${ }^{15}$ »ULIMO-fighters $[\ldots]$ assisted the Guinean military to patrol its

14 Derartige Bedrohungsszenarien wurden u.a. in der Regierungszeitung Horoya (z.B. 16.-21.09.1991) geäußert, und es ist nicht unwahrscheinlich, dass die Gerüchte auf eine entsprechende Einschätzung von Regierungskreisen zurückgingen. Am Falle Sierra Leones zeigte sich, dass Taylor durchaus bereit war, andere Länder der Region zu destabilisieren. Dort unterstützte Taylor 1991 den Einmarsch der Rebellen der »Revolutionary United Front« (RUF) mit Waffen und Kombattanten.

15 Als Militär kann dem guineischen Präsidenten Conté die strategische Bedeutung von Flüchtlingen in den Kriegen der Region nicht entgangen sein. So hatte die NPFL vor einem 1992 begonnenen Großangriff auf die Hauptstadt als Flüchtlinge getarnte Rebellen in Regierungsterritorium eingeschleust. Auch die sierraleonische RUF eröffnete bei einem Angriff auf Freetown 1998 in der Stadt eine ebenso vorbereitete zweite Frontlinie. 
borders and screen those seeking asylum in Guinea and assistance for refugees « (Milner/Christoffersen-Deb 2006: 59). Im Gegenzug für ihre Sicherheitsleistungen wurde die ULIMO von der guineischen Regierung materiell und logistisch unterstützt. Die enge Verbindung der Rebellen mit dem guineischen Militär bedeutete, dass Flüchtlingssiedlungen nur vergleichsweise wenig militarisiert waren. Die meisten ULIMO-Kombattanten waren im regionalen Militärhauptquartier in Macenta untergebracht, weitere vor allem zu Trainingszwecken in einer Basis in Kankan etwa 200 Kilometer nördlich der Grenze.

Mit Übernahme der Präsidentschaft Taylors 1997 endete die direkte Unterstützung der ULIMO durch Guinea. Allerdings wurde die Präsenz der LURD weiterhin geduldet. Hierfür spielten sicherlich etablierte Beziehungen zwischen den liberianischen Rebellen und dem guineischen Militär eine Rolle. Wichtiger aber waren die weiterhin kaum verhüllt feindlichen Beziehungen zwischen dem guineischen und dem liberianischen Präsidenten sowie die regional destabilisierende Rolle des letzteren. Charles Taylor unterhielt weiterhin enge Beziehungen zur RUF (Panel of Experts 2000). Nicht zuletzt aufgrund dieser Kontinuität betrachtete Guinea Taylor weiterhin als unzuverlässigen Nachbarn mit Bereitschaft zur Ausweitung seines regionalen Einflusses mit militärischen Mitteln. In diesem Kontext bildeten die LURD eine Reservetruppe, die im Falle eines Angriffs eingesetzt werden konnte.

Ab September 2000 kam es zu einer Reihe koordinierter Attacken auf Guinea entlang der sierra-leonischen und liberianischen Grenze, die von Taylor loyalen RUF-Einheiten, von ihm kontrollierten Paramilitärs und verbündeten guineischen Dissidenten durchgeführt wurden. Der Angriff hatte nicht nur die Rückzugsbasen der LURD zum Ziel, sondern zielte auf den Sturz der Regierung, die Einsetzung eines Marionettenregimes und Erhalt des Zugriffs auf natürliche Ressourcen ab (International Crisis Group 2002: 4; Reno 2007: 75-78).16 Die LURD

16 In Folge der Kämpfe kam es zu massiven, von der Regierung unterstützten Übergriffen von Zivilisten, Soldaten und Milizen auf Flüchtlinge in der Waldregion und der Hauptstadt. Der Interpretation des Autors nach handelte es sich insbesondere bei den Vorfällen in der Hauptstadt im Kern um vorbeugende Ge- 
wurden den an sie gestellten Erwartungen voll gerecht. »The over 500 LURD fighters in Guinea played a key role in repulsing the Taylor-backed forces « (International Crisis Group 2002: 5). Zusammen mit frisch rekrutierten guineischen Jugendmilizen kämpften sie an der Frontlinie, während die Armee hauptsächlich Artillerieunterstützung gab.

In der Folgezeit wurde aus der Duldung der LURD eine aktive Unterstützung durch Guinea in Form von Waffen, Ausbildung, logistischer Unterstützung etc. Die LURD gewannen dadurch massiv an Stärke. Ein bedeutender Teil der LURD war fortan wieder in der Militärbasis in Macenta untergebracht, wo sie ihr Hauptquartier einrichteten. Darüber hinaus galten zwei Viertel Macentas, Patrice Lumumba und Mohamed V, als LURD-Territorium. Bei den Angriffen der zu Taylor loyalen Einheiten waren die meisten Flüchtlingssiedlungen zerstört worden, die übrigen wurden mit einer Ausnahme von der guineischen Regierung aufgelöst. Diese war Kouankan, dessen Bevölkerung in Folge zunehmender Kämpfe rapide anschwoll. Kouankan war, offenbar aufgrund einer Entscheidung des UNHCR, die ethnischen Gruppen zu trennen, klar von Mandingo dominiert. Es wurde zum einzigen militarisierten Flüchtlingslager, LURD-Kombattanten waren dort uniformiert und bewaffnet zu sehen. Einige Kilometer südlich der Siedlung war angeblich ein Trainingsgelände eingerichtet. Kouankan war etwa 50 Kilometer von der liberianischen Grenze entfernt, die jedoch von LURD-Kombattanten unbehelligt in Autos zurückgelegt werden konnten. ${ }^{17}$

Die engere Anbindung an den Präsidenten hatte auch Veränderungen in der Führungsspitze der LURD zur Folge. Im Dezember 2001 wurde Sekou Danmate Conneh zum Vorsitzen-

walt gegenüber potenziellen Infiltratoren. Siehe hierzu Gerdes (2006).

17 Laut Flüchtlingskonvention der Organisation für Afrikanische Einheit (OAU) sollten Flüchtlingssiedlungen »a reasonable distance« von der Grenze entfernt sein, um grenzüberschreitende Angriffe aus den Siedlungen heraus zu verhindern. Die »reasonable distance entspricht gängigen Interpretationen zufolge mindestens 50 Kilometern. Unter den gegebenen Umständen waren jedoch auch wesentlich längere Wegstrecken kein relevantes Hindernis für die irregulären Kombattanten. 
den der LURD gewählt,18 seine zweite Frau Aicha Conneh wurde Vizevorsitzende. Aicha Conneh war eine einfache Marktfrau gewesen, bis sie angeblich den guineischen Präsidenten Lansana Conté vor einem (gescheiterten) Militärputsch 1996 gewarnt hatte. Anschließend wurde sie zur bedeutendsten spirituellen Beraterin des Präsidenten. ${ }^{19}$ Ihre Verbindung zum guineischen Präsidenten galt als Grund für die Wahl ihres Mannes zum Vorsitzenden (Brabazon 2003: 3).

Die Integration der LURD in den Militärapparat wurde durch eine komplementäre politische Integration einer wichtigen Untergruppe der Mandingo Guineas gestärkt. Die so genannten Konia-Mandingo sind die bedeutendste MandingoGruppierung der Waldregion Guineas und haben als solche starke ethnische Bindungen an liberianische Mandingo. KoniaMandingo wurden über die Partei »Alliance Nationale de Progrès« (ANP) integriert, deren Funktionäre nahezu ausschließlich der ethnischen Untergruppe zuzurechnen waren. ${ }^{20}$ Die Partei wurde in das Patronagesystem des autoritär herrschenden Präsidenten eingebunden und unterstützte diesen. In den massiv gefälschten Wahlen 2002 erhielt die ANP 2 von 114 Sitzen - ein respektables Ergebnis für eine Minorität, die nur in zwei Städten (Macenta und Beyla) signifikant vertreten ist. ${ }^{21}$

Der Krieg in Liberia endete mit der faktischen Niederlage Charles Taylors im August 2003. Die LURD wurden an der an-

18 Der Vorsitzende wurde vom »National Executive Council« gewählt, der (angeblich) allgemein von den Mitgliedern der LURD gewählt wurde (Brabazon 2003: 11).

19 Jüngeren Meldungen zufolge hatte dagegen ihr Vater diesen Status inne. Sind diese Informationen richtig, so handelt es sich bei der offenbar gezielten Desinformation um den Versuch der Inszenierung von Charisma auf Seiten des LURD-Führungspersonals.

20 Die Mandingo Nordost-Guineas dagegen galten vielfach als Anhänger der Oppositionspartei »Rassemblement du Peuple Guinéen« (RPG). Es lag evidenter Weise im Interesse des guineischen Regimes, einer Allianzbildung zwischen den liberianischen Rebellen und der RPG vorzubeugen.

21 Dies bedeutet nicht unbedingt, dass das Ergebnis für die ANP gefälscht war. Patronage der Regierung kann auch für einen starken Rückhalt der Partei in ihren zwei Wahlkreisen verantwortlich gewesen sein. 
schließend eingesetzten Übergangsregierung beteiligt und ihr militärischer Verband aufgelöst. Nichtsdestoweniger blieben informelle Beziehungen zwischen LURD-Kommandanten und guineischer Regierung bestehen. Diese Beziehungen scheinen im Kontext einer innenpolitischen Krise Guineas Anfang 2007 reaktiviert worden zu sein. Präsident Conté war durch einen von Demonstrationen begleiteten Generalstreik unter Druck geraten. Die Demonstrationen wurden blutig niedergeschlagen, woran auch von Aicha Conneh vermittelte LURD-Kombattanten mitgewirkt haben sollen (Analyst 19.02.2007, ICG 2007:14). ${ }^{22}$ Auch nach Ende des liberianischen Krieges blieben LURDKräfte vorerst in den Sicherheitsapparat des guineischen Regimes integriert. ${ }^{23}$

\section{Beziehungen zwischen LURD und Flüchtlingen}

Die oben geschilderten Beziehungen zwischen dem guineischen Präsidenten und den LURD hatten die Form von Patronagebeziehungen, in denen politische Loyalität und Sicherheitsdienstleistungen der LURD mit Schutz und materieller Unterstützung der Regierung vergolten wurden. Diese Patronagekette wurde dergestalt in Teile der liberianischen Zivilbevölkerung verlängert, dass die LURD für diese die Rolle eines Patrons übernahm. Diese Beziehungen können dabei weder als harmonisch noch als durchgehend durch Zwang charakterisiert dargestellt werden. Die LURD benötigten Ressourcen der Zivilbevölke-

22 Bei der Niederschlagung kamen etwa 150 Menschen ums Leben (International Crisis Group 2007: 13). In Reaktion brannten aufgebrachte Bürger zwei Häuser Aicha Connehs und ein Haus Sekou Connehs in Guinea nieder (vgl. Analyst 14.02.2007).

23 Im Anschluss an den Tod des Präsidenten Guineas im Dezember 2008 putschte sich Hauptmann Moussa Dadis Camara an die Macht. Dieser ließ den in Guinea verweilenden LURD-Führer Sekou Conneh im Juni 2009 festnehmen. Vermutlich war Conneh aufgrund seiner Beziehungen zum alten militärischen Establishment als Bedrohung eingeschätzt worden. Alten Stereotypisierungen folgend verkündete die liberianische Regierung, der Fall sei eine innere Angelegenheit Guineas, da Conneh guineischer Staatsbürger sei. Unter liberianischen Mandingo löste diese Aussage Befürchtungen der Marginalisierung und entsprechende (friedliche) Proteste aus (siehe Analyst 03.07.2009). 
rung. Diese wurden teilweise durch Zwang erworben, teilweise wurden aber auch in legitimierender Absicht Güter zugeteilt oder Dienste geleistet, um die Kooperationsbereitschaft der zivilen Bevölkerung zu erhöhen (vgl. Brabazon 2003).

Der erste Krieg von 1989 bis 1996 war durch ein hohes Maß an Gewalt gegen die Zivilbevölkerung charakterisiert. Wie andere Gewaltakteure hatte auch die ULIMO sich kaum aktiv zu legitimieren versucht, und war für Plünderungen und Gewaltexzesse berüchtigt. Im zweiten Krieg 2000 bis 2003 schienen die LURD dagegen eine Strategie zu verfolgen, die zumindest partiell auf die Unterstützung der Zivilbevölkerung setzte. So waren im letzten Krieg Flüchtlingsströme weit überwiegend durch Regierungstruppen oder Gefechte verursacht, und waren nur selten Ausdruck einer Flucht vor den LURD. Regierungstruppen galten bei Beobachtern als bedeutend gewalttätiger und undisziplinierter als die LURD. Zum Teil kreierten sie Flüchtlingsströme, indem sie von Gräueltaten der Rebellen berichteten - um wenig später die verlassenen Dörfer zu plündern. Die LURD zwangen daraufhin gelegentlich Flüchtlinge zurück in eingenommene Gebiete, damit diese sich ein Bild von der Lage machen konnten. Diesen wurden für den Aufenthalt in den Dörfern teilweise Medikamente und Lebensmittel von den LURD überlassen (International Crisis Group 2002: 10). Im Gegensatz zur Situation zwischen 1991 und 1996 etablierten die LURD eine rudimentäre Verwaltung in den eroberten Gebieten, die den Erhalt eines Minimums an öffentlicher Ordnung ermöglichte. ${ }^{24}$

Die relative Kontrolle von Gewalt gegenüber der Zivilbevölkerung erlaubte des Weiteren die Legitimität stiftende Bereitstellung von Sicherheitsleistungen für Zivilisten.

"After the temporary loss of Bopolu in July 2002, many civilians volunteered to carry ammunition for LURD in a (successful) bid to retake the town as reports of systematic human rights abuses by the government army filtered through to them. Generally, LURD seem to enjoy a high degree of cooperation and a reasonably strong degree of support from the civilian population. The much-publicized blind community in Tubmanburg, for example, were well treated by LURD, their only casualty

24 Recherchen des Verfassers, Oktober 2006 bis März 2007. Vgl. auch Reno 2007. 
resulting from indiscriminate government fire. Over 400 civilians voluntarily followed LURD forces retreating from Tubmanburg in July 2002 fearing government reprisals. Villagers in Bella Mballona, south of Bopolu, described their readiness to accept LURD soldiers in their village after government troops entered it in January 2002 and partially razed it« (Brabazon 2003: 5).

Bei einer anderen Gelegenheit eskortierten LURD-Kämpfer 800 muslimische Zivilisten der Ethnie der Gbandi, welche den LURD als nahe stehend galten, sicher nach Guinea (International Crisis Group 2002: 10). Teilweise kehrten MandingoFlüchtlinge bereits vor Ende des Krieges in von den LURD kontrollierte Gebiete zurück, um ihre Felder zu bestellen. ${ }^{25}$

Bei weitem bedeutendste Gründe für Spannungen zwischen Zivilisten und LURD waren Plünderungen bzw. »Requirierungen« von Lebensmitteln und erzwungene Trägerdienste. Für Trägerdienste wurden insbesondere Flüchtlinge verwendet, da diese sich an der Grenze zu Guinea sammelten, von wo aus Nachschub an die Front gebracht werden musste. Zunächst wurden Träger für ihre Dienste bezahlt, mit zunehmender Gefährlichkeit der Missionen stellten sich dennoch Schwierigkeiten ein, willige Helfer $\mathrm{zu}$ finden. Zeitweilig wurde vermehrt Zwang angewendet (Brabazon 2003: 5). So wurden von den LURD Genehmigungen zum Grenzübergang verkauft. Diese wurden vom guineischen Militär kontrolliert und stellten einen Beweis der erfolgten Sicherheitsüberprüfung der Flüchtlinge dar. Flüchtlinge, die keine Genehmigung vorweisen konnten, wurden wieder den LURD übergeben. Flüchtlinge ohne Geld mussten sich die Pässe durch Trägerdienste verdienen, wobei sowohl Kriegsausrüstung von der Grenze ins Landesinnere als auch von den LURD gehandelte Güter - überwiegend Kaffee und Kakao - vom Landesinneren nach Guinea zu tragen waren (Médecins Sans Frontières 2002; Human Rights Watch 2002: 1517).

Allerdings wurde der Verkauf von »Ausreisegenehmigungen« zeitweilig eingestellt (Médecins Sans Frontières 2002: 18). Auch wenn ein Großteil der LURD-Kämpfer freiwillig rekrutiert war, waren Zwangsrekrutierungen außerhalb wie inner-

25 Interviews in Lofa County, Februar 2007. 
halb der Flüchtlingssiedlungen zumindest zeitweise wichtig für die personelle Stärke der LURD. Unter Teilen der Bevölkerung der Flüchtlingssiedlung Kouankan waren die LURD insbesondere aufgrund von Entführungen von Kindern und Jugendlichen gefürchtet.

Die LURD stellten also zumindest in rudimentärem Maße Patronage in Form von Sicherheit und materieller Unterstützung für Flüchtlinge bereit, nutzten aber auch ihre Kontrolle über Gewaltmittel, um von diesen Ressourcen einzufordern. Gleichzeitig übten sie eine sicherheitsrelevante Kontrolle über Flüchtlinge aus. Diese sollte verhindern, dass sich ihre Gegner und die des guineischen Präsidenten in den Rückzugsgebieten in Guinea einrichteten. Die Position der LURD in Guinea stellte sich damit als eine des patrimonialen Intermediärs dar. Dem guineischen Präsidenten untergeordnet nahmen sie eine Klientenrolle ein, erfüllten aber auch für ihn Herrschaftsfunktionen der Kontrolle von Zivilisten. Es war wahrscheinlich, dass die veränderte Strategie der LURD zumindest teilweise auf die guineische Regierung zurückging (vgl. Reno 2007: 77). Eine Stärkung der LURD durch eine Steigerung ihrer Verwaltungskapazitäten und ihrer Legitimität bei Zivilbevölkerung sowie internationaler Gemeinschaft bediente auch Sicherheitsinteressen der guineischen Regierung.

\section{Fazit: Militarisierte Flüchtlinge, Staatlichkeit und regionale Beziehungen}

Die hier dargelegte Analyse unterschied zwei für das Phänomen der Militarisierung von Flüchtlingen wichtige Dimensionen. Erstere ist die Situation der Flüchtlinge selbst. Im behandelten Fall wurden vor dem Krieg latente Gegensätze zwischen gesellschaftlichen Gruppen durch Ausübung von Gewalt zugespitzt. Damit konstituierten sich für Mandingo Interessen und Motive, als Gewaltakteur an den Kampfhandlungen teilzunehmen. Anders formuliert brachte der Krieg selbst erneut Kriegsursachen hervor, welche eine international als Staatszerfall wahrgenommenen Eskalation bewirkten. Bei der Analyse von Kriegsursachen sind auch Entwicklungen einzubeziehen, die erst nach Beginn des Krieges eintraten, aber auf die kriege- 
rische Dynamik einwirkten. Dies ist auch in Hinblick auf die Konfliktbearbeitung in Nachkriegssituationen von hoher Relevanz.

Allerdings können Interessen der Kämpfenden die Entstehung einer Rebellengruppe nicht umfassend erklären. Organisatorische und materielle Fähigkeiten zur Kriegführung werden auch bei offensichtlichen Kampfmotiven oft nicht erlangt. Flüchtlinge aufnehmende Staaten können und werden im Regelfall eine Bewaffnung ausländischer Kräfte auf ihrem Territorium unterbinden. Unterlässt ein Staat dieses, so müssen seine Motive dafür in die Analyse einbezogen werden. Im Falle Guineas verweisen diese Motive auf die strukturelle Verfasstheit des Landes. Genauer gesagt, sind die Beziehungen zwischen dem guineischen Präsidenten und den liberianischen Rebellen der ULIMO bzw. LURD aufschlussreich für die Struktur des guineischen Staates. Guinea hat wenig gemein mit dem Weberschen "Anstaltsstaat", jenem auf einer gesatzten, legalrationalen Ordnung basierenden politischen Verband. Im Gegensatz hierzu war der guineische Staat in seiner kurzen Geschichte stark personalisiert. Politische Macht wurde über personale, auf den Präsidenten ausgerichtete Netzwerke ausgeübt, während formellen Institutionen nur eine geringe Bedeutung zukam (vgl. Gerdes 2009). Diese (neo-)patrimonialen Arrangements erstreckten sich dabei bis in den Sicherheitssektor, und wurden darüber hinaus in den regionalen Beziehungen reflektiert.

Ein beständiges Problem patrimonialer Verwaltung ist, dass Amtsträger ihre Posten zur Akkumulation von Machtressourcen nutzen können und regelmäßig zur Bedrohung des Herrschers werden. Zur Umgehung dieses Problems war in patrimonialen politischen Verbänden die Besetzung des Sicherheitsstabes mit Fremden (»Stammfremden « und »Religionsfremden « in der Sprache Webers) eine verbreitete Praxis (Weber 1956: 595-598). Diese können nur schwer Verbindungen mit einheimischen Rivalen aufbauen und wenig Machtressourcen akkumulieren. Sie sind somit stark vom Wohlwollen des Herrschers abhängig. Einer ähnlichen Logik folgt die Eingliederung von Flüchtlingsarmeen oder auch Söldnern in afrikanische Sicherheitsapparate, wobei Flüchtlinge sich generell in einer stärkeren Abhängigkeit befinden und kostengünstiger sind. 
Die personalisierte Natur der Staatlichkeit Guineas und Liberias wurde auch in den regionalen Beziehungen reflektiert. In den Beziehungen zwischen Guinea und Liberia kam dieses darin zum Ausdruck, dass diese keine Beziehungen zwischen "Staaten", verstanden als institutionell gefestigte Einheiten, waren. Im ersten liberianischen Krieg waren die »internationalen Beziehungen « personalisierte Allianzen zwischen Präsident Conté und liberianischen Netzwerken des alten Regimes, insbesondere der ULIMO-K. Mit Machtübernahme Taylors übertrugen sich die feindlichen Beziehungen zwischen Conté und Taylor auf die zwischen »Guinea und "Liberia«. Die »internationalen Beziehungen « blieben im Wesentlichen Beziehungen zwischen dem guineischen Präsidenten und einem nichtstaatlichen bewaffneten Akteur. Dieser Akteur war darüber hinaus kaum einem "Staat " zuzuordnen. Vielmehr war dieser in seiner Struktur selbst grenzübergreifend. Die Verbindungen zwischen dem guineischen Präsidenten und den liberianischen Rebellen zeigen damit deutlich in der wissenschaftlichen Forschung bisher konzeptionell kaum erfasste Muster von Herrschaft jenseits von Staat und Grenzen.

\section{Literatur}

Ad Hoc Presidential Commission (2006): Preliminary Report of the Ad Hoc Presidential Commission on the Land/Property Dispute in Nimba County, October (unveröffentlichtes Dokument).

Analyst (14.02.2007) (Monrovia): Mobs Set Aichia Conneh's Home Ablaze in Conakry, http://www.analystliberia.com/ aicha_conneh_homes_destroyed_feb14_07.html, 09.05.2007.

Analyst (19.02.2007) (Monrovia): Aichia Confirms Ex-LURD Fighters Regroup in Guinea http:/ / www.analystliberia.com /new_afl_completes_training_feb19_07.html\#lurd, 09.05.2007.

Analyst (03.07.2009) (Monrovia): Sekou Conneh is Treated as Guinean, Says Information Minister, http://allafrica.com/ stories/200907061572.html, 07.07.2009. 
Black, Richard/Sessay, Mohamed (1997): »Forced Migration, Land-Use Change and Political Economy in the Forest Region of Guinea«. African Affairs 96, S. 587-605.

Brabazon, James (2003): Liberia. Liberians United for Reconciliation and Democracy, Royal Institute for African Affairs, Armed Non-State Actors Project, Briefing Paper No. 1. http://www.chathamhouse.org.uk/pdf/research/africa/Br abazon\%20BP.pdf, 10.05.2007.

Conneh, Augustine (1996): Religion, Commerce, and the Integration of the Mandingo in Liberia, Lanham et al: University Press of America.

Damme, Wim van (1999): »How Liberian and Sierra Leonean Refugees Settled in the Forest Region of Guinea (1990-96)«. Journal of Refugee Studies 12, Nr. 1, S. 36-53.

Davies, Victor A. B. (2000): »Sierra Leone. Ironic Tragedy«. In: Journal of African Economies, Vol. 19, No. 3, S. 349-369.

Dolley, Varfley A. (2007): Taylor's Genocide, the Mandingo Ordeal and Compensation, Limany, 21 July. http://limany.org/article_2007_07_21_3058.html, 10.09.2007 Ellis, Stephen (1999): The Mask of Anarchy. The Destruction of Liberia and the Religious Dimension of an African Civil War, New York: New York University Press.

Elwert, Georg (1989): »Nationalismus und Ethnizität: Über die Bildung von Wir-Gruppen«. Kölner Zeitschrift für Soziologie und Sozialpsychologie, 41, Nr. 3, S. 440-464.

Ernst \& Young (2005): National Port Authority: Systems and Financial Audit, Detailed Report, Volume 2, http://www.zenwebhosting/delbrussels.com, 20.11.2005.

Gerdes, Felix (2006): »Forced Migration and Armed Conflict. An Analytical Framework and a Case Study of RefugeeWarriors in Guinea «, Forschungsstelle Kriege, Rüstung und Entwicklung, Arbeitspapier Nr. 1, Universität Hamburg http://www.akuf.de, 01.07.2006.

Gerdes, Felix (2009): Militärputsch in Guinea. Hintergründe der aktuellen Entwicklungen, AKUF Analysen Nr. 3 (Januar), Forschungsstelle Kriege, Rüstung und Entwicklung, Universität Hamburg, http:/ / www.akuf.de, 17.01.2009.

Grovogui, Mathias Siba (1996): L'impact socioculturel et politico-économique de l'arrivée des réfugiés dans le district de Nzinigrozou (Macenta), Mémoire de maîtrise, Option Socio- 
logie, Année universitaire 1994/1995, Université de Conakry.

Hemstedt, Klaus (1992): »Guinea«. In: Afrika-Jahrbuch 1991: Politik, Wirtschaft und Gesellschaft in Afrika südlich der Sahara, Institut für Afrika-Kunde (Hamburg), Opladen: Leske + Budrich, S. 105-107.

Human Rights Watch (2002): Liberian Refugees in Guinea. Refoulement, Militarization of Camps and Other Protection Concerns, 14, Nr. 8 (A). New York, November, http:// www.hrw.org/reports/2002/guinea/guinea1102.pdf, 10.05. 2007.

Horoya (Conakry) (16.-21.09.1991): Crise libérienne: Pas de strapontin pour la Guinée.

Horoya (Conakry) (24.-26.04.1999): La Guinée ne servira jamais de base arrière pour déstabiliser un pays.

Inegbedion, E. John (1994): »ECOMOG in Comparative Perspective«. In: Timothy M. Shaw/Julius Emeko Okolo (Hg.), The Political Economy of Foreign Policy in ECOWAS, New York: St. Martins Press, S. 218-244.

International Crisis Group (2002): Liberia. The Key to Ending Regional Instability, Africa Report No. 43, 24 April, Freetown/Brüssel http://www.crisisgroup.org, 22.04.2004.

International Crisis Group (2007): Guinée. Le changement ou le chaos, Rapport Afrique Nr. 121, 14. Februar, Dakar/Brüssel http://www.crisisgroup.org, 10.05.2007.

Körner, Peter (1996): »Macht- und Interessenpolitik in der ECOWAS-Region und der Krieg in Liberia. Die politische Dimension regionaler Integration in Westafrika«. Institut für Afrika-Kunde, Hamburger Beiträge Nr. 51, Hamburg.

Liebenow, Gus J. (1969): Liberia. The Evolution of Privilege, London/Ithaca: Cornell University Press.

Le Lynx (Conakry) (17.01.2000): »Quel >Tomassacre«!«.

Le Lynx (Conakry) (17.01.2000a): »Amers fruits de la carence«.

Médecins Sans Frontières (2002): Populations Affected by War in the Mano River Region of West Africa. Issues of Protection, MSF Report, May, http://www.msf.org/countries/ page.cfm?articleid=EB07B3BF-3442-4FDEA1D6E36464BB6 EA9, 22.04.2004.

Milner, James/Christoffersen-Deb, Astrid (2006): »The Militarization and Demilitarization of Refugee Camps in Guinea, 
1999-2004«. In: Robert Muggah (Hg.), No Refuge. The Crisis of Refugee Militarization in Africa, London/New York: Zed Books, S. 51-87.

Panel of Experts (2000): Report of the Panel of Experts Appointed Pursuant to Security Council Resolution 1306 (2000), Paragraph 19, in Relation to Sierra Leone, Security Council Document S/2000/1195, December, http://www. un.org/sc/committees/1132/selecdocs.shtml, 15.06.2005.

Panel of Experts (2006): Report of the Panel of Experts Submitted Pursuant to Paragraph 5 of Security Council Resolution 1689 (2006) Concerning Liberia. Security Council Document S/2006/976, December, http://www.un.org/sc/commit tees/1521/liberiaPOE.shtml, 15.06.2005.

Reno, William (2007): "Liberia: The LURDs of the New Church«. In: Morten Bøås/Kevin C. Dunn (Hg.): African Guerillas. Raging Against the Machine, Boulder/London: Lynne Rienner, S. 69-80.

Le Républicain (Conakry) (18.01.00): Les Incidents de Macenta.

Resolution 2005: Resolution Prepared by the Lormas and Mandingos of Voinjama District, Lofa County, Liberia. $19 \mathrm{Au}-$ gust (unveröffentlichtes Dokument).

Richards, Paul (1995): »Rebellion in Liberia and Sierra Leone. A Crisis of Youth? «In: Oliver Furley (Hg.), Conflict in Africa, London/New York: Tauris, S. 134-170.

Rufin, Jean-Christophe (1999): »Kriegswirtschaft in internen Konflikten«. In: François Jean/Jean-Christophe Rufin (Hg.), Ökonomie der Bürgerkriege, Hamburg: Hamburger Edition, S. 15-46.

Weber, Max (1956): Wirtschaft und Gesellschaft. Grundriss der verstehenden Soziologie, 4. Auflage, 2. Halbband, Tübingen: J. C. B. Mohr (Paul Siebeck). 



\section{Schuld und Sühne:}

\section{Mechanismen der Finanzierung von Bürgerkriegen aus der Diaspora}

KATRIN RADTKE

»The people in the Diaspora they saw that Eritreans in the field were dying. So, everybody started to feel this and they said I must join and if I don't join I must do something. Especially for youngsters to stay behind is something like shameful.«1

Ob im Kosovo, in Sri Lanka, dem Libanon, Eritrea oder im kurdischen Konflikt, immer wieder spielen in den bewaffneten Konflikten der Gegenwart im Exil lebende Akteure eine wichtige Rolle ${ }^{2}$. So eilten beispielsweise im Kosovo-Krieg junge Albaner aus Westeuropa, mit Waffen ausgerüstet, der albanischen Befreiungsbewegung UÇK zur Hilfe. Über transnationale Finanzfonds wurden Millionen US Dollar für die Rebellen gesammelt und über informelle Netzwerke in die Konfliktregion transferiert. ${ }^{3}$ In der Türkei war es der »Kurdischen Arbeiterpartei« (PKK) nicht zuletzt aufgrund ihrer straffen Kontrolle und

1 Interview mit Ahferom Tewelde (PFDJ), Asmara, 28.10.2003.

2 Die Liste der Konflikte bzw. Konfliktregionen ließe sich noch erheblich länger fortführen. $\mathrm{Zu}$ nennen sind besonders noch: Irland, Bosnien, Serbien, Kroatien.

3 Beate Andrees, Dissertationsprojekt. 
Organisation der in Deutschland lebenden Kurden, möglich, einen Jahrzehnte andauernden Kampf gegen die türkische Regierung zu führen. Auch die eritreische Befreiungsbewegung (EPLF) profitierte von ihren Verbindungen zu den im Ausland lebenden eritreischen Gemeinden. Durch eine so genannte Revolutionssteuer, die in einer jährlichen Abgabe in Höhe eines Monatsgehalts bestand und häufig im Rahmen der in den Exilländern entstehenden Vereinen eingetrieben wurde, konnte ein wesentlicher Teil der für den bewaffneten Kampf notwendigen Ausgaben abgedeckt werden.

Bei der Mobilisierung der Diaspora kommt den bewaffneten Gruppen, die in den Bürgerkriegen kämpfen, die Dynamik des Migrationsprozesses zur Hilfe. In vielen Migrantengruppen entstehen, nicht zuletzt aufgrund von Erfahrungen der Diskriminierung und Ausgrenzung und als institutionelle Antwort auf die mit der Migrationssituation verbundene Unsicherheit, Systeme der gegenseitigen Hilfe, die auf dem Prinzip der "generalisierten Reziprozität « (Sahlins 1972) beruhen. ${ }^{4}$

Insofern sich die generalisierte Reziprozität durch moralische Forderungen zu einem Muster stabilisiert, das über den Kreis von Verwandten und Bekannten hinausgeht und sich auf eine »imaginierte Gemeinschaft« (Anderson 1992) erstreckt, lässt sie sich auch als »moralische Ökonomie« der Diaspora bezeichnen. ${ }^{5}$

4 In diesem Tauschsystem ist die Äquivalenz des Tauschs nicht genau bestimmt, $\mathrm{d}$. h. die Tauschpartner werden nicht mehr ausschließlich als spezielle Personen angesehen, sondern als Angehörige einer größeren Gruppe. Dabei kommt es nicht auf das Gleichgewicht zwischen spezifischen Agenten an, sondern auf die Balance innerhalb einer Gruppe (Faist 2000: 37 ff.).

5 Zwar existiert der Begriff der moralischen Ökonomie schon mindestens seit Mitte des 19. Jahrhunderts (vgl. z.B. Chalmers 1832, Perry 1909), bekannt und für diesen Zusammenhang relevant wurde er jedoch v.a. durch den Historiker E. P. Thompson. In seinem 1971 veröffentlichten Artikel, »The Moral Economy of the English Crowd in the Eighteenth Century«, verwendet er den Begriff im Zusammenhang mit den Hungeraufständen im England des 18. Jahrhunderts. Grundlage seines Artikels ist die Kritik an dem ökonomischen Reduktionismus vieler Historiker, deren gemeinsame Schwäche er in ihrer zu kurz greifenden Sicht des Menschen als »homo economicus« sieht. Mit dem Konzept 
An diese moralische Ökonomie der Diaspora können bewaffnete Gruppen anknüpfen. Ziel dieses Kapitels ist es anhand von zwei Fallbeispielen - der »Eritrean People's Liberation Front« (EPLF) und der eritreischen Diaspora in Frankfurt am Main sowie den »Liberation Tigers of Tamil Eelam« (LTTE) und der tamilischen Diaspora in Toronto- die Anknüpfungspunkte an die Diaspora zu identifizieren, die sich im Rahmen der morali-

der moralischen Ökonomie stellt er dieser Perspektive seine eigene entgegen, in der er ökonomisches Handeln als eng mit sozialen Normen und Verpflichtungen verknüpft beschreibt. Für Thompson greift eine Erklärung der Hungeraufstände durch »instinktiven Hunger « zu kurz. Die »elementaren Bedürfnisse « fasst er als notwendige, jedoch nicht hinreichende Bedingungen für die Aufstände auf. Als hinreichende Bedingung bezeichnet er hingegen die moralische Ökonomie der Bevölkerung (Thompson 1971, vgl. auch Thompson 1993 und 1993a). Thompsons Konzept der moralischen Ökonomie, selbst begrenzt auf eine bestimmte Zeit und Lokalität, wurde nach der Veröffentlichung seines Artikels auf eine Vielzahl unterschiedlicher Felder und Kontexte erweitert. Zunächst fand es Anwendung in Studien über Hungeraufstände in verschiedenen historischen Kontexten. In der Folge benutzte man das Konzept der moralischen Ökonomie jedoch auch, um Arbeiterproteste und industrielle Konflikte im achtzehnten Jahrhundert zu untersuchen (vgl. Charlesworth/Randall 2000). Die hier verwendete Definition lehnt sich eng an das von James Scott (1976) entwickelte Verständnis der moralischen Ökonomie an. In Scotts Überlegungen sind alle wichtigen Aspekte der Ökonomie der von ihm untersuchten südostasiatischen Bauern in Bezug auf ihre Einbettung in ein nicht-ökonomisches, moralisches Universum der Solidarität und des Rechtes auf Subsistenz zu erklären. Das Recht auf Subsistenz, das jedem Bauern zusteht, wird durch technische - Pflanztechniken, Variation der Samen, und Aussaatzeit - und soziale Arrangements - Reziprozitätsmuster, Umverteilungsmechanismen, gemeinsamer Landbesitz und Arbeitsteilung - gesichert. Es dient der Minimierung des Risikos einer Gesellschaft, die immer an der Grenze des Existenzminimums lebt. Eine schlechte Ernte bedeutet in ihr nicht nur eine Kürzung der Nahrungsmittelrationen, sondern möglicherweise auch die Veräußerung von Land oder Vieh und damit eine Verringerung der Voraussetzungen für eine angemessene Subsistenz im nächsten Jahr (Scott 1976: 3 ff.). 
schen Ökonomie für bewaffnete Gruppen ergeben. ${ }^{6} \mathrm{Zu}$ diesem Zweck werden die beiden Diasporagemeinschaften und ihre Entstehungsphasen sowie die Lebensbedingungen ihrer Mitglieder vor allem in Bezug auf die Bereiche Arbeit, Bildungszugang und Wohnsituation vorgestellt. Daran anschließend wird die moralische Ökonomie der beiden Gemeinschaften in Form der entstehenden reziproken Austauschbeziehungen vorgestellt, die in den prekären Verhältnissen des Exils die Existenz der Diasporamitglieder absichert. Schließlich werden unter Bezug auf die Gefühle der Schuld und der Heimat die Anknüpfungspunkte der bewaffneten Gruppen an die moralische Ökonomie herausgearbeitet.

\section{Die tamilische Diaspora in Kanada}

Nach Angaben von »Statistics Canada « 7 lebten im Jahr 2001 etwa 92.010 tamilischsprachige Personen in Kanada, davon 72.715 in Toronto. ${ }^{8}$ Von Vertretern tamilischer Organisationen wird

6 Die vorgestellten Ergebnisse beruhen auf mehrmonatigen Feldforschungen in den Konfliktländern sowie in der eritreischen Diaspora in Frankfurt und der tamilischen Diaspora in Toronto.

7 »Statistics Canada « ist das staatliche Statistikamt in Kanada und entspricht etwa dem »Statistischen Bundesamt « in Deutschland.

8 Es ist an dieser Stelle notwendig einige einschränkende Anmerkungen zu den verfügbaren statistischen Daten zu machen. Das größte Problem bei der Einschätzung des Umfangs und der Entwicklung der tamilischen Diaspora aus Sri Lanka verursachen Überschneidungen der Kategorien, in die sich srilankische Tamilen einordnen können. So differenziert etwa ein Bericht über die ethnische Ungleichheit in Toronto (Ornstein 2000), der den folgenden Ausführungen maßgeblich zugrunde liegt, zwischen Tamilen und Srilankern. Durch die parallele Verwendung von nationalen und ethnischen Zuordnungsmöglichkeiten ist jedoch eine Erfassung der Tamilen aus Sri Lanka nicht möglich. Während unter die Kategorie "Srilanker« nicht nur Singhalesen und Tamilen fallen, sondern auch die muslimische Minderheit Sri Lankas, die sich keiner der beiden Gruppen zuordnet, vereint die Kategorie »Tamilen « neben den Tamilen aus Sri Lanka auch diejenigen Personen, die aus dem indischen Bundesstaat Tamil Nadu stammen. Ein ähnliches Problem gilt auch für die von »Statistics Canada« aufgestellten Zahlen zur Größe der tamilischspra- 
die Größe der gesamten tamilischen Bevölkerung in Kanada jedoch auf etwa 200.000 Personen geschätzt.

Die tamilische Gemeinde ist eine der am schnellsten wachsenden Bevölkerungsgruppen in Kanada. Seit 1981, dem ersten Jahr in dem »Tamil « als Kategorie für die Frage nach der »Muttersprache« im Volkzählungsfragebogen auftauchte, ist die tamilischsprachige Bevölkerung in Kanada nahezu um das Fünfzigfache gewachsen. Seit 1986 kamen in dem Zeitraum von fünf Jahren zwischen den Zensi jeweils mehr als 25.000 tamilischsprachige Personen nach Kanada, von 1991 bis 1996 wanderten sogar 33.820 Personen ein.

Tabelle 1: Größe und Wachstum der tamilischsprachigen Immigranten in Kanada und Toronto zwischen 1981 und 2001

\begin{tabular}{|l|c|c|c|c|c|}
\hline & $\mathbf{1 9 8 1}$ & $\mathbf{1 9 8 6}$ & $\mathbf{1 9 9 1}$ & $\mathbf{1 9 9 6}$ & $\mathbf{2 0 0 1}$ \\
\hline Kanada & 1.975 & 6.655 & 33.015 & 66.835 & 92.010 \\
\hline Toronto & & & & 54.260 & 72.715 \\
\hline
\end{tabular}

Quelle: Statistics Canada, zit. nach Wayland (2002b: 18)

Die Entstehung der Exilgemeinde hängt sowohl zeitlich als auch ursächlich eng mit dem Bürgerkrieg in Sri Lanka zusammen. Seit dem Beginn der achtziger Jahre kämpfen dort die »Liberation Tigers of Tamil Eelam« (LTTE) im Norden und

chigen Bevölkerung. Dennoch sind die im Folgenden verwendeten Statistiken nicht ohne Aussagekraft. Zum einen vermuten Experten der tamilischen Diaspora, dass der Anteil der Singhalesen bzw. indischen Tamilen in Kanada nur sehr gering ist. Zum anderen unterscheiden sich die Gruppe der »Srilanker « und der »Tamilen« im Hinblick auf Alter, Geschlecht, Bildung, Sprachkenntnisse und Berufstätigkeit kaum. Lediglich die Einschätzung der Größe der srilanka-tamilischen Diaspora stellt daher ein Problem dar. Grundsätzlich ist zu vermuten, dass offizielle Angaben die Größe der tamilischen Bevölkerung wesentlich unterschätzen. Sarah Wayland (2002a: 38) führt diese Tatsache darauf zurück, dass viele der »neuen « Immigranten die Volkszählungsformulare aufgrund von Sprachproblemen nicht ausfüllen können. Im Folgenden werden daher die Angaben, die auf den alle fünf Jahre durchgeführten Zensi beruhen, durch Schätzwerte von tamilischen Organisationen ergänzt. 
Nordosten des Landes um einen unabhängigen Staat für die tamilische Minderheit.

Zwar lebten schon vor Ausbruch des Bürgerkrieges einige Tamilen aus Sri Lanka in Toronto, die Mehrzahl der Migranten reiste jedoch nach dem Beginn des Krieges ein. Grundsätzlich lässt sich die tamilische Bevölkerung in Toronto in drei unterschiedliche Kategorien einordnen: Immigranten, Flüchtlinge und Familienangehörige. ${ }^{9}$ Diese drei Kategorien korrespondieren weitgehend mit unterschiedlichen Migrationsphasen. Als Immigranten können in diesem Fall diejenigen Tamilen gelten, die mit der Absicht, sich dauerhaft anzusiedeln nach Kanada eingereist sind. Diese Gruppe stellte bis zum Ausbruch des Bürgerkrieges den größten Teil der Tamilen in Toronto. Die meisten ihrer Mitglieder hielten sich aus Studien- bzw. Arbeitsgründen in Kanada auf, kamen aus wohlhabenden Familien und gehörten höheren Kasten in Sri Lanka an. Ihre Migration stand in engem Zusammenhang mit der Bildungspolitik der srilankischen Regierung seit der Unabhängigkeit 1948, die Tamilen systematisch den Zugang zu Bildungseinrichtungen erschwerte, um die Überrepräsentation der Tamilen in der öffentlichen Verwaltung zu minimieren.

Nach dem Pogrom gegen die tamilische Bevölkerung in Sri Lanka im Jahr 1983 änderte sich die Sozialstruktur der tamilischen Gemeinschaft in Kanada schlagartig. Die zu tausenden einreisenden Flüchtlinge, meist junge Männer, stammten aus unterschiedlichsten sozialen Verhältnissen, waren hoch politisiert und durch den Wunsch auf Rückkehr nach Sri Lanka gekennzeichnet. Das Verhältnis der beiden Gruppen in der Anfangszeit wird von Mitgliedern der tamilischen Gemeinde als hoch problematisch beschrieben. Die teilweise geringe Bildung der Flüchtlinge, ihre Kastenzugehörigkeit und ihre Herkunft aus weniger wohlhabenden Familien ließ die ursprüngliche tamilische Gemeinde den Neuankömmlingen eher zurückhaltend gegenüberstehen. ${ }^{10}$

9 Eine ähnliche Einteilung wird auch von anderen Autoren für die tamilische Diaspora in Deutschland (Gottstein et al. 1992), Großbritannien (Daniel/Thangaraj 1995: 240 ff.) und der Schweiz (McDowell 1996) vorgenommen.

10 Interview, Toronto, 30.4.2003. 
Die dritte Kategorie der tamilischen Gemeinde in Toronto wird von den nachziehenden Familienangehörigen der Flüchtlinge gebildet. Es handelt sich hier häufig um Frauen oder ältere Personen, die ihren Ehemännern oder Söhnen ins Exil nachfolgen. Die beiden letzten Gruppen lassen sich nur schwer in einen zeitlichen Rahmen einordnen. Grundsätzlich kann wohl angenommen werden, dass jedes Aufflammen des Konfliktes in Sri Lanka von einem Anschwellen des Flüchtlingsstroms begleitet ist, auf den wiederum Familienzusammenführungen folgen.

Eine Analyse der Benachteilung von verschiedenen Minderheiten innerhalb Kanadas (Ornstein 2000) identifiziert die Gruppe derjenigen, die sich im 1996er Zensus als Tamilen bezeichneten, als schwerwiegend bis extrem benachteiligt in den Bereichen Ausbildung und Arbeit. Ein Vergleich der Volkszählungen von 1991 und 1996 ergibt nur geringe Veränderungen.

Tabelle 2: Höchste Ausbildung der Tamilen in Toronto im Alter zwischen 25 und 64 im Jahr 1996

\begin{tabular}{|c|c|c|c|c|c|c|c|c|}
\hline $\begin{array}{l}\text { Keine } \\
\text { High- } \\
\text { school }\end{array}$ & $\begin{array}{l}\text { Etwas } \\
\text { High- } \\
\text { school }\end{array}$ & $\begin{array}{l}\text { High- } \\
\text { school- } \\
\text { abschluss }\end{array}$ & $\begin{array}{l}\text { Handels- } \\
\text { schul- } \\
\text { abschluss }\end{array}$ & $\begin{array}{l}\text { College- } \\
\text { abschluss }\end{array}$ & $\begin{array}{l}\text { Etwas } \\
\text { Univer- } \\
\text { sität }\end{array}$ & $\begin{array}{l}\text { Universi- } \\
\text { täts- } \\
\text { abschluss }\end{array}$ & $\begin{array}{l}\text { M.A.- } \\
\text { Abschluss } \\
\text { und höher }\end{array}$ & Gesamt \\
\hline $7,1 \%$ & $34,3 \%$ & $31,5 \%$ & $5,2 \%$ & $9,8 \%$ & $2,0 \%$ & $8,5 \%$ & $1,6 \%$ & $100 \%$ \\
\hline
\end{tabular}

Quelle: Ornstein (2000: 36)

Innerhalb der tamilischen Gemeinde in Toronto verfügen 41,4 Prozent der Personen zwischen 25 und 64 Jahren über keinen Highschool-Abschluss. Damit liegt die Zahl der Personen mit geringer Schulbildung deutlich über der vieler anderer Gruppen. Der Durchschnitt der Highschool Abschlüsse in Kanada beträgt 69,5 Prozent. Nur 8,5 Prozent der Tamilen erreichen einen Universitätsabschluss und nur 1,6 Prozent ist es möglich, ihr Studium mit einem M.A oder einem höheren Grad abzuschließen. Im Vergleich dazu verlassen 22,7 Prozent aller Einwohner Torontos zwischen 25 und 64 die Universität mit einem B.A. Abschluss und immerhin 5,5 Prozent erlangen den M.A.

Die Zahl der arbeitslosen Tamilen in Kanada ist hoch. Insgesamt besitzen 24,7 Prozent der über 15-jährigen keinen Arbeits- 
platz. Die Arbeitslosigkeit der unter 25-jährigen ist mit 32,7 Prozent höher als die der 25-64 Jährigen (23,9 Prozent). Vor allem die Beteiligung der tamilischen Frauen am Arbeitsmarkt ist mit nur etwa 41 Prozent gegenüber dem Durchschnitt von 71,1 Prozent aller Frauen in Toronto sehr gering. Von denjenigen, die über Arbeit verfügen, sind 86,2 Prozent Vollzeit beschäftigt.

Tabelle 3: Arbeitslosigkeit der Tamilen in Toronto nach Alter und Anteil an der Arbeitskraft nach Geschlecht im Jahr $19966^{11}$

\begin{tabular}{|l|l|l|l|l|}
\hline \multicolumn{2}{|l|}{ Prozent der Arbeitslosen } & \multicolumn{2}{l|}{ Anteil an der Arbeitskraft in Prozent } \\
\hline 15-24 Jahre & $25-64$ Jahre & Gesamt & Frauen & Männer \\
\hline $32,7 \%$ & $23,9 \%$ & $24,7 \%$ & $41,2 \%$ & $78,6 \%$ \\
\hline
\end{tabular}

Quelle: Ornstein (2000: 54)

Die meisten Tamilen arbeiten in Berufen, für die nur eine geringe Qualifikation erforderlich ist. Der Anteil der Frauen in niedrig qualifizierten Jobs ist dabei mit 79 Prozent wesentlich größer als der der Männer mit 64 Prozent. Sowohl tamilische Männer als auch Frauen sind sehr viel häufiger in Berufen beschäftigt, die eine geringe Qualifikation erfordern, als der Durchschnitt der Einwohner Torontos. Denn nur 52,8 Prozent aller Frauen in Toronto und 44,4 Prozent aller Männer arbeiten in Jobs, für die keine Ausbildung erforderlich ist (Ornstein 2000: 66-74).

Entsprechend beträgt das Mittel der Jahreseinkommen von Tamilen in Toronto etwa 10.000 C\$ für Frauen und 14.000 C\$ für Männer und unterschreitet so wesentlich das Mittel der Einkommen in der Stadt (22.000 C\$). ${ }^{12}$ Der Großteil der tamilischen Familien (53,5 Prozent) lebte 1996 unterhalb der Armutsgrenze (Ornstein 2000: 97).

11 Die Tabelle schließt Personen aus, die 1995 und 1996 nach Kanada eingewandert sind.

12 Das Mittel der Einkommen unterscheidet sich von dem durchschnittlichen Einkommen. Nach der Definition des Mittels haben genau die Hälfte der Mitglieder einer Gruppe ein Einkommen, das über dem Mittel liegt und die andere Hälfte eines, das darunter liegt. Auf diese Weise können Verzerrungen etwa durch einige besonders hohe Einkommen ausgeschlossen werden. 


\section{Die eritreische Diaspora in Deutschland}

Ähnlich wie die tamilische Gemeinde in Toronto, entwickelte sich die eritreische Diaspora in Deutschland in verschiedenen Phasen. ${ }^{13}$ Bis Mitte der siebziger Jahre war die Zahl der in Deutschland lebenden Eritreer relativ gering. Bei den meisten Personen handelte es sich um allein stehende junge Männer, die sich aus Studien- oder Berufsgründen in Deutschland aufhielten. Mit der im Februar 1974 einsetzenden » ̈̈thiopischen Revolution« veränderte sich die Sozialstruktur der Zuwanderer aus Äthiopien und den Gebieten des heutigen Eritrea. Zwar dominierten noch immer allein stehende junge Männer die Gemeinde, jedoch fanden sich auch zunehmend Frauen unter den Flüchtlingen wieder, die sich entweder im Rahmen der äthiopischen Linksopposition gegen das Militärregime engagiert, oder für die eritreische Unabhängigkeitsbewegung gearbeitet hatten.

Im Jahr 1992, kurz nach der Unabhängigkeit Eritreas, waren im Ausländerzentralregister der Bundesrepublik Deutschland 20.997 äthiopische Staatsangehörige registriert. Hinzu kam die Zahl von 2.796 im Zeitraum zwischen 1981 und 1992 eingebürgerten Personen »äthiopischer Herkunft«. Experten gehen jedoch von einer sehr viel höheren Zahl aus. So gibt Günter Schröder an, dass die Zahl der in Deutschland lebenden Perso-

13 Die folgenden Ausführungen basieren auf einer im Auftrag der Zentralstelle für Arbeitsvermittlung durchgeführten Studie zur personellen Zusammenarbeit mit Eritrea (Gebreyesus et al. 1991). Da alle Eritreer bis zur Unabhängigkeit in Deutschland als Äthiopier registriert waren, stehen bis 1993 keine offiziellen Angaben über Größe und Entwicklung der eritreischen Diaspora zur Verfügung. Zusätzlich verkompliziert wird die Einschätzung der Anzahl der in Deutschland ansässigen Eritreer durch die Tatsache, dass auch nach der Unabhängigkeit viele Personen eritreischer Herkunft ihre äthiopische Staatsangehörigkeit behielten. Diese Tatsache mag zunächst erstaunen, denn ein Großteil der Eritreer hatte aus dem Exil die eritreische Unabhängigkeit unterstützt. Nina von Nolting (2002: 25) verweist auf Interviews in denen die Befragten zu erkennen gaben, dass sie aus Angst vor dem Kontakt mit den deutschen Behörden auf die eritreische Staatsangehörigkeit verzichtet hatten. Bei allen hier präsentierten Daten handelt es sich daher um die Schätzwerte einiger weniger Experten. 
nen äthiopischer und eritreischer Herkunft in diesem Jahr auf etwa 24.500 geschätzt werden müsse. Davon seien ungefähr 18.000 eritreischer und 6.500 äthiopischer Herkunft gewesen (Schröder 2003:1).

Tabelle 4: Äthiopische StaatsbürgerInnen in der Bundesrepublik Deutschland von 1969 bis 1992 - Auszählung des Ausländerzentralregisters

\begin{tabular}{|c|c|c|}
\hline$J a h r^{14}$ & Absolut & Wachstum in \% \\
\hline 1969 & 265 & \\
\hline 1970 & 339 & 28,0 \\
\hline 1971 & 454 & 34,0 \\
\hline 1972 & 529 & 16,5 \\
\hline 1973 & 641 & 22,2 \\
\hline 1974 & 787 & 23,8 \\
\hline 1975 & 964 & 7,8 \\
\hline 1976 & 1.039 & 22,5 \\
\hline 1977 & 1.184 & 14,0 \\
\hline 1978 & 1.424 & 20,3 \\
\hline 1979 & 1.760 & 23,6 \\
\hline 1980 & 4.658 & 164,7 \\
\hline 1981 & 5.766 & 23,8 \\
\hline 1982 & 7.034 & 22,0 \\
\hline 1983 & 7.792 & 10,8 \\
\hline 1984 & 9.523 & 22,2 \\
\hline 1985 & 13.049 & 37,0 \\
\hline 1986 & 14.707 & 12,7 \\
\hline 1987 & 15.414 & 4,8 \\
\hline 1988 & 15.763 & 2,3 \\
\hline 1989 & 16.278 & 3,3 \\
\hline 1990 & 17.956 & 10,3 \\
\hline 1991 & k. A. & k. A. \\
\hline 1992 & 20.997 & \\
\hline
\end{tabular}

Quelle: Schröder (2003)

Der Großteil der äthiopischen und eritreischen Flüchtlinge in Deutschland gehörte städtischen Bevölkerungsgruppen an.

14 Bis 1984 Stand 31.9., ab 1985 Stand 31.12. 
Während sich die meisten Äthiopier dem Bildungsbürgertum zuordnen ließen, setzten sich die Eritreer in Deutschland aus den unterschiedlichsten Gesellschaftsschichten zusammen, wurden aber von Arbeitern dominiert. Infolge der äthiopischen Großoffensiven und Repressionswellen der Jahre 1978-80 kam es zu Massenfluchten aus Eritrea. Mehr als 250.000 Eritreer flohen vor der vorrückenden äthiopischen Armee in den Sudan. In Deutschland schlug sich dieser Exodus mit etwa 3000 neu ankommenden » ̈̈thiopiern « im Jahre 1980 nieder. In dieser neuen Flüchtlingswelle befanden sich zum ersten Mal in größerem Umfang auch Familien, Frauen und Kinder ${ }^{15}$.

Insgesamt ist in Deutschland der Anteil der Flüchtlinge aus dem Tiefland Eritreas größer als der der Hochlandbewohner. Diese Tatsache hängt eng mit der Geschichte des Krieges zusammen, denn der Unabhängigkeitskampf der Eritreer begann im Tiefland, und diese Region blieb der Schauplatz für die meisten kriegerischen Auseinandersetzungen. Die Flüchtlingsgruppen aus dem Hochland und Tiefland orientierten sich bei ihrer Flucht in unterschiedliche Weltregionen. Vor allem religiöse Gründe waren hierfür verantwortlich. Während die meist muslimischen Tieflandbewohner eher in die Länder des Nahen Ostens und benachbarte afrikanische Länder wanderten, bewegten sich die großteils städtischen, christlichen Flüchtlinge eher nach Europa oder Nordamerika (Gebreyesus et al. 1991: 21).

Insgesamt kann die Gruppe der äthiopischen Ausländer in Deutschland bis zu Beginn der 1990er Jahre im Hinblick auf Bildung und Ausbildung als stark benachteiligt gelten. ${ }^{16}$ Allgemein lässt sich sagen, dass die Kinder eingebürgerter Eltern meist bessere Schulleistungen erbrachten, da ihre Familien grundsätzlich materiell besser gestellt waren und über ausreichend Wohnraum verfügten. Zusätzlich förderte auch die sprachlich-kulturell im Allgemeinen wesentlich bessere Integration der eingebürgerten Eltern die Schulleistung der Kinder.

15 Zunehmend reisten ab Anfang der achtziger Jahre auch unbegleitete Minderjährige nach Deutschland ein.

16 Im Vergleich mit anderen ausländischen Gruppen, etwa Portugiesen oder Marokkanern, die schon länger in Deutschland ansässig waren, verfügten äthiopische Kinder und Jugendliche jedoch über eine bessere Schulbildung. 
Insgesamt war die Bildungssituation für ältere Kinder schwieriger als für jüngere. Grund dafür war die Tatsache, dass viele der älteren Kinder aufgrund ihrer Fluchtgeschichte nicht auf einen kontinuierlichen Ausbildungsverlauf verweisen konnten. In Deutschland wurden sie aber ihrem Alter gemäß in das Schulsystem eingestuft. Unter dieser Gruppe der Jugendlichen kam es überdurchschnittlich häufig zu keinem Schulabschluss und damit zu größeren Schwierigkeiten bei der Suche nach einem Ausbildungsplatz (Gebreyesus et al. 1991: 81 ff.).

Obwohl die äthiopischen Ausländer in Deutschland im Vergleich mit anderen afrikanischen Migrantengruppen über eine relativ hohe berufliche Qualifikation verfügten, waren sie im Zeitraum zwischen 1983 und 1990 auf dem deutschen Arbeitsmarkt extrem benachteiligt. Aus den Angaben der Bundesanstalt für Arbeit wird jedoch zwischen 1983 und 1990 ein Anstieg der Erwerbstätigkeit deutlich. Die Beschäftigungsquote stieg in Relation zur Gesamtbevölkerung von rund 15,6 Prozent im Jahr 1983 auf 19,16 Prozent im Jahr 1990.17

Tabelle 5: Beschäftigte äthiopische StaatsbürgerInnen in der BRD 1983 bis $1990^{18}$

\begin{tabular}{|l|l|l|l|l|l|}
\hline & \multicolumn{2}{l}{ Männlich } & \multicolumn{2}{l|}{ Weiblich } & Gesamt \\
\hline & Absolut & $\%$ & Absolut & $\%$ & Absolut \\
\hline $\mathbf{1 9 8 3}$ & & & & & 1.212 \\
\hline $\mathbf{1 9 8 6}$ & 1.511 & 78,5 & 415 & 21,5 & 1.926 \\
\hline $\mathbf{1 9 8 7}$ & 1.744 & 78,5 & 476 & 21,5 & 2.220 \\
\hline $\mathbf{1 9 8 8}$ & 1.948 & 77,0 & 580 & 23,0 & 2.528 \\
\hline $\mathbf{1 9 8 9}$ & 2.259 & 76,8 & 684 & 23,2 & 2.943 \\
\hline $\mathbf{1 9 9 0}$ & 2.594 & 75,4 & 847 & 24,6 & 3.441 \\
\hline
\end{tabular}

Quelle: Bundesanstalt für Arbeit (1983)

17 Die Zahlen zur Beschäftigung wurden jeweils zum 30.6 jeden Jahres erhoben, die Bevölkerungszahlen jedoch bis 1984 zum 30.9 und bis 1990 zum 31.12. jeden Jahres.

$18 \mathrm{Zu}$ der offiziellen Statistik muss eine nicht unbeträchtliche Zahl an nicht registrierten Arbeitsverhältnissen hinzugerechnet werden. 
Dabei lag der Anteil der weiblichen Beschäftigten erheblich unter dem der männlichen Arbeitnehmer. Jedoch begann auch diese Diskrepanz sich im Untersuchungszeitraum langsam zu reduzieren.

Insgesamt war ein großer Teil der Eritreer und Äthiopier in Deutschland in den achtziger Jahren auf Sozialhilfe angewiesen und lebte an der Armutsgrenze. Besonders die Wohnsituation stellte ein großes Problem dar. Aufgrund von Wohnraumknappheit, steigenden Mieten und Ausländerfeindlichkeit bestanden kaum Chancen auf dem Wohnungsmarkt eine Bleibe zu finden (Gebreyesus et al. 1991: 93).

Zusammenfassend lässt sich festhalten, dass sowohl in der tamilischen als auch in der eritreischen Diaspora die soziale Situation im Aufnahmeland durch eine starke Benachteiligung in den Bereichen Arbeit, Bildung und auf dem Wohnungsmarkt gekennzeichnet ist. Die im Heimatland erlernten Fertigkeiten sind auf dem aufnehmenden Arbeitsmarkt nicht gefragt. Besonders in der ersten Zeit wird meist die Sprache des Ziellandes nicht beherrscht.

\section{Die moralische Ökonomie der Diaspora}

In diesen prekären Verhältnissen werden die sozialen Bindungen unter den Immigranten zum überlebenswichtigen Band. Dabei resultiert die entstehende moralische Ökonomie der Diaspora nicht notwendigerweise aus dem Import traditionaler Organisationsformen ins Exil. Seine große Bedeutung erhält das System der moralischen Ökonomie in der Diaspora durch die äußeren Umstände des Exils. Die von Scott im Hinblick auf die moralische Ökonomie südostasiatischer Bauern festgestellte Funktion der Risikominimierung und des Rechtes auf Subsistenz (vgl. FN 5) ist auch in der Diaspora zu beobachten. In differenzierten Systemen der Gabe und Verpflichtung wird in der Diaspora Hilfe bei der Arbeits- und Wohnungssuche, die Versorgung mit Kleidung, Unterkunft und Nahrung in kurzfristigen Übergangszeiten geleistet. In der Zeitspanne, die zwischen Gabe und Gegengabe liegt, schaffen und reproduzieren sich Bindungen. Die Trias der Pflichten, die Marcel Mauss (1989: 71 ff) für die Gabenökonomie archaischer Gesellschaften heraus- 
gearbeitet hat, greift auch in der Ökonomie der Diaspora: Geben, Nehmen und Erwidern müssen nicht unmittelbar aufeinander folgen. Die Zeitdifferenz zwischen der Erfüllung dieser Pflichten spannt die Beziehung zwischen den Tauschenden. Die vorgängigen Grundlagen der Prozesse, über die der Zusammenhalt und die Tauschbeziehungen in der Diaspora hergestellt werden, sind die geteilte Sprache, das identische Schicksal und die Erfahrungen des Exils.

Diese Dynamik lässt sich sowohl in der tamilischen Diaspora in Toronto als auch der eritreischen Diaspora in Frankfurt beobachten. In der tamilischen Diaspora in Toronto bildeten sich einige Stadtteile heraus, die von der tamilischen Community als »Tamil neighborhoods" bezeichnet werden. Schon seit den achtziger Jahren wurde St. Jamestown, ein Viertel mit zahlreichen Hochhäusern des sozialen Wohnungsbaus, zum Anziehungspunkt für tamilische Einwanderer. Zunächst konzentrierten sich die Einwanderer in den so genannten "Sherbourne Street Apartments«. Oft wurden kleine Wohnungen von mehreren jungen Männern bewohnt. Das folgende Zitat eines tamilischen Einwanderers veranschaulicht die Lebensumstände der Neuankömmlinge eindrücklich:

»...We were probably six or seven guys living in a one-bedroom apartment at the beginning. I remember that. And our food budget, when we split it comes to about \$ 60 a month or \$ 100 a month, that's all. [...] And two of these guys take the evening shift, and some guys work night shift or day shift so the beds are available to all the others. Maybe we all sleep on the floor, or go out to the bars, $[\ldots]$, somewhere outside [...] That is how we lived in the early stages. Very hard.«19

Mit der Ankunft der Familienangehörigen Ende der achtziger Jahre verteilten sich die tamilischen Einwanderer im gesamten Viertel. Besonders die beiden Hochhäuser 650 und 280 Parliament Street, Ecke Wellesley Street wurden zu tamilischen Hochburgen, in deren Fluren sich teilweise sogar Gemeinschaften bildeten, die auf nachbarschaftlichen Beziehungen in Sri Lanka beruhten (Sandercock et al. 2004: 13). Zur selben Zeit begannen auch die ersten tamilischen Geschäfte im Norden der

19 Zitiert nach Sandercock et al. (2004: 12). 
Parliament Street zu öffnen und bald verfügte das Viertel über mehrere tamilische Lebensmittelläden, ein Restaurant und das so genannte »Tamil Resource Center« mit einer Bibliothek, die auf die Belange der tamilischen Community spezialisiert war.

In Parkdale und Wallace Emmerson, ebenfalls Viertel in der Innenstadt Torontos, entstanden weitere Siedlungsschwerpunkte der tamilischen Einwanderer. Dort wurde 1988 von der "Society for the Aid of Sri Lankan Minorities « (SACEM) eine tamilische Wohnkooperative gegründet. Über die Kooperative werden noch heute alltägliche Aufgaben, etwa die Betreuung von Kindern, gemeinschaftlich geregelt. Sie unterhält eine kleine Bibliothek, führt Englischsprachkurse durch, bietet Gottesdienste für Hindus, Moslems und Christen an und stellt Räume für kulturelle Veranstaltungen zur Verfügung (Schiewer 1999: 80). Auch verschiedene andere "Community Organisationen " entstanden in Toronto, die sich um die Belange der tamilischen Bevölkerung kümmerten (vgl. Kapitel 6.1). ${ }^{20}$

Die bestehenden Netzwerke zwischen den Einwanderern erleichterten besonders neu ankommenden Flüchtlingen die Ankunft in Toronto. So antworteten viele Interviewpartner ähnlich wie der Folgende: »Two components helped me to settle in Canada: my relatives and my political relations. When I came to Canada people here had already established a network. This helped me to find work.«21

20 Inzwischen ist ein großer Teil der tamilischen Bevölkerung aus der Innenstadt in die Vororte Scarborough und North Yorck umgezogen. Sandercock et al. (2004: 15) führen diese Tatsache auf den besseren Zugang zu kanadischen Bildungseinrichtungen zurück und den damit einhergehenden größeren Chancen auf dem Arbeitsmarkt. Besser verdienende Tamilen kauften in diesen Gegenden Häuser. Doch während die Anzahl der tamilischen Hausbesitzer steigt, finden sich auch in diesen Stadtteilen zahlreiche Apartmenthäuser, in denen Tamilen unter oft sehr beengten Verhältnissen leben. Auch in Scarborough entwickelte sich ein lebhaftes soziales Leben in der tamilischen Community. Zahlreiche Geschäfte richten sich an tamilische Kunden, mehrere Tempel bieten Tamilen, die dem Hinduismus angehören, eine Anlaufstelle. Auch einige Organisationen verlagerten ihre Büros nach Scarborough.

21 Interview, Toronto, 23.4.2003. 
Die gerade Eingereisten wurden oft mit einer Unterkunft für die erste Zeit und Informationen über Arbeits- und Studienmöglichkeiten versorgt. Die folgende Erzählung eines kanadischen Tamilen kann als typisch für die erste tamilische Flüchtlingswelle gelten.

»The first time I came, actually it was a real wintertime [...]. When I went out of the airport I felt like I have to go back to India. I never realized this kind of weather. It was minus 20 or 25 at that time. Then I called my friends and they came. I contacted them before I left to India and then I said to them rjust actually I have arrived in Montreal . Then I stayed almost one month in Montreal. Then I contacted some friends in Toronto. They advised me and they said sif you stay in Montreal it will be difficult to find a job and to study because you have to take the exams in French. You better come to Toronto.< Then after one month I came to Toronto and I stayed here. I stayed with my friends in Toronto at the beginning.«22

Eines der wichtigsten Tauschgüter in der moralischen Ökonomie der Diaspora, so macht dieser Interviewausschnitt deutlich, sind Informationen. Dabei handelt es sich um sachbezogene Hinweise und die Weitergabe von praktischem Wissen. ${ }^{23}$ Eine wichtige Rolle in dem entstehenden Selbsthilfenetzwerk spielten dabei auch, wie die Aussage eines von Sandercock et al. zitierten Tamilen deutlich macht, die tamilischen Organisationen. Die »Tamil Eelam Society of Canada« (TESOC) beispielsweise bot Rechtsbeistand in Asylfragen an ${ }^{24}$ und fungierte als Kontaktvermittler zwischen den Neuankömmlingen und denjenigen, die schon länger in Kanada lebten. »The community organisation would say they would take care of them, so they wouldn't have to be detained in custody: then a recent arrival would undertake to help one person, feed and cloth, get metro

22 Interview, Toronto, 19.5.2003.

23 Die Bedeutung des Austausches von Informationen im Zusammenhang mit Migration wird von vielen Autoren hervorgehoben. Zum Zusammenhang von Kettenmigration und Informationsaustausch vgl. z. B. von Schorlemer (1997: Kapitel 5). Zur Risikominimierung durch Informationen in Migrationsnetzwerken vgl. Pries (2001: 35). Zum Austausch von Informationen als zentraler Netzwerkleistung allgemein vgl. Diewald (1991: 72).

24 Interview, Toronto, 30.4.2003. 
pass, etc, until the guy's got a job...then he does it for the next person. $\ll 25$

Der Interviewausschnitt verweist auf das vielen Hilfeleistungen zugrunde liegende Prinzip der generalisierten Reziprozität. Die Tauschpartner sind in diesem Selbsthilfesystem nicht genau bestimmt. Die Balance des Tausches wird nicht unter spezifizierten Individuen, sondern innerhalb der Gruppe der Tamilen erhalten, indem die Hilfe, die eine Person bei ihrer Ankunft in Toronto erhält, nicht direkt an den Helfenden zurückgegeben wird, sondern an einen anderen Hilfsbedürftigen.

In der eritreischen Diaspora in Frankfurt am Main ist eine ähnliche Dynamik beobachtbar. Frankfurt verfügte bei Beendigung des Bürgerkrieges 1991 mit 2.170 Personen über die größte »äthiopische" Gemeinde in Deutschland (Gebreyesus et al. 1991: 16). Angaben über die eritreische Gemeinde liegen für Frankfurt in diesem Zeitraum nicht vor. Schätzungen zufolge lebten aber im Großraum Rhein-Main (Frankfurt, Offenbach, Hanau, Darmstadt, Wiesbaden, Friedberg) etwa 4.000 Personen eritreischer Herkunft (Gebreyesus et al. 1991: 14).26 Gründe für die Konzentration im Rhein-Main Gebiet werden in der Nähe zum Frankfurter Flughafen, über den viele der Flüchtlinge einreisten, und der Arbeitsmarktlage in diesem Gebiet gesehen (vgl. Schmalz-Jacobsen/Hansen 1997). Den größten Anreiz für Eritreer ab einem bestimmten Zeitpunkt, sich in Frankfurt niederzulassen, dürfte jedoch die Tatsache gespielt haben, dass Frankfurt über eine relativ große eritreische Gemeinde verfügte. Aussagen wie die eines durch von Nolting zitierten Eritreers veranschaulichen diese Tatsache:

»Ich habe früher in Göttingen gewohnt, alleine in einer Ein-ZimmerWohnung. Ich hatte da eigentlich keine Freunde. Um die zu besuchen, bin ich dann immer in die anderen Städte gefahren. Aber das war kein Leben. Ich war ziemlich einsam ohne Landsleute...da fühlst du dich noch mehr als Ausländer. Niemanden zum Reden und so. Und dann habe ich mich entschlossen, nach Frankfurt zu gehen. Hier gibt es viele

25 Anonym zit. nach Sandercock et al. (2004: 13).

26 Weitere Ballungsräume befinden sich im Großraum Stuttgart (3.500) und im Großraum Rhein-Neckar - Mannheim, Ludwigshafen, Heidelberg und Viernheim - (1.200). 
Eritreer, und auf der Straße bin ich auch nur ein Ausländer unter vielen.«27

Die schon ansässigen Eritreer konnten oft als erste Anlaufpunkte genutzt werden. Dabei wird, wie die Antwort eines interviewten Eritreers zeigt, auf die sozialen Zusammenhänge vor der Migration zurückgegriffen: »Die ersten Leute, die du in einem neuen Land ansprechen kannst, sind die Leute von früher. $« 28$

In den meisten Fällen beruhten die Kontakte auf Verwandtschaft, oft boten aber auch Freundschaften oder frühere Nachbarschaft in Eritrea erste Kontakte. Der Migrationsprozess entwickelte demnach eine Eigendynamik, die in Form einer »Kettenmigration « (Heckmann 1992) zu einer verstärkten Zuwanderung nach Frankfurt führte. ${ }^{29}$ Im Vergleich mit kleineren Städ-

27 Yosef, zit. n. von Nolting (2002: 29).

28 Interview, Frankfurt, 14.12.2003.

29 Der Begriff der Kettenwanderung wurde zuerst von MacDonald und MacDonald (1964: 82) definiert. Friedrich Heckmann nahm den Begriff zur Abgrenzung gegen das in der Öffentlichkeit weit verbreitete Bild des entwurzelten Einwanderers (vgl. Kamphoefner 1984: 321) auf. Dabei versteht er unter Kettenwanderung "eine Form der Wanderung, in welcher Migranten soziale Beziehungen $\mathrm{zu}$ bereits Ausgewanderten, die im Herkunftskontext begründet sind, vor allem Verwandtschaft und (frühere) Nachbarschaft, für ihren Migrationsprozeß nutzen: von den Ausgewanderten erfahren sie über Chancen, erhalten Hilfe für ihre Reise, für das Finden von Arbeitsplätzen und Wohnungen, auch für die Anpassung an die neue Umgebung. Beziehungen aus dem Herkunftskontext werden in die Einwanderungsgesellschaft >verpflanzt< bzw. am neuen Ort wiedererrichtet.« (Heckmann 1992: 99) Von einigen Autoren wird die Kettenmigration als eigener Migrationstypus verstanden. So unterscheidet etwa Charles Tilly (1990: 88) zwischen fünf Migrationstypen: kolonialisierende Migration, erzwungene Migration, Migrationskreisläufe, Kettenmigration und Karrieremigration. In anderer Weise differenziert Goldscheider (1971: 71) vier Migrationsformen: Wanderungen von Individuen oder Gruppen von Individuen, Familienwanderungen, kettenähnliche Wanderungen und Massenmigration als Wanderungen substantieller Teile der Gemeinde. Nach der Einschätzung von Heckmann und anderen Autoren (vgl. 
ten waren die Eritreer in Frankfurt jedoch auch mit größeren Problemen konfrontiert. Dies galt besonders für die Wohnraumsituation, aber auch im Hinblick auf die Schulbildung konnten die Eritreer in Frankfurt als besonders benachteiligt gelten. Aufgrund der materiellen und ideellen Rahmenbedingungen des familiären Umfeldes in Frankfurt waren die Schulabschlüsse von eritreischen Jugendlichen durchschnittlich schlechter als in kleineren Städten (Schröder 2003a: 82).

In Reaktion auf diese Verhältnisse entstanden in Frankfurt unter Bezugnahme auf das traditionelle Organisationsprinzip "wefera" Systeme der kollektiven Selbsthilfe. Wefera bezeichnet ein soziales Versicherungssystem, das schon vor der italienischen Kolonisierung im Hochland Eritreas bestand. Auf Dorfebene wurden kollektive Arbeitseinsätze zur Unterstützung Bedürftiger geleistet. So wurde Witwen bei der Bestellung der Felder geholfen. Auch zum Bau neuer hidmo $o^{30}$ trug jeder Dorfbewohner mit Geschenken oder Hilfe bei. Schwangere wurden kollektiv betreut und Kranke gepflegt. Man konnte beim Ältestenrat um diese Hilfe bitten. (Gärtner 2001: 27-28). Von wefera können genauso wie im Fall der Selbsthilfesysteme der tamilischen Diaspora besonders die neu angekommenen eritreischen Flüchtlinge profitieren. Dies bestätigt die folgende Antwort eines Interviewpartners. »Es gibt ein funktionierendes soziales Gefüge in der eritreischen Gemeinschaft: Die Leute, die schon länger hier sind, helfen denen, die neu kommen. « 31

Neben dem Austausch von Informationen findet wefera in der Diaspora unter anderem Ausdruck in der Einrichtung zahlreicher Sparzirkel $(e k u b)$ und Sterbekassen. Letztere entspringen dem Wunsch vieler Eritreer nach einer Beerdingung im Heimatland. Die Kosten einer Rückführung sind jedoch mit ungefähr 5000 Euro sehr hoch und können nur von wenigen Familien aufgebracht werden. In die Sterbekassen werden monatlich kleine Geldbeträge eingezahlt. In Frankfurt wird die Sterbekasse von dem größten Verein der eritreischen Gemeinde der ma-

Han 2000: 12; Kritz/ Zlotnik 1992: 4) ist Kettenwanderung die wahrscheinlich quantitativ bedeutendste Form der Migration.

30 Als hidmo wird eine verbreitete Hüttenform in Dörfern des eritreischen Hochlandes bezeichnet.

31 Interview, Berlin, 10.12. 2003. 
habere $\operatorname{com}^{32}$ geführt. Etwa 30 Prozent der mahabere comMitglieder zahlen in die Sterbekasse ein. Stirbt ein Mitglied, erhält seine Familie den gesammelten Betrag und zwar unabhängig davon, ob der Gestorbene oder seine Familie selbst in die Kasse eingezahlt hat (Gärtner 2001: 45).

Ein ähnliches Prinzip liegt den $e k u b$, den genannten Sparzirkeln zugrunde. Auch ekub werden von Diasporamitgliedern im Hinblick auf traditionelle Handlungszusammenhänge beschrieben. Sparzirkel wurden schon im Vorkolonialen Eritrea abgehalten. Meist wurden sie von Frauen veranstaltet und »waren zugleich soziale Räume, bei denen bei Kaffee und Popcorn Neuigkeiten ausgetauscht wurden. Von dem Geld wurden hauptsächlich kleinere Luxusartikel wie Schmuck und Kleider gekauft« (Gärtner 2001: 46). Die ekub in Deutschland sind heterogener zusammengesetzt als in Eritrea. Zwar bestehen auch reine Frauen-ekub, doch kommen in den meisten Fällen Männer und Frauen zusammen. Auch die Altersstruktur ist gemischt. Allerdings sind Sparzirkel offensichtlich bei Jugendlichen besonders verbreitet. Das Verfahren ist immer gleich. Einmal wöchentlich (in manchen Fällen auch monatlich) treffen sich die Mitglieder des ekub in der Wohnung eines Mitgliedes und zahlen einen festgelegten Betrag ein. Am Ende des Monats wird das gesammelte Geld an eine Person ausgezahlt. Die Reihenfolge wird beim ersten Treffen - meist durch Auslosung - festgelegt (Gärtner 2001: 47).

Ähnlich wie in anderen Migrantengemeinden entstand auch in der eritreischen Diaspora die Idee, einen Kreditzirkel zu gründen, um informelle Kredite zur Gründung von Unternehmen vergeben zu können. ${ }^{33}$ Als Vorbild dienten in diesem Fall nicht traditionelle Vorformen, sondern die informellen Kreditpraktiken der Libanesen in Westafrika. Bei einer jeweiligen Eigenbeteiligung von 25 Prozent soll den Mitgliedern des Zirkels der Reihe nach ein Kredit gewährt werden, der ihnen die

32 »Mahabere« bedeutet Verein, die Abkürzung »com «steht für das englische »community«. »Mahabere com« lässt sich demnach mit Gemeindeverein übersetzen. $\mathrm{Zu}$ den »mahabere com« siehe auch Kapitel 6.2.

33 Für die Kreditzirkel der chinesischen und karibischen Migranten in den USA vergleiche Light (1972), vgl. auch Auster/Aldrich (1984: 48). 
Gründung eines Unternehmens erlaubt. Sobald ein Kreditnehmer mit seinem Unternehmen Gewinn erwirtschaftet, ist er verpflichtet seinen Anteil an den Krediten für die anderen Mitglieder des Zirkels zu erhöhen, so dass sich die Belastung für die übrigen Teilnehmer reduziert (Gebreyesus et al. 1991: 99).

Obwohl die gegenseitigen Unterstützungsleistungen in der Diaspora unter Bezugnahme auf das Prinzip wefera als lange Tradition dargestellt werden, die auf der Basis von geteilten Werten und moralischen Normen ausgetauscht werden, zeigen die oben aufgeführten Beispiele, dass die Selbsthilfeeinrichtungen durchaus auch dazu dienen, individuelle Interessen zu verfolgen. Die Norm der Gegenseitigkeit wird als traditionelle Handlungsanweisung gelebt aber auch benutzt (vgl. Gärtner 2001). Die Zugehörigkeit zur moralischen Ökonomie der Diaspora eröffnet dem Einzelnen eine Vielzahl von Ressourcen, die von Informationen bis zu finanzieller Unterstützung reichen.

\section{Die Transnationalisierung der moralischen Ökonomie}

Die Grenzen der moralischen Ökonomie fallen nicht notwendigerweise mit nationalstaatlich gefassten Grenzen zusammen. Die Mitglieder der Diaspora unterhalten typischerweise Kontakt mit Personen oder Gruppen des gleichen Hintergrundes sowohl in den Gastländern als auch im Herkunftsland und in anderen Migrationsländern. Sofern die reziproken Austauschprozesse der Diaspora nationalstaatliche Grenzen überschreiten, kann man daher auch von einer transnationalen moralischen Ökonomie sprechen.

Die bekannteste und wirtschaftlich bedeutsamste Form des moralökonomischen Austauschs zwischen Migranten und den Daheimgebliebenen sind die so genannten »labor remittances", Überweisungen, die von Arbeitsmigranten aus dem Ausland in ihre Heimatländer getätigt werden. In Staaten wie El Salvador, Marokko oder Jemen, beispielsweise, werden jährlich jeweils um die zwei Milliarden US-Dollar dieser im Ausland erzielten Einkünfte, überwiesen. Die rund acht Millionen Philippinos und Philippinas, etwa ein Zehntel der Gesamtbevölkerung, die als Arbeitsmigranten in Nordamerika, in Europa und in den 
Golfstaaten leben, überweisen rund die Hälfte ihrer Einkommen an ihre Familien, und selbst von den rund 200.000 Kriegsflüchtlingen aus Somalia, die seit dem Kriegsbeginn 1988 nach Europa oder in die Golfstaaten gelangt waren, flossen 1996 rund 140 Millionen US-Dollar in ihr Heimatland zurück (Pérouse de Montclos 2003: 167).

Aber auch im Rahmen der Ökonomien der gegenwärtigen Bürgerkriege entstehen grenzüberschreitende Austauschprozesse zwischen Migranten und den Akteuren der Bürgerkriege. Der wichtigste Anknüpfungspunkt für bewaffnete Gruppen ist zunächst der Bezug auf die gemeinsame »Heimat", wobei Heimat im Grunde einen "Nichtort « bezeichnet, »den man erst in der Fremde zu schätzen lernt. Das eigentliche Heimatgefühl ist das Heimweh. Erst Erinnerungen und Sehnsüchte machen den Ort zur Heimat, die man vermisst und die im Grunde nur eine Utopie ist« (von Nolting 2002: 87). In engem Zusammenhang mit der Sehnsucht nach der Heimat und dem damit verbundenen Wunsch nach Rückkehr steht die Frage nach der kulturellen Identität. Auf der vergemeinschaftenden Wirkung des Heimwehs aufbauend können bewaffnete Gruppen, so die These dieses Textes, in ihren Bemühungen um die Mobilisierung der Diaspora an die Schuldgefühle anknüpfen, die in der Diaspora gegenüber den im Heimatland Verbliebenen verbreitet sind, vor allem gegenüber den Kämpfern, die ihre Leben opfern für ein gemeinsames Ziel, die Erschaffung eines unabhängigen Staates.

\section{Heimat und Heimweh}

In der Erinnerung vieler Tamilen der ersten Einwanderergeneration wird Sri Lanka, meist die Halbinsel Jaffna, zu einem Paradies, in das sie in unbestimmter Zeit zurückkehren wollen. Dabei wird die idealisierte Vorstellung der Heimat mit der Situation der tamilischen Diaspora in Kanada verglichen. Gerade die erste Zeit in Kanada wird immer wieder als großer Schock dargestellt, der sich in den niedrigen Temperaturen des Landes versinnbildlicht. ${ }^{34}$ Dem gegenüber wird das Bild des tropischen Sri Lanka ausgemalt mit seinen Palmenhainen und paradiesi-

34 Z. B. Interview, Toronto, 19.5.2003, Interview, Toronto, 25.5.2003. 
scher Landschaft. Ein weiterer wichtiger Unterschied, der in einem Interview genannt wurde, ist der Verfall von Werten in der Diaspora im Vergleich mit der traditionalen Gesellschaft in Jaffna. ${ }^{35}$

In vielen Fällen wird die Rückkehr in die Heimat als ausdrücklicher Wunsch formuliert, jedoch an Bedingungen wie die Beendigung des Krieges geknüpft oder insgesamt in die Zeit des Ruhestandes geschoben. Oft werden auch die im Exil geborenen oder aufgewachsenen Kinder als Grund für den Verbleib im Exil "wider Willen" genannt. Wenn die Kinder erst selbständig seien, würde man nach Sri Lanka zurückkehren. So kann die folgende Antwort einer Tamilin auf die Frage, ob sie über eine Rückkehr nach Sri Lanka nachgedacht habe, als typische Antwort gelten: »You know one thing I was thinking more of, maybe I will go back when I am older.« ${ }^{36}$

Der Wunsch nach Rückkehr gerät zu einem unbestimmten Ziel in ferner Zeit. Doch die gemeinsame Utopie stärkt die Gemeinschaft der Diaspora. ${ }^{37}$

Eine ähnliche Dynamik lässt sich auch in der eritreischen Diaspora nachweisen. Der Gedanke an die Heimat und der Wunsch dorthin zurückzukehren, war besonders vor der Unabhängigkeit bei vielen EritreerInnen ausgeprägt, wurde aber von vielen Interviewpartnern auch für die Gegenwart zum Ausdruck gebracht. So gab etwa ein Interviewpartner an:

35 Interview, Toronto, 25.5.2003.

36 Interview, Toronto, 25.5.2003.

37 Nach dem 2001 in Kraft getretenen Waffenstillstandsabkommen und dem einsetzenden Friedensprozess reisten viele Exiltamilen nach Jaffna, um die Möglichkeit einer Rückkehr zu überprüfen. Keiner der dort interviewten »Besucher « konnte sich nach dem Aufenthalt vorstellen, tatsächlich wieder in Sri Lanka zu leben. $\mathrm{Ob}$ sich durch das Ende des Krieges und die durch den Besuch einsetzende Desillusionierung der Wunsch nach Rückkehr nachhaltig ändert, ist jedoch fraglich. Das Beispiel der eritreischen Diaspora zeigt, dass sich vor allem die Gründe für das Abwarten im Exil ändern. Wird während des Krieges die Kriegssituation angeführt, geht es später um die Stabilität der politischen Lage oder die Kinder, denen im Exil eine Ausbildung ermöglicht werden soll. Der Wunsch nach Rückkehr bleibt. 
»Unsere Anwesenheit hier ist rein förmlich. Unser alltägliches Leben ist mit der Heimat verbunden.«38

Eritrea wird in der Erinnerung bzw. in der Phantasie zum idealen Ort, auf den Sehnsüchte projeziert werden. Nicht selten auch beeinflusst durch die Propaganda der EPLF entstand in der Vorstellung der Diaspora-Mitglieder ein Bild Eritreas, das durch fruchtbare Landschaften und eine sehr gute Infrastruktur gekennzeichnet war. Eine Interviewpartnerin berichtet beispielsweise rückblickend: »Ich dachte zehn Jahre nachdem das Land befreit ist, wird es sein wie in Singapur. Sie haben so hart gearbeitet, Straßen gebaut...«39

Als Grund für den Bezug auf das Heimatland und die Entstehung einer eritreischen Identität werden unter anderem auch Diskriminierungserfahrungen angeführt:

»Die meisten Leute haben in der Pubertät erfahren, dass sie nicht hierher gehören. Das ist ein Alter, in dem man nicht auffallen will. Der Gedanke an deine Identität als Eritreer wird durch die Reaktion der Aufnahmegesellschaft immer wieder aufrechterhalten: Woher kommst $\mathrm{du} ? \ll 40$

Auch in der eritreischen Diaspora wurde ähnlich wie in der tamilischen Diaspora von vielen InterviewpartnerInnen der Wunsch geäußert, nach Eritrea zurückzukehren, und auch hier bezieht sich dieser Wunsch auf einen Zeitpunkt in unbestimmter Zukunft. Zunächst wurde der Zeitpunkt der Rückkehr auf das Ende des Krieges gesetzt und für viele Eritreer bestand kein Zweifel, dass nach der Unabhängigkeit eine große Rückkehrerwelle einsetzen würde. So kann etwa die Aussage eines kurz vor der Unabhängigkeit interviewten Eritreers als typisch gelten: »Was glaubst $\mathrm{Du}$, wenn Eritrea frei wird, keiner bleibt hier! $« 41$

Das Gefühl der Verbundenheit mit dem Heimatland und der Wunsch nach Rückkehr werden sowohl von der LTTE als

38 Interview, Frankfurt am Main, 14.12.2003.

39 Interview, Frankfurt am Main, 19.11.2003.

40 Interview, Berlin, 11.12.2003.

41 Dieser und die folgenden Interviewausschnitte stammen aus einer unveröffentlichten Magisterarbeit von Heike Bauer und sind hier zitiert nach Abraham Gebreyesus et al. (1991: 104). 
auch von der EPLF aufgenommen. In den Worten eines tamilischen Diasporamitglieds: »The diaspora has a common dream of return and the LTTE feeds that dream. «42

Die Förderung der Heimatverbundenheit zeigt sich deutlich in den zahlreichen kulturellen Veranstaltungen, die die LTTE und ihre Frontorganisationen ${ }^{43}$ in Toronto ausrichten. Neben der Aufführung von Theaterstücken und traditionellen Tänzen werden auf vielen Veranstaltungen der LTTE auch srilankische Speisen angeboten. Darüber hinaus bemüht sich die LTTE auch um die zweite Generation der Tamilen in Kanada, indem sie tamilischen Sprachunterricht anbietet und Heimatkundeunterricht erteilt. ${ }^{44}$ Auch die EPLF begann während ihres Befreiungskampfes kulturelle Veranstaltungen in der Diaspora auszurichten. Neben einem alljährlich in Bologna stattfindenden Festival, auf dem sich Eritreer aus ganz Europa versammelten, wurden in den Städten und Orten der jeweiligen Länder auch kleinere Veranstaltungen durchgeführt, auf denen eritreisches Essen verkauft und ein kulturelles Programm geboten wurden. Diese Veranstaltungen waren besonders ergiebige Einkommensquellen für die EPLF.

Das Interesse der beiden bewaffneten Gruppen, die Heimatverbundenheit der Diaspora aufrecht zu erhalten, lässt sich einfach erklären. Die Bindung an die Heimat ist die Basis der transnationalen Gemeinschaft. Lässt diese Bindung nach, so

42 Interview, Toronto, 6.5.2003.

$43 \mathrm{Zu}$ den verschiedenen Organisationen der LTTE in der Diaspora vergleiche die Fallstudie im folgenden Kapitel.

44 Den Unterricht benutzt die Gruppe dafür, den Kindern ihre Version der srilankischen Geschichte nahe zu bringen. Eine kritische Auseinandersetzung der Kinder und Jugendlichen wird dabei den Aussagen einer Interviewpartnerin zufolge verhindert. Nur wer die »richtige« Version der Geschichte in Aufsätzen aufbereitet bekommt gute Noten. Die Interviewpartnerin meldete ihren Sohn aufgrund dieser Praxis von dem Unterricht ab (Interview, Toronto, 19.4.2003). An diesem Beispiel wird ein Zwiespalt deutlich, der für viele Mitglieder der tamilischen Diaspora gilt. Die »Pflege« der tamilischen Identität, die von vielen Mitglieder als wichtig empfunden wird, ist so eng mit den Angeboten der LTTE verbunden, dass es kaum möglich ist, der Gruppe zu entgehen, selbst wenn die Ziele für die sie steht und ihre Praxis nicht geteilt werden. 
wird auch die transnationale moralische Ökonomie geschwächt und die Finanzierungsquellen eingeschränkt. Ohnehin kommt es in der Diaspora zu deutlichen Individualisierungsprozessen, wie etwa die folgenden Erläuterungen einer Tamilin nahe legen:

"I noticed most of the Sri Lankans here are more selfish than ever before. Myself, my family... they always talk about >my< and not the community anymore. It's my daughter, it's your son, it's my, my, my...They don't talk about the community. We lost our community sense. We are still together, but we lost the community. In Sri Lanka, if I do something, the whole community knows. In the sense they will correct you. When you are hanging around somewhere they will tell you. But here it's not because it's all my, my, my. «45

Es ist dieser Individualisierungsprozess, der sich ebenso in der eritreischen Diaspora abzeichnet, gegen den die bewaffneten Gruppen versuchen, mit ihren Veranstaltungen anzuarbeiten.

\section{Schuld und Sühne}

Das Gefühl der Schuld und Scham gegenüber den im Heimatland Zurückgelassenen ist trotz der oft schwierigen Lebensumstände, unter denen die Einwanderer leben, in der Diaspora weit verbreitet. Besonders jüngere Leute der ersten Einwanderergeneration solidarisieren sich stark mit den Kämpfern. Die folgende Aussage eines ehemaligen LTTE Kämpfers zu der Frage der Schuld kann als typisch für die jungen Männer der ersten Einwanderungswelle gelten, die häufig in einer der tamilischen Guerillaorganisationen gekämpft hatten oder kämpfen wollten und von ihren Familien ins Ausland geschickt wurden: »I have a lot of guilt feelings because I am safe here. People I trained have died, friends have died, are in prison: I feel bad on how much money we are spending here on movies etc. «46

Auch die folgenden Erinnerungen eines PFDJ Kaders machen das Gefühl der Schuld in einer ganz ähnlichen Rhetorik wie bei dem oben zitierten Tamilen deutlich:

45 Interview, Toronto, 25.5.2003.

46 Interview, Toronto, 23.4.2003. 
"In fact most of those in the Diaspora, or the cadres as we call it, our representatives they were not happy to stay in Europe. They were feeling a sort of guilty. They were saying I am here, eating and drinking and sleeping in a very good life in relation to the field, but my friends, my equals they are dying and they are living in hunger [...], all the problems you can face in the field. «47

In den Interviewausschnitten werden die Lebenssituation in der Diaspora und die der im Heimatland zurückgebliebenen, einander gegenübergestellt. Das Schuldgefühl der jungen Männer, das hier beschrieben wird, erwächst aus dem Ungleichgewicht der beiden Lebensumstände und der ungleichen Opfer, die für die gemeinsame "Sache« erbracht werden. Im Rahmen der transnationalen moralischen Ökonomie muss das Individuum eine Balance gegenüber drei Gruppen herstellen: der Diaspora, der bewaffneten Gruppe und der Bevölkerung im Heimatland. Die Tauschgüter, die die jeweiligen Gruppierungen in die Waagschale legen, sind unterschiedlich. Kann innerhalb der Diaspora noch ein Ausgleich erreicht werden, weil gleiche Güter eingebracht werden, etwa Lobbyarbeit oder finanzielle Unterstützung, ist die Herstellung eines Gleichgewichts gegenüber den Kämpfern und der Zivilbevölkerung im Kriegsgebiet schwieriger. Getauscht wird hier der Einsatz im Krieg gegen ein finanzielles oder politisches Engagement für das Heimatland. In dieser Beziehung bleiben die Gaben der Diasporamitglieder notwendigerweise immer unzureichend. Weder der heroische Einsatz der Kämpfer, noch das Leid der Zivilbevölkerung im Kriegsgebiet können adäquat durch das persönliche Engagement zurückgegeben werden. Dieses Gefühl wird auch im folgenden Interviewausschnitt deutlich: »Alle Beiträge sind nichts, wenn man die Opfer bedenkt und die Menschen, die für uns gestorben sind und für die Freiheit, die wir jetzt haben. «48

In den Schuldgefühlen der Diasporamitglieder gegenüber den im Bürgerkriegsland zurückgebliebenen drückt sich deutlich das Prinzip der generalisierten Reziprozität aus. In der Lesart der moralischen Ökonomie kann die Unterstützung von bewaffneten Gruppen durch die Diaspora auch als ein Versuch

47 Interview, Ahferom Tewelde, Asmara, 28.10.2003.

48 Interview, Frankfurt am Main, 4.12.2003. 
des Ausgleichs gegenüber den erbrachten Opfern der im Heimatland zurückgebliebenen verstanden werden.

Das Gefühl der Schuld wird von bewaffneten Gruppen in ihren Bemühungen, finanzielle Ressourcen in der Diaspora zu erschließen, geschickt aufgenommen und genährt. Den Aussagen verschiedener tamilischer Interviewpartner zufolge zielen viele Veröffentlichungen und Ansprachen der LTTE auf die Schuldgefühle der Diaspora ab und bieten implizit oder explizit Möglichkeiten der Sühne an. So gab etwa ein Interviewpartner an: »The LTTE plays on our guilt. They write: >You left the country and we are fighting $<\ldots \ll 49$

Auch in dieser Gegenüberstellung wird wieder die Bezugnahme auf die generalisierte Reziprozität deutlich. Es wird ein Ungleichgewicht angesprochen, in dem die Aufforderung zum Ausgleich implizit enthalten ist. Explizit wird die Forderung zum Ausgleich in zahlreichen Spendenaufrufen, Haustürsammlungsaktionen und im Rahmen der großen Festivals formuliert. Gleichzeitig veranschaulicht dieser Interviewausschnitt die Instrumentalisierung und Reimplementierung des Schuldgefühls der Diasporamitglieder durch die LTTE.

Der Bezug der EPLF auf die moralische Ökonomie der Diaspora und das System der generalisierten Reziprozität wurde ebenfalls in vielen Interviews sowohl mit Angehörigen der Diaspora, als auch mit Kadern der EPLF deutlich. »The people in the Diaspora they saw that Eritreans in the field were dying. So, everybody started to feel this and they said I must join and if I don't join I must do something. Especially for youngsters to stay behind is something like shameful.«50

Grundsätzlich wird in den Erzählungen der EPLF offensichtlich, dass die Gruppe darum bemüht war und immer noch ist, ein Bild des vollkommenen Zusammenhalts zu schaffen, das jedoch westlichen Werten wie Demokratie und Meinungsfreiheit Rechnung trägt.

"I can say 100 percent every Eritrean was in support of the armed struggle. But whether he supports EPLF or ELF differs. Whether he

49 Interview, Toronto, 6.5.2003, vgl. auch Interview, Toronto, 21.5. 2003.

50 Interview mit Ahferom Tewelde (PFDJ), Asmara, 28.10.2003. 
supports active or not it differs. So, there were differences in the role they were playing, whether too active, active or less active. But still every Eritrean was in support of the Eritrean struggle. You can ascertain this by the referendum that took place after independence immediately. It was 99 Prozent of the Eritreans. Even those 1 Prozent or point some percent they did it, because they didn't know how to vote. This tells you that Eritreans wherever they are - because the referendum was not only in Eritrea, it was in Sudan, it was in Ethiopia, it was everywhere and these people were free to say whatever they want - unanimously all Eritreans said >Yes< for Eritrea. This shows how Eritreans were coherent, how they were united in their quest for independence. They may differ politically, so natural, but concerning Eritrea there was no difference. This is our strength as Eritreans. All Eritreans, wherever they are, if there is an opportunity to support they are doing it. Deep in their heart every Eritrean was Eritrean, every Eritrean was in support of the armed struggle, every Eritrean was in support of independence. This was our strength.«51

Dabei wurden in der Rhetorik der EPLF die Rolle der Exileritreer und ihre Aufgabe in der eritreischen Gemeinschaft klar festgelegt. Die folgende Erzählung einer Eritreerin über ihre Zeit in der Revolutionsschule im Sudan macht diese Aufgabenteilung deutlich:

»Sie wollten auch nicht, dass jeder Kämpfer wird, sondern im Gegenteil. Bildung war das A und O bei denen. Das haben sie uns klipp und klar gesagt. Denkt bloß nicht zwei drei Jahre später, wenn ihr in der Pubertät seid, nach Eritrea zu fliehen. Sondern ihr müsst wirklich, wenn es irgendwie geht, ins Ausland gehen und dort Eure Schule fertig machen, das Land braucht Euch auf jeden Fall. Es hat keinen Sinn, dass wir kämpfen und keiner baut das Land auf.«52

\section{Zusammenfassung und Fazit}

Viele bewaffnete Gruppen, die in den Bürgerkriegen der Gegenwart kämpfen, greifen im Rahmen ihrer materiellen Reproduktion auf finanzielle Ressourcen aus der Diaspora zurück. Dabei können sie an Systeme der gegenseitigen Hilfe anknüp-

51 Interview mit Ahferom Tewelde (PFDJ), Asmara, 28.10.2003.

52 Interview, Frankfurt, 8.12.2003. 
fen, die in der Diaspora als Antwort auf die prekäre Situation des Exils besonders in der ersten Zeit nach der Flucht entstehen und die hier als moralische Ökonomie der Diaspora bezeichnet wurden. Die moralische Ökonomie der Diaspora ist nicht notwendigerweise auf die Exilländer beschränkt sondern bezieht häufig auch die Herkunftsländer mit ein. In diesem Papier wurde argumentiert, dass ein wichtiger Anknüpfungspunkt, der sich bewaffneten Gruppen im Rahmen dieser transnationalen moralischen Ökonomie bietet, die Schuldgefühle sind, die viele Diasporamitglieder gegenüber den im Heimatland verbliebenen Verwandten, Freunden und insbesondere gegenüber den Kämpfern empfinden. Diese Schuldgefühle werden von den bewaffneten Gruppen genährt und genutzt. Sie und die Möglichkeit zur Sühne stellen den zentralen Mechanismus der Mobilisierung der Diaspora durch bewaffnete Gruppen dar.

Die Interviewausschnitte aus der tamilischen und eritreischen Diaspora machen deutlich, dass die Einsichten in die moralische Seite der Ökonomie der Diaspora nicht dazu verleiten dürfen, sie zu romantisieren. In der Not des Exils ist das freiwillige Angebot von Hilfe von Zwang schwer zu unterscheiden. Denn je prekärer die Lage in der Fremde ist, desto größer ist der soziale Druck, sich den Regeln und Erwartungen der Gemeinschaft zu beugen. Wie fast immer, so lässt sich die praktizierte Solidarität auch in diesem Fall sowohl als selbstlose Hilfe, als funktionale Erfordernis oder aber als Praxis der symbolischen Selbstaufwertung interpretieren. Die moralische Ökonomie der Diaspora ist außerdem kein lückenlos funktionierendes Hilfswerk. Sie erfasst nicht alles und jeden, und ihre Exklusionsmechanismen sind nicht weniger rigide als die entwickelter Staaten. Die Gerechtigkeit, die sie praktiziert, ist nicht egalitär und auch nicht über Verfahren einklagbar. Ihr haftet etwas Willkürliches und Unausweichliches an. Dennoch sind die Versuche bewaffneter Gruppen, die moralische Ökonomie der Diaspora politisch zielgerichtet unter Kontrolle zu bringen, nicht einfach als kriminelle Strategie zu denunzieren. Denn die Institutionalisierung dieses Feldes, die durch die Politik bewaffneter Gruppen einsetzt, schafft auch Erwartungsverlässlichkeit und Eindeutigkeit. Auch schließt sie die Solidarität persönlicher Beziehungen nicht aus. Ihr Modus, die politische Indienstnahme von sozialen Beziehungen, ist schließlich jeder 
Form von politischer Herrschaft eigen. Und wie stark der Druck und die Sanktionsmöglichkeiten bei Nichtbefolgung der politischen Absichten ist, hängt nicht zuletzt von den Chancen alternativer sozialer Integration ab, die von den Gastländern der Exilanten definiert werden. Wo rechtsstaatliche Appelations- und Schutzinstanzen fehlen, unterscheidet sich das racket der bewaffneten Gruppen nicht von den Mechanismen anderer Akteure, die Werte appropriieren (Radtke/Schlichte 2004).

\section{Literatur}

Anderson, Benedict (1992): Imagined Communities. Reflections on the Origin and Spread of Nationalism, London: Verso.

Auster, Ellen/Aldrich, Howard (1984): »Small Business Vulnerability, Ethnic Enclaves and Ethnic Enterprise«. In: Robin Ward/Richard Jenkins (Hg.), Ethnic Communities in Business. Strategies for Economic Survival, Cambridge: Cambridge University Press, S. 39-54.

Bundesanstalt für Arbeit (1983): Ausländische Beschäftigte. Äthiopien 1986-90, LOO1 ATOS.

Chalmers, Thomas (1832): On Political Economy, in Connection with the Moral State and Moral Prospects of Society, Glasgow: Collins.

Charlesworth, Andrew/Randall, Adrian (2000): »The Moral Economy: Riot, Markets and Social Conflict «. In: dies. (Hg.), Moral Economy and Popular Protest: Crowds, Conflict and Authority, Großbritannien: Macmillan Press Ltd., S. 1-32.

Daniel, Valentine/Thangaraj, Yuvaraj (1995): »Forms, Formations, and Transformations of the Tamil Refugee«. In: Valentine Daniel/John Kundsen (Hg.), Mistrusting Refugees, Berkley: University of California Press, S. 225-256.

Diewald, Martin (1991): Soziale Beziehungen - Verlust oder Liberalisierung. Soziale Unterstützung in informellen Netzwerken, Berlin: edition sigma.

Faist, Thomas (2000): Transstaatliche Räume: Politik, Wirtschaft und Kultur in und zwischen Deutschland und der Türkei, Bielefeld: Transcript.

Gärtner, Kathrin (2001): Verborgene Dynamiken - Sozioökonomische Netzwerke von Eritreern in Deutschland, Magis- 
terarbeit, Institut für Ethnologie, Freie Universität Berlin (unveröffentlichtes Manuskript).

Gebreyesus, Abraham/Ghebre, Ghidey/Schröder, Günter/Zerai, Freweini (1991): Eritrea: Personelle Zusammenarbeit. Studie zum eritreischen Fachkräftepersonal, Zentralstelle für Arbeitsvermittlung.

Goldscheider, Calvin (1971): Population, Modernization and Social Structure, Boston: Little Brown and Company.

Gottstein, Margit/Richter, Franz-Helmut/Ruet, Catherine/ Thoß, Gabriele (1992): »Tamilen aus Sri Lanka in Deutschland «. In: Berliner Institut für Vergleichende Sozialforschung (Hg.), Handbuch ethnischer Minderheiten in Deutschland, Berlin: Edition Parabolis, S. 1-14.

Han, Petrus (2000): Soziologie der Migration. Erklärungsmodelle, Fakten, Politische Konsequenzen, Perspektiven, Stuttgart: Lucius \& Lucius.

Heckmann, Friedrich (1992): Ethnische Minderheiten, Volk und Nation: Soziologie inner-ethnischer Beziehungen, Stuttgart: Enke.

Kamphoefner, Walter. D. (1984): »'Entwurzelt< oder >verpflanzt ?? Zur Bedeutung der Kettenwanderung für die Einwandererakkulturation in Amerika«. In: Klaus. J. Bade (Hg.), Auswanderer, Wanderarbeiter, Gastarbeiter. Bevölkerung, Arbeitsmarkt und Wanderung in Deutschland seit der Mitte des 19. Jahrhunderts, Ostfildern: Scripta Mercaturae Verlag.

Kritz, Mary M./Zlotnik, Hania (1992): „Global Interactions. Migration Systems, Processes, and Policies«. In: Mary M. Kritz/Lin L. Lim/Hania Zlotnik (Hg.), International Migration Systems, Oxford: Clarendon Press, S. 1-18.

Light, Ivan (1972): Ethnic Enterprise in America, Berkeley: University of California Press.

MacDonald, Beatrice D./MacDonald, John S. (1964): „Chain Migration, Ethnic Neighborhood Formation and Social Networks«. Milbank Memorial Fund Quarterly, 42, S. 82-97.

Mauss, Marcel (1989): »Die Gabe. Form und Funktion des Austauschs in archaischen Gesellschaften «. ders., Soziologie und Anthropologie, Band 2, S. 9-144. 
McDowell, Christopher (1996): A Tamil Asylum Diaspora: Sri Lankan Migration, Settlement and Politics in Switzerland, Providence: Berghahn Books.

Ornstein, Michael (2000): Ethno-Racial Inequality in the City of Toronto: An Analysis of the 1996 Census, Toronto: York University.

Pérouse de Montclos, Marc-Antoine (2003): Diaspora et terrorisme, Paris: Presse de Sciences Po.

Perry, Ralph (1909): The Moral Economy, New York: C. Scribner's Sons.

Pries, Ludger (2001): Internationale Migration, Bielefeld: transcript.

Radtke, Katrin/Schlichte, Klaus (2004): »Bewaffnete Gruppen und die moralische Ökonomie der Diaspora«. In: Jens Beckert u.a. (Hg.), Transnationale Solidarität - Chancen und Grenzen, Frankfurt/M.: Campus, S. 181-194.

Sahlins, Marshall (1972): Stone Age Economics, Chicago: Aldine and Atherton.

Sandercock, Leonie/Dickout, Leslie/Winkler, Ranja (2004): The Quest for an Inclusive City: An Exploration of Sri Lankan Tamil Experience of Integration in Toronto and Vancouver, RIIM Working Paper, Nr. 04-12, Vancouver Center of Excellence.

Schiewer, Heike (1999): »Stadtplanung in einer multikulturellen Gesellschaft: Planerisches Rollenverständnis und Planungsprozesse in Toronto/Kanada«. Dortmunder Beiträge zur Raumplanung, Nr. 88, Institut für Raumplanung, Universität Dortmund.

Schmalz-Jacobsen, Cornelia/Hansen, Georg (Hg.) (1997): Kleines Lexikon der ethnischen Minderheiten in Deutschland, München: Beck.

Schröder, Günter (2003): Äthiopier und Eritreer in Deutschland 2002, unveröffentlichtes Manuskript.

Schröder, Günter (2003a): Eritreer in Deutschland - Materialien für eine Soziographie, überarbeitete und aktualisierte Version von 1992, unveröffentlichtes Manuskript.

Scott, James (1976): The Moral Economy of the Peasant: Rebellion and Subsistence in Southeast Asia, New Haven/London: Yale University Press. 
Thompson, Edward P. (1971): »The Moral Economy of the English Crowd in the 18th Century«. Past and Present 50, S. 76136.

Thompson, Edward P. (1993): »The Moral Economy of the English Crowd in the Eighteenth Century «. ders., Customs in Common, New York: New Press, S. 185-258.

Thompson, Edward P. (1993a): »The Moral Economy Reviewed «. In: ders., Customs in Common, New York: New Press, S. 259-351.

Tilly, Charles (1990): »Transplanted Networks«. In: Virginia Yans-McLaughling (Hg.), Immigration Reconsidered. History, Sociology, and Politics, Oxford: Oxford University Press, S. 79-95.

von Nolting, Nina (2002): »Gemeinschaft im Exil: Eritreische Flüchtlinge in Frankfurt am Main«. Arbeitspapiere, Nr. 11, Institut für Ethnologie und Afrikastudien, J. Gutenberg Universität Mainz.

von Schorlemer, Georg (1997): Die netzwerkbezogene Kettenmigration unter besonderer Berücksichtigung der migrationsfunktionalen Aspekte von Unterstützungsleistungen in sozialen Netzwerken, Berlin: Dr. Thomas Gerstmeyer Verlag.

Wayland, Sarah (2002a): Nationalist Networks and Transnational Opportunities: The Sri Lankan Tamil Diaspora, unveröffentlichtes Manuskript.

Wayland, Sarah (2002b): Immigration and Transnational Political Ties: A Comparison of Croatians and Sri Lankan Tamils in Canada, unveröffentlichtes Manuskript. 


\section{Palästinensische Flüchtlingslager}

neu denken: Von Abhängigkeit zu

\section{ziviler Selbstverwaltung}

PHILIPP MISSELWITZ

Abbildung 1

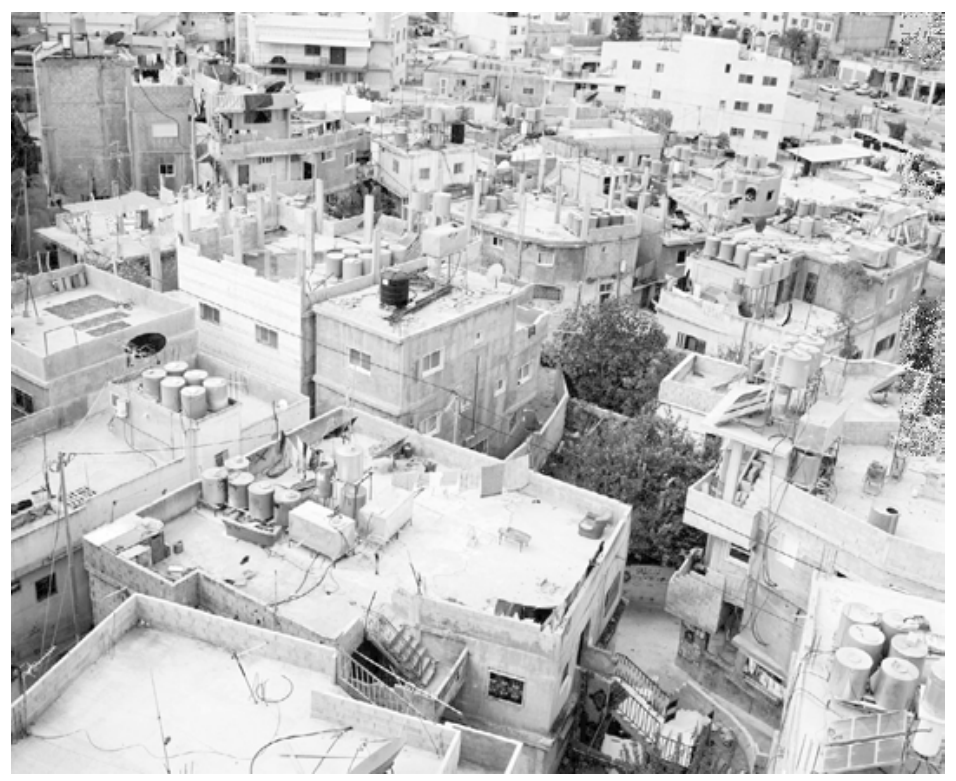

Foto Armin Linke: Flüchtlingslager Al Amari, Westbank 


\section{Urbanisierte Flüchtlingslager}

Flüchtlingslager werden im Allgemeinen als notwendige Übergangssituation begriffen, die für den Schutz und Unterbringung von vertriebenen Menschen eingerichtet wurden - von Technokraten entworfen, von einer humanitären Organisationen geführt und vom Militär beschützt. In Diskursen von Architekten und Stadtplanern finden Flüchtlingslager kaum Erwähnung und wenn doch, dann meist im Sinne einer Perfektionierung der vorübergehenden Notfallstrukturen. Ein Besuch in einem der weltweit existierenden Flüchtlingslager zeigt allerdings eine wesentlich komplexere Realität, die uns zwingt, unsere Vorstellung davon zu überdenken. Anstelle einer vorübergehenden Situation finden wir ein Szenario vor, das de facto auf Dauer eingerichtet ist und sich einer Auflösung widersetzt. Statt geordneter Zeltstädte treffen wir auf Straßen, Märkte, Läden und öffentliche Gebäude, die von einem Dickicht improvisierter Gebäude umgeben sind: Ein urbanes Gebiet, das sich von der restlichen Umgebung nur noch durch eine gehisste UN-Flagge oder durch Logos von internationalen NGO's unterscheiden lässt. Wir sind konfrontiert mit einem hybriden Raum, der irgendwo zwischen Notlager und Stadt rangiert.

Ein genauer Blick auf die Entwicklung der Flüchtlingslager zeigt, dass dieser Zwischenzustand mit fast sofortiger Wirkung entsteht. Sobald erste Formen der Normalität einsetzen, manchmal nur Wochen oder Monate nach der Ankunft, passen sich die Flüchtlinge ihrer neuen Umgebung an und werden $\mathrm{zu}$ Lagerbewohnern. Sie werden zu Experten, was das Überleben mit geringsten Mitteln angeht, sie improvisieren, behelfen sich mit allem, was vor Ort als brauchbar verwendet werden könnte und transformieren damit in kürzester Zeit den physischen, räumlichen, sozialen und ökonomischen Zustand ihrer anfänglichen Notsituation. Zelte werden umgestaltet, erweitert oder durch stabilere Strukturen ersetzt. Provisorische Tische mit Verkaufsgegenständen verwandeln sich in Läden. Ethnographen, Geographen oder Ethnologen haben angefangen diese hybriden Situationen in den Lagern zu erforschen und entwickelten neue konzeptionelle Modelle wie »Virtual Cities" (Perouse de Montclos/Kagwanja 2000) oder "Camp Cities« (Agier 2008). Viele dieser Untersuchungen waren von der Mo- 
tivation geleitet, bei den humanitären Organisationen und Geldgebern ein Bewusstsein für die aktuellen Bedürfnisse der verarmten, dicht besiedelten und Slum-ähnlichen Siedlungen zu schaffen. Von den zuständigen Organisationen wurde jedoch die Realität der urbanisierten Lager nur sehr zögerlich anerkannt. In vielen Fällen wurden progressive Maßnahmen von Seiten der Regierungen der Aufnahmeländer - manchmal auch von den Flüchtlingsgemeinschaften selbst - blockiert, aus Angst vor einer Normalisierung, bzw. davor, das Flüchtlingslager zu permanenten Städten werden könnten. Für viele ist daher das Konzept der »Camp Cities« ein Tabuthema.

In diesem Beitrag möchte ich am Beispiel der palästinensischen Flüchtlingslager im Mittleren Osten, »Camp Cities « in einen stadtplanerischen Kontext stellen. Palästinensische Flüchtlingslager sind weltweit die ältesten offiziellen Flüchtlingslager. Mit der Entwicklung von Zeltstädten zu Kasbahähnlichen Strukturen ${ }^{1}$ verkörpern palästinensische Flüchtlingslager eines der stringentesten Beispiele für den globalen Trend in Richtung "Camp Urbanisierung «. Der Beitrag beginnt mit einer kurzen Einführung in die historische Entwicklung der Palästinensischen Flüchtlingslager von Zeltstädten zu einigen der am dichtesten besiedelten Orte der Welt, die für viele jüngere Flüchtlingslager aufzeigen könnte, was die Zukunft für sie bereithält. Im Folgenden möchte ich die Konzeptionalisierung und Anwendung einer Stadtplanungsmethode vorstellen, die erstmalig von Flüchtlingen selbst mitgestaltet wurde. Der Beitrag beruht dabei auf direkten Erfahrungen des Autors bei der Entwicklung und Durchführung eines Pilotplanungsprojekts, das als Teil eines größeren Forschungsprojekts des SIAAL "Department for Planning in Asia, Africa and Latin Amerika" von der Universität Stuttgart durchgeführt und von der »United Nations Relief and Works Agency « (UNRWA) (2006-2008) in Auftrag gegeben wurde. Ich möchte mit diesem Beitrag die These aufstellen, dass obwohl urbanisierte Flüchtlingslager außergewöhnliche Orte sind, da sie zu den weltweit instabilsten, übervölkertsten und inhumansten Wohnumfeldern gehören,

1 Kasbah (arabisch): hoch verdichtete, teppichartige Bebauungsstruktur; typisch für traditionelle Stadtzentren im arabischen Raum. 
viele Gemeinsamkeiten mit den informell gewachsenen Slums vorherrschen, die den Großteil jeder urbanen Umgebung weltweit ausmachen. Die historische Entwicklung der drei im Beitrag angeführten palästinensischen Flüchtlingslager in der Westbank, wie auch ihre derzeitigen Herausforderungen, entsprechen trotz offensichtlicher Differenzen vielfach den Problemen von klassischen Slums. Es scheint daher ebenso angemessen wie einleuchtend, eine Brücke zu schlagen zwischen dem vergleichsweise neuen Diskurs über urbanisierte Flüchtlingslager und den bereits existierenden, reichhaltigen Erfahrungen im Umgang mit informeller Urbanisierung. Mehr als vier Dekaden intensive Beschäftigung mit informeller Urbanisierung ergab Einblicke in die Improvisationsfähigkeiten, Widerstandsfähigkeit und in die Bewältigungsstrategien innerhalb informeller Viertel und zeigen wie diese Praktiken für die Rehabilitation und Verbesserung von Slums genutzt werden können. Diese Erfahrungen liefern wertvolle konzeptionelle und operationelle Werkzeuge zur Anwendung auf die Bedürfnisse von »Camp Cities«.

\section{Von Flüchtlingslagern zu »Camp Cities «: 60 Jahre palästinensische Flüchtlingslager}

Palästinensische Flüchtlingslager sind die Folge des ArabischIsraelischen Krieges. Nach dem Abzug der Briten aus Palästina im Mai 1948 entlud sich die bereits seit Jahrzehnten anhaltende Spannung und Gewalt in einem großflächigen Krieg. Berichte von Gewalt und Massaker verbreiteten sich schnell und dreiviertel der eine Million arabischen Palästinenser begaben sich auf die Flucht. Dabei ließen sie sich so nah wie möglich zum Land ihrer Vorfahren nieder. Bewohner der südlichen Gebiete flohen meist in die südliche Westbank oder in den GazaStreifen, Bewohner aus dem Norden nach Südlibanon oder Syrien. Die meisten Flüchtlinge hingegen gingen in das Königreich Jordanien (ehemals britisches Mandatsterritorium von Transjordanien). Ungefähr 100.000 arabische Palästinenser blieben zurück und wurden später als Minderheit in den neu geschaffenen Staat Israel integriert. Die Ereignisse von 1948 werden von den Palästinensern als »Nakbah« bezeichnet, was in 
Arabisch »Katastrophe« heißt. Die »Nakbah« von 1948 war aber nicht der einzige Auslöser für palästinensische Vertreibung und Zerstreuung in den Ländern des Mittleren Ostens. Eine zweite Fluchtwelle von Gaza in die Westbank folgte nach dem SechsTage-Krieg 1967, als Israel das jordanische Ostjerusalem annektierte und die bis heute anhaltende Okkupation von Gaza und der Westbank begann. Am Beispiel der drei Fallstudien in der Westbank zu den Flüchtlingslagern Amari, Deheishe und Fawwar, gibt dieser Beitrag einen Überblick zu den Entwicklungsphasen, die das 60 Jahre anhaltende Wachstum der Flüchtlingslager in der Westbank markieren. ${ }^{2}$ Vier Entwicklungsphasen können den einzigartigen Prozess von den Zeltsiedlungen zu den heute extrem dicht besiedelten urbanen Zentren aufzeigen.

\subsection{Die Herausbildung einer räumlichen und sozialen Ordnung in Amari, Deheishe und Fawwar (1948-1955)}

Der Übergang vom nomadischen Umherziehen der Flüchtlinge hin zur Formierung von festen Flüchtlingslagern dauerte in etwa zehn Jahre. Während dieser ersten schwierigen Jahre versuchten die internationalen Hilfsorganisationen dieses Chaos zu bewältigen und handelten vorrangig reaktiv. Zunächst lieferte das Rote Kreuz mehr oder weniger spontan Zelte an Orte, wo sich größere Gruppen von Flüchtlingen niederließen. Dies wiederum zog mehr Flüchtlinge an, da man sich dort Zugang zu humanitären Hilfsmaßnahmen und Schutz vor zum Teil feindlichen gesinnten lokalen Anwohnern von den internationalen Hilfsorganisationen versprach. Nichts deutet darauf hin, dass die eigenartige Verteilung der Flüchtlingslager in der Westbank einem zentralen Masterplan entsprach. Vielmehr ist anzunehmen, dass im Fall von Fawwar und Deheishe (wie auch für viele andere Flüchtlingslager in der Westbank) Flüchtlinge selbst den Ort der ersten Ansiedlung bestimmten. Offenbar wa-

2 Der Beitrag basiert auf den Resultaten des zweijährigen Forschungsprojekts von SIAAL der Universität Stuttgart in Kooperation mit der UNRWA, vgl.: »Camp Development Pilot Research Project - Main Research Report«, interne Veröffentlichung der UNRWA. 
ren einige lokale Faktoren ausschlaggebend, wie die Verfügbarkeit über Wasser (Fawwar), die Nähe zu einer Straße (Deheishe, Fawwar) und die Einstellung der Nachbardörfer den Flüchtlingen gegenüber (einige von ihnen waren mehr gastfreundlich als andere). Im Fall von Amari war wahrscheinlich die Entscheidung für den Ort des Lagers durch eine kollektive Absprache zwischen den lokalen Stadt- und Dorfgemeinden und den privaten Landbesitzern bestimmt, um den ständigen Zustrom von Flüchtlingen in die Städte Al-Bireh und Ramallah zu stoppen.

Aufgrund eines fehlenden koordinierten regionalen Katastrophenplans in den Jahren nach 1948 erscheint es wahrscheinlich, dass die Aufnahmefähigkeit eines jeden Flüchtlingslagers durch lokale Faktoren bestimmt wurde. Traditionelle soziale Beziehungen bestimmten die interne räumliche Organisation. Nach der Ankunft in einem Flüchtlingslager gruppierten sich die Flüchtlinge nach ihrem Herkunftsort oder gemäß der Familienzugehörigkeit und stellten so die ehemaligen Dorf- und/ oder Familienstrukturen (hosh) wieder her. Das Prinzip der traditionellen Familienunterstützung versprach Sicherheit in Zeiten der Not und der Krise. Die vorher existierenden sozialen und räumlichen Beziehungen wurden so akkurat wie möglich reproduziert, was zur Entstehung von Familiencluster auf Mikroebene und zur Formierung von »Vierteln« als größere Organisationseinheiten innerhalb der Flüchtlingslager führte.

Die ältesten zur Verfügung stehenden Aufzeichnungen sind archivierte Pläne, die die Aufstellung der Zelte und der selbstgebauten Unterkünfte wiedergeben, die die UNRWA 1950 vom Roten Kreuz übernahm. Eine Analyse dieser Pläne ergab, dass das Land im Flüchtlingslager ungleich verteilt war. Die ersten Aufzeichnungen für Amari zum Beispiel zeigen sehr unterschiedliche Anwohnerdichten: mit einem geräumigeren Cluster der Lydd- und Lifta-Flüchtlinge und einem sehr dichten $\mathrm{Na}^{\prime}$ ani Cluster. Diese unterschiedliche Dichte ist bis heute vorhanden. Für Deheishe und Fawwar sind die Aufzeichnungen weniger aussagekräftig, da dort nur die Standorte von Steinhäusern festgehalten wurden (Zeltunterkünfte wurden nur in ihrer Gesamtzahl angegeben). Aber sogar hier können Cluster mit unterschiedlicher Dichte ausgemacht werden. Die ungleiche Anordnung weist auf die Präsenz einer komplexen integrierten 
und differenzierten sozial-räumlichen Ordnung hin. Obwohl dies dem egalitären Anspruch humanitärer Organisationen (gleiche Landverteilung etc.) widerspricht, wurde indirekt das Vorhandensein unterschiedlicher Viertel im Flüchtlingslager hingenommen und damit bestätigt.

Die plausibelste Erklärung für die ungleiche Landverteilung (die Formierung von weniger und stärker besiedelten Vierteln) muss im Zusammenhang mit den speziellen Machtbeziehungen zwischen verschiedenen Klans, Familien und Herkunftsdörfern gesehen werden. Folgt man dieser Annahme könnten geräumigere Viertel als »stärker" im Sinne von sozialen Status und Macht bezeichnet werden als dichtere und damit »schwächere« Viertel. Im Lager von Amari war es zum Beispiel allgemein bekannt, dass die Mitglieder des Lifta-Klans sehr gute Beziehungen in Ramallah und Al-Bireh besaßen. Es ist anzunehmen, dass diese Machtbeziehungen bei der Sicherung von besser positionierten und geräumigeren Territorien innerhalb des Lagers eine signifikante Rolle spielten. Familien aus Lydd und Dir Tarif waren ebenfalls zahlreich und mächtig und konnten dadurch auch ihre eigenen Viertel bilden. Fragmentierte kleinere Familien von Na'ani oder Ramleh hingegen konnten keine größeren Stammesnetzwerke formieren und blieben im dichten Zentrum des Flüchtlingslagers.

In dieser frühen Phase der Flüchtlingslager wurden bereits die entstandenen sozialen Cluster öffentlich anerkannt und als "Viertel« (hara) oder Blocks bezeichnet. Untersuchungen ergaben, dass in Amari, Deheishe und Fawwar die Formierung von Vierteln ähnlich strukturiert war. Amari und Deheishe bestehen aus acht Vierteln, Fawwar besitzt neun. Neben der Tatsache, dass die Viertel spezielle Namen tragen hatten sie folgende Gemeinsamkeiten:

Erstens, sie waren räumlich eindeutig definiert. Vorher existierende Straßen, Flurgrenzen und Feldwege machten die natürlichen Grenzen zwischen den Vierteln aus. Sowohl in Deheishe als auch in Amari wurde eine bereits existierende Straße zum Zentrum des Lagers, um das sich die verschiedenen Viertel herum anordneten. Die Lagerbewohner machten sich die existierende Infrastruktur zu Nutze und bauten diese auf eine pragmatische, fast organische Weise aus. Zweitens, in jedem Viertel bildeten sich repräsentative Strukturen heraus. Jedes 
Viertel wurde von einem »Führer « repräsentiert, der im Namen des Clans oder des Herkunftsortes auftrat und in Konfliktfällen vermittelte. Diese Position hatte je nach Umständen normalerweise der Dorfälteste (kabeer alqariyah) oder ein einflussreiches und respektiertes Familienoberhaupt (kabeer alaileh) inne. In den meisten Vierteln wurden so genannte dawaween (Klubs für Männer vom selben Klan oder Herkunftsort) und/oder andere gemeinnützige Räume für formelle Treffen und zur Unterbringung von Besuchern eröffnet. Für einzelne Flüchtlinge und kleinere Familien wurde das gemischte Viertel (das den Namen des Dorfes Na'ani trägt) ein Ersatz für die hamule, und bot ihnen Schutz und eine neue Identität. Die Straßen des Viertels wurden für Feste, wie sahare Nächte (Feier vor der Heirat) oder Beerdigungen, genutzt. Drittens, die Viertel waren durch mehr oder weniger stark geschlossene soziale und kulturelle Grenzen bestimmt. Vor allem in Amari war die soziale Interaktion zwischen den Lagerbewohnern vom traditionellen gegenseitigen Misstrauen zwischen ehemaligen Dorfbewohnern (fallahin) und Stadtbewohnern (maddani) bestimmt. In anderen Flüchtlingslagern in der Westbank, wie beispielsweise in Jenin, gab es zusätzliche Spannungen zwischen den Flüchtlingsgruppen und den Beduinen. Im beengten Amari führten die kulturellen Unterschiede zwischen dem urbanen Lebensstil und den traditionellen Sitten zu besonderen Schwierigkeiten. Die durch diese "Zwangsehe« entstandenen Spannungen wurden von Amaris Camp Service Officer, ein von UNRWA angestellter lokaler Hilfskoordinator, wie folgt beschrieben:

"In the early years of life in camp, one could easily sense the tension and cultural segregation. Amari's refugees came from different Palestinian cities and villages with different cultures. The camp brought together Palestinians from both rural and urban areas. Palestinians from the town of Lyd found themselves sharing the same spaces with farmers from the small villages of Saris, $\mathrm{Na}^{\prime}$ ani, and Almalha. Refugees from Lyd and Ramleh felt superior and more sophisticated than the rural refugees. The cultural division dominated and affected camp life until the early 1980s. New generations were born in the camps, and this gradually diminished the social differences and cultural segregation. $\ll^{3}$

3 Interview mit Ghaleb Al Bess, Amari CSO, 31. Juli 2006. 
Frühe Pläne der Flüchtlingslager zeigen zudem, dass innerhalb der Viertel weitere sozial-räumliche Mikro-Ordnungen von Familiencluster entstanden waren. Mitglieder einer bestimmten Familie (oft mehrere Generationen) fanden sich auf der Grundlage eines gemeinsamen Herkunftsdorfes oder einer Heimatstadt zusammen und reproduzierten kleine hosh-ähnliche Cluster, die wiederum ein Sub-Ordnungysystem innerhalb der Viertel darstellten. Diese räumlichen Mini-Cluster entstanden anfangs durch die kreisförmige oder block-mäßige Anordnung der Zelte vom Roten Kreuz. In den folgenden Jahren wurden sie durch den zusätzlichen Anbau von selbstgebauten Lehmoder Steinhäusern zum Schutz vor harten Wintern verstetigt. Die meisten dieser selbstfinanzierten Häuser hatten dünne Dächer und variierten je nach familiärer finanzieller Situation in Größe und Qualität. Oft umfasste ein Familiengrundstück kleine Felder oder Weideflächen, von niedrigen Mauern umgeben, die aus gefundenem Material wie Feldsteine gebaut waren.

Diese sozial-räumlichen Ordnungen der Familiencluster und Viertel haben sich tief in das Bewusstsein der Lagerbewohner eingegraben und bestehen bis heute, obwohl sie einem dynamischen Prozess ausgesetzt waren, der ihre Rolle im alltäglichen Leben verändert hat. In gewisser Weise ist die räumliche Ordnung, die das Leben der ersten Jahrzehnte in den Flüchtlingslagern charakterisierte, vergleichbar mit der räumlichen Ordnung typischer arabischer Stadtzentren. Beide beruhen auf ein ähnlich strenges räumliches Ordnungssystem der »hosh « (der Hof wird mit der erweiterten Familie geteilt), der "hara" (Viertel, auch manchmal als Klan beschrieben; in Zentralasien »mahalla" genannt) und auf dem generellen Zugehörigkeitsgefühl zur Stadt. Die Organisation alter Stadtzentren wie Nablus, Hebron und Aleppo ist noch immer nach diesen Prinzipien angeordnet.

\subsection{Konsolidierung: Formelles Planen versus informelles Wachstum (1955-1967)}

In den 1950er Jahren begann UNRWA das erste groß angelegte Bauprogramm, das die Zelte des Roten Kreuzes durch standardisierte Unterkunftseinheiten ersetzen sollte. Dieser erste und einzige Versuch, das gesamte Flüchtlingslager zentralistisch zu 
planen, folgte denselben rational modernistischen Planungsprinzipien der Nachkriegszeit, die bereits in europäischen Städten und Militärcamps getestet und ausgeführt wurden. Von den verschiedenen Planungsphasen dieses Programms gibt es einige Archivdokumente, die über die Jahre den Fortschritt dieser Pläne anzeigen. Für Amari konnten zwei Planungsentwürfe in dem UNRWA FECSO Archiv (Jerusalem) gefunden werden: Der Bauplan für den ersten Block von 1955 und ein Bauplan von 1957 für das gesamte Flüchtlingslager. Ein ähnlicher Bauplan von 1957 konnte für Deheishe gefunden werden. Für Fawwar waren keine Dokumente aus dieser Zeit auffindbar. Alle Baupläne wurden nachweislich von dem selben Ingenieursbüro entworfen und basierten auf den folgenden Prinzipien: Erstens, die neuen Entwürfe ignorierten vorhandene soziale und räumliche Ordnungen wie Straßen, Viertel und Familiencluster und skizzierten eine radikale Neugestaltung, die einen kompletten Abriss aller vorheriger Strukturen vorsah ( $t a-$ bula rasa). Zweitens, die neue rationale Anordnung beruhte auf der strikten Einteilung von Zonen (eine eigene Zone für die Dienstleistungen der UNRWA, Zonen für Wohnhäuser, eine Zone für die Wassersammelstellen und öffentliche Toiletten und alles durch ein strikt hierarchisch angelegtes Straßensystem miteinander verbunden). Drittens, alle Wohnhäuser sollten nach einem übergeordneten Raster angeordnet werden, eingeteilt in klar umrissene Häuserblöcke, die aus etwa 20 einzelnen Grundstücken bestanden und nach außen von breiten Straßen und großen offenen Plätzen umgeben waren. In Amari ist das Raster willkürlich gemäß der Ausrichtung der Grenze zwischen dem Flüchtlingslager und den angrenzenden Gebäuden Richtung Süden angeordnet. Das hügelige Territorium von Deheishe führte zu einem Raster, das der topographischen Krümmung des Tals folgte. In beiden Plänen wurde die bestehende Infrastruktur gänzlich ignoriert: weder Fußwege, Eigentumsgrenzen noch selbstgebaute Häuser wurden berücksichtigt. Auch wenn in Amari die ursprüngliche Straße beibehalten wurde, so ignorierte der Entwurf für Deheishe den alten und zu der Zeit noch sehr wichtigen Pfad, der sich den Hügel nach Bethlehem hoch schlängelte. Viertens, der Entwurf beabsichtigte, alle Zelte und selbstgebauten Lehm- und Steinhäuser durch standardisierte einstöckige Häusereinheiten zu ersetzen (von jeweils ca. 20 
Quadratmeter oder ein Raum pro Familie mit bis zu fünf Mitgliedern, zwei Räume für größere Familien), die aus leichtem Material, wie aus Betonhohlsteinen gebaut werden sollten.

Spätere Entwürfe, wie der Entwurf von Amari aus dem Jahr 1972, zeigen, dass die Bauvorhaben von UNRWA für Deheishe und Amari, wie auch für andere Flüchtlingslager, nur zum Teil realisiert wurden. Dies wird besonders deutlich im Fall von Amari, wo sich heute so gut wie keine Spuren eines Rasters finden lassen. In Deheishe sind einige Teile des Lagers, insbesondere im Zentrum, nach einem Raster angelegt, während die Anordnung der Häuser in anderen Teilen keinen Rückschluss darauf zulässt. Interessant ist vor allem die Tatsache, dass der alte Pfad Richtung Bethlehem in genau derselben Position blieb, wie er auf der Karte von 1957 aufgezeichnet war. Es ist anzunehmen, dass die Entwürfe mehr oder weniger zurückgestellt wurden, entweder aufgrund von fehlenden finanziellen Mitteln oder weil die Flüchtlinge selbst sich dagegen wehrten (auch aus politischer Ablehnung gegenüber einer "Normalisierung", die das Recht auf Rückkehr beeinträchtigen könnte). Die Realisierung der Entwürfe hätte zudem in Zeiten der Not den Abriss der meisten selbstgebauten Häuser bedeutet, die, in Verbindung mit den Zelten, wesentlich größer waren, als die geplanten Unterkünfte der UNRWA. Da die Bewohner des Flüchtlingslagers bereits einen Eigentumssinn gegenüber ihren komplett selbst finanzierten Strukturen entwickelt hatten, wäre der Abriss extrem unpopulär und nur mit kostspieligen Kompensationen durchführbar gewesen. Es ist sehr wahrscheinlich, dass die Flüchtlinge ihren Anspruch auf Unterkunft von UNRWA nutzten, aber selbst entschieden, wo sie ihr Haus letztlich hinplatzierten. Ein Vergleich der Amari-Pläne von 1957 und 1978 zeigt, dass diese UNRWA-Unterkünfte einfach neben die Zelte und selbstgebauten Strukturen gesetzt wurden und damit die Anordnung der Familien hoshes konsolidierten, statt diese zu ersetzen. Dies führte letztlich zu einer horizontalen Verdichtung des Lagers. Das partielle Scheitern des Hausbauprogramms in Amari und Deheishe stellt einen bedeutsamen Präzedenzfall dar, aus dem derzeitige Planungsvorhaben lernen können. Die informellen Kräfte des Alltagslebens im Flüchtlingslager kollidierten mit der Planungsbürokratie, die die existierenden Realitäten einfach ignorierte. Das Resultat dieser Kol- 
lision zeigt zudem, dass trotz der derzeit relativ autoritären und unumstrittenen Rolle UNRWAs, der tatsächliche Einfluss der Flüchtlinge auf die Entwicklung des Lagers weitaus stärker war als das externe Planungsregime. Die informell entstandenen räumlichen und sozialen Ordnungen im Flüchtlingslager, einschließlich das System der Viertel, erwiesen sich als effektiv und verfestigten sich.

\subsection{Interne räumlich-soziale Reorganisation und horizontales Wachstum (1967-1987)}

Der Beginn der israelischen Besetzung der Westbank 1967 hatte einen zwiespältigen Effekt auf das Leben in den Flüchtlingslagern der Westbank. Bis zu 80 Prozent der Flüchtlinge flohen aus den Flüchtlingslagern in Jericho und durften danach nicht wieder zurück. In der gesamten Westbank flohen vor den vorrückenden israelischen Truppen zwischen 5 und 30 Prozent der Bewohner der Flüchtlingslager, denen danach das Recht auf Rückkehr in die besetzten Gebiete abgesprochen wurde. Die Folge war, dass viele Familien auseinander gerissen wurden und als Flüchtlinge noch einmal ganz von vorn und völlig mittellos in Jordanien anfangen mussten. Auf der anderen Seite brachte diese geopolitische Veränderung für diejenigen, die nicht geflohen waren, überraschende neue Möglichkeiten. Durch die Flucht von Teilen der Lagerbevölkerung entstanden in den völlig überfüllten Flüchtlingslagern neue Räume für die Dagebliebenen. Verlassene Häuser und Grundstücke wurden schnell von bedürftigen Flüchtlingen übernommen, was die Situation der überbevölkerten Lager entschärfte. UNRWA war zum Teil an der Umverteilung beteiligt, aber es ist gemeinhin bekannt, dass viele Häuser und Grundstücke auch verkauft wurden. Zugleich war der Beginn der israelischen Okkupation von einer Verbesserung der sozioökonomischen Bedingungen begleitet. In den frühen 1970er Jahren öffnete sich für Palästinenser langsam der israelische Arbeitsmarkt, die vor allem im Baugewerbe Arbeit als Niedrigqualifizierte fanden. Hinzu kam, dass eine wachsende Zahl von jungen Flüchtlingen, die sich in dem Bildungssystem von UNRWA qualifiziert hatten, in anderen arabischen Staaten, zum Beispiel in der Golfregion, Arbeit fand. Von der zweiten Flüchtlingsgeneration (geboren im 
Flüchtlingslager) wurden diese neuen Arbeitsmöglichkeiten enthusiastisch wahrgenommen, eifrig bemüht die finanziellen Anforderungen für eine Heirat zu erfüllen und einen eigenen unabhängigen Haushalt zu gründen. Die Einkommen wurden reinvestiert in den Bau von zusätzlichen Häusern (die der Ehemann nach dem Brauch vor einer Heirat für seine neue Familie vorweisen muss) und führte zum ersten bedeutenden Bauboom innerhalb der Flüchtlinslager, der mit einer »horizontalen« Erweiterung einherging. Die hybride Struktur der UNRWABauten und die frühen Lehm- oder Steinhäuser wurden erweitert durch zusätzliche Räume und Anbauten, wie Außenküchen oder Toiletten. In einigen Fällen wurden die UNRWA-Bauten komplett abgerissen, um sie durch größere Gebäude zu ersetzen. Somit wurde die relativ lichte Bebauung der Cluster, die jeweils von Gärten und Nutzflächen umgeben waren, graduell in einen homogenen einstöckigen Teppich verwandelt, der nur noch vereinzelt von einigen verbliebenen Gärten unterbrochen wurde. Die vorherigen breiten Straßen und öffentlichen Plätze schrumpften langsam oder verschwanden vollkommen.

Obwohl sich für die gesamte Lagerbevölkerung die sozioökonomischen Bedingungen verbesserten, nutzen einige Familien die neuen Chancen besser als andere, abhängig von den zur Verfügung stehenden Fähigkeiten, der Bildung und der Bereitschaft und Fähigkeit, unter harten Bedingungen zu arbeiten. Der Beginn der ökonomischen Segregation fand somit in den späten 1970er Jahren statt. Indem die Einwohner ihr neu verdientes Geld in die Aufwertung und den Ausbau der Häuser investierten, wurde die Segregation auch im Flüchtlingslager sichtbar. Da die Freiflächen wieder knapper wurden entschlossen sich einige Flüchtlinge in ein neues Leben außerhalb der Flüchtlingslager zu investieren. Damit setzte eine erste signifikante »Auswanderung " aus den Lagern ein. Im Fall von Amari kauften mehr als 300 wohlhabendere Familien relativ billiges Land außerhalb der Lager und bauten sich in der Nachbarschaft der nicht-geflohenen palästinensischen Gemeinden neue Häuser, die manchmal die Größe von Villen hatten. Einige mieteten auch außerhalb Wohnungen, die zu der Zeit günstig zu bekommen waren. Diese »Auswanderung « schuf weitere Freiräume im Lager, die schon durch die Flucht von 1967 entstanden waren und beförderte eine interne Mobilität. Viele Flücht- 
linge konnten ihre Grundstücke erweitern, indem sie Nachbargrundstücke aufkauften. Die »Auswanderung" veränderte grundlegend die räumliche Situation in den Lagern, aber auch die Beziehung mit dem äußeren urbanen oder ländlichen Umfeld. Einige ökonomisch erfolgreiche Flüchtlinge legten ihren Flüchtlingsstatus $a b$ und lösten alle Bindungen zum Flüchtlingslager und der UNRWA. Sie nahmen einen städtischen Lebensstil in Städten wie Ramallah und Jerusalem an oder emigrierten ins Ausland. Die zweite und dritte Flüchtlingsgeneration, die das Bildungssystem der UNRWA durchliefen, waren gut ausgebildet und sehr gefragte Arbeitskräfte im Persischen Golf. Viele erwarben Stipendien oder fanden Arbeit im Persischen Golf, Europa oder in den USA und unterstützten währenddessen ihre Familien in den Flüchtlingslagern.

Die interne Mobilität und Migration hatten entscheidende Auswirkungen auf die Kultur und die soziale Ordnung in den Flüchtlingslagern. Indem sich die Flüchtlinge freier im Lager bewegen konnten und ohne Rücksicht auf die Zugehörigkeit zu bestimmten Vierteln neue Haushalte gründeten, verlor die interne räumliche Logik der kohärenten Viertel zunehmend an Bedeutung - ein Prozess, der als langsame Erosion der etablierten Grenzen innerhalb des Flüchtlingslagers bezeichnet werden könnte. Traditionelle Rivalitäten zwischen Familien (oder zwischen Stadt- und Dorfbewohnern), die vor allem für Amari typisch waren, nahmen ab und Heiraten zwischen den Gruppierungen wurden zunehmend akzeptiert. In dem Prozess des horizontalen Wachstums veränderte sich stark die Morphologie des Flüchtlingslagers, indem zunehmend solide Gebäudeblöcke unabhängig von den Clustern entstanden. Die Straßen und Gassen, die die Grenzen zwischen den Vierteln seit Anbeginn markierten, ließen sich nun kaum mehr unterscheiden von den Gassen und Wegen der umliegenden Blöcke. Langsam entstand eine räumliche Ordnung, die auf der Grundlage von Blöcken statt Vierteln basierte. Diese Blöcke zeichnen sich durch eine bestimmte Größe, interne Dichte und Struktur aus.

Über die Jahrzehnte wurden die Flüchtlingslager zur primären Identifikationsquelle der Lagerbewohner. Zu Beginn ergab sich die Identifikation mit dem Flüchtlingslager durch die gemeinsame Verteidigung nach außen gegenüber externer Bedrohung, wie beispielsweise Konflikte mit feindseligen Nachbarn. 
Insbesondere in der konservativen ländlichen und eng zusammengewachsenen kulturellen Umgebung der Westbank fühlten sich einheimische Palästinenser oft durch die Präsenz der Flüchtlinge bedroht. Die neuen ökonomischen Möglichkeiten der 1970er Jahre beschleunigten die Bildung der Lageridentität, ermöglichten der zweiten und dritten Flüchtlingsgeneration die Gründung eines eigenen Haushalts und verbesserten ihre Lebensbedingungen. Der Bau von neuen und moderneren Familienhäusern ermöglichte eine neue und positivere Identität als Lagerbewohner statt, wie bisher, als Mitglied einer bestimmten Familie oder eines Klans. Wachsende politische Mobilisierung, die zur Ersten Intifada führte, ließ auch das Selbstbewusstsein der Flüchtlinge anwachsen.

Die interne Reorganisation der Flüchtlingslager wurde erst möglich durch die neuen Praktiken des Kaufens, Verkaufens, Tauschens und Vermietens von Unterkünften und Land. Nach den Regeln von UNRWA gelten diese Praktiken als »informell« bzw. »illegal«, da die Grundstücke UNRWA lediglich temporär zur Nutzung übertragen wurden, und sie diese Nutzungsrechte ebenfalls auf temporärer Basis an die Flüchtlinge übertrug. Aber weder UNRWA noch andere Autoritäten konnten diese Entwicklungen kontrollieren und entschlossen sich, sie im Wesentlichen zu ignorieren.

\subsection{Vertikalisierung (1987-2006)}

Die vierte Phase der Entwicklungsgeschichte der Flüchtlingslager ist sehr komplex. Die Jahre der Ersten Intifada markierten einen radikalen Wendepunkt im Leben der palästinensischen Flüchtlinge. Ein wichtiger Nebeneffekt dieser neuen »Flüchtlingsemanzipation" war auch die abnehmende Kontrolle der UNRWA über informelle Bebauung im Lager. Obwohl der Bau von zweiten oder dritten Etagen verboten war, begannen Flüchtlinge diese Vorschriften zu ignorieren. Vor dem Hintergrund allgemeiner politischen Unruhen, Not und Instabilität konnte UNRWA sie auch nicht durchsetzten. So setzte ein beispielloser Bauboom ein, der bis zum Ende der 1990er Jahre anhielt. Für alle Flüchtlingslager in der Westbank begann mit unterschiedlichem Ausmaß eine Phase der Vertikalisierung. Von den drei Städten der Fallstudien geschah dies besonders 
stark in Amari. 1990 stimmte UNRWA offiziell dem Bau einer zweiten Etage zu. Obwohl nach 1991 nur zwei Etagen zugelassen waren, setzten die Flüchtlinge weitere Stockwerke hinzu. Von 1995 bis 1996 griff UNRWA nicht gegen die Vertikalisierung ein, sondern ließ sich lediglich von den Flüchtlingen eine Erklärung unterschreiben, dass UNRWA im Falle eines Einsturzes von der Verantwortung befreit sei.

Die Geburt und das Heranwachsen der dritten und vierten Flüchtlingsgeneration hatte ein starkes demographisches Wachstum zur Folge. Gleichzeitig waren nach dem vorherigen Bauboom alle räumlichen Ressourcen, wie offene und verlassene Flächen im Lager, aufgebraucht. Die Grenzen der horizontalen Expansion waren erreicht. Weniger Arbeitsmöglichkeiten und die Zunahme der politischen Instabilität in den Jahren der Intifada hatten zur Folge, dass immer weniger Menschen sich ein Leben außerhalb der Flüchtlingslager leisten konnten. Diese Situation änderte sich auch nicht in den relativ stabilen Jahren während der Oslo-Verhandlungen. Die Rückkehr vieler Diaspora-Palästinenser und relativ friedliche Zeiten lösten einen beispiellosen Bauboom aus und führten zu dem Anstieg der Bodenpreise. Das sozioökonomische Gefälle zwischen der Bevölkerung aus Ramallah/Al-Bireh und beispielsweise den Flüchtlingen aus Amari wurde zunehmend größer und die meisten Flüchtlinge konnten sich kein Land mehr außerhalb der Lager leisten.

Mit dem Beginn der Zweiten Intifada im Jahr 2000 brach die palästinensische Wirtschaft erneut zusammen und der Bau der israelischen Mauer versperrte nun gänzlich den Palästinensern Zugang zu Arbeit in Israel. Arbeitslosigkeit und Armut stiegen an. Die ständigen Ausgangssperren und Straßenabsperrungen beeinträchtigten zusätzlich das Leben der Flüchtlinge. So gut wie alle räumlichen Ressourcen, die den Vertikalisierungsprozess in den 1990er Jahren während des Baubooms ermöglichten, waren aufgebraucht. Mit dem Bau eines vierten, fünften oder gar sechsten Stockwerks vergrößerte sich dramatisch die Einsturzgefahr. Heute sind die Flüchtlingslager komplett ausgelastet. Gleichzeitig, und trotz der ökonomischen Krise, steigen die Mieten drastisch. Die monatliche Miete für eine 3Zimmer-Wohnung innerhalb des Flüchtlingslagers Amari betrug 2006 bereits ca. 300 Dollar. Verschärfend kommt die Tatsa- 
che hinzu, dass es immer noch wenig alternative Mietoptionen in den umliegenden urbanen Gebieten gibt und die Grundstückspreise exorbitant gestiegen und somit für die meisten Flüchtlinge unbezahlbar geworden sind. Flüchtlinge sind daher in den Lagern »gefangen«, sie kämpfen dort um ihr Überleben und können diese trotzdem nicht verlassen. Bisher hat UNRWA keine Strategie entwickelt, wie diese Lager das natürliche Wachstum in den kommenden Jahren auffangen sollen.

Zusammenfassend ist die jetzige Situation in den Flüchtlingslagern durch folgende Charakteristika gekennzeichnet: Erstens, komplette Auslastung und die Gefahr eines physischen Kollaps. Die Grenzen der vertikalen und horizontalen Expansion sind so gut wie erreicht. Trotzdem wächst die Bevölkerung in den Lagern weiter an. Die meisten Baukonstruktionen in den Lagern werden keine weitere Vertikalisierung aushalten und viele Häuser zeigen bereits baukonstruktive Mängel. Zweitens gibt es eine uneinheitliche Baudichte. Die intensive Bebauung der letzten 15 Jahre hatte einen polarisierenden Effekt auf die Baussubstanz in den Flüchtlingslagern und verstärkte die Ungleichheit. Während einige Gebiete das Wachstum auffangen konnten, kam es in anderen Gebieten zu einer extremen Überlastung. Drittens, wurde offener Raum als Garant für minimale Lebensqualität und Sicherheit zugunsten radikaler baulicher Expansion geopfert. Das horizontale und vertikale Wachstum privater Häuser verengte Zugangswege und Straßen und ließ öffentliche Plätze auf ein absolutes Minimum schrumpfen. In Notfällen sind die meisten Gebiete im Lager für Feuerwehrautos, Ambulanz etc. unzugänglich. Gesundheitsrisiken wie mangelnde Ventilation und fehlendes Tageslicht beeinträchtigen das Leben im Flüchtlingslager. Schließlich stehen die Lagerbewohner kurz vor einem sozioökonomischen Kollaps. Der beinahe komplette Verlust von Arbeitsmöglichkeiten in Israel aufgrund der israelischen Mauer führte zu einem dramatischen Anstieg der Armut. Der internationale Boykott der Palästinensischen Autonomiebehörde und der ökonomische Zusammenbruch hatten zur Folge, dass traditionelle generationsübergreifende Familienunterstützungssysteme wieder an Bedeutung gewannen und zum zentralen Überlebensmechanismus wurden. 


\section{Partizipative Planung in Flüchtlingslagern}

Die sich zunehmend verschlechternden Lebensbedingungen in den palästinensischen Flüchtlingslagern verlangen nicht weniger als ein radikales Umdenken: Was sind die Grenzen der Belastbarkeit für ein Flüchtlingslager? Kann ein Flüchtlingslager als ein Lebensumfeld mit Mindeststandards in Bezug zu Raumund somit Lebensqualität neu gedacht werden? Kann ein Flüchtlingslager zu einem Ort werden, in dem die zivilen Rechte der Flüchtlinge auf Mitgestaltung ihres Lebensumfeldes voll respektiert werden? Angesichts der mittlerweile bedrohlich gewordenen Verdichtung und Verslummung der Flüchtlingslager erscheinen bloße technokratische Hilfslieferungen kaum angemessen. Vor diesem Hintergrund initiierte UNRWA ein neues Programm zur Verbesserung der Flüchtlingslager (Infrastructure and Camp Improvement Programme (ICIP)), das zugleich Ausdruck einer versuchten Neudefinition der Rolle von UNRWA ist: eine Verschiebung vom traditionellen Notversorgungsansatz hin zu einem auf Nachhaltigkeit zielenden Entwicklungsansatz. Diese Reformbestrebungen reflektieren einen globalen, auch andere UN-Flüchtlingsorganisationen wie $\mathrm{UNHCR}^{4}$ umfassenden Umdenkungsprozess. Bestärkt wurde diese neue Strategie durch die Genfer Konferenz ${ }^{5}$ im Jahr 2004,

4 Ein entscheidendes Dokument zur neuen Strategie des UNHCR, ist das »Framework for Durable Solutions for Refugees and Persons of Concern« (2003), in dem der Fokus weg von Nothilfe hin zu Entwicklung verschoben wurde. Das Dokument kam aus dem vom UNHCR extra eingerichteten Think tank - der Kerngruppe $\mathrm{zu}$ »Durable Solution « und zeigt ein neues Interesse an dem Leben und eigenständigen Strategien der Flüchtlinge (vgl. Loescher/Betts/Milner 2008), auch als »development-based approach « bezeichnet. Darin wird behauptet: »The basic criterion for a good programme is self-reliance. In protracted refugee situations however, refugees - sometimes for decades - remain dependent on humanitarian assistance. One essential key to solving such situations is political; but, in the meantime, a facilitating element of any durable solution is development.«

5 Zur Mobilisierung von Spenden und Unterstützung der Aufnahmeländer, wie auch als Anstoß des Reformprozesses und zur Sicherung des nötigen Mandats, organisierte UNRWA eine internationale Konferenz, die als Genfer Konferenz (von 7-8. Juni 
bei der eine klare Unterscheidung zwischen dem politischen »Recht auf Rückkehr« und dem zivilen »Recht in einem würdigen Lebensumfeld zu leben « postuliert wurde. UNRWA wollte einen ganzheitlichen Entwicklungsansatz einführen, der die physische und soziale Umwelt der Lager durch eine partizipatorische, gemeinsam mit den Flüchtlingen entwickelte Planung verbessern sollte. ${ }^{6}$ Diese neue Strategie folgte dem Scheitern des Osloprozesses im Jahr 2000, das bereits zu einer gewissen Enttabuisierung von physischen Rehabilitierungs- und Verbesserungsinitiativen in Flüchtlingslagern beigetragen hatte.

Dennoch war die Einführung dieses neuen Ansatzes nicht einfach. Bis heute bleibt das Programm schwach finanziert, sowohl von außerhalb als auch innerhalb der UNRWA wird es häufig hinterfragt und missverstanden. Das ist nicht überraschend, da das CIP sowohl das Mandat von UNRWA als auch ihre Beziehung zu den repräsentativen Institutionen der Flüchtlinge infrage stellt. Obwohl es für eine Evaluation des Programms noch zu früh ist, machen erste Piloterfahrungen bei der Umsetzung des "Infrastructure and Camp Improvement Programme « die potentiellen Aufgaben deutlich.

Zwei wesentliche, miteinander eng verbundene Themen sollen hier erörtert werden: Das erste betrifft die räumlichen und physischen Bedingungen der Lager und die Strategien und Instrumente, die für einen effektiven Wandel nötig sind. Wie bereits angeführt, war UNRWAs Sensibilität und Offenheit gegenüber der sozialen und kulturellen "Infrastruktur" in Flüchtlingslagern traditionell stark begrenzt und charakterisiert durch eine technokratische Denkweise, die gegenüber aktuellen Urbanisierungsprozessen und der Komplexität der räumlichen Organisation und Produktion blind war. Das CIP hat zum ersten Mal anerkannt, das Flüchtlingslager komplex gebaute Lebensräume mit verschiedensten Bedürfnissen darstellen. Vor

2004) bekannt wurde. Die Ergebnisse und Empfehlungen der Konferenz sollten direkt in UNRWA's »Medium Term Plan« (MTP 2005-2009) einfließen und den internen Reformprozess anleiten (mehr zu der Konferenz im Folgekapitel).

6 Der neue entwicklungsorientierte Ansatz von UNRWA ist im »Commissioners General's memorandum: "Agency Policy on Shelter Rehabilitation « vom 25. Oktober 2004 und in UNRWAs Medium Term Plan (MTP 2005-2009) vermerkt. 
diesem Hintergrund werde ich UNRWAs Bemühungen zur Entwicklung von angemessenen Planungs- und Steuerinstrumenten kritisch reflektieren, die zu einer ganzheitlichen Verbesserung nötig sind.

Das zweite Thema bezieht sich auf die Partizipation und den Entscheidungsprozess, der in der CIP-Implementierung vorgesehen ist. Dies betrifft vor allem die bisher fehlenden Selbstverwaltungsstrukturen in den Flüchtlingslagern. Das CIP wurde von UNRWA als das Ergebnis eines partizipatorischen Planungsprozesses definiert, in dem die Flüchtlinge Entscheidungsträger sein sollten, statt wie bisher lediglich Empfänger von Hilfspaketen. ${ }^{7}$ Die pragmatischen Fragen, die daraus entstanden, waren: Wer spricht im Namen der Flüchtlinge? Wer definiert die Prioritäten? Wer nimmt am Planungsprozess teil? Wer kann die Nachhaltigkeit der implementierten Maßnahmen garantieren? Welche Rolle spielt in diesem Prozess die UNRWA und wie soll sie zukünftig aussehen? All diese offenen Fragen erklären die Missverständnisse, die derzeit den Status quo charakterisieren. Seinem Mandat nach versteht sich eine humanitäre Organisation wie UNRWA als ein zeitlich begrenzter Hilfslieferant für eine temporäre Gruppe von Schutzbedürftigen. Dabei wird sorgfältig darauf geachtet, keine größere Verwaltungsverantwortung zu übernehmen. Gleichzeitig schreiben die meisten Flüchtlinge der UNRWA eine zentrale Rolle zu, für die Probleme im Flüchtlingslager verantwortlich zu sein.

Diese Phantomherrschaft der UNRWA resultiert aus diesem grundsätzlichen Missverständnis hinsichtlich der Rollen und Verantwortlichkeiten und hinterlässt ein problematisches Vakuum, das zu dem Gefühl eines ständigen Ausnahmezustands

7 In UNRWAs »Camp Improvement Manual« (Misselwitz et al. 2008a), eine interne Veröffentlichung des »Camp Development Pilot Research Project « (Misselwitz et al. 2008b) - eine Kooperation der UNRWA und der Universität Stuttgart - heißt es: »Camp Improvement cannot be imposed; it can only succeed as the joint effort of all stakeholders. Camp communities themselves hold the key: As 'local experts' camp dwellers themselves know best what is most urgently needed, can implement actions most efficiently and ensure that achieved results are lasting. Rather than remaining 'receiving beneficiaries,' local communities must 'drive' the process at all stages.«(S. 5). 
beiträgt und gleichzeitig Misstrauen und Argwohn säht. Jahrzehnte der internen und internationalen Auswanderung der meist Gebildeten aus den Lagern, die aus der Falle der Passivität und Abhängigkeit von Hilfsleistungen heraus wollten, hinterließen in den Lagern eine volatile Flüchtlingsgemeinschaft. Letztlich kann diese Situation nur durch die Einführung von effektiven und demokratisch bestätigten Verwaltungsstrukturen im Lager rückgängig gemacht werden, welche die Gemeinschaftsinteressen repräsentieren und somit zur Verbesserung in den Lagern führen kann. UNRWA müsste die existierenden repräsentativen Strukturen anerkennen und mit diesen zusammenarbeiten, seinen paternalistischen Ansatz und die bisweilen institutionelle Arroganz überwinden und behutsam die Selbstverwaltung unterstützen und stärken. An dem Beispiel der Flüchtlingslager von Nahr el Bared in Nordlibanon und Fawwar in der Westbank werde ich aufzeigen, wie die Implementierung des CIP die Verwaltungsfrage aufwarf.

\subsection{Komplexe urbane Lebensräume benötigen komplexe Handlungsansätze}

Die traditionelle Rolle von UNRWA bei der Unterbringung der Flüchtlinge und dem Bau von Lagern war auf zwei Hauptinstrumente reduziert, die die vorrangig technokratische Haltung gegenüber Flüchtlingslagern widerspiegelt: Erstens, Katastrophenhilfe und Wiederaufbau als Antwort und in Folge eines bewaffneten Konflikts - ein reaktiver Ansatz, dessen Defizite an den folgenden zwei Beispielen gezeigt werden: UNRWAs Rolle beim Wiederaufbau des Flüchtlingslagers Shatila (Libanon) zeigt auf alarmierende Weise die Konsequenzen eines fehlenden strategischen Weitblicks. In dem libanesischen Bürgerkrieg wurde das Flüchtlingslager so gut wie völlig zerstört. 1986 verteilte UNRWA zum Wiederaufbau Spendengelder an die betroffenen Flüchtlinge, versäumte es aber, klare Regeln und Planungskoordination für den Wiederaufbauprozess zu entwickeln. In Kombination mit anderen Faktoren war die Folge verheerend. Das Flüchtlingslager ist heute eines der dichtesten und überfülltesten Lager mit den schlechtesten Gesundheitsbedingungen und einer äußerst prekären Gebäudesicherheit. 
Am Beispiel von Rafah und Jenin zeigte sich, wie nach der Zerstörung das Fehlen von etablierten Wiederaufbaukriterien die UNRWA für die Forderungen der Geldgeber anfällig machte. Ein UNRWA-Mitarbeiter beschrieb die Situation nach der Zerstörung im Gaza in der Zweiten Intifada wie folgt: »In Gaza we have the Japanese shelter, the UAE shelter and the Swedish shelter, each vary in size and standard, creating confusion and jealousy amongst the camp population... «8 . Statt einer strategischen Planung, um das bestmögliche Ergebnis zu erreichen, machten die Geldgeber jeweils eigene Vorgaben zum Zeitplan für die Implementierung, zum Design und Arbeitsumfang und setzten die UNRWA immens unter Druck, diesen Erwartungen $\mathrm{zu}$ entsprechen. Dies wurde besonders deutlich beim Wiederaufbau des zerstörten Zentrums des Jenin-Flüchtlingslagers, wo "many mistakes of alienating the local population could have been avoided with proper tools in place « ${ }^{9}$. Das Vorhaben, mit dem offiziellen Namen »The Jenin Camp Rehabilitation Project « war insofern innovativ, als dass Entwicklungsaspekte, wie beispielsweise die Unterstützung des lokalen Gewerbes und der lokalen Institutionen, berücksichtigt wurden. Jedoch setzten die Geldgeber aus den Vereinigten Emiraten das lokale Planungsteam unter Druck, die Häuser zu vergrößern und drängten sie letztlich zu einem nicht-transparenten und unfairen Verteilungssystem.

Das zweite Instrument, UNRWAs "Shelter Rehabilitation Programme«, unterstützt Flüchtlinge, deren Häuser und Lebensbedingungen nicht den Minimalstandards entsprechen. Um sich für das Sanierungsprogramm für einzelne Häuser zu qualifizieren, müssen die Bewohner strikte Armutskriterien (Special Hardship Criteria - basierend auf Haushaltseinkommen) erfüllen. Während die Auswahlkriterien garantieren sollten, dass von den begrenzten Mitteln vor allem die ärmsten Bewohner profitierten - aus einem humanitären Standpunkt sehr verständlich - verursachte die Anwendung dieses Programms in der Praxis viele Probleme. Neue Häuser konnten

8 Interview mit einem UNRWA-Mitarbeiter in Amman im Juni 2007.

9 Interview mit einem UNRWA-Mitarbeiter in Amman im Juni 2007. 
nur am selben Ort wieder erbaut werden, egal ob dieses Gebiet überbevölkert war und mehr offene Flächen benötigte. Häuser, die saniert werden konnten, waren zufällig verteilt innerhalb des Flüchtlingslagers. Oft waren es nicht die mit den größten Schäden und häufig waren sie verbunden mit Nachbarhäusern, was die Möglichkeit der Intervention begrenzte.

Das bis dato größte Versäumnis lag jedoch in dem Fehlen eines gesamtheitlichen Ansatzes. Die zur Verfügung stehenden Werkzeuge kamen meist unkoordiniert und als reaktive AdHoc-Gesten zum Einsatz. Vorausschauende strategische Planung im Sinne gesamtheitlicher Entwicklungsplanungen fehlte völlig. Dies war teils der blockierenden Haltung der Gastländer anzulasten. Doch auch UNRWA selbst betrachtete die Unterkunft der Flüchtlinge als rein technokratisch zu lösendes Problem und versäumte es, mittels strategischer Konzepte für die sich rasant verschlechternde und die Lebenssituation der Flüchtlinge massiv beeinträchtigende bauliche Situation in den Flüchtlingslagern zu planen.

Die Unzulänglichkeit und negativen Konsequenzen dieses reaktiven Ansatzes waren vielen UNRWA-Mitarbeitern längst bekannt. Erste Versuche eines Umdenkens lassen sich bereits in die frühen 90er Jahre zurückdatieren, doch scheiterten sie zumeist am Widerstand der Gastländer wie das Beispiel des syrischen Neirab-Camps illustriert. Das Camp war einst in von der französischen Armee zurückgelassenen Baracken eingerichtet worden. Nach Jahrzehnten des informellen Wachstums wurden diese Baracken buchstäblich unter der dichten Masse der Wohngebäude begraben. Die nun einsturzgefährdeten Barackenstrukturen waren so untrennbar mit den Wohngebäuden verbunden, dass effektive Abhilfe nur im Rahmen einer Gesamtsanierung (und teils Neubau) des Lagerzentrums sinnvoll war. Nach dem Einspruch der syrischen Regierung scheiterte jedoch ein erster Planungsversuch. ${ }^{10}$

10 Im Jahre 2001 änderte die syrische Regierung schließlich ihre Blockadehaltung und das teils vom Bundesministerium für wirtschaftliche Zusammenarbeit und Entwicklung BMZ unterstützte »Neirab Camp Rehabilitation Project« begann als ein erster Experimentalversuch einer gesamtheitlichen Sanierungsplanung. 
Erst die bereits erwähnte Genfer Konferenz (2004) schaffte letztlich die politischen Rahmenbedingungen für eine umfassendere Neuorientierung. Die wichtigste strukturelle Reform war die geplante Eröffnung eines neuen Departments innerhalb der UNRWA. Das »Infrastructure and Camp Improvement Department (ICID)« erhielt den Auftrag, Werkzeuge für eine gesamtheitlich ausgerichtete, integrierte Verbesserung der Lebensbedingungen in den Flüchtlingslagern zu entwickeln. Ein erster Schritt war die Initiierung von zwei Forschungsprojekten. Wichtige fehlende Grundlagedaten über die Lebenssituation in den 58 Flüchtlingslagern sollten durch eine regionale Datenerhebung unter Leitung des Genfer Institut Universitaire d'études du Développement (IUED) beschafft werden. Der Abschlussreport der Studie gab erstmals einen umfassenden Einblick in die prekäre Gesamtsituation der Flüchtlingslager, die in Bezug auf Bevölkerungsdichte, Gebäudedichte und Überbelegung nicht nur die wesentlichen UN-HABITAT-Kriterien für "Slums « erfüllen ${ }^{11}$, sondern generell als die dichtesten und überbevölkertsten Wohnviertel weltweit bezeichneten werden müssen ${ }^{12}$.

Das zweite von ICID initiierte Forschungsprojekt sollte komplementär zu den quantifizierbaren Basisdaten detaillierte, qualitative Fallstudien zur Urbanisierung einzelner Flüchtlingslager erstellen. Die Idee des »Camp Development Pilot Research Projects « begann als gemeinsame Initiative von UNRWA und der Universität Stuttgart, die mit der akademischen Gesamtleitung beauftragt wurde. Ein Forschungsteam untersuchte drei exemplarische West Bank Flüchtlingslager (Amari, Deheishe und Fawwar) mit dem Ziel, die sozialen, kulturellen und räumlichen Muster und internen Regeln des Urbanisierungsprozesses zu untersuchen ${ }^{13}$ Zum ersten Mal in der Geschichte

11 Für mehr Information über die UN-HABITAT Definition für "Slums« siehe UN-HABITAT (2006).

12 Für vergleichende Daten über die Verdichtung von Flüchtlingslager und urbane Wohnviertel weltweit vgl. J. AL Husseini/ Bocco/Brunner (im Erscheinen).

13 UNRWA-Camp Development Pilot Research Project: Main Research Report (2006-2008), im Auftrag vom »Infrastructure and Camp Improvement Department«, finanziert von der Europäischen Kommission. 
der UNRWA, wurden palästinensische Flüchtlingslager als lokal spezifische Lebensumfelder gesamtheitlich untersucht. Räumliche Kartierungen zeigten, wie bereits oben beschrieben, die komplexe, stadtähnliche Ausdifferenzierung der Nutzung in klar unterscheidbare Zonen in den Lagern. Auch ohne Lenkung durch Planung oder Kontrolle von Außen garantierten allgemein akzeptierte Baunormen und interne Systeme der Konfliktaushandlung das informelle Wachstum. Das Forschungsprojekt zeigte auch die komplexen Identitäten und sozialen Netzwerke auf Block-, Quartiers- und Lagerebenen. Die fest zusammengeschweißte Lagergemeinschaft garantiert nicht nur für gegenseitige Unterstützung in Notlagen, sondern schafft auch ein Gefühl vertrauter Zugehörigkeit. In diesem Sinne zeigten die Untersuchungen in den Fallstudien, dass Flüchtlingslager heute nicht nur die Summe ihrer dramatischen Geschichten, Probleme und Defizite sind. Sie sind auch das Produkt jahrzehntelanger Investition von Flüchtlingen in Baustruktur, Institutionen und soziale Netzwerke. Flüchtlingslager sind Orte extremer ökonomischer und politischer Not, aber gleichzeitig auch Orte des Experimentierens und der Innovation. Die Bewohner haben Überlebenspraktiken, Geschick und Expertise entwickelt, die es ihnen möglich machte, ihre Situation zu ertragen und neue Lebensgrundlagen innerhalb und außerhalb der Flüchtlingslager zu schaffen. Es sind die zum Teil verwirrenden und komplexen Normen und Vorschriften, die es den Lagerbewohnern ermöglichen, unter den Bedingungen extremer Dichte und Armut zu überleben.

Das CIP für Fawwar, welches im Sommer 2007 entworfen wurde, ist das erste Planungsdokument, das aufzeigt, wie mit Sensibilität und unter Berücksichtigung der lokalen Bevölkerung ein umfassender Entwicklungsplan erstellt werden kann. Über einen Zeitraum von zwei Jahren erarbeitete das StuttgartUNRWA-Forschungsteam mit der lokalen Gemeinde einen ersten umfangreichen räumlichen Koordinations- und Planungsentwurf für ein palästinensisches Flüchtlingslager, das außerhalb einer Notfallsituation entwickelt wurde. Statt einer groß angelegten Intervention, wie das »Neirab Rehabilitation Project " (das dem CIP in Fawwar voranging) oder wie der derzeitige Umbau von Nahr el Bared, war hier das Ziel eine sensible Verbesserung, durch ein kontinuierliches step-by-step- 
Verfahren. Dies geschah zum Teil auch aus pragmatischen Gründen, da das Budget für dieses Projekt nur einen Bruchteil im Vergleich für die zwei anderen genannten Projekte ausmachte.

Doch der Fokus auf kleinen Schritten anstatt umfassender Veränderungen ist nicht nur pragmatisch. Der hier vertretene Ansatz sieht eine Verschiebung von einem umfassenden, zentral geleiteten Projekt hin zu einer Liste von Projekten vor, die von den Lagerbewohnern selbst durchgeführt werden können. Die Absicht ist, einen sanften und flexiblen urbanen Transformationsprozess anzustoßen, der sowohl die urbane Bausubstanz wie auch die Lagergemeinschaft stärken soll, was auch den Aufbau von lokalen Organisationsstrukturen einschließt, die dafür sorgen sollen, das bereits Erreichte zu bewahren und fortzusetzen. Die Alternative, ein selbstherrlicher top-down Ansatz zur Verbesserung der Lager, läuft Gefahr als ignorant und respektlos wahrgenommen zu werden und ruft vermutlich nicht nur Widerstand und Boykott hervor sondern - was viel wichtiger ist - würde es auch versäumen, die lokalen Erfahrungen und Bewältigungsstrategien zu nutzen, die von lokalen Experten zusammengetragen wurden und besser als irgendeine externe humanitäre Organisation effektive Veränderungen einleiten könnten.

Parallel zu räumlichen Optimierungsplanung macht das CIP in Fawwar Vorschläge zur Stärkung der sozialen Gemeinschaft und hinsichtlich ökonomischer Aspekte, wie die Einführung eines selbstverwalteten Mikro-Kredit-Systems, Konsolidierung des lokalen Gewerbes, infrastrukturelle Kapazitäten und Schulung von Mitarbeitern der lokalen Institutionen. Durch physische und sozioökonomische Maßnahmen sollen vorhandene positive Dynamiken und Prozesse unterstützt, dynamisiert und strategisch gelenkt werden - ein Ansatz, der als "Akupunktur Stadtplanung « bezeichnet werden könnte.

\subsection{Von UNRWAs "Phantomherrschaft« zu lokaler Selbstverwaltung}

Traditionell sah UNRWA, wie auch viele andere humanitäre Hilfsorganisationen, in Flüchtlingen hilfsbedürftige Opfer. So wie die UNRWA es versäumt hat, den Urbanisierungsprozess 
anzuerkennen, der die Zeltstädte in komplex gebaute Umwelten verwandelte, wurde es auch versäumt, anzuerkennen, dass die traumatisierten und stimmlosen Opfer emanzipierte Subjekte werden wollen, sobald eine Art Normalisierung im Lagerleben eingekehrt ist. Der paternalistische Ansatz - eine Hilfsorganisation hilft einer anonymen Gruppe von Begünstigten vermag in der Regel nicht die vielfältigen Formen sozialer Mobilisierung wie das Entstehen von lokalen Initiativen oder Institutionen anzuerkennen und zu nutzen. So ist auch die Beziehung zwischen UNRWA und der Lagergemeinde eine Beziehung, die jahrzehntelang durch Frustration, Mistrauen, Fehlkommunikation und gegenseitigen Missverständnis gekennzeichnet war.

Ein erster Schritt auf dem Weg einer Neuorientierung des Verhältnisses von UNRWA und den Lagergemeinschaften ist die Anerkennung der tatsächlichen sozialen und politischen Strukturen und Netzwerke in den Lagern. Hier liegen offizielle Rollendefinition und tatsächliche Situation oft weit voneinander entfernt. Hinzu kommen erhebliche Unterschiede in den fünf Länderregionen. In Syrien und Jordanien kontrolliert vor allem der Staat durch verschiedene Organe die Flüchtlingslager. Im Kontrast zu dieser klassischen Kontrolle des Staates ist die Situation in den palästinensischen Gebieten und im Libanon völlig anders. Hier gibt es ein Netz von komplexen Machtstrukturen, das sich zusammensetzt aus ein oder zwei miteinander im Konflikt stehenden Komitees (im Libanon), einem Sicherheitskomitee, Prominenz, politischen Fraktionen, »Palestine Scholars' League " (ein Zusammenschluss, der der Hamas nahe steht), PLO-Gewerkschaften und -organisationen (Arbeiter, Frauen, Ingenieure etc.), »Community based Organizations« $(\mathrm{CBOs})^{14}, \mathrm{NGOs}^{15}$ und lokalen UNRWA-Einsatzkoordinatoren

14 Die meisten CBOs sind Jugend- und Frauenzentren, wie auch soziale Einrichtungen für Menschen mit besonderen Bedürfnissen. Sie wurden in den 1980er Jahren von UNRWA aufgebaut, sind aber heute quasi-finanziell unabhängig, da sie effektive Verbindungen $\mathrm{zu}$ lokalen und internationalen Organisationen hergestellt haben, die ihnen in den Jahren von 2002 bis 2003 mehr als 3 Millionen US-Dollar einbrachten (MTP Relief and Social Services Program). (Genfer Geberkonferenz 2004) 
(»Camp Service Officers«). ${ }^{16}$ Die Machtballance zwischen diesen Kräften verändert sich dynamisch, und variiert von Lager zu Lager und zwischen den verschiedenen Regionen. Eine besonders hervorzuhebende Struktur ist jedoch das »Lokale Flüchtlingslagerkomitee« (»Local Committee« oder »Popular Committee «) das sich als wichtigster, von der Lagergemeinschaft selbst bestimmter Verwaltungskörper sowohl in den palästinensischen Gebieten der Westbank und in Gaza, als auch im Libanon herausgebildet hat.

Für alle Flüchtlingslager trifft jedoch zu: Statt von einem Souverän werden Flüchtlingslager von einem Verbund mehrerer Teilsouveräne regiert. Nach der Rechtslage steht den Institutionen der Gastländer die Rolle des klassischen Souveräns zu. Doch vor allem in der Westbank und im Libanon bleibt diese Rolle de facto unausgefüllt. Anstelle der Libanesischen Regierung oder der israelischen Militärbesatzung (Westbank) treten die Teilsouveränitäten von PLO/PNA und ein Netz von weiteren Akteuren. Die Situation wird noch komplexer, wenn auch noch die Rolle von UNRWA in diesem Herrschaftsgefüge berücksichtigt wird. Dafür möchte ich den Begriff »Phantomherrschaft « einführen, um die spezielle Position von UNRWA gegenüber den Flüchtlingslagern zu beschreiben.

Michel Foucault erinnert uns daran, dass unser Interesse nicht der Macht, die von der Ausübung von Herrschaft an sich ausgeht, gelten muss, sondern vielmehr den Folgen einer durch eine bestimmte Regierungsführung erzeugten Macht. Obwohl UNRWA nicht mit dem Ziel gegründet wurde oder das Ziel anstrebt die Flüchtlingslager zu verwalten, wird ihr von vielen Bewohnern der Flüchtlingslager der Status des Machtinhabers zugeschrieben. Dies wird vielleicht am deutlichsten an der ambivalenten Rolle der lokalen UNRWA-Einsatzkoordinatoren (»Camp Service Officers«), ein im Flüchtlingslager angesiedel-

15 In einigen Flüchtlingslagern ist die soziale Rolle von NGOs viel wichtiger als die von politischen Fraktionen. Aber es sind auch einige dieser NGOs mit politischen Fraktionen verbunden. Interviewte berichteten, es gäbe ein generelles Mistrauen gegenüber NGOs. Unterdessen nimmt Hamas eine immer größer werdende soziale Rolle in den Flüchtlingslagern ein.

16 Für eine weitergehende Analyse dieser Strukturen empfehle ich Kortam (2007) die Kapitel 2-3. 
ter UNRWA Mitarbeiter, der traditionell eine einflussreiche Position gegenüber der Flüchtlingslagergemeinschaft einnimmt. Diese Machtposition beinhaltete in der Vergangenheit beispielsweise die Möglichkeit, Zuteilungen an Personen zu kürzen, die den UNRWA-Regulierungen nicht nachgekommen waren. Die Beamten wurden durch UNRWA nach Absprache und mündlicher Billigung der lokalen Stammes- und Dorfführer aus den Reihen der Flüchtlinge eines Lagers ernannt.

Für UNRWA war dieses Auswahlverfahren in zweifacher Hinsicht vorteilhaft. Von der Ernennung eines Repräsentanten der lokalen Lagereliten in eine offizielle Mitarbeiterposition erhoffte sich UNRWA sowohl Legitimation als auch Akzeptanz. Seit den frühen neunziger Jahren hat UNRWA zunehmend Mitglieder der neuen Lagerelite, wie gut ausgebildete Flüchtlinge (Ingenieure, Lehrer, Apotheker und Wissenschaftler), eingestellt, die teilweise für ihren politischen Aktivismus und ihre guten Beziehungen zu den Bewohnern der Flüchtlingslager bekannt waren. ${ }^{17}$ In den von Sari Hanafi durchgeführten Interviews sprechen Lagerbewohner von diesem Beamten oftmals als »Direktor « des Flüchtlingslagers. Die offizielle Funktion ist jedoch eher die eines Mittelsmannes für Dienstleistungen der UNRWA. Interviews bestätigen eine deutliche Diskrepanz zwischen der wahrgenommenen und tatsächlichen Funktion dieses Beamten. Diese Verwechslung rührt von der ursprünglichen Rolle des UNRWA Direktors her, der nicht nur Dienstleistungen vermittelte, sondern auch viele Koordinations- und Verwaltungsaufgaben im Leben der Flüchtlinge übernahm. Demzufolge werden die "Camp Service Officers" wahrgenommen, als hätten sie eine führende Position inne, ohne diese allerdings tatsächlich auszuführen.

Das Missverständnis bei der Bewertung der Position des "Camp Service Officers« ist symptomatisch für die herrschende Unklarheit zur Rolle der UNRWA im Allgemeinen. Viele Bewohner machen UNRWA für alle Missstände in den Flüchtlingslagern verantwortlich. Ihrem Ärger über die scheinbare Passivität von UNRWA Ausdruck verleihend, stellte eine Be-

17 UNRWA hat jedoch, aus Vorsicht vor israelischen Reaktionen auf palästinensischem Territorium, von der Einstellung politisch bekannter Personen abgesehen. 
wohnerin die Frage: »Where is UNRWA when my neighbour builds a second and third floor without leaving any proper space for my apartment? «In der Tat benutzten viele Befragte den Begriff »Chaos«, um die Situation in den Flüchtlingslagern $\mathrm{zu}$ beschreiben und bezeichneten die Untätigkeit der UNRWA als eine Hauptursache dafür.

Nach dem deutschen Philosophen Carl Schmitt ist der Machthaber derjenige, der den Ausnahmezustand ausruft. Er zeichnet sich nicht durch die Ordnung, die er über die Verfassung institutionalisiert hat aus, sondern durch die Aufhebung dieser Ordnung (vgl. Agamben 1998). In den Flüchtlingslagern wird der Ausnahmezustand durch mehr als einen Machthaber bewirkt. Viele Akteure, oftmals die politischen Vertreter dieser Flüchtlingslager und diejenigen, die als lokale Machthaber bezeichnet werden können, bestehen auf den Ausnahmestatus der Flüchtlingslager und lehnen deshalb sowohl deren Unterordnung unter staatliche Kontrolle ab, also auch die Schaffung von demokratisch legitimierten (gewählten) Selbstverwaltungen, die für sie einer »Normalisierung" gleichkäme. Tatsächlich handelt es sich aber oft um eine Machtsicherungsstrategie und die Vermeidung von möglicher Machtbedrohung durch jede Form von Wahlen.

Das Leben in einem solchen Sonderraum, der entweder von realen, scheinbaren oder lokalen Machthabern proklamiert wird, hat ernsthafte Folgen für seine Bewohner, insbesondere aber für die Urbanisierung des Flüchtlingslagers wie auch für seine Beziehung zur urbanen oder ländlichen Umwelt. Eine umfassende Verbesserung der Bedingungen in den Flüchtlingslagern kann jedoch nicht in einem Sonderraum stattfinden, in dem kaum eine städtische Ordnung angewandt, Regeln und Gesetze aufgehoben sind. Tatsächlich ist er dem diametral entgegengesetzt. Dies führt zu einem nicht einfach zu lösenden Dilemma. Das Anliegen, partizipative und strategische Planungsansätze sowie »community empowerment« einzuführen, bleibt leere Rhetorik, wenn nicht das Problem der »camp governance« direkt angegangen wird.

Der Pilotplanungsprozess in dem in der Westbank gelegenen Flüchtlingslager Fawwar macht die großen Schwierigkeiten deutlich, die auch in einem verhältnismäßig stabilen Flüchtlingslager im Zusammenhang mit der Frage der lokalen Macht- 
verhältnisse auftreten können. Die vielfältigen Konflikte legen exemplarisch dar, wie ein partizipativer Planungsprozess etablierte Machtpositionen hinterfragen und verändern kann. Insbesondere das schwierige Verhältnis zwischen der Lagergemeinschaft und UNRWA wandelte sich von einer durch Mistrauen (gegenüber Agentur und Camp Improvement Programme) geprägten Atmosphäre zu einer erstmalig gleichberechtigten Partnerschaft bei der Definition von Maßnahmen und Entwicklungsprioritäten. Das konkrete Ziel - die Verbesserung der Lebensbedingungen im Flüchtlingslager zu erreichen - schuf hierfür einen konstruktiven Rahmen. Neben den Erfolgen im pragmatischen Umgang miteinander zeigte der Planungsprozess ein noch viel grundlegenderes Potenzial auf: Partizipation und lokales Empowerment bei Planungsinitiativen an der gesellschaftlichen Basis sind dazu verurteilt, projektbezogen und temporär zu bleiben, wenn der Status Quo sich nicht ändert. Ein radikales Umdenken in Bezug auf Selbstverwaltung ist notwendig, damit Versprechen und Potential der Verbesserung der Lebensbedingungen in den Flüchtlingslagern vollkommen ausgeschöpft werden können - hier ist vorausgesetzt, dass UNRWA die Flüchtlingsgemeinschaft weder repräsentieren kann noch sollte. Ein Planungsprozess könnte hierbei als Katalysator wirken. Die im Planungsprozess gebildeten Strukturen könnten sich zu dauerhaften, lokalen Verwaltungsstrukturen verstetigen die mit UNRWA und anderen Akteuren auf gleichberechtigter Ebene agieren und die mittel- und langfristige Eigentümerschaft für den »Camp Improvement Plan« übernehmen.

Der Planungsprozess von Fawwar hat in ersten Anfängen gezeigt, wie sich eine solche Struktur entwickeln könnte. Es entstand eine Arbeitsplattform (»Working Group«) unter dem Dach des "Local Committees", das alle wichtigen Entscheidungen im Planungsprozess traf und als ein »Türöffner in die Gemeinde « fungierte. Die Working Group garantierte erstmals eine breite Einbeziehung einer Vielzahl neuer, bislang unterrepräsentierter Gruppen wie Frauen oder Jugendliche. Im Arbeitsprozess verschwand allmählich der anfängliche Widerstand der Lagereliten, "gewöhnliche" Lagerbewohner am Entscheidungs-prozess teilhaben zu lassen. So entstand eine zielorientierte und im Sinne der Gesamtgemeinschaft arbeitende 
breite Plattform, die nicht nur bottom-up-Planung, sondern auch effektives Verhandeln mit Partnern auf der kommunalen und staatlichen Ebene ermöglichte. Vertreter von Nachbargemeinden und externen NGOs wurden zu Beratungen eingeladen und wichtige Entscheidungen wurden einvernehmlich getroffen.

\section{Schlussfolgerungen: \\ Die Flüchtlingslager nach CIP?}

Worin werden die kurz-, mittel- und langfristigen Auswirkungen des Camp Improvement Programmes in den Flüchtlingslagern bestehen? Bis dato bleibt das Vorhaben, eine grundlegende Verbesserung der Lebensbedingungen in den hochverdichteten Flüchtlingslagern zu erreichen, ein verbales Versprechen. Zwar konnten erste Erfolge im Pilotvorhaben erreicht werden, doch der breiten Anwendung und Umsetzung des Programms stehen weiterhin gewaltige Hürden im Weg. Die anhaltenden finanziellen Schwierigkeiten der UNRWA verhindern die baldige Eingliederung des CIP in das allgemeine Budget der Organisation. Dies beeinflusst einerseits den Status, den das Programm innerhalb des Portfolios der UNRWA einnimmt. Andererseits ist die Kontinuität der Aktivitäten in Gefahr und der Aufbau notwendiger Kapazitäten wird erschwert. Eine vorwärts gerichtete Planung und Bestimmung der Zielvorgaben und Entwicklungsziele ist deshalb kaum möglich.

Anstatt die vielen operationellen Schwierigkeiten zu analysieren, die es noch zu lösen gilt, sollen abschließend noch einmal die wesentlichen Potenziale, die die Einführung von partizipativer Planung in Flüchtlingslager bieten, diskutiert werden. Hierfür soll ein bewusst positives Szenario skizziert werden ein bestmögliches Entwicklungsszenario für Flüchtlingslager bei anhaltender ungelöster Flüchtlingskrise. Das Szenario geht davon aus, dass das Camp Improvement Programme sowohl institutionalisiert und voll finanziert wird, so dass strategische Kernziele auf der Ebene der Flüchtlingslager erreicht werden können. Dazu gehören zum Beispiel Lösungen für die sich aus der überhöhten Bebauungs- und Bevölkerungsdichte ergebenen Probleme, wie die Schaffung von Zugangs- und Wegesystemen, 
einer adäquaten technischen Basisinfrastruktur, der Schaffung von ausreichend öffentlichem Raum und Aspekten der räumlich-physischen Gemeindeentwicklung. Weiterhin geht dass Szenario davon aus, dass eine von allen Konfliktparteien getragene, politische Lösung des palästinensischen Flüchtlingsproblems in naher Zukunft nicht absehbar ist und UNRWA weiterhin hauptsächlicher Anbieter zentraler Dienstleistungen in den »Camp Cities« bleibt. Bei einer erfolgreichen Umsetzung von Camp Improvement könnten partizipative Planungsprozesse die Beziehung zwischen Hilfsorganisation und Flüchtlingsgemeinden radikal neu definieren, im Sinne einer Verlagerung von Verantwortung von UNRWA in Richtung einer in der Gemeinschaft verankerten Selbstverwaltungsstruktur.

Ein solches Entwicklungsszenario gleicht der Forderung der Migrationsforscherin Susan Bankis nach »local integration in the intermediate term " als best mögliche Zwischenlösung (vgl. Banki 2004; Crisp 1999). In Überlegungen zu kenianischen Flüchtlingslagern argumentierte Banki, dass die Fähigkeit der Flüchtlinge im wirtschaftlichen und kommunalen Leben der Aufnahmeregion teilzuhaben nicht notwendigerweise ihren Status als Flüchtlinge aufhebt. Vielmehr ist ihre volle Partizipation am gesellschaftlichen Leben der Aufnahmeregion als ein grundlegendes Menschenrecht zu verstehen, welches ihr politisches Recht auf Rückkehr oder Entschädigung nicht komprometieren sollte. Auf den palästinensischen Fall übertragen, könnte diese Vorstellung zu einem fundamental neuen Verständnis der Flüchtlingslager als im sozialen und wirtschaftlichen Leben der Aufnahmeregion vollkommen integrierten »Camp Cities« auf palästinensischem Territorium führen.

Angesichts der vielen bereits genannten Hindernisse erscheint ein solches Szenario aus heutiger Perspektive vielleicht unrealistisch. Allerdings zeigt eine globalere Sicht, dass solch eine Rekonzeptionalisierung nicht nur notwendig, sondern auch möglich ist. Alternative Modelle von eigenständigen und nachhaltigen ländlichen Siedlungen für Flüchtlinge, die völlig im sozialen und wirtschaftlichen Leben der Gastregion eingegliedert sind, wurden seit den frühen achtziger Jahren im afrikanischen Kontext erprobt und werden gegenwärtig wiederbelebt. 
Eine erfolgreiche, groß angelegte Anwendung der CampImprovement-Prinzipien könnte, bei ausreichender Unterstützung der Gastländer, eine tief greifende Transformation der gegenwärtigen urbanisierten Flüchtlingslager zur Folge haben. Schließlich bietet das Programm eine Gelegenheit, eine neue Typologie der Ansiedlung von Flüchtlingen zu begründen, die sich in ihrer Struktur, Perspektive und Organisation von jeder anderen Form der Konzentrierung von Flüchtlingen unterscheidet - eine urbane Umwelt, in der Flüchtlinge fast alle Bürgerrechte haben und dabei ihren Status als Flüchtlinge, d.h. als Nicht-Staatsbürger, beibehalten. Die räumlichen und baulichen Charakteristika dieser »Integrated Camp Cities« könnten wie folgt aussehen:

Der bereits existierende Bevölkerungsüberschuss müsste anerkannt werden und die Verbesserung der Bedingungen würde darauf abzielen, alte und neue Flüchtlingslager zu integrieren. Dies würde die offiziellen Lagergrenzen der UNRWA weiter verwischen. Wenn »Camp Improvement Plans« tatsächlich über diese Grenzen hinaus angewendet würden, wäre ihre Wirkung auf den Alltag der Flüchtlinge weiter vermindert. Es wäre zunehmend schwieriger, die Flüchtlingslager von ihrer urbanen oder suburbanen Umgebung zu unterscheiden. Jedoch ist es wahrscheinlich, dass die Grenzen der Flüchtlingslager auch weiterhin über reale Besitzgrenzen definiert würden (innerhalb der Grenzen würden Pachtverträge von 1948 bestehen bleiben, während außerhalb Eigentum im Einklang mit den Gesetzen des Aufnahmelandes reguliert würde).

Zur Reduzierung der Bevölkerungs- und Bebauungsdichte müssten Zwischenlösungen, in den meisten Fällen außerhalb der gegenwärtigen Flüchtlingslagergrenzen gefunden werden. De facto würde dies einer Expansion der Flüchtlingslager gleichkommen und könnte die Einführung von sozialem Wohnungsbau und neuen Gebäudetypen wie zum Beispiel Hochhäusern mit sich bringen.

Die durchschnittliche Bevölkerungszahl der Flüchtlingslager in den palästinensischen Territorien beträgt etwa 35.000, was der Größe einer Kleinstadt entspricht. Es ist deshalb nur folgerichtig, dass nachhaltige »camp governance« von kommu- 
nalem Management lernen sollte. ${ }^{18}$ Der Prozess in Fawwar hat gezeigt, dass die bereits bestehenden »Local Committees« der Westbank sich zu solchen Strukturen entwickeln könnten. In der Tat sind ihre Erfahrungen bei der Bereitstellung kommunaler Serviceleistungen und bei der Vertretung der Gemeindeinteressen ein guter Ansatzpunkt, der als Modell für andere Länder dienen könnte.

Verwaltungsinstitutionen in den Flüchtlingslagern würden wie andere Stadtverwaltungen auch auf zwei Ebenen agieren müssen. Einerseits müssten sie gewährleisten, dass sich die breite Basis der Flüchtlingslagergemeinde an wichtigen Entscheidungsprozessen beteiligen kann. Andererseits müssten diese Institutionen von den Behörden des Gastlandes als legitime Partner und Repräsentanten der Interessen der Flüchtlingslagergemeinde anerkannt werden. Dabei sollten diese neuen Verwaltungsstrukturen der Flüchtlingslager nicht nur gegenüber denjenigen, für die sie da sind (den Bewohnern der Flüchtlingslager), sondern auch gegenüber den übergeordneten Behörden rechenschaftspflichtig bleiben. Zentrale Entscheidungen dürften dabei nicht im Alleingang gefällt werden, vielmehr bedürften sie der Partizipation und der Abstimmung mit der UNRWA, den entsprechenden regionalen Vertretern und den nationalen Regierungen. Externe Akteure müssten hinzu gezogen werden, um die Effektivität der Lagerverwaltungsstrukturen, einen transparenten Wahlprozess, die Form der Entscheidungsfindung und die Ausgaben zu überwachen.

Worin könnten die mittelfristigen Wirkungen bestehen? Eine Verlagerung der Entscheidungsgewalt von einer zentralisierten Behörde wie UNRWA auf Verwaltungsstrukturen der Flüchtlingslager sowie Lager-spezifische CIP würden zu einer wachsenden Diversifizierung von Flüchtlingslagern führen.

18 Dieser Ansatz wurde erstmals von einem von Piet Goovaerts geleiteten Beraterteam vorgeschlagen, das die UNRWA bei der Entwicklung der Initiative zur Verbesserung der Lebensbedingungen in den Flüchtlingslagern unterstützte. Goovaerts behauptete, dass camp governance wie städtische Verwaltung von demokratisch gewählten Individuen geleitet werden sollte und dabei transparent, rechenschaftspflichtig und auf regionaler Ebene in die staatlichen Strukturen des Aufnahmelandes integriert sein sollte (vgl. Goovaerts 2006). 
Einflussfaktoren wie politischer Kontext und Lage, ortsspezifische Gegebenheiten und Potentiale, lokal existierende Initiativen und Kompetenzen würden dabei neue Bedeutung erlangen und veränderten jedes Flüchtlingslager auf andere Weise. Es ist sogar wahrscheinlich, dass integrierte Flüchtlingslager, ähnlich wie Gemeinden, miteinander in den Wettbewerb um Ressourcen, Hilfe von Gebern und Programme der Regierung des Gastlandes treten.

Erfolgreiche CIP würden die lokale Entwicklung anschieben und könnten die Flüchtlingslager in eine vorteilhafte Position gegenüber umliegenden Dörfern und Städten bringen, die keine internationale Unterstützung erhalten. Unterschiede beim Zugang zu Bildung, Gesundheitsangeboten und Hilfsprogrammen machen sich schon heute bemerkbar. In abgelegenen ländlichen Gebieten haben sich Flüchtlingslager bereits zu wirtschaftlichen Zentren entwickelt und könnten zukünftig verstärkte Bedeutung als regionale Motoren für Entwicklung gewinnen. Lokale Modelle von »camp governance« könnten ihre Umgebung dahingehend beeinflussen, dass dies möglicherweise auch zur Anregung eines Reformprozesses der politischen und administrativen Strukturen führt und die Bevölkerung ermutigt, stärkere Transparenz, Rechenschaft und direkte Partizipation in Planungsprozessen einzufordern.

Die Funktion der UNRWA in Bezug auf die Flüchtlingslager würde sich im Zuge klarer definierter Verantwortlichkeiten und der Etablierung lokaler Verwaltungsinstitutionen zwangsläufig ändern. Dies kann der Organisation möglicherweise helfen, ihr Budget einzuhalten und ihre Hauptleistungen im Bildungs- und Gesundheitsbereich effektiver auszuüben. Letztere werden aufgrund des projizierten natürlichen Bevölkerungswachstums in den Flüchtlingslagern ausgebaut werden müssen. Mit der vollständigen Implementierung dieses Entwicklungsansatzes würde UNRWA gefordert sein, andere Leistungen wie Ausbildung, Training und Monitoring sowie die Interessensvertretung im Namen der Flüchtlingslager bereit zu stellen. Dies würde bedeutende interne Reformen der UNRWA zur Folge haben. 


\section{Literatur}

Agamben, Georgio. (1998): Homo Sacer: Sovereign Power and Bare Life, Palo Alto, CA: Stanford University Press.

Agier, Michel 2008: On the Margins of the World - Refugee Experience Today, Cambridge: Polity Press.

AL Husseini, J./Bocco, R./Brunner, M. (im Erscheinen): "Status of Palestinian refugees in the Near East: The Right of Return and UNRWA in Perspective«. In A. Knudsen and S. Hanafi (Hg.), Palestinian Refugees in the Levant: Identity, Space and Place. London: Routledge.

Banki, Susane (2004): »Refugee Integration in the Intermediate Term: A Study of Nepal, Pakistan, and Kenya«, New Issues in Refugee Research, Working Paper Nr. 108, Genf: UNHCR.

Crisp, Jeff. (1999): »Who has counted the refugees? UNHCR and the politics of numbers, New Issue in Refugee Research«, Working Paper Nr. 12, Genf: UNHCR.

Goovaerts, Piet (2006) et al.: »Consultancy to Assist in the Development of the Concept, Policies \& Strategies for the new UNRWA Camp Development Approach «, Smooth Managing, Amman: Report erstellt im Auftrag von UNRWA.

Kortam, M. (2007): Le Rôle des Acteurs Locaux dans le Processus d'Incorporation des Palestiniens du Liban, unveröffentlichte Masterarbeit, Beirut: Université Saint Joseph.

Loescher, Gil/Betts, Alexander/Milner, James (2008): The United Nations High Commissioner for Refugees (UNHCR) The Politics and Practice of Refugee Protection into the 21st Century, Abingdon, New York: Routledge.

Medium Term Plan (2005-2010): Internes UNRWA Strategiepapier; Amman: UNRWA Headquarters

Perouse de Montclos, Marc-Antoine/Kagwanja, Peter Mwangi (2000): »Refugee Camps or Cities? The Socio-economic Dynamics of the Dadaab and Kakuma Camps in Northern Kenya«, Journal of Refugee Studies 13, S. 205-222.

UN-HABITAT (2006): "State of the World's Cities 2006/ 2007 The Millennium Development Goals and Urban Sustainability«, UN-HABITAT/ London: Earthscan publications.

Universität Stuttgart/UNRWA (Mai 2008): »UNRWA-Camp Development Pilot Research Project: Main Research Report 
(2006-2008) «, erstellt von der Universität Stuttgart im Auftrag des »Infrastructure and Camp Improvement Department «, UNRWA Headquarter Amman.

Misselwitz, Philipp et. al. (2008a): „Camp Improvement Manual« (2008), interne Veröffentlichung des »Camp Development Pilot Research Project« - eine Kooperation der UNRWA und der Universität Stuttgart.

Misselwitz, Philipp et.al. (2008b): „Camp Development Pilot Research Project - Main Research Report«, Ergebnisreport der Kooperation der UNRWA und der Universität Stuttgart. 
RÜCKKEHR IN DIE FREMDE 



\section{Palästinenser im Exil und nach ihrer Rückkehr ${ }^{1}$}

PÉNÉLOPE LARZILLIÈRE

Rückkehrer, ausgewanderte Ingenieure und Studenten im Ausland: Sie alle teilen die Erfahrung einer längeren Entfernung von den palästinensischen Gebieten, die die Voraussetzung dafür ist, dass sich die persönliche biographische Erfahrung von der nationalen Geschichte der Palästinenser daheim unterscheidet. Tatsächlich bietet nur diese Entfernung eine Möglichkeit, alltäglichen Demütigungen zu entkommen, die immer wieder erneut an den schon mythisch gewordenen »nationalen Kampf der Palästinenser« erinnern.

Besonders aufschlussreich ist das Phänomen der jungen Rückkehrer. Im Moment ihrer Rückkehr wurden sie alle zunächst von der stark konservativen palästinensischen Gesellschaft abgelehnt. Die Zurückgebliebenen warfen der ausgewanderten und zurückgekehrten Jugend vor, reich zu sein und ein ausschweifendes Leben zu führen. Doch je mehr Zeit die Rückkehrer in den palästinensischen Gebieten verbrachten, desto mehr nahmen sie den nationalistischen Diskurs wieder auf, besonders seit der Zeit der Al Aqsa-Intifada. ${ }^{2}$

1 Übersetzung von Klaus Schlichte aus: Etre jeune en Palestine, Paris: Editions Balland, 2005, S. 163-182.

2 Während die »Erste Intifada«, die 1987 begann und mit dem Abkommen von Oslo 1993 ihr Ende fand, sich durch zivilen Unge- 
Eine umgekehrte Haltung haben die Ingenieure entwickelt, jene Diplomierten, die über einen ihrer Ausbildung entsprechenden Arbeitsplatz verfügten, und die, verglichen mit dem Rest der palästinensischen Bevölkerung, ebenso wie die Rückkehrer als die »Goldjugend « bezeichnet werden könnten. Sie können ihre Ablehnung des lebensgefährlichen und strategielosen nationalen Kampfes nur dadurch äußern, indem sie das Land verlassen. Doch diese Alternative, die es dem Individuum erlaubt, das eigene private Leben vom nationalen Ziel zu trennen, lässt die Frage nach der Entsolidarisierung vom gemeinsamen Schicksal offen. Genau diese Frage teilen sie mit den palästinensischen Studenten im Ausland, die Anfang der 1990er Jahre in Deutschland studierten und von der Autorin zwischen 1999 und 2002 interviewt wurden. (Anm. d. Übers.)

\section{Die jungen Rückkehrer}

Die jungen palästinensischen Rückkehrer sind zu einem großen Teil im arabischen Ausland aufgewachsen, vor allem in Tunesien. Mehrheitlich sind sie - häufig gegen ihren Willen - zurückgekehrt, als ihre Väter, die PLO-Kader waren, Arafat 1994 folgten, um die palästinensische Selbstverwaltung aufzubauen. Schätzungen über die Zahl derer, die nach dem Abkommen von Oslo zurückgekehrt sind, schwanken zwischen 50.000 und 60.000 (Van Hear 1997: 35). ${ }^{3}$ Das Personal der PLO war darunter die größte Gruppe mit ca. 38.000 Personen. Diese Kategorie umfasste die eigentlichen Kader der PLO (18.000), die Polizisten, die unter jenen Palästinensern rekrutiert wurden, die eine ägyptische Aufenthaltserlaubnis oder einen jordanischen Pass besaßen (12.000), und ihre Familienmitglieder (8.000). Die geringe Zahl der Familienmitglieder erklärt sich dadurch, dass

horsam und dann gewaltsame Eskalationen auszeichnete, war die "Zweite Intifada" - auch Al Aqsa-Intifada genannt - durch eine Zunahme von Bombenattentaten durch Palästinenser und die Raketenangriffe auf Häuser mutmaßlicher Täter durch Israel gekennzeichnet. Die Zweite Intifada begann im September 2000 und endete 2005 mit dem Abkommen von Scharm El-Scheich (Anm.d.Übers.).

3 Dies ist auch die Quelle aller nachfolgenden Zahlen. 
viele der Kader, besonders solche, die den Sicherheitsdiensten angehörten, ohne ihre Familien zurückgekehrt sind. Hinzu kam noch jene kleine Gruppe, die von einem Familienzusammenführungsprogramm Israels profitierte (6.000). ${ }^{4}$ Schließlich müssen die »Ameriko-Palästinenser« hinzugezählt werden. Über diese Gruppe lagen leider keine Zahlen vor. Es handelte sich um die Familien derer, die nach dem Sechs-Tage-Krieg 1967 in die USA emigriert sind. Ein Teil von ihnen ist nach dem Abkommen in die A-Zone zurückgekehrt ${ }^{5}$, während die Familienväter aus beruflichen Gründen in den USA blieben. Obwohl diese Gruppe von Rückkehrern viel kleiner als die der oben aufgeführten Gruppen war und sich der zahlenmäßige Umfang nicht abschätzen ließ, ist diese Gruppe sehr präsent, da sich die »Ameriko-Palästinenser « vor allem in Ramallah und Umgebung konzentrierten. Mit einem US-amerikanischen Pass versehen, wurden sie anders als die anderen genannten Gruppen, von Israel nicht mit einer Aufenthaltserlaubnis versehen, sondern erhielten nur ein dreimonatiges Touristenvisum, das alle drei Monate zu erneuern war, um den Status der Illegalität zu vermeiden.

Die Gruppe der Rückkehrer war in allen genannten Kategorien gleichermaßen jung. Gut 47 Prozent waren zwischen 15 und 39 Jahre alt, und ihre Schulbildung lag höher als der palästinensische Durchschnitt: 14 Prozent haben ein BA-Studium absolviert, was nur bei 4 Prozent der sonstigen palästinensischen Bevölkerung der Fall ist (el-Malki 2001: 14).

\section{Der Kulturschock}

Die Rückkehr in die Gebiete erwies sich für die meisten der Jugendlichen als eine ambivalente Erfahrung. Sie bedeutete zunächst die Entwurzelung aus den Ländern, in denen sie sich wohl fühlten und die sie nicht verlassen wollten. In ihrem Diskurs kamen immer wieder nostalgische Erinnerungen an die

4 Die Quote wurde von Israel auf 6.000 jährlich festgelegt. Das Programm fand aber keine dauerhafte Fortsetzung.

5 Die A-Zone der West-Bank ist vollständig der Palästinensischen Autonomiebehörde unterstellt, während die B- und C-Zonen teils direkt von Israel kontrolliert werden (Anm.d.Übers.). 
Vergangenheit in Tunesien und Jordanien vor. In manchen ameriko-palästinensischen Familien wurde den Jugendlichen erst gar nicht angekündigt, dass ihre Rückkehr definitiv sein würde, um mögliche Diskussionen darüber im Vorfeld zu vermeiden. Eine solche Umsiedlung bedeutete eine Konfrontation zwischen einer vermittelten Erinnerung und den Realitäten in den Palästinensischen Gebieten. Palästina wurde in solchen Erinnerungen als idyllisches und paradiesisches Land glorifiziert. Die Übermittlung dieser Erinnerung geschah nicht nur durch elterliche Erzählungen, sondern auch durch mediale Diskurse, besonders durch das Internet. Aber im Gegensatz zu den Erinnerungen ihrer Eltern, beruhten ihre »Erinnerungen « nicht auf eigene Erfahrungen (Tamini 2002: 7).

Entsprechend groß war der Schock bei der Ankunft, vor allem im Vergleich mit der idealisierten Erinnerung und dem Wohlstand in den Ländern, in denen die Rückkehrer aufgewachsen waren. So fanden sie sich in einer ausgesprochen ambivalenten Lage wieder: Inmitten der Palästinensischen Gesellschaft, die alles aus ihrem früheren Leben - und damit sie selbst - brüsk zurückwies, und zugleich angezogen von einem Lebensstil in Israel, der dem ihres früheren Lebens weit mehr ähnelte.

Der Kontrast war für die jungen Frauen besonders stark. Ihre Väter wollten in der palästinensischen Gesellschaft beweisen, dass ihre Familien in der Fremde intakt geblieben sind und ihre Identität bewahrt haben. Dies sollte sich besonders am »ehrenhaften « Lebensstil zeigen, der sich am Verhalten der jungen Frauen am ehesten belegen ließ. Deshalb bezog sich die Kritik der jungen Rückkehrerinnen an der palästinensischen Gesellschaft auch in erster Linie auf Probleme der Reputation, während die jungen Männer eher die mangelhafte Infrastruktur an geselligem Leben oder an Freizeitmöglichkeiten thematisierten.

Vor der Al Aqsa-Intifada (vor 2000) ließ sich auch eine Welle der Repatriierung von »Problemjugendlichen « durch ihre Eltern beobachten, da die Eltern glaubten, sie in einem »strengeren« sozialen Umfeld einfacher kontrollieren zu können. So konnte es in der palästinensischen Diaspora in den USA vorkommen, dass sich Eltern zur Rückkehr der Familie entschlossen, wenn ihre Kinder begannen, Drogen zu nehmen. 
Allerdings konnte auch die Rückkehr nach Palästina für einige junge Frauen den paradoxen Effekt haben, dass sich ihre persönliche Freiheit nach der Rückkehr vergrößerte. Denn die Eltern vertrauten darauf, dass sich diese Umgebung komplementär zu ihren Erwartungen strukturierte, und gewährten ihren Töchtern deshalb mehr Freiheiten als in der "gefährlichen" amerikanischen Gesellschaft (Tamini 2002: 8).

In der Regel aber ging mit dem Eintritt in die palästinensische Gesellschaft ein Verlust an bisherigen Freiheiten einher. Doch die jungen Rückkehrer entwickelten eine Reihe von Strategien, um ihre verlorenen Freiheitsräume wiederzugewinnen. Dies geschah zunächst durch die Schaffung von RückkehrerMilieus, in denen die alten Aktivitäten wie Cafébesuche und Abendveranstaltungen fortgesetzt werden konnten. Oft profitierten sie von ihren ausländischen Pässen, weil ihnen diese erlaubten, fern der kontrollierenden Blicke der palästinensischen Gemeinschaft, Einrichtungen in Israel aufzusuchen, wie Geschäfte, Cafés, Diskotheken usf. »Hier gibt es ja nichts, deshalb langweilen wir uns! Das einzige, was mich interessiert, ist, mit dem Auto eine Spritztour nach Tel Aviv zu machen! «6 Jenseits dieser Ausflüge, war die »Langeweile« der Gesellschaft, in der man nichts machen kann, ein wiederkehrendes Thema der Konversation:

»Das Leben hier macht mich verrückt. Von Zuhause in die Uni, von der Uni nach Hause. Ich habe zwar ein paar Freunde gewonnen, aber das ist hier nicht dasselbe. Ich bin an das amerikanische Leben gewöhnt, an die amerikanische Lebensart, beispielsweise auch was meinen Kleidungsstil angeht. Wenn ich dort eine grüne Hose und einen roten Pullover anziehe, dann interessiert das niemanden. Tue ich das hier, kriege ich von allen Seiten Kommentare zu hören. Das ist total oberflächlich! «7

Es entwickelte sich eine Ablehnung gegenüber der palästinensischen Gesellschaft, die wegen ihrer »Unterentwicklung «, ihres Konservatismus und ihrer starken sozialen Kontrolle auf die

6 Student, 21 Jahre alt, in Tunis aufgewachsen, 1994 mit seinem Vater in die Gebiete zurückgekehrt.

7 Sana, aus Amman: Sie verlangt einen Lebensstil, den sie "amerikanisch« nennt, weil sie ihn von der Universität in Amman kennt. 
Kritik der jungen Rückkehrer stieß. Die sozialen Unterschiede waren groß und wurden stark empfunden: »In unseren Familien hat man maximal zwei Kinder, das ist nicht wie bei den Leuten hier. Weißt $\mathrm{Du}$, hier sind die Leute verrückt. «8

Doch der Gegensatz zwischen den Rückkehrern und der lokalen palästinensischen Gesellschaft beruhte auf Gegenseitigkeit. Während die jungen Rückkehrer ihr Leben eingeschränkt sahen, empfanden die lokalen Palästinenser den Stil der jungen Rückkehrer als zügellose Zurschaustellung ihres Reichtums. Ihnen wurde vorgehalten, nicht an den entbehrungsreichen Kämpfen der Intifada teilgenommen zu haben, nun aber von der Selbstverwaltung zu profitieren, indem sie die Posten und Ämter übernahmen und ein schönes Leben führen würden. Diese Vorwürfe äußerten sich gelegentlich auch in gewaltsamen Übergriffen.

Anfangs waren diese Unterschiede so stark, dass eine Integration der jungen Rückkehrer gar nicht stattfand. Sie waren einfach zu unterschiedlich, sowohl was ihre finanziellen Mittel anging als auch ihre Bewegungsmöglichkeiten - ein gewichtiger Unterschied in Palästina - und schließlich auch in Bezug auf ihre Identität und ihre Ideenwelt. Ihre Beziehung zum nationalen Projekt »Palästina « war grundsätzlich anders: Während ihre Eltern zurückgekehrt waren, um das Land aufzubauen, stand die Mehrheit der Jungen diesen Plänen distanziert gegenüber und war eher apolitisch. Alle träumten davon, wieder auszureisen und keiner der Interviewten konnte sich vorstellen, das weitere Leben in den palästinensischen Gebieten zu verbringen. Doch auf unvorhergesehene Weise nahmen die Dinge einen anderen Verlauf. Statt einer Zunahme an Antagonismen entwickelten die jungen Rückkehrer ein stärkeres Verständnis für die Situation, und begannen mit eigenen Vorstellungen an der palästinensischen Öffentlichkeit teilzuhaben.

\section{Von der Ablehnung zur Anpassung}

Auch wenn die jungen Rückkehrer über größere Ressourcen und über mehr Bewegungsfreiheit verfügten, so bedeutete ihre Rückkehr doch die Konfrontation mit dem realen palästinensi-

8 Studentin an der Universität Bit Zeit, aufgewachsen in Tunis. 
schen Alltag. Ihre anfängliche Ablehnung der palästinensischen Ordnung wurde langsam schwächer, insbesondere in dem Maße, wie sie zunehmend den sozialen Raum selbst markierten:

»Jetzt verhalten sich die Leute uns gegenüber nicht mehr so wie früher. Sie fragen uns nicht mehr, >Was hast du hier verloren? \& Ich würde auch nicht in einem Land bleiben, in dem die Leute mich dauernd fragen >Was hast du hier verloren? Das hier ist mein Land, ich mache, was ich will. Jetzt sind die Leute anders, weil sie gemerkt haben, dass wir mehr können als sie. Das war doch hier'n Bazar, die Leute haben ihr Gemüse irgendwo auf der Straße verkauft. Wir ${ }^{9}$ haben einen Markt gebaut. Früher gab es zum Beispiel diese Straße mit den Cafés und Restaurants nicht. Wir haben hier alles gemacht, wir haben auch die Mentalität verändert. ${ }^{10}$

An dieser Passage lässt sich erkennen, dass sich die jungen Rückkehrer die Ziele ihrer Eltern zu Eigen gemacht haben und auf das von der Autonomiebehörde Erreichte ebenfalls stolz waren. Dieser Stolz verdrängte aber nicht das Gefühl, einer besonderen, überlegenen sozialen Gruppe anzugehören. Aber durch die Teilhabe an diesen Projekten entstand zugleich ein Gefühl der Zugehörigkeit zum Gebiet.

Für die Ameriko-Palästinenser traf diese Form der Einfügung in den sozialen Raum Palästinas nur bedingt zu. Ramallah hat sich zum Beispiel durch die Anwesenheit der Rückkehrer sehr verändert. Überall sind Restaurants, Cafés und Internet-Cafés entstanden, wo sich die jungen Rückkehrer treffen. Direkt neben den Graffitis der Intifada lassen sich amerikanische »tags « finden.

Ihre Beziehung zum kollektiven Gedächtnis der Palästinenser hat sich auch durch diesen neuen Raum verändert, an dessen Veränderung sie direkt teilhatten. Die Ameriko-Palästinenser passten sich aber nicht komplett an, obwohl sie den sozialen Raum mit beeinflussten. Trotz ihrer größeren Bewegungsfreiheit bekamen sie aber nach und nach die Wirklichkeit der Besetzung zu spüren. Das geschah besonders in der Zeit nach der zweiten Intifada, in der sie mit der sonstigen palästinensischen

9 Das kollektive »Wir« bezieht sich in diesem Fall auf die Palästinensische Autonomiebehörde.

10 Student, 21 Jahre, s. Fn. 7. 
Bevölkerung die Ausgangssperren, Bombardements und die Vervielfachung der Checkpoints miterlebten.

Da die Blockaden der Flughäfen durch Israel häufiger stattfanden wurde auch für die Ameriko-Palästinenser das Reisen in die USA schwieriger. Diese Veränderungen schlugen sich auch in ihrer Einstellung nieder, für die die »nationale Sache« der Palästinenser nun eine größere Rolle spielte.

Die zunehmende Bedeutung des »nationalen Ziels Palästina « führte aber bei der Mehrheit der Rückkehrer nicht zur gleichen Form des Engagements, wie sie es in der lokalen Bevölkerung vorfanden. Wenn sie sich engagierten, dann eher friedlich und in zivilen Formen:

»Wir brauchen neue Ideen. Wir können doch nicht immer nur diese Demonstrationen machen, wo dann immer nur Reden gehalten werden. Ich komme, weil ich denke, man muss sich zusammenschließen, aber doch nicht immer nur so. Zum Beispiel könnten doch all die, die nicht mehr in Israel arbeiten dürfen, sich zusammentun und Bäume pflanzen, um die zu ersetzen, die von Israel gefällt werden. Mit ein paar Freunden mache ich nächstes Semester so ein Projekt, also einen Verein zu gründen, der solche Sachen organisiert, Bäume pflanzen, Zwei-, Drei-TageSeminare über palästinensische Geschichte. Denn die Mehrheit der Leute hier kennen die Geschichte Palästinas gar nicht, weil es verboten war, das an der Schule zu unterrichten.«11

Sensibler für den internationalen Kontext, achteten die Rückkehrer viel stärker darauf, wie der palästinensisch-israelische Konflikt in den westlichen, vor allem US-amerikanischen Medien dargestellt wurde. Wenn sie aktiv wurden, dann auf dieser Ebene, vor allem über das Internet.

Mit der Zeit veränderte sich auch ihre Einstellung zur palästinensischen Gesellschaft. Von einer kompletten Ablehnung der

11 Dieser Student an der Universität Bir Zeit, genannt »der Tunesier«, war zum Zeitpunkt des Interviews Praktikant bei der BauAbteilung der Stadtverwaltung von Al Bireh in einem Projekt zur Verbesserung der Wasserversorgung. Das Interview fand in der Nacht statt, die der Liquidierung von Abu Ali Mustafa durch die israelische Armee am 27. August 2001 folgte. Abu Ali Mustafa war der Generalsekretär der linksgerichteten »Popular Front for the Liberation of Palestine«. 
palästinensischen Gesellschaft, insbesondere aufgrund der ausgesprochen starken sozialen Kontrolle, wandelten sich die Einstellungen hin zu einem stärkeren »Verständnis«. Verständnis allerdings nicht im Sinne von Akzeptanz, sondern eher im Sinne der Entwicklung eines Umgangs mit der Situation der Palästinenser. Diese Veränderung fand sich vor allem bei den jungen Frauen, denen, anders als ihren Brüdern, in der Regel nicht erlaubt wurde, wieder ins Ausland zu gehen, um dort ihr Studium zu beenden. Assala zum Beispiel bestand noch 1997 darauf, dass sie auf keinen Fall in den Palästinenser-Gebieten bleiben würde und ihr Studium in Tunesien zu Ende bringen wolle. Im Jahr 2001 hingegen haben sich ihre Pläne geändert, was unter anderem auch auf eine Liebesbeziehung zurückzuführen ist:

»Ich habe einen Freund, wir treffen uns, ich bin auch schon bei seiner Familie gewesen. Meine Verwandten wissen davon. Aber mein Vater weiß nicht alles, er weiß nicht, dass ich schon bei der Familie war. Für ihn ist die Ehre das Allerwichtigste. Wenn sich nun herausstellen sollte, dass wir doch nicht für einander gemacht sind, dann würden die Leute sagen 'Sie war doch schon bei seiner Familie war immer nur da, wenn auch seine Mutter da war. Wir verstehen uns gut. Diese Beziehung hilft mir sehr, das Leben hier zu ertragen. Ich liebe dieses Land, aber ich habe mich noch nicht an die Einstellungen der Leute hier gewöhnt. Aber das Gute ist, dass die Leute hier mich nicht kennen. Sie sprechen nicht über mich. In meiner Stadt bin ich eine Fremde, und in Ramallah auch. Aber ich passe auf, ich weiß, dass ich nichts Schlechtes tue. Wenn man einmal anfängt, darauf zu achten, was die Leute sagen könnten, dann macht man gar nichts mehr. Aber ich glaube, dass ein Fremder sich an die Sitten des Landes anpassen muss. Ich weiß noch nicht, wie es weitergehen soll, wenn ich mein Studium fertig habe, wenn ich zurückkomme. Ich mag meine Stadt, weil sie grün und schön ist. Aber ich mag das Leben hier nicht, ich kenne niemanden, man kann nichts unternehmen. Letzten Sommer war ich zwei Monate in den Gebieten, dann konnte ich nicht mehr. Ich habe gefragt, ob ich für eine Woche nach Jordanien gehen kann, um zu atmen, aber meine Eltern hatten kein Geld. Ich bin trotzdem gegangen, ich hatte nur 20 Schekel in der Tasche."

»Kannst Du nicht in Ramallah bleiben?«

»Das wird schwierig. Ich habe noch nicht mit meinem Vater gesprochen. Die einzige Möglichkeit in Ramallah zu bleiben ist entweder einen 
Job zu finden oder $\mathrm{zu}$ heiraten. Aber ich überlege das. Mit meinem Freund denke ich darüber nach. Wir wollen uns verloben und heiraten, aber nicht jetzt, sondern wenn ich mit meinem Studium fertig bin.«

An dieser Stelle muss der besondere Charakter Ramallahs in den Palästinensergebieten erklärt werden. Bedingt durch den hohen Anteil von Rückkehrern, scheint die Stadt von etwas freieren Umgangsformen gekennzeichnet, die auch eine gewisse Anonymität erlauben. Hier gibt es Freizeit- und Kultureinrichtungen, die mehr Möglichkeiten bieten. Das Kulturleben, das sich hier entwickelt hat, machte die Stadt in ihren Augen attraktiver als Ost-Jerusalem, und hat dazu geführt, dass sich auch einige junge Künstler und palästinensische Ingenieure aus Jerusalem in Ramallah niedergelassen haben.

\section{Eine transnationale Identität}

Das kollektive palästinensische Gedächtnis ist in der Diaspora erhalten geblieben. So war die palästinensische Identität, die Geschichte des Exils auch den Rückkehrern bekannt. Sie wurde durch eine transnationale soziale Geographie verstärkt. Obwohl sich zunehmend die Identität der Rückkehrer mit den Zielen des nationalen Aufbaus verband, blieben die jungen Rückkehren eng mit den Ländern verbunden, in denen sie aufgewachsen waren. Viele wollten in diese Länder zurückkehren, vor allem die jungen Männer, die in dieser Hinsicht über eine größere Freiheit verfügen und für die eine Rückkehr leichter war als für die jungen Frauen. Diese externen Bindungen zu erhalten, war für die jungen Rückkehrer eine entscheidende Ressource, vor allem dann, als die Bedingungen in den Territorien schwieriger wurden. Diese Bindungen erlaubten es, eine persönliche $\mathrm{Zu}$ kunft zu planen, unabhängig davon, welchen Wechselfällen die Situation in den palästinensischen Gebieten unterlag.

Das Selbstverständnis der Rückkehrer war also in diesem Kommen und Gehen zwischen den Palästinensergebieten und diesen Ländern verankert. Sie verstanden sich deshalb als doppelte Elite: eine der Diaspora und eine nationale. Verbunden mit den damit einhergehenden Ressourcen, wie ein ausländischer Pass, finanzielle Mittel und Studienabschlüsse, bedeutete dies auch die Möglichkeit, nicht der Geschlossenheit der Situa- 
tion ausgeliefert zu sein, die für die anderen palästinensischen Jugendlichen so typisch ist.

Ihre Beziehung zum »nationalen Ziel« war aus diesen Gründen auch weniger verzweifelt. Die jungen AmerikoPalästinenser, die das Leben im Westen besser kannten, glaubten daran, die öffentliche Meinung im Westen beeinflussen zu können, und richteten ihr Handeln danach aus. Im Gegensatz dazu hielten die jungen Rückkehrer, die in arabischen Ländern aufgewachsen waren und sich am Aufbau der nationalen Verwaltung engagiert haben, ein solches Projekt für wenig Erfolg versprechend. In dieser Hinsicht standen sie der palästinensischen Bevölkerung näher, auch wenn sie faktisch über mehr Ressourcen verfügten.

\section{Die Ingenieure}

Es gibt zwar keine Statistiken darüber, aber es ist deutlich wahrnehmbar: Junge Palästinenser aus den palästinensischen Gebieten, die die Möglichkeit dazu haben, verlassen diese, vor allem in Richtung USA oder Kanada. Die Ingenieure sind dafür archetypisch. Es handelt sich hierbei vor allem um junge Männer, die nach ihrer Ingenieursausbildung im Ausland einen ihren Kompetenzen entsprechenden Arbeitsplatz gefunden haben, während es für die jungen Frauen aus Gründen des sozialen Rufs ungleich schwieriger ist, allein ins Ausland zu gehen und dort $\mathrm{zu}$ arbeiten.

Der Wunsch zu gehen hatte zwei Dimensionen. In erster Linie ging es darum, einer geschlossenen Situation zu entkommen und die im Berufsleben schon angehäuften Mittel oder das Vermögen der Familie hierfür nutzbar zu machen. Diese Ingenieure konnten zum einen auf die Netzwerke der palästinensischen Diaspora zurückgreifen, zum anderen nutzten sie ihre beruflichen Verbindungen, etwa um sich in den USA beruflich zu spezialisieren oder in Kanada zu arbeiten. Diese Aufenthalte empfanden sie nicht als definitives Exil, sondern als zeitweilige Aufenthalte, die der beruflichen Verwirklichung dienen. Die Rückkehr wurde aber letztlich von der Situation in den Palästinensergebieten abhängig gemacht und ob sie dort eine entsprechende Arbeit finden konnten. 
Die zweite Dimension ihres Reisewunsches steht im Zusammenhang mit dem »nationalen Kampf«. Diese jungen Ingenieure engagieren sich massiv für die nationale Sache und fühlen sich ihr eng verbunden. Einerseits können sie die internationale Wirkung der politischen Maßnahmen der Palästinenser besser abschätzen, weil sie die Reaktionen des Auslands darauf besser kennen. Andererseits sind sie dadurch, dass sie sich ihr persönliches Leben außerhalb Palästinas vorstellen können, weniger in die tödliche Logik des Kampfes eingebunden.

Ihre Haltung zur Intifada wird insbesondere in der folgenden Aussage deutlich:

„Unser Problem ist, dass es sich hier um einen Konflikt handelt, bei dem eine Nation mit einer Armee gegen Individuen kämpft. Keiner will die Intifada machen, alle wollen, dass die Intifada aufhört. Die Israelis sagen, und in diesem Punkt ist das auch die Wahrheit, dass die Verwaltung die Intifada organisiert. Die Leute wollen doch eigentlich nur in Ruhe ihr Bier trinken, ihre kleine Freundin haben, zur Arbeit gehen, usw., also ein normales Leben führen. Sie wollen die Intifada nicht fortführen. Wir müssen verstehen, dass selbst vor 1948, die Lage eine Koexistenz war, und dann haben wir die Lage von innen heraus verändert, und das wird wieder passieren, schon durch die Geburtenrate. Wenn wir den Kampf führen wollen, dann müssen wir das ohne die Verwaltung tun und von der Basis aus anfangen. Dann werden wir internationale Unterstützung bekommen und uns nicht mehr anhören müssen, dass die Verwaltung korrupt und diktatorisch ist. Die Palästinenser müssen sich zusammentun und gemeinsam bestimmen, was sie wollen. «12

Hier lässt sich vor allem der Klassenaspekt der Intifada beobachten: Dieser palästinensische Wasserbauingenieur, der gut verdiente und seine Ausbildung und Sozialisation teilweise in Israel erhalten hatte, teilte nicht unbedingt die Wahrnehmungen und Forderungen derer aus den Flüchtlingslagern. Israel stand er kritisch gegenüber: Durch seinen Beruf erfuhr er täglich die Beschränkungen, die den Palästinensern bei der Wasserversorgung auferlegt wurden. Doch weil er die israelische Gesellschaft besser kannte, thematisierte er eher eine Reform von innen als die Konfrontation. Diese Ablehnung der Intifada

12 Interview im Mai 2001. 
hinderte ihn jedoch nicht, einen Aktivist der zweiten Intifada zum Freund zu haben. Seine Idee einer inneren Reform Israels, die das Zusammenleben ermöglichen würde, stützte sich auch auf die Vorstellung einer reichen kulturellen Identität, die die Befürchtung einer Assimilation gar nicht erst aufkommen lässt, sondern die Grundlage eines Dialogs wäre. Der Ingenieur, der zugleich ein bekannter Dichter war, hatte Ramallah als Wohnort gewählt, um dort vom reichen Kulturleben zu profitieren. Zugleich hatte er an mehreren Dichterwettbewerben in Israel teilgenommen. Er war stolz auf den Erfolg, den er, trotz aller sprachlichen Hindernisse, mit seinen Gedichten hatte.

Bei diesen Ingenieuren war eine gewisse Distanz gegenüber dem »nationalen Kampf« zu spüren, insbesondere dann, wenn es um das eigene, persönliche Leben ging. Nicht alle standen dem "Kampf « so kritisch gegenüber wie dieser Wasserbauingenieur - einige unterstützten den bewaffneten Kampf und auch die Hamas als nationalistische Bewegung. Aber selbst wenn es diese Unterstützung gab, dann äußerte sie sich nie in Form persönlicher Beteiligung.

Wie bei den jungen Rückkehrern, ließ sich bei den Ingenieuren eine Trennung zwischen dem nationalen Ziel und der Privatsphäre beobachten. Die Abwanderung erschien ihnen als einzige Möglichkeit, eine individuelle persönliche Zukunft zu entwickeln. Zugleich bedeutete der Eintritt in einen »internationalen Raum « aber auch, dass andere Strategien des "nationalen Kampfes« vorstellbar wurden. Das ließ sich ganz allgemein beobachten: Kamal zum Beispiel war Mitglied des Stadtrats von Hebron. Der junge Rollstuhlfahrer war zwar kein Ingenieur, aber auch er hatte nach mehreren Aufenthalten im Ausland seine Haltung gegenüber dem israelisch-palästinensischen Konflikt verändert. Sein Engagement war vor allem der Aufklärung gewidmet:

»Die Leute im Westen wissen ja nicht, was hier los ist, weil die israelischen Informationen viel einflussreicher sind. Die haben nur eine minimale Vorstellung von dem, was in Palästina passiert. Es gibt Leute, die kennen Palästina gar nicht, sondern nur Israel. Die müssen mehr über die Situation erfahren, oder herkommen und sehen, was hier los ist. Die Nachrichten im Westen sagen, es sind die Palästinenser, die die Probleme machen, die die Terroristen sind. In meiner Arbeit mit internationa- 
len Freiwilligen versuche ich, an diesem Bild etwas zu ändern. ${ }^{13}$ Wir sind keine Terroristen, wir haben Rechte. Ich versuche die Jungen davon zu überzeugen, dass man sich nicht nur in Büchern und Zeitschriften informieren kann. Man muss herkommen und sehen, wer für all das verantwortlich ist. Die wissen zum Beispiel nichts über 1948. Sie wissen etwas über Israel, aber sie wissen nichts über Palästina, als ob es hier vor 1948 nichts gegeben hätte. Es spielt keine Rolle, ob du Jude bist oder nicht. Wenn es ein guter Mensch ist, dann kann man sich unterhalten. Was das palästinensische Volk angeht, wenn du da glaubst, dass wir keine Identität und keine territorialen Rechte haben, dann töte uns. Denn wir wollen nicht auf einem Land leben, das uns nicht gehört. Es ist unser Recht, hier zu sein. Die Palästinenser lieben den Frieden, aber Frieden bedeutet nicht Niederlage, sich zu ergeben und auf alles zu verzichten. Wir brauchen einen gerechten Frieden. Die Menschen in Europa sind gut, wir können ihren Standpunkt ändern, indem wir ihnen mehr Informationen geben. Wir können das Gleiche machen wie die Juden und mehr Informationen rausgeben, und auf diese Weise die Meinungen verändern, in der gleichen Weise, wie es die Israelis machen. Wir sind eine Nation wie die anderen. Wir sind normal. Wir sind keine Terroristen. [...] Ich hoffe einmal ein Sprecher der Palästinenser zu werden und von den Israelis zu lernen, wie sie über ihre Probleme sprechen, wie sie es schaffen, die Morde an Palästinensern als Verteidigungsakte hinzustellen und aus Palästinensern Terroristen zu machen. Wir müssen also aus den Erfahrungen der Israels lernen, aus ihrer Methode der Kommunikation. Ein Sprecher sein, der gut spricht und die Europäer davon überzeugt, was hier wirklich passiert.«

Der Bezug zum Ausland erscheint hier als eine wesentliche Ressource bei der Veränderung des Selbstbildes. Doch was passiert, wenn ein junger Palästinenser sich wirklich für eine längere Zeit im Ausland niederlässt? Wie verhält er sich hinsichtlich des Konflikts zwischen privatem Leben und »nationalem Kampf «? Um dieser Frage nachzugehen, wenden wir uns den jungen Palästinensern zu, die zum Studieren nach Deutschland gegangen sind, statistisch gesehen ihr häufigstes Zielland.

13 Gemeint sind die Freiwilligen, mit denen Kamal in seinem Verein in Kontakt kommt. 


\section{Die palästinensischen Studenten in Deutschland}

In Deutschland gibt es eine relativ große palästinensische Gemeinde, die in drei Wellen entstanden ist. ${ }^{14}$ Die erste bestand aus »Gastarbeitern« der sechziger Jahre. Die zweite, bei weitem die wichtigste, besteht aus Flüchtlingen der 1970er und 1980er Jahre. Sie wird auf 30.000 bis 45.000 Personen geschätzt. Die meisten davon, etwa 25.000, kamen aus dem Libanon, wo sie, nachdem sie dorthin 1948 und 1967 schon einmal vertrieben wurden, erneut zu Kriegsflüchtlingen wurden. Die dritte Welle, die nur ungefähr 5.000 Menschen umfasst, besteht aus Studenten, die aus dem Gaza-Streifen oder dem Westjordanland gekommen sind. Sie sind von den Einwanderern der zweiten Generation zu unterscheiden, die auf 15 . bis 20.000 geschätzt werden, und von denen nur sehr wenige an die Universität kommen. Vielen Mittelklassefamilien und selbst einfachen Familien, vor allem aus Flüchtlingslagern, war es möglich, ihre Söhne zum Studium zu schicken, weil es ein effizientes System der gegenseitigen Hilfe gibt und weil - erleichtert durch die deutsche Studienorganisation - ein Teil des Studiums über Lohnarbeit finanziert werden konnte. Diese Jungen nahmen vor al-

14 Es ist schwierig, diese Gemeinde zahlenmäßig genau zu bestimmen. Viele Palästinenser haben einen jordanischen, syrischen oder israelischen Pass oder ägyptische, libanesische oder palästinensische »Reisepapiere«. Die lokalen Behörden in Deutschland und die Studentenbüros der Universitäten kennen die palästinensische Staatsangehörigkeit als statistisches Merkmal nicht. Deshalb beschränken wir uns hier auf die Angaben der »Palästinensischen Gemeinde Berlin-Brandenburg e.V.«. Nach dem Abkommen von Oslo und der Errichtung der Palästinensischen Autonomiebehörde 1994 sind die israelischen »Reisedokumente« für Palästinenser aus dem Gaza-Streifen und dem Westjordanland durch palästinensische »Pässe« ersetzt worden. Auf Arabisch heißen diese Dokumente »jawaz al safar«, auf Englisch »Passport/Travel Document«. Doch weil der endgültige Status der Gebiete in den Abkommen noch nicht geklärt wurde, dürfen diese Dokumente noch keine palästinensische Staatsangehörigkeit benennen. $\mathrm{Zu}$ dem sehr komplexen juristischen Thema der palästinensischen Staatsangehörigkeit vgl. Qaficha 2001: 39-77. 
lem technische Studiengänge in den Bereichen Informatik, Elektrotechnik, Bauwesen, sowie Medizin und Pharmazie auf.

Diese Gruppe war fast ausschließlich männlich. Frauen waren eigentlich nur dann Teil der Gruppe, weil sie ihren studierenden Ehemann begleiteten. Nur eine sehr kleine Minderheit der Frauen studierte tatsächlich selbst.

\section{Auswanderung - Ausweg und Chance}

Wie lässt sich diese Abwanderung nach Deutschland erklären? Insbesondere in den Jahren 1999 und 2000 kamen besonders viele palästinensische Studenten nach Deutschland. Tatsächlich ließ sich ein bedeutsamer Unterschied für das Studienvorhaben der jungen Palästinenser in Deutschland ausmachen, abhängig davon, ob sie in Palästina nur die Anfänge der palästinensischen Autonomiebehörde (ab 1993) miterlebt hatten oder mit der Erfahrung der letzten Intifada (2000 - 2005) nach Deutschland gekommen waren. Für letztere, war nämlich die Auswanderung zum Studium nach Deutschland nicht nur vom Wunsch bestimmt, neue Kompetenzen zu erwerben, sondern vor allem einer unlebbaren Situation zu entkommen.

»Ich möchte in Berlin bleiben, denn in Gaza kann man nicht leben. Es gibt nichts dort. Ständig beobachten dich alle Leute, alle deine Bewegungen. Du kannst nichts machen. Du kannst nicht ausgehen. Es macht mir nichts aus zu studieren und gleichzeitig zu arbeiten. Ich will nur woanders sein. $\ll 15$

Die Motivation in Deutschland zu studieren war weniger davon geprägt in Palästina einen höheren Status zu erreichen, als viel mehr der unerträglichen Situation in den besetzten Gebieten zu entkommen.

»Ich will in die USA gehen, um dort einen M.A. zu machen. Mein Onkel lebt dort, und danach will ich mein Leben leben. [...] Ich will hier nicht meine Zukunft verbringen. Wir haben hier Schwierigkeiten, Probleme. Ich mache mir nichts vor: es gibt hier keinen Grund zum Träumen, so

15 Moussa, 24 Jahre, Berlin, Juli 1998. 
ist die Situation mit Israel. Mein Traum ist, in irgendein anderes Land zu gehen, denn hier gibt es nichts zum Träumen. «16

Zwischen diesen neu hinzugekommenen Studenten und jenen Palästinensern, die schon seit Jahrzehnten in Deutschland lebten und nach wie vor an eine Rückkehr und die Verwirklichung von Projekten dachten, entwickelte sich schnell ein Unverständnis. Jene, die noch »im Geist der ersten Intifada« lebten, sprachen von einem »einigen Volk, das kämpft und voranschreitet«. Die neu Hinzugekommenen hingegen, thematisierten das Scheitern des Oslo-Abkommens und der Selbstverwaltung, den wirtschaftlichen Zusammenbruch, die Engpässe und den Verzicht.

Nach der Ankunft in Deutschland benötigten die meisten neu hinzugekommenen palästinensischen Studenten zunächst eine Orientierungsphase, um ihre weitere Zukunft zu planen. Im Vergleich zu anderen Studenten brauchten sie dafür mehr Zeit. Die Umstände, die sie zur Ausreise veranlasst hatten, ließen ihnen keine Ruhe. Über Nachrichten und Kontakte blieben sie mit den Ereignissen in Palästina verbunden und hatten Schwierigkeiten, sich auf ihr Studium zu konzentrieren. Oft brauchten sie Monate, sogar bis zu einem Jahr, bevor sie irgendwelche Pläne entwickeln konnten, an die sie selbst glaubten. Mit wachsendem zeitlichen und räumlichen Abstand zur bedrückenden Situation in den Palästinensergebieten wuchs jedoch die Möglichkeit, eine eigene Privatsphäre aufzubauen, die weniger davon bestimmt war.

Die Studenten, die bereits während der ersten Jahre der Autonomiebehörde ihr Studium in Deutschland aufgenommen hatten, taten dies mit der festen Verankerung im »Geist der ersten Intifada«: Sie gingen, um mit neuen Kompetenzen in ein besseres Leben zurückzukehren. Und obwohl sie die Entwicklung vor Ort verfolgten, änderte sich ihre Einstellung nicht grundsätzlich. Eine solche Veränderung hätte ihr Selbstverständnis und ihre Situation im Ausland zu sehr beeinflusst. Dieses Selbstverständnis war nämlich die Vorraussetzung,

16 Kamal, 20 Jahre, Student der Anglistik. Sein Vater ist Arbeiter in Israel und seine Mutter unterrichtet. Er lebt in einem Neubauviertel für die Einwohner des Flüchtlingsviertels in Jabalya. Das Interview fand im August 1999 statt. 
nicht dem Vorwurf der »Entsolidarisierung « gegenüber dem kollektiven Schicksal der Palästinenser ausgesetzt zu sein.

Die schwieriger werdende Situation infolge der Zweiten Intifada verursachte dann aber doch auch Veränderungen unter den Studenten im Ausland. Ihr Auslandsaufenthalt wurde nun nicht mehr moralisch infrage gestellt. Ihre Aufgabe im Ausland galt nicht mehr der Qualifizierung, um diese bei der Rückkehr dem palästinensischen Projekt zur Verfügung zu stellen, vielmehr sollten sie nun eine wichtige externe Ressource für die Familie in Palästina werden. Priorität hatte nicht mehr die schnellstmögliche Beendigung des Studiums, sondern die finanziellen Transfers, so gering sie auch sein mochten. Damit wuchs der Druck auf die Studenten. Sie wurden Teil der palästinensischen Strategie, wobei die im Ausland studierenden Palästinenser eine etwas weniger anfällige wirtschaftliche Basis stellen sollten, als dies in den besetzten Gebieten möglich wäre. ${ }^{17}$

Wie Majdi el-Malki gezeigt hat, trieb die Verschlechterung der wirtschaftlichen Lage in den Gebieten und die Zerstörung der Infrastruktur der Selbstverwaltung die Palästinenser zu Formen der Solidarität und der Reorganisation, die zumeist entlang familiärer Bande verlief (el-Malki 2002: 176-179). Diese Bande waren nicht bloß lokal, vielmehr bedeutete die »Hamula«, die palästinensische Großfamilie, eine weit über die Grenzen der Palästinensergebiete hinausreichende Geographie, die die Diaspora mit einschloss. Sie besteht aus Netzen der Solidarität, die lange Zeit ruhen können, sich aber schnell aktivieren lassen, wie etwa zu Zeiten der Al-Aqsa-Intifada.

\section{Was ist eine westliche Gesellschaft?}

Für die palästinensischen Studenten sind Individualismus, Materialismus, technologischer Modernismus und Amoralismus

17 Der Gesamtbeitrag der palästinensischen Diaspora für die palästinensische Ökonomie wurde 1997 auf 410 Millionen US-Dollar geschätzt. Davon sollen 76 Prozent Investitionen und 24 Prozent Schenkungen gewesen sein, wobei die Einordnung der Transfers innerhalb von Familien schwer zu beurteilen ist. Diese Gesamtsumme erreichte 95 Prozent der internationalen Hilfe desselben Jahres (432 Millionen US-Dollar) (Hanafi 1998: 64-65). 
die Werte, die in der deutschen, oder allgemein in westlichen Gesellschaften transportiert werden. Sie selbst verhalten sich diesen Werten gegenüber mehr oder weniger abweisend. Der einzige Wert, der bei dieser Zurückweisung eine Ausnahme bildet, ist der technologische Modernismus, denn dieser war ja auch eine Hauptmotivation für die Ausreise nach Deutschland. Ständig schwankten sie zwischen dem eigenen Willen zum Individualismus und der Freiheit und ihrer Ablehnung des »chacun pour soi« (dt. »jeder für sich«) der westlichen Gesellschaften. Zwar behaupten sie, den Materialismus zurückzuweisen, aber gleichzeitig sind sie Konsumenten mit einem klaren Markenbewusstsein. Letztlich sind sie Teil einer internationalen Jugendkultur, genauso wie im Gazastreifen, nur mit viel mehr Wahlmöglichkeiten.

Die Zurückweisung des Materialismus und des übertriebenen Individualismus drückt sich unter anderem in ihrem Urteil über die Zerstörung der Familie aus, wie sie sich nach Ansicht der Studenten im Westen beobachten lässt. Dies ist das am häufigsten angeführte Beispiel, um den Zerfall und die Ziellosigkeit der westlichen Gesellschaften zu belegen. Auf diese Weise versuchen die Studenten eine eigene Identität zu bewahren, die aus ganz widersprüchlichen Referenzen besteht, wie etwa eine eher spirituelle als traditionelle Religiosität, die Zurückweisung einer als anomisch empfundenen westlichen Ordnung, eine Konsumorientierung, aber auch der Erhalt der Gemeinschaft als Solidaritätsnetzwerk. Zu diesen Referenzen gehören auch die arabische Kultur und der technologische Modernismus.

Aus diesen möglichen Identitätskonfigurationen sticht der Islamismus aus zwei Gründen hervor. Er ist ein Modell, das nicht bloß von Einzelpersonen vertreten wird, sondern von ganzen Gruppen. Dieses Modell genießt in weiten Teilen der palästinensischen Bevölkerung Legitimität, auch wenn es nicht von allen gelebt und weiter getragen wird. Diese religiöse Referenz bezieht sich auf die Idee des Islam als eine Totalität, und zwar in dem Sinne, als dass dieser für alle Bereiche des Lebens, wie auch für die Politik, Leitlinien bereithält. Vor dem Hintergrund der westlichen Welt entwickelte sich die Vorstellung einer islamischen Modernität. Dabei wurden aus der westlichen Welt als positiv empfundene Aspekte in den Islam aufgenom- 
men, der sich dadurch mittlerweile vom traditionellen palästinensischen Islam weit entfernt hat.

Die Vorstellung eines solchen Werteverfalls im Westen wird vor allem an der Frage nach den Beziehungen der Geschlechter festgemacht, bei der die Studenten die westliche Flüchtigkeit der Beziehungen hervorheben und kritisieren. Sie stellen dieser Art der Beziehungen die Idee einer arabischen Tradition gegenüber, die auf Gemeinschaft, gegenseitiger Hilfe und Solidarität sowie auf moralischer spiritueller Bildung beruhe. Die Vorstellung einer islamischen Moderne ist folglich der Versuch, moderne und traditionelle Elemente miteinander zu verbinden:

»Die Technologie und die Verbesserung der materiellen Bedingungen, das ist ein Teil der Modernisierung, den wir unterstützen und den wir in unsere Gesellschaft importieren wollen. Hier geht das aber mit einem starken Wachstum der individuellen Freiheiten, ohne jegliche moralische Schranke einher. Das will ich aber nicht in meinem Leben haben, und so filtere ich nach meinen Werten aus. Im Islam ist zum Beispiel die Keuschheit sehr wichtig, und ganz bestimmt schätze ich die Zurschaustellung des weiblichen Körpers in der Werbung nicht. «18

Diese Vorstellungen muss man auch als Versuch verstehen, eine eigene stolze Identität $\mathrm{zu}$ schaffen, die Anerkennung finden kann. Die westlichen Medien und besonders die Fernsehsender spielen dabei eine wesentliche Rolle. Die jungen Muslime sehen unaufhörlich Filme und Fernsehserien, in denen Araber nur als Bösewichte vorkommen oder lächerlich gemacht werden, mit den ewiggleichen Stereotypen von vielen Frauen und vielen Kamelen.

»Das Fernsehen bringt nur einen kleinen Teil der Wirklichkeit, der dafür ausgesucht wurde. Innerhalb von zwei Wochen gibt es immer Momente, in denen du doof bist oder schlau, lustig oder interessant, sympathisch oder genervt. Aber wenn du immer nur als Idiot gezeigt wirst, denken mit der Zeit alle, dass du wirklich dumm bist. Mit den Arabern passiert genau das. Nimm irgendeinen amerikanischen Film, der Araber ist immer der Doofe, der Gewalttätige, der Bösartige mit den vielen Frauen und den Kamelen. Schlimmer ist es noch mit den Nachrichten

18 Qandil, 28 Jahre, Student und islamischer Intellektueller, mit einer französischen Konvertitin verheiratet, Berlin, Januar 2002. 
zu Palästina: Die Israelis haben unser Land besetzt und bringen uns um, und wir werden als Terroristen dargestellt!«19

Das Prinzip der Identifikation, auf dem die audiovisuellen Produktionen unter anderem beruhen, funktioniert hier umgekehrt: Diese Bilder erscheinen ihnen wie Aufforderungen, sich mit den demütigenden Karikaturen zu identifizieren. Die Heftigkeit, mit der die Studenten über diese Medien sprechen, belegt, für wie wichtig sie sie in der Öffentlichkeit halten.

»Der Krieg der Kulturen, das ist Quatsch. Aber es gibt auf jeden Fall eine Globalisierung der amerikanischen Kultur. Ich wundere mich nicht mal mehr, wenn ich hierher komme. Die gleichen Marken, die gleichen Filme, die gleichen MacDonalds. Aber was mich wirklich aufregt, das ist die ständige Desinformation über den Nahen Osten. «20

Diese Diskriminierung wirkt, trotz des Zugangs zu Sozialleistungen und Bildungschancen, wie ein Angriff auf die Würde und ruft viel Bitterkeit hervor: "Sie reden von Demokratie, und dem Gesetz nach gibt es sie. Aber in der Wirklichkeit, sieht man sie nie. Als Araber werde ich niemals so respektiert wie ein Deutscher.«21

Die islamistische Ideologie schafft es, mit diesen beiden Registern zu spielen, indem sie technische Beherrschung mit der Ablehnung »moralischer Korrumpierung " verbindet, wobei diese Ablehnung sich auch auf ein faktisches Herrschaftsverhältnis bezieht. Diese Vision erstreckt sich im weiteren Sinne auf die ganze arabische Welt in ihrem Verhältnis zum Westen und übersteigt damit den israelisch-palästinensischen Konflikt, auch wenn dieser ein Kristallisationskern des Verhältnisses ist.

Die palästinensischen Studenten im Westen verschreiben sich einer Forderung nach Anerkennung, die auf ihren speziellen Status als auch auf ihre konkreten Erfahrungen von Herrschaft im Alltag zurück zu führen ist. Die Frage der Anerkennung, die sonst eher Minderheiten in einem Nationalstaat aufwerfen, stellt sich für sie auf globaler Ebene. Israel stellt sich für

19 Student der Architektur, 22 Jahre, Berlin Januar 2002.

20 Mahmoud, 26 Jahre, M.A. in angewandter Mathematik, seit sechs Monaten in Deutschland, Berlin, Januar 2002.

21 Jamal, 26 Jahre, Student der Pharmazie, Berlin, Januar 2002. 
sie als eine Art Vorposten der Vorherrschaft des Westens dar. Die Frage der Anerkennung geht also über den Rahmen des israelisch-palästinensischen Konflikts weit hinaus und wird zu einer Frage der Beziehungen zum Westen.

Mit den Anschlägen vom 11. September 2001 ist diese Konfliktlinie noch deutlicher geworden, denn eine indirekte Folge davon war, dass im Westen jeder Muslim tendenziell zu einem Verdächtigen wurde. Einige Studenten haben infolge dessen aufgehört, auszugehen, weil sie aufgrund von umlaufenden Gerüchten in muslimischen Milieus, Übergriffe fürchteten. Die meisten empfanden eine Zunahme feindlicher Blicke:

»Was glaubst du denn, wie ich mich im Betrieb fühle? Als am 11. September die Türme einstürzten, da brachen sie auch in meinem Büro zusammen: Schau mal, die Palästinenser bombardieren New York! Ich habe das alles nicht verstanden. Später war ich erleichtert, als herauskam, dass das keine Palästinenser waren. Aber seitdem ist es vorbei, ich habe nicht mehr den gleichen Status wie die anderen Ingenieure.«22

Die Beziehungen zwischen der palästinensischen Gemeinde und der deutschen Gesellschaft haben sich also durch das Verhalten einiger und durch Sicherheitsforderungen verschlechtert, die eine ganze Bevölkerungsgruppe pauschal unter Verdacht stellen. Wenn auf diese Weise Anerkennung verweigert wird, verstärkt das die Neigung zum Islamismus.

In der Erfahrung des Exils entsteht damit eine Neubewertung des nationalen Ziels. Die Palästinenser bewerten ihre Optionen neu, weil sie mehr über die westlichen Gesellschaften und das internationale System lernen. Aber diese Kenntnisse und Erfahrungen, die auch immer individuell sind und stark variieren, führen nicht $\mathrm{zu}$ einer einheitlichen Meinung oder Haltung. Man kann aber beobachten, dass sie die Entstehung einer transnationalen Elite begleiten, die es im Westen zu einem gewissen Wohlstand gebracht hat und die daran glaubt, dass der Konflikt mit den Mitteln geführt werden kann, die in westlichen Gesellschaften akzeptiert sind: demokratisch, unter Wahrung der Menschenrechte, usw. Diese Eliten nehmen den Wes-

22 Informatikingenieur, aus Gaza stammend, seit zehn Jahren in Deutschland lebend. 
ten nicht als einheitlich und unbeweglich wahr, sie sind zudem Teil des Spektrums, den man "palästinensischen Pazifismus« nennt, der auch den gewaltfreien Widerstand und die Mobilisierung der internationalen Öffentlichkeit bevorzugt.

Auf der anderen Seite lässt sich aber auch beobachten, dass die bessere Kenntnis der westlichen Gesellschaften auch konfrontative Haltungen und negative Eindrücke befördern kann. Der Versuch, eine eigene stolze Identität herzustellen, stützt sich auf den Entwurf einer islamischen Modernität und betont die Ablehnung bestimmter westlicher Werte im Namen einer höheren Spiritualität. Diese Ablehnung drückt sich auf sehr verschiedene Weise und unterschiedlich stark aus. Sie reicht von der Ausbildung einer persönlichen Moral bis hin zum Beitritt zu einer islamistischen Partei oder zur militanten Opposition. Der Übergang von einem Niveau zum anderen geschieht aber nicht automatisch. So gibt es eine Reihe islamistischer Gruppen, die der Anwendung von Gewalt sehr kritisch gegenüberstehen:

»Diese (gewaltsamen) Bewegungen sind ein Problem für ihre eigenen Gesellschaften geworden. Sie glauben neue Lösungen zu haben und dafür werden sie verfolgt. Aber solche Gruppen zu schaffen, die sich auf den Islam beziehen und zugleich potentiell gewaltsam sind, das bedeutet nur, dass es noch mehr Probleme gibt.«23

Die Ideologie der palästinensischen Islamisten, die sehr durch den palästinensischen Nationalismus und den »Kampf für die palästinensische Sache" geprägt war, macht es wenig wahrscheinlich, dass sie sich etwa der Al Qaida anschließen. Tatsächlich wurde Bin Laden der Vorwurf gemacht, sich der palästinensischen Sache erst sehr spät angenommen zu haben und sie eher als Rechtfertigung für sein eigenes Tun benutze, als die Palästinenser wirklich zu unterstützen.

»Die Amerikaner müssten sich fragen, warum ihnen soviel Hass entgegenschlägt. Tausende Tote im Irak und in Palästina, dafür sind sie verantwortlich. Das vergessen wir nicht. Leider ist es für extremistische Gruppen sehr einfach, diesen Hass auszunutzen. Aus meiner Sicht muss man da einen Unterschied machen zwischen dem nationalen Kampf wie

23 Qandil, vgl. Fn. 124. 
dem der Palästinenser und solchen Aktionen (wie denen von Bin Laden). Bin Laden hat für die palästinensische Sache überhaupt nichts geleistet und benutzt das nur, um seine eigenen Aktionen zu rechtfertigen. ${ }^{24}$

Der Aufenthalt im Ausland bedeutete für die große Mehrheit auch eine Chance, kulturelles und finanzielles Kapital zu akkumulieren, wenn er nicht zu schnellem Scheitern führt oder die Rückreise nicht direkt nach Erhalt des Studienabschlusses geschieht, weil dann die Arbeitslosigkeit in den Palästinensergebieten sehr wahrscheinlich ist. Nicht alle Studienabsolventen werden anschließend Teil der Elite werden, da dies von ihrer Stellung zum Zeitpunkt ihrer Ausreise abhängig ist. Aber sie alle werden einen sozialen Aufstieg erleben. Ein Teil von ihnen wird zur transnationalen Elite gehören, eine Elite, die sich weniger durch materiellen Wohlstand auszeichnet als durch ein bestimmtes Wissen. ${ }^{25}$

In ihrer Vision der nationalen Ziele rangiert die persönliche Entwicklung weit vor der Unabhängigkeit. Wenn es um den Kampf um die Macht geht, dann stehen ihnen vor allem die lokalen Eliten des bewaffneten Kampfes gegenüber. Diese verfügen über einen anderen sozialen Horizont und über eine ganz andere Erfahrung: Kämpfe und Gefängnisaufenthalte in Israel. Die Wahrnehmungen der internationalen Einbettung des Konflikts sind grundverschieden. Die Beziehungen zwischen diesen

24 Ahmed, Architekturstudent und Sympathisant der Islamisten, Berlin, Januar 2002.

25 »Die Art und Weise, in der in einer Umwelt gelebt wird, wie sie interpretiert wird, wie eine Person auf sie reagiert, unterscheidet sich von einer Person zur nächsten, abhängig vom genauen Inhalt des individuellen Wissens. Das Wissen ist der Schlüssel, denn es definiert unsere Weltwahrnehmung im Lichte unserer besonderen Erziehung und unserer Lebenserfahrungen. Man kann daraus plausibel schließen, dass das Wissen eines der wichtigsten Kriterien ist, um die beiden politischen Haltungen in unserer Stichprobe der palästinensischen Eliten zu unterscheiden.« Dieses Zitat stammt aus einer Untersuchung über eine Stichprobe von neun Personen aus der palästinensischen Führungsriege: Mustafa Barghouti, Hanan Ashrawi, Salam Fayad, Ghassan Khatib, Ziad Abou Amr, Yassir Arafat, Marwan Barghouti, Ahmed Sa'adat, Sheikh Yassin, vgl. Badawi 2002. 
beiden Gruppen und ihr jeweiliges politisches Gewicht sind zwei wesentliche Bedingungen für die laufenden Veränderungen der Machtverteilung in Palästina.

\section{Literatur}

Badawi, Ahmed (2002): Determinent of change in elite behaviour and relative influence in Palestine, Forschungsprojekt »Elitenwandel in der arabischen Welt«, Stiftung Wissenschaft und Politik, Berlin, August 2002, unveröff. Entwurf.

el-Malki, Majdi (2001), Social Monitor, Special Issue 1995-1999, Palestine Economic Policy Research Institute (MAS), Nr. 4, Mai 2001.

el-Malki, Majdi (2002): "Soutien social informel et néopatrimonialisme«. In: Nadine Picadou (Hg.), La Palestine en transition. Crise du project national et de construction de l'Etat, Lille: Inalco, S. 176-179.

Hanafi, Sari (1998): »Contribution de la diaspora palestinienne à l'économie palestinienne«. In: Bernard Botiveau (Hg.), La Palestine d'Oslo: les avatars d'une construction nationale, Monde Arabe Maghreb-Machrek, Nr. 161, Juli-September 1998, S. 64-65.

Qaficha, Mu'taaz (2001): »La nationalité palestinienne selon les principes du droit interantional«. In: Nadine Picadou (Hg.), La Palestine en transition, Les Annales de l'autre islam, Nr. 8, Paris: ERISM, INALCO, S. 39-77.

Tamini, Tamara (2002): »Al Awda: The Negotiation of Identity among Palestininen-American Returnees", Beitrag für das Colloquium »Palestinian Return Migration: Socio-economic and Cultural Approaches«, geleitet von Sari Hanafi, Meawars (Populaiton Council) and Shami Ramallah, 13.-14. Juni 2002, www.shaml.org7agenda/2001/workshop-1206/tentat ive/tamini.htm.

Van Hear, Nicholas (1997): »Reintegrating Returnees: Opportunities and Constraints«. In: Nicholas Van Hear, et alii, Reintegration of Palestinian Returnees, Publication Nr.6, Ramallah: Shaml-Palestinian Diaspora and Refugee Center. 



\title{
Nach der Abschiebung: Abgeschobene Jugendliche aus Deutschland im Kosovo
}

\author{
MARGARETE MISSELWITZ
}

Kriegsflüchtlinge erhalten häufig und in zunehmendem Maße nur zeitlich befristeten Schutz in Aufnahmeländern, wo sie bis zur Beendigung der Kriege geduldet werden. Damit stellt sich verstärkt auch die Frage, wie Flüchtlinge mit diesem zeitlich befristeten Asyl umgehen und was eine erzwungene Rückkehr in ihre Heimatländer für die Flüchtlinge bedeutet, insbesondere dann, wenn vorher eine weitgehende Integration in das Aufnahmeland stattgefunden hatte. Der vorliegende Beitrag geht auf der Grundlage von Interviews im Kosovo der Frage nach, was Jugendliche', die in Deutschland aufgewachsen sind, nach ihrer Abschiebung dort erwartet. Dabei waren insbesondere Jugendliche aus der kosovarischen Minderheit der Aschkali und »Ägypter « ${ }^{2}$ von Interesse, deren Minderheitengruppen im Zuge des Kosovokriegs von der albanischen Mehrheit vertrieben wurden. ${ }^{3}$

1 Als »jugendlich« werden hier Menschen im Alter zwischen 14 und 24 Jahren bezeichnet. Dies entspricht der Einteilung des World Youth Report der Vereinten Nationen.

2 Die Bezeichnung von Roma als Aschkali oder »Ägypter « ist neueren Ursprungs. Oft geht es bei den Selbstzuschreibungen als Aschkali oder »Ägypter« um unterschiedliche politische Interessen. Die Grenzen zwischen diesen Gruppen sind fließend. Vom UNHCR wurde aber diese Unterscheidung übernommen und verschiedene Empfehlungen hinsichtlich der Rückkehr der Gruppen gegeben und damit auch die Trennung zwischen Asch- 
Mit dem Problem einer erzwungenen Rückkehr nach jahrelangem Aufenthalt im Aufnahmeland waren in Deutschland 2006 nach unbestätigten Regierungsangaben ca. 65.000 Personen $^{4}$ konfrontiert, die ausreisepflichtig sind und nur eine sog. »Duldung « in Deutschland besitzen. Die Mehrheit (ca. 50.000) davon sind Menschen, die aus dem Kosovo nach Deutschland kamen.

Anfang der 1990er Jahre führte das gewaltsame Auseinanderfallen des jugoslawischen Staates in ethnisch definierte Nachfolgestaaten zu einem erheblichen Zuwachs der weltweiten Flüchtlingszahlen. ${ }^{5}$ Der Kosovokrieg 1998/99 war der letzte gewaltsame Abspaltungsprozess eines Territoriums aus dem Jugoslawischen Verbund, der im Kosovo mit einer Intervention der NATO-Streitkräfte endete. In ihrer Folge wurde das Kosovo umgewandelt in ein UN-Protektorat, das von einer UN-In-

kali, »Ägypter« und Roma institutionalisiert. Während Aschkali und »Ägypter« albanisch sprechen, sprechen Roma neben Romanes meist Serbokroatisch. Das ändert nichts daran, dass sie alle von der albanischen Umgebung unterschiedslos als Roma wahrgenommen werden. Die Bezeichnung »Ägypter" geht auf die Annahme zurück, dass diese Gruppe über Ägypten in das Kosovo eingewandert sei.

3 Insgesamt wurden im Frühjahr 200614 Interviews geführt, mit Jugendlichen aus Vushtri/Vucitrn, Pec/Peja, Istok und NordMitrovica. Dabei wurden sieben weibliche und sieben männliche Jugendliche befragt, um mögliche Unterschiede in der »Integrationsgeschichte« von Mädchen und Jungen zu erfassen. Die Mehrzahl der Interviewten kam im Jahr 2005 im Kosovo an. Zusätzlich wurden mit zwei Repräsentanten der UNMIK - Karsten Lüthke »Repatriation Adviser « in Prishtina und David J. Halley, Return Office in Pec/Peja, - Experteninterviews durchgeführt. Mit ihrem Wissen und Erfahrungen konnten die Ergebnisse der Interviews mit den Jugendlichen abgeglichen werden. Der Rahmen dieser Arbeit bot nicht die Möglichkeit einer größeren und damit repräsentativen Befragung. Der Forschungsbeitrag dieser Arbeit ist daher eher explorativ und kann nur mögliche allgemeine Tendenzen aufweisen, die von weiterführenden Untersuchungen ergänzt oder bestätigt werden könnten.

4 Diese Zahl ergibt sich aus ca. 50.000 Personen aus dem Kosovo, 10.400 aus Irak und 4.000 aus Afghanistan.

5 Die Jugoslawienkriege hinterließen insgesamt über zwei Millionen Flüchtlinge und Vertriebene (vgl. Helsinki Committee for Human Rights in Serbia, 2003). 
terimsverwaltung (UN Administration Mission in Kosovo, kurz UNMIK) geleitet wurde, bis das Kosovo am 17. Februar 2008 seine Unabhängigkeit erhielt. Mit dem Ende der NATOBombardierung im Juni 1999 kehrten zehntausende von serbischen Streitkräften vertriebene albanische Flüchtlinge in das Kosovo zurück. Zeitgleich wurden aber über 200.000 NichtAlbaner (UNHCR 2005), bzw. 80 Prozent der Minderheitenbevölkerung (GfbV 2005), trotz Anwesenheit der internationalen Streitkräfte, von albanischen Extremisten aus dem Kosovo vertrieben. In der Mehrheit waren dies Serben, aber auch Minderheiten wie Roma, Aschkali, » ̈̈gypter«, Bosniaken, Gorani und Türken. Um eine Rückkehr zu verhindern, wurden ihre Häuser geplündert und niedergebrannt. Von den 150.000 einst im Kosovo vor Beginn der Jugoslawienkriege (1990 bis 1999) ansässigen Roma, Aschkali und "Ägypter" waren 34.431 Menschen nach Deutschland gelangt: 24.351 Roma, 8.197 Aschkali, 1.138 "Ägypter" (GfbV 2005). Diese Menschen lebten zum Zeitpunkt der Untersuchung seit mindestens sechs, viele von ihnen aber schon seit zehn oder fünfzehn Jahren in Deutschland. Die meisten ihrer Kinder waren in Deutschland geboren und sprachen inzwischen Deutsch als erste Sprache. Aschkali und »Ägypter« erhielten meist kurzfristige Duldungen, die alle drei Monate verlängert werden mussten (GfbV 2005). Seit 2003 werden Aschkali und »Ägypter« in das Kosovo abgeschoben.

Bei den Interviews wurde insbesondere der Kapitalienansatz von Nee und Sander (2001) angewendet, der eine Methodik bereitstellt, mit der erklärt werden kann, wie sich Immigranten in unterschiedlichen Formen in Aufnahmegesellschaften inkorporieren. Es sollte damit festgestellt werden, welche Kapitalien die Jugendlichen in Deutschland akkumuliert haben und welche Relevanz diese im Kosovo bezüglich ihrer Integration haben. Unterschiedlich stark ausgeprägte Inkorporation wird als Produkt der Interaktion zwischen den Eigenschaften der Immigranten und ihrer Gemeinschaften - human-kulturelles $^{6}$, soziales ${ }^{7}$ und finanzielles Kapital ${ }^{8}$ - und den Bedingungen

6 Unter kulturellem Kapital wird nach Bourdieu das institutionalisierte Kapital - wie Bildungstitel - und das inkorporierte kulturelle Kapital als »andauernde Disposition des Geistes und Körpers« (Bourdieu 1983: 243) verstanden. Der Begriff Humankapital 
im Aufnahmeland - wie strukturelle, rechtliche Rahmenbedingungen und Einstellungen gegenüber den Immigranten - verstanden.

Der Beitrag ist in sechs Teile gegliedert. Vorab werden Hintergrundinformationen zur Abschiebung in das Kosovo gegeben (1.). Da der Integrationsgrad der Jugendlichen und ihre Lebensweise in Deutschland ausschlaggebend sind für den Eingliederungsprozess im Kosovo, soll zunächst geklärt werden, in wie weit die Jugendlichen in Deutschland integriert waren (2.). In einem weiteren Schritt werden die Bedingungen im Kosovo hinsichtlich der Möglichkeiten zur Integration in die kosovarische Gesellschaft dargestellt (3.). Bei der Integration in die Minderheitsgesellschaft dient der Ansatz der »segmented assimila-

deckt ersteres ab und bezieht sich auf die Theorie von Schulz (1963) und Becker (1964), mit der Annahme, dass eine Investition in Bildung und Akquirierung von Arbeitserfahrungen und -fähigkeiten eine Rückzahlung auf dem Arbeitsmarkt durch Karriere erwirkt. Inkorporiertes kulturelles Kapital bezieht sich auf Kompetenzen in kulturellen Praktiken, die wiederum umgewandelt werden können in andere Kapitalienformen (siehe auch Di Maggio und Mohr 1985). Mit der Berücksichtigung von humankulturellem Kapital von Migranten können qualitative Unterschiede zur Aufnahmegesellschaft hinsichtlich Sprache, Werte und Glauben, spezielles Wissen und Fähigkeiten, die mit dem Herkunftsland assoziiert sind, erfasst werden.

7 Soziales Kapital von Immigranten wird verkörpert durch Beziehungen innerhalb und außerhalb der Familie. Es wird akkumuliert durch sozialen Austausch über einen bestimmten Zeithorizont hinweg und lässt Verpflichtungen und Solidarität entstehen. Soziale Netzwerke bieten Nutzen, sowohl bei der Informationsbeschaffung, in geschäftlicher Hinsicht, als auch hinsichtlich Bildung oder Status (siehe auch Coleman 1990; Portes 1990). Das Konzept des sozialen Kapitals bezieht sich auf kulturelle, ethnische oder nationale Eigenheiten der sozialen Interaktion. Darunter fallen Vertrauen, Loyalität, Normen der Reziprozität, Eigenarten der Kommunikation und des Informationsaustausches etc. Im Unterschied zur ersten Form bezieht sich soziales Kapital auf soziale Beziehungen als Analyseeinheit, nicht auf Individuen.

8 Unter finanziellem Kapital verstehen Nee und Sander Einkommen im Aufnahmeland sowie mitgebrachtes Geld oder Geldzufuhr aus dem Heimatland, über welches eine Familieneinheit verfügt (Nee/ Sander 2001: 391). 
tion « von Portes und Zhou (1993) als Orientierung (4.), der auch im Zuge der Inkorporation in die Minderheitsgesellschaft die Ressourcen und Verpflichtungen, sowie die Konfrontation mit deren Normen und Werten thematisiert. Die Differenzen, die sich im Kontakt zur Minderheitsbevölkerung, insbesondere über unterschiedliches humankulturelles Kapital herauskristallisieren, sollen ebenfalls vorgestellt werden. Als Folge der schwierigen Bedingungen im Kosovo und der Differenzen zur einheimischen Bevölkerung wurde eine starke Deutschlandorientierung (5.) beobachtet. Diese Entwicklungen werden sowohl auf die Integrationschancen als auch auf Erfolgschancen der Abgeschobenen im Kosovo hin geprüft. Dabei geht es zunächst einmal darum, das eigene Überleben im Kosovo sichern zu können, aber auch um die Frage der sozialen Mobilität. Da die Abschiebung gegenüber der freiwilligen Migration eine besondere Form der Migration darstellt, werde ich abschließend kurz auf dieses Thema eingehen (6.).

\section{Abschiebung von Minderheiten ins Kosovo}

Hinter dem Begriff "Abschiebung " oder »Rückführung "verbirgt sich im Gegensatz zur freiwilligen Rückkehr eine unfreiwillige oder forcierte Rückkehr, die von Seiten der Aufnahmeländer gegen den Willen der Abzuschiebenden durchgeführt wird. »Abzuschiebende « sind im Falle der Kosovo-Flüchtlinge Personen, denen ein temporäre Duldung ihres Aufenthalts in Deutschland entzogen wurde aufgrund einer ausgewiesenen verbesserten Situation im Heimatland, in dem die Sicherheit der Betroffenen nicht mehr als gefährdet eingestuft wird.

Die politische Grundlage für eine Abschiebung von Minderheiten in das Kosovo aus Deutschland wurde am 31. März 2003 mit dem "Memorandum of Understanding " geschaffen. Darin einigten sich der deutsche Innenminister und der damalige UNMIK-Chef Michael Steiner auf eine freiwillige aber auch unfreiwillige Rückkehr von Minderheiten in das Kosovo. ${ }^{9}$ Das

9 Hierbei wurde sich auf das UNHCR »Position Paper « vom Januar 2003 bezogen, welches mit Ausnahme von Kosovo-Serben und Roma, keine Gefahr mehr für Minderheiten im Kosovo feststellte. 
Memorandum sah vor, dass Abschiebungen von Aschkali und "Ägyptern" erst nach einer individuellen Prüfung der Bedingungen vor Ort zugelassen werden sollten.

Offizielle Kriterien für eine mögliche Rückkehr waren ein für Minderheiten rückkehrerfreundliches und sicheres Umfeld, vorhandene Unterkunftsmöglichkeiten (eigene Häuser der Abzuschiebenden oder Unterkunftsmöglichkeiten bei Verwandtschaft ersten Grades), sowie der Zugang zu sozialen Diensten und nachweislich die Gesundheit ${ }^{10}$ der Abzuschiebenden. ${ }^{11}$ Die Prüfung dieser Umstände erfolgte durch die UNMIK, der mindestens 33 Tage vor einer geplanten Abschiebung eine Liste mit den abzuschiebenden Personen und deren Daten zugesendet werden musste. 12

Da es im März 2004 erneut zu gewaltsamen Übergriffen und Vertreibungen von Minderheiten, sowie zu Plünderungen und Brandschatzungen von Häusern kam, denen auch abgeschobene Aschkali und »Ägypter« zum Opfer fielen, wurden die Abschiebungen kurzzeitig ausgesetzt und erst wieder im April 2005 durch ein weiteres Abkommen zwischen Deutschland und der UNMIK für Aschkali, »Ägypter « und straffällig gewordene Roma zugelassen. ${ }^{13}$ Hier wurde vereinbart, dass Deutschland monatlich bis zu 500 Aschkali und »Ägypter « für eine Abschiebung vorschlagen kann ${ }^{14}$. Nach Angaben des UNMIK Repatriation Adviser Karsten Lüthke wurden im Durchschnitt über 50 Prozent der vorgeschlagenen Abschiebungen von der UNMIK

10 Dies bezieht sich vor allem auf Menschen mit posttraumatischen Stresssyndromen (post-traumatic stress disorder), die für eine Abschiebung abgelehnt werden.

11 UNMIK Draft - Transition Paper 2006.

12 Problematisch an dem Memorandum zwischen der UNMIK und Deutschland war nach Halley die Nichteinbeziehung der kosovoalbanischen Institutionen. Das führte dazu, dass kosovoalbanische Institutionen sich nicht für die Rückkehrer, die ethnischen Minderheiten angehörten, verantwortlich fühlten und zum Teil ihre Kooperation mit der Begründung verweigerten, dass das Memorandum von ihnen nicht gezeichnet wurde (Interview mit Halley: 2.Mai 2006).

13 Die Abschiebung von Bosniaken, Türken, Gorani und Torbeschi wurde bereits Mitte 2004 wieder aufgenommen (UNMIK Draft Transition Paper 2006).

14 UNMIK Draft - Transition Paper 2006. 
abgelehnt (vgl. auch Lindemann, Zentrale Ausländerbehörde Düsseldorf). Letztlich kamen nur 20-25 Prozent der zunächst gelisteten Personen im Kosovo an, da entweder vor der Abschiebung noch rechtliche Einwände oder Krankheitsatteste vorgelegt wurden, oder die Personen untertauchten (Interview mit Lüthke: 29. April 2006, Lindemann 2006: 7).

Es ist schwer eine genaue Anzahl von abgeschobenen Aschkali und »Ägyptern« im Kosovo anzugeben. Nach Schätzungen des UNMIK Repatriation Adviser wurden seit der Wideraufnahme der Abschiebungen 2005 jährlich etwa 1.000 Aschkali und »Ägypter« in das Kosovo abgeschoben. ${ }^{15}$

\section{Assimilation in Deutschland}

Um zu verstehen, wie es den Jugendlichen nach ihrer Abschiebung im Kosovo ergangen ist, muss berücksichtigt werden, wie sie in Deutschland gelebt und sich assimiliert haben. Der Migrationssoziologe Hartmut Esser versteht unter Assimilation die Angleichung an einen »institutionellen und kulturellen Kern «, den eine jede nationalstaatlich definierte Aufnahmegesellschaft besitze. Dieser wirke auf die Migranten über alle Differenzen und Distanzen hinweg als eine Art unwiderstehliche zentripetale Kraft und zwinge sie, schon von den »objektiven" eigenen Interessen her, letztlich über die Generationen hinweg auf den Weg der Assimilation sich an diesen Kern kontinuierlich anzunähern (vgl. Esser 2004: 44). Esser unterscheidet vier Dimensionen einer individuellen Assimilation: Die kulturelle

15 Seit der Unabhängigkeit des Kosovos im Februar 2008 wurden nach Angaben des UNHCR in Berlin bis zum Jahresende 2008 aus Deutschland 661 Menschen in das Kosovo abgeschoben. Die Verringerung der Zahl hat vor allem mit einem neuen Gesetz für Geduldete in Deutschland (»Altfallregelung«) zu tun, nach dem Geduldete ein Aufenthaltsrecht erhalten, falls sie bis zum 31. Dezember 2009 ihre finanziellen Unabhängigkeit vom Staat vorweisen können. Allerdings ist seit der kosovarischen Unabhängigkeit die UNMIK nicht mehr für Abschiebungen zuständig, womit es seitdem keinerlei Kontrollinstanzen mehr gibt, die gegebenenfalls unzulässige Abschiebungen abhalten könnten. Die große Welle der Abschiebung von Roma aus Deutschland wird erst noch erwartet. 
Assimilation beziehe sich vor allem auf den Spracherwerb der Aufnahmegesellschaft. Strukturelle Assimilation sei hauptsächlich der Erwerb von Bildungsqualifikationen und die Platzierung auf dem Arbeitsmarkt. Unter sozialer Assimilation versteht Esser die Existenz von Kontakten zur einheimischen Bevölkerung und unter emotionaler Assimilation eine mehr oder weniger "milde« Identifikation mit den Verhältnissen im Aufnahmeland. Insgesamt wird die individuelle Assimilation damit als "Angleichung der sozialen Positionierung, der Eigenschaften und Verhaltensweisen an einen bestimmten Standard « verstanden (Esser 2004: 46).

Die Auswertung der Interviews ergab, dass alle Dimensionen der Assimilation für die interviewten Jugendlichen in Deutschland zutrafen. Alle Interviewten sprachen ein flüssiges, nur mit minimalen grammatikalischen Fehlern behaftetes Deutsch. In der Mehrzahl sprachen die Jugendlichen einen regionalen, vor allem schwäbischen Akzent. ${ }^{16}$ Die Jugendlichen gaben an, dass sie besser Deutsch als Albanisch sprächen. Albanisch schreiben konnte niemand. Nach Esser wäre damit die kulturelle Assimilation der Jugendlichen gegeben.

Die strukturelle Assimilation konnte ebenfalls für die befragten Jugendlichen nachgewiesen werden. Alle Jugendlichen gingen in Deutschland in die Schule, neun von 14 Interviewten waren zum Zeitpunkt ihrer Abschiebung Schüler/innen. Zehn von 14 Interviewten besuchten die Hauptschule, zwei die Realschule und eine Interviewte das Gymnasium. ${ }^{17}$ Fünf Personen hatten die Schule bereits beendet, von denen sich drei in Deutschland in einer Ausbildung (als Krankenschwester, Automechaniker und Friseurin) befanden und zwei erwerbstätig waren (Getränkelagerarbeiter und Kinokartenverkäufer). Auch wenn die strukturelle Assimilation vorrangig in »unteren« sozialen Schichten stattgefunden hatte, so waren dennoch alle Jugendlichen im Bildungssystem bzw. auf dem Arbeits-

16 Meist sprachen die Geschwister untereinander Deutsch und mit den Eltern einen Mix aus beiden Sprachen.

17 Damit wäre die Mehrzahl von einer weitergehenden Bildung ausgeschlossen gewesen und es ist anzunehmen, dass sie sich nach Beendigung der Schule in »untere« soziale Schichten eingegliedert hätten. 
markt integriert, was auch mit verstärkten Kontakten mit der einheimischen Bevölkerung einherging.

Hinsichtlich der sozialen Assimilation wurden die Jugendlichen befragt, mit wem sie den meisten Teil ihrer Freizeit verbrachten und wer ihre beste Freundin/ihr bester Freund in Deutschland war. Acht von 14 gaben an, dass sie in Deutschland den überwiegenden Teil ihrer Freizeit mit deutschen Freunden verbrachten, vier zu gleichen Teilen mit deutschen und ausländischen Freunden und zwei vor allem mit der Familie. ${ }^{18}$ Es war auffällig, dass die Mehrzahl der Jugendlichen nicht isoliert in Ausländerheimen in Deutschland wohnte. Oft lebten sie in kleineren Städten oder größeren Dörfern, so dass die Kontakthäufigkeit mit Deutschen relativ hoch war - auch schon allein aufgrund der geringen "Ausländerdichte" in diesen Gegenden. Wenn die meiste Zeit mit Deutschen verbracht wurde, ist es nahe liegend, dass auch deren Verhaltensweisen und Denkmuster durch "peer group« Sozialisation übernommen wurden.

Auch Essers vierte Dimension - die emotionale Assimilation schien bei den Befragten zuzutreffen, obwohl das Messen von Identifikation nie ganz eindeutig sein kann. Sicherlich wird durch den im Kosovo vorgefundenen extremen Kontrast das Zugehörigkeitsgefühl zu Deutschland massiv verstärkt, aber auch auf mich wirkten die Jugendlichen wie "Deutsche« im Kosovo. Immer wieder wurde betont, dass sie sich als Deutsche fühlten und sie nicht wüßten, was sie mit dem Kosovo verbinde. Nur drei der Interviewten konnten sich an die Zeit vor ihrem Weggang nach Deutschland erinnern. Sie waren damals nicht älter als sieben. Die Mehrzahl kam 1991/92 nach Deutschland im Alter von maximal zwei Jahren. Die Hälfte der Befragten gab an, dass sie sich vor ihrer Abschiebung nie für das Kosovo interessiert hätten, selbst wenn ihre Eltern davon erzählten. Häufig kam als Antwort auf diese Frage, »Ich wußte noch nicht mal, was das »Kosovo « überhaupt sein soll!«

Dieser Befund ist besonders wichtig, um zu verstehen, wie es den Jugendlichen nach ihrer Abschiebung im Kosovo ergangen ist. Wendet man die Kriterien von Esser auf die Assimila-

18 Einer der Befragten war zum Zeitpunkt der Befragung mit einer Deutschen verlobt. 
tion im Kosovo an, so ergibt sich - umgekehrt zur Lage der abgeschobenen Jugendlichen in Deutschland - auf Grundlage der vorliegenden Untersuchung für alle Dimensionen ein Defizit. Bei der Mehrzahl der Befragten (zehn von 14) bestand in der Sprache eines der Hauptprobleme, welches die soziale wie auch die strukturelle Assimilationsdimension negativ beeinflusste. Im Bildungssystem und auf dem Arbeitsmarkt waren - mit jeweils einer Ausnahme - die abgeschobenen Jugendlichen nicht integriert. Generell waren die Kontakte zur Mehrheitsgesellschaft äußerst selten. Was die emotionale Assimilation betrifft so ließ sich in der Untersuchung feststellen, dass selbst bei denjenigen, die am längsten im Kosovo lebten, die Identifikation mit Deutschland nach wie vor in starker Form gegeben war. Rabije, die bereits vor drei Jahren abgeschoben worden war und sich im Vergleich zu den anderen Befragten am aktivsten in ihrem Umfeld engagierte, erklärte ihre Situation wie folgt:

»Äußerlich gelte ich als angepasst. Ich kann mittlerweile halbwegs die Sprache, ich mache hier eine Polizeiausbildung und kenne relativ viele Leute, aber innerlich fühle ich mich hier überhaupt nicht zugehörig. Und das wird immer so bleiben. Ich bin anders als die Kosovaren - ich bin einfach eine Deutsche«(Vushtri/Vucitrn 1. Mai 2006).

Als Ergebnis der Prüfung dieser Assimilationskriterien ließ sich vorerst nur festhalten, dass die abgeschobenen Jugendlichen nicht in der Mehrheitsgesellschaft des Kosovos assimiliert waren.

\section{Integrationsbedingungen im Kosovo}

Die Ursachen für die Defizite hinsichtlich der Assimilationskriterien können nur erklärt werden, wenn die Strukturiertheit und die Bedingungen der Aufnahmegesellschaft berücksichtigt werden. Die Abschiebung in das Kosovo bedeutet für die Jugendlichen sowohl einen Ausschluss aus einer angestammten Gemeinschaft als auch ein »Hineingeworfensein « in eine ihnen fremde Nachkriegsgesellschaft. Seit 1999 gab es im Kosovo einen offiziell ausgehandelten Frieden, die Folgen des Krieges waren aber auch nach sieben Jahren weiterhin massiv spürbar. 
Gesellschaftliche Zerrüttung, eine lahm gelegte Wirtschaft, soziale Desintegration, politische Instabilität und Sicherheitsdefizite prägten die kosovarische Nachkriegsgesellschaft. Das Rechts-, Bildungs- und Gesundheitssystem funktionierte nur teilweise. Korruption war überall verbreitet. Die offizielle Arbeitslosigkeit lag im Kosovo zum Zeitpunkt der Untersuchung bei über 60 Prozent, mit Hinzurechnen der verdeckten Arbeitslosigkeit war von einer achtzigprozentigen Arbeitslosigkeit auszugehen (vgl. AWO 2005: 39).

Die Roma-Gemeinschaften befanden sich im Kosovo in einer doppelten Zwangslage: Zum einen bestand das Problem aktueller Diskriminierung und Benachteiligung als Minderheit, zum anderen verschärfte sich die strukturelle Benachteiligung mit der Abdrängung der Roma in die unteren sozialen Schichten unter allgemein verschlechterten wirtschaftlichen und politischen Bedingungen. ${ }^{19}$ In vielen Bereichen des täglichen Lebens waren Roma-Gemeinschaften auf eine Weise benachteiligt, die ihre Existenzgrundlage massiv gefährdet. Im Vergleich zur albanischen Mehrheit sind sie im Durchschnitt ärmer, wohnen schlechter und leben isolierter.

Nach einem Krieg entlang ethnischer Fronten bildeten diese auch weiterhin die wesentlichen Strukturmerkmale der Nachkriegsgesellschaft. Die im Krieg angewendete Gewalt verfestigte die ethnische Trennung; die Beziehungen zwischen der albanischen Mehrheit und den einst vertriebenen und noch immer bedrohten Aschkali und "Ägypter" waren maßgeblich von Misstrauen und Angst geprägt. Die Inkorporation in die albanische Mehrheitsgesellschaft war daher undenkbar.

Die Roma-Gemeinschaften lebten im Kosovo stark isoliert. Zehn der befragten Jugendlichen gaben an, dass sie gar keinen Kontakt zu Albanern hätten. Die Siedlungen und Häuser der Aschkali und »Ägypter« wurden zum Teil komplett zerstört und sind zum Großteil auch nicht wieder aufgebaut worden (vgl. SFH: 2006: 4). Auch wenn europäische Staaten in ihrer Si-

19 Der ökonomische und soziale Verelendungsprozess hat sich für die Mehrheit der Roma-Gemeinschaften vor allem als Folge des Krieges ergeben. Vor dem Krieg waren Roma-Gemeinschaften im Kosovo im Vergleich zu anderen Balkanregionen relativ wohlhabend (vgl. AWO 2005: 12). 
cherheits- und Gefährdungsanalyse für kosovarische Minderheiten von aktuellen Fortschritten ausgingen und eine Rückkehr von Flüchtlingen für vertretbar ansahen, konnte von einer stabilen Sicherheitslage nicht die Rede sein. Vier der interviewten Jugendlichen erlebten aufgrund ihrer frühen Abschiebung 2003 die gewaltsamen Unruhen im März 2004 mit. Bei zwei von ihnen wurde ihr Haus geplündert und anschließend niedergebrannt.

Auch wenn seitdem gravierende Übergriffe auf Minderheiten (Ermordungen, Körperverletzungen, Brandstiftungen) abgenommen haben, waren meist nicht gemeldete Bedrohungen, Beschimpfungen oder Diskriminierungen der Minderheiten noch immer alltäglich (SFH 2006). Auch die Jugendlichen wurden als "Zigeuner« beschimpft und ständig wurde ihnen vorgehalten: »Im Kosovo gibt es kein Platz für Zigeuner! « oder »Zigeuner haben mit den Serben kollaboriert!« (Bekim 2. Mai 2006 in Peja/Pec / Mohamed 1. Mai 2006 in Vushtri/Vucitrn). ${ }^{20}$

Eine der schwerwiegendsten Folgen der Abschiebung ist der mehrheitliche Schulabbruch unter den abgeschobenen Schulkindern. Damit war eine der wenigen Möglichkeiten zur Eingliederung in die kosovarische Gesellschaft verbaut und zugleich bedeutete dies eine enorme Einschränkung der persönlichen Zukunftsperspektiven. Die strukturellen Hindernisse für die schulische Wiedereingliederung lagen vor allem darin, dass die absolvierten Schuljahre in Deutschland nicht anerkannt wurden. Aufgrund von Sprach- und Schreibproblemen aber auch fehlendem Wissen in Schulfächern wie Geschichte oder Literatur hätten die abgeschobenen Schüler mehrere Klassen wiederholen müssen. Da von Seiten der Jugendlichen zum einen die Vorstellung, der Älteste in der Klasse zu sein, wenig attraktiv war und zum anderen die Notwendigkeit eines Schulabschlusses im Kosovo nicht gesehen wurde, gingen die Jugendlichen meist nicht wieder in die Schule. Ein weiterer Hinderungsgrund war auch die Angst vor Diskriminierungen und sozialer Ausgrenzung als Aschkali oder » ̈̈gypter«. Eine Interviewte verließ aus diesem Grund nach einem Monat wieder die

20 Die Kollaboration der Roma mit den Serben war 1999 ein Generalvorwurf, der als Vorwand für die ethnische Vertreibung von Roma diente. 
Schule, andere gingen deshalb erst gar nicht hin. Von Seiten der kosovarischen Behörden wurde kein Schulzwang für schulpflichtige Kinder durchgesetzt, so dass auch kein Handlungsdruck für die Betroffenen entstand. Für die Mädchen galt generell, dass ihre Eltern sie nur ungern aus dem Haus ließen, weil sie um ihre Sicherheit noch mehr besorgt waren als um die ihrer Söhne. Sechs von den neun ehemaligen Schülern wären sofort wieder in die Schule gegangen, wenn es eine deutsche Schule gegeben hätte. Von ihnen wurde aus Deutschland auch am meisten die Schule vermisst. ${ }^{21}$

Die berufliche Eingliederung war ebenfalls kaum möglich trotz der Qualifikation »Deutschkenntnisse «.22 Angesichts der allgemein hohen Arbeitslosigkeit im Kosovo schien auch eine zukünftige berufliche Integration eher unwahrscheinlich. Unabhängig von ihren mangelnden Albanischkenntnissen war den Roma-Gemeinschaften aufgrund von ethnischen Vorurteilen zusätzlich der Zugang zum Arbeitsmarkt weitestgehend versperrt. Die Arbeitslosenquote bei Roma-Gemeinschaften tendiert an vielen Orten des Kosovos gegen 100 Prozent (AWO 2005).

Doch gab es in der vorliegenden Untersuchung auch Beispiele von Kontakten zur Mehrheitsbevölkerung. Drei von den sechs männlichen Befragten gaben an, dass sie über Schule, Fußball und Moscheebesuche Kontakt zu Albanern aufgenommen haben. Interessant war im Zusammenhang mit den Moscheebesuchen, dass die Jugendlichen die Religion erst im Kosovo für sich entdeckten. Erklärt werden könnte dies zum einen damit, dass in einer schwierigen Situation oft eine Hinwendung

21 Dass die Abschiebung meist ein Ausstieg aus dem Schulleben bedeute, wurde auch von den UNMIK-Vertretern Lüthke und Halley bestätigt.

22 Deutschkenntnisse sollen aber in der südlichen kosovarischen Provinz Prizren von Bedeutung sein. Dies erzählte David Halley - Returns Cordinator in Pec/Peja. Dort sind seit 1999 deutsche Soldaten als KFOR stationiert. Deutschsprachige Abgeschobene können Kontakte zu ihnen herstellen, die wiederum von Vorteil sein können, wenn es um Übersetzerjobs geht. Gleiches gilt für Orte, in denen sich deutsche Organisationen, wie NGOs befinden. Deutschkenntnisse können dann einen privilegierten $\mathrm{Zu}$ gang dazu sicherstellen. 
zur Religion stattfindet, zum anderen aber auch, dass die Moscheen zu den wenigen öffentlichen Orten zählten, in denen ein ethnisch bedingungsloser Zutritt gewährt wurde. Gute Beziehungen zu Albanern könnten im Kosovo nicht nur einen Sicherheitsgewinn darstellen. Es könnten sich daraus andere Möglichkeiten ergeben, die in Form von Informationen über Arbeitsmöglichkeiten etc. von Vorteil für das weitere (Über-) Leben im Kosovo sein könnten. Jedoch wäre dafür eine relativ enge Beziehung notwendig, die zwischen Albanern und RomaGemeinschaften eher unüblich war oder gesellschaftlich nicht toleriert wurde. Möglicherweise würden sich aber dennoch für diese Jugendlichen über solche Kontakte bessere Zukunftsperspektiven erschließen.

\section{Einbindung in die Minderheitsgesellschaft}

Die Beschreibung entlang der Assimilationskriterien geben im Kosovo nur wieder, welche Defizite vorherrschen, ohne den Blick darauf $\mathrm{zu}$ richten, welche alternativen Entwicklungen stattfinden. Über den Ansatz des sozialen Kapitals ließ sich jedoch feststellen, dass zwar die Eingliederung in die Mehrheitsgesellschaft versperrt war, stattdessen aber eine Einbindung in die Minderheitengesellschaft erfolgte.

\section{"Man muss hier Leute kennen, sonst geht hier gar nichts."}

Da Abgeschobene meist ohne oder nur mit geringem finanziellen Kapital in das Kosovo gelangten, waren sie gezwungen, soziale Netzwerke (soziales Kapital) zu aktivieren, um auf seine Ressourcen zurückzugreifen. Trotz der Direktiven von UNMIK, dass für eine Abschiebung eine Unterkunft im Kosovo bereitstehen muss, wohnte nur die Hälfte der Befragten in ihrem eigenen Haus. Die andere Hälfte kam notdürftig bei entfernten Verwandten oder ehemaligen Nachbarn unter. In einem Fall musste eine Unterkunft angemietet werden, was mit Mietzahlungen einherging, die eine erhebliche finanzielle Bürde darstellten. 
Da Abschiebungen meist unvorbereitet durchgeführt wurden - oft kamen nachts Polizisten und gaben den Betroffenen nur eine halbe Stunde Zeit zum Packen bevor sie zum Flughafen gebracht wurden - kamen die Menschen mit sehr wenig Gepäck im Kosovo an. So waren in der Regel Abgeschobene bei ihrer Ankunft mittellos und extrem bedürftig (vgl. Interview mit Lüthke 29. April 2006 und Halley 2. Mai 2006). Nur ein Viertel der befragten Abgeschobenen konnte gespartes Geld mitnehmen. ${ }^{23}$ Sozialstaatliche Unterstützung wurde trotz rechtlichen Anspruchs keinem der Befragten von den kosovarischen Behörden bewilligt. Auch wurde abgeschobenen Flüchtlingen von Seiten internationaler Organisationen oder Nichtregierungsorganisationen keine Unterstützung gewährt (vgl. Lüthke 29. April 2006). Somit bedeutete Abschiebung in das Kosovo faktisch eine Abschiebung in die Armut. ${ }^{24}$

Unter diesen Umständen war die (Re)Aktivierung von sozialen Kontakten aus der erweiterten Familie oder der ethnischen Gruppe von überlebenswichtiger Bedeutung. Verwandte, ehemalige Freunde und Bekannte der Eltern unterstützen Neuangekommene mit anfänglicher Unterkunft, Gebrauchsgegenständen und Möbeln. Die Beziehungen der Eltern beschränkten sich im Wesentlichen auf die ethnische Minderheit. Bei einigen wurde angegeben, dass lokale Minderheiteninstitutionen vor allem bei administrativen Fragen behilflich waren. Die Einbettung in nachbarschaftliche Strukturen bedeutete zudem einen gewissen Schutz, bzw. vermeidet Aggressionen gegen Rückkehrer von außerhalb, was eine sehr wichtige Ressource in der Nachkriegsgesellschaft darstellte.

23 So gab es vor allem hinsichtlich der Wohnsituation unter den Abgeschobenen sichtbare Unterschiede, die auf mitgebrachtes Kapital und Immobilienbesitz zurückzuführen sind. Während die einen auf dem Boden schliefen und mindestens zu fünft ein Zimmer bewohnten, hatten andere mehr Raum zur Verfügung, schliefen auf Betten und verfügten über deutlich mehr Möbel.

24 Alle Befragten gaben an, dass selbst das nötige Geld für Brennholz im Winter nur unter enormen Schwierigkeiten aufzubringen war. In vier Fällen mussten bereits Winter ohne jegliche Heizung überstanden werden. Auch Arztbesuche konnten aufgrund von fehlendem finanziellen Kapital nicht unternommen werden. 
Mit dem Rückgriff auf die Familie oder die ethnische Gruppe zur sozialen Organisation des ökonomischen Handelns intensivierten sich die Solidarität aber auch die Verpflichtungen untereinander. Neuankömmlinge mussten ihre individuellen Bedürfnisse der Familie bzw. der ethnischen Gruppe unterordnen. Für die Mehrzahl der Jugendlichen war dies eine neue und schwierige Erfahrung, vor allem dann, wenn sie in Deutschland eigene Interessen oder Berufswünsche entwickelt hatten. Als Gegenleistung für Unterstützung aus der Minderheitsgesellschaft half die Mehrzahl der Abgeschobenen unentgeltlich im Haushalt der Unterstützer. Exemplarisch ist dafür die 15jährige Gyke aus Istok, die gegen ihren Willen nicht wieder in die Schule durfte und stattdessen sich um den Haushalt und die kleinen Kinder der Nachbarn kümmern musste, die der Familie von Gyke ihren ehemaligen Stall als Unterkunft zur Verfügung stellten.

Aufgrund der fast hundertprozentigen Arbeitslosigkeit in der Minderheitsgesellschaft entstanden in Orten mit einer größeren Zahl von Minderheitenangehörigen ethnische Strukturen der unentgeltlichen Arbeit. Dies traf vor allem im Fall von Vushtri/Vucitrn und Pec/Peja zu. In diese Strukturen integrierten sich auch die Abgeschobenen. Je nachdem, welche Fähigkeiten jemand mitbrachte, wurden diese angeboten und erbrachte Arbeiten mit Nahrungsmittel/Mahlzeiten oder anderen Gegenleistungen entlohnt. Innerhalb der Gemeinschaft wussten die Mitglieder untereinander, wer für bestimmte Arbeiten geeignet sein könnte. Das Zurückgreifen auf Familien oder ethnische Strukturen für verschiedene Unterstützungsformen nach der Ankunft führte offensichtlich bei Männern und Frauen zu verschiedenen Formen der Verpflichtungen, die dem traditionellen Rollenverständnis zwischen Männern und Frauen entsprachen: Während die Mädchen im Haushalt, beim Kinderhüten oder im Garten halfen, führten die Jungen meist physischen Arbeiten, wie Holzhacken oder Bauarbeiten, durch. Arbeitsmöglichkeiten gab es aber bei den Befragten eher unregelmäßig. Die Mehrzahl der Jugendlichen klagte über zuviel freie Zeit, die sie als langweilig und eintönig empfanden.

In einer Familie mussten die befragten Jugendlichen einer ihnen von Albanern zugeschriebenen »typischen« Roma-Arbeit nachgehen. Sie besteht darin, Sperrmüll in den Mülltonnen der 
Stadt zu sammeln und diesen zu verkaufen. Dieser Arbeitssektor schien tatsächlich ausschließlich von Mitgliedern der RomaGemeinschaften besetzt zu sein und bedeutete eine körperlich schwere, äußerst niedrig bezahlte und schlecht angesehene Arbeit. In gewisser Weise könnte dies als eine Art »ethnische Wirtschaft« betrachtet werden, bzw. als eine Ressource, die die ethnische Gemeinschaft bereithält. Von den anderen Abgeschobenen wurde diese Tätigkeit aber (noch) kategorisch abgelehnt, da dies als ein kompletter, für alle sichtbarer sozialer Abstieg angesehen wurde. Im Falle der in diesem Bereich tätigen Befragten, war die wirtschaftliche Situation dermaßen schwierig, dass ihnen wohl kaum eine andere Wahl zur Überlebenssicherung blieb.

Die Ausübung einer solchen Arbeit ging bei den Betroffenen einher mit Gefühlen des Verlusts der deutschen Identität und der sozialen Degradierung und der Scham. Jeglicher Stolz und der in Deutschland gewohnte Lebensstandard mussten abgelegt werden. »In Deutschland hätte ich nie gedacht, dass ich soweit sinken könnte. [...] Das bin nicht mehr ich, wie ich in Deutschland war...« (Emina 2. Mai 2006).

Integration bedeutet also für die Abgeschobenen die Eigliederung in eine diskriminierte und mehrheitlich verarmte Minderheit. Soziale Netzwerke schienen in der Untersuchungsgruppe durchaus vorhanden und absolut notwendig, allein die Qualität der Ressourcen, die diese bereithielten und die $\mathrm{Zu}$ gangsbedingungen $\mathrm{zu}$ öffentlichen Ressourcen, unterschieden sich von denen der Mehrheitsgesellschaft. Mit der Eingliederung kam es auch zu einer Konfrontation mit den Normen und Werten der Minderheitsgesellschaft

\section{„Bevor ich herkam, wusste ich gar nicht, dass ich Ägypter bin und was das heißen soll.»}

Ethnische Gruppen definieren sich jeweils über das Verhältnis oder im Gegensatz zur anderen ethnischen Gruppe. ${ }^{25}$ Auch die

25 Nach Fredrik Barth ist die ethnische Gruppe oder ethnische Identität nur in Beziehung zwischen Gruppen sinnvoll. Bei Ethnizität ginge es vor allem darum, wie verschiedene Gruppen sich voneinander abgrenzen und ihre Differenzen artikulieren (Barth 1969; vgl. auch Elwert 1989). 
Roma-Gemeinschaften im Kosovo hielten bestimmte Einstellungen und Verhaltensweisen gegenüber der albanischen Mehrheitsgesellschaft bereit, die sich die Abgeschobenen zu Eigen machen mussten: »Vor allem muss man sich unauffällig verhalten!« sagten sieben der abgeschobenen Jugendlichen.

$\mathrm{Da}$ in der Minderheitsgesellschaft Geschichten über albanische Verbrechen gegenüber Minderheiten kursierten, wurde auch eine bestimmte Einstellung gegenüber Albanern generiert. Die Distanz zu Albanern schien für abgeschobene Jugendliche vor allem erst vor Ort durch die Übernahme von Misstrauensmustern von Seiten der Minderheitsgesellschaft zu entstehen. Man sagte ihnen, dass von Albanern Gefahr ausgehe und ihnen nicht zu trauen sei. Von Seiten der Roma-Gemeinschaften wurde auch von den Abgeschobenen erwartet, dass sie keine Kontakte zu Albanern aufnehmen. Es ist also nicht nur die äußere Zuordnung durch die Mehrheitsgesellschaft zur Minderheit, die einen Prozess der ethnischen Identitätsformation fördern, sondern zugleich der Anpassungsdruck, der innerhalb der eigenen ethnisch definierten Gruppe ausgeübt wird. ${ }^{26}$

Gleichzeitig wird den Abgeschobenen von der eigenen ethnischen Gruppe vermittelt, dass sie als Mitglieder der RomaGemeinschaft in der albanischen Mehrheitsbevölkerung keine Chance hätten und das individuelle Bemühen in bestimmten Bereichen der Mehrheitsgesellschaft von vornherein vergeblich sei. Damit wurde eine negativ besetzte ethnische Identifikation hergestellt: »Wenn du Aschkali bist, hast du eh keine Chance, egal wie viel du drauf hast« (Visar 2. Mai 2006). Die anfänglichen Bemühungen, insbesondere der männlichen Befragten, eine Arbeit zu finden, wurden bald gänzlich aufgegeben. Auch wenn angesichts der tatsächlichen Diskriminierung von RomaGemeinschaften im Kosovo soziale Aufwärtsmobilität unwahrscheinlich erscheint, so reduziert eine solche Einstellung zusätzlich die Chancen auf individuellen Erfolg, da keine weiteren Versuche unternommen werden. Diese Abwehrhaltung hilft zwar Minderheitenmitgliedern, ihr eigenes Selbstwertgefühl

26 Drei der Befragten wussten vor ihrer Ankunft im Kosovo nicht, dass sie zu der ethnischen Gruppe der »Ägypter« gehören - dies lernten sie erst vor Ort. 
angesichts von Diskriminierungen von außen zu wahren, blockiert aber gleichzeitig ihre Chancen auf sozialen Aufstieg.

\section{"Wir sind einfach deutsch: \\ Wir verstehen die nicht, und die uns nicht."}

Im Zuge der Inkorporierung in die Minderheitsgesellschaft mit ihren Normen und Verpflichtungen wurde den Abgeschobenen - aber auch den anderen Minderheitenangehörigen - bewusst, dass sie aufgrund ihrer stark abweichenden, in Deutschland erfolgten Sozialisation, sich auch nicht zur eigenen Gruppe zugehörig fühlen konnten. Dies war besonders schwierig für die Jugendlichen. Das Normen- und Wertesystem und die Verhaltens- und Denkweisen entsprachen vielfach nicht ihren eigenen Erfahrungen. »Man hätte uns ebenso gut auch nach Afrika abschieben können, das wär' ungefähr das gleiche gewesen.«sagte Murat aus Vushtri/Vucitrn (1. Mai 2006).

Dabei zeigten sich deutliche Unterschiede zwischen den Erfahrungen der weiblichen und der männlichen Befragten. Die Aufforderung sich unauffällig zu verhalten war für die weiblichen Befragten schwieriger zu erfüllen als für die Jungen. Djamilija aus Vushtri/Vucitrn fasste es wie folgt zusammen:

»Aber wir können das nicht! Ich weiß auch nicht warum, aber jeder sieht uns an, dass wir nicht von hier sind. Nicht nur weil wir schlecht Albanisch sprechen. Die sehn' das irgendwie, vielleicht an unseren Sachen. Die finden uns eingebildet und arrogant, dabei sind wir so, wie wir in Deutschland auch waren. Und da waren wir ganz normal...« (1. Mai 2006).

Hier war insbesondere das selbstbewusste Auftreten von Mädchen gemeint. Das Kosovo gilt als eine patriarchiale Gesellschaft, in der Frauen eine untergeordnete Rolle spielen. Das gilt sowohl für die Albaner als auch für die Roma-Gesellschaft. Den abgeschobenen Mädchen wurde vorgehalten, sie wären »zu stolz und würden den Männern »zu offen entgegen treten «.27 Tatsächlich ergab die Befragung eine eindeutige Tendenz, dass

27 Man dürfe Männern nicht in die Augen schauen, meinten genervt die weiblichen Befragten, »sonst wird man hier gleich als »Schlampe« bezeichnet« (Gjy 1. Mai 2006). 
Mädchen mehr zu Hause bleiben mussten, während ihren männlichen Geschwistern mehr Freizügigkeit zugestanden wurde. Dies war für die Mehrzahl der weiblichen Interviewten eine neue Erfahrung, die als Ungerechtigkeit empfunden wurde und zur Isolation führte. Als Grund gaben sie an, dass sich die Eltern stärker um ihre Töchter sorgten, was vor allem Männerkontakte betraf - aber auch weil sie im Haushalt benötigt wurden und es gesellschaftlich von ihnen erwartet wurde, nicht so oft aus dem Haus zu gehen.

Im Kosovo, insbesondere in den Roma-Gemeinschaften ist es üblich, dass Frauen oftmals schon im Teenager-Alter verheiratet werden und Kinder bekommen. Dies wurde von den meisten Mädchen mit Unverständnis und Befremden aufgenommen. »Die können gar nicht das Leben genießen.", sagte Gyke aus Istok (3. Mai 2006).28

Von den weiblichen Befragten wurden die Männer im Kosovo als »Machos" beschrieben, die sich »alles rausnehmen" könnten. Oft stellten die Mädchen bei ihren Brüdern fest, dass diese es im Kosovo wesentlich einfacher hätten und sie zum Teil auch die traditionelle Rollenverteilung "genießen« würden.

Aber auch den männlichen Befragten, die über wesentlich mehr Kontakte verfügten, wurden Differenzen im Umgang mit Gleichaltrigen bewusst. Eine besondere Bedeutung hatten diesbezüglich kollektive historische Schlüsselerlebnisse des Kosovos, zu denen sie keinen Zugang fanden. Täglich waren sie mit Kriegserzählungen konfrontiert, mit denen sie nichts anfangen konnten. »Alle reden ständig darüber, aber ich weiß überhaupt nicht was das ist, Krieg!« sagte Bekim aus Vushtri. Von Seiten

28 In einem Fall wurde die Befragte von ihren Eltern verheiratet. Wahrscheinlich spielten dabei auch ökonomische Überlegungen eine Rolle, da die Familie besonders arm war. Für die Heirat der Tochter erhielt sie Geld von der Familie des Ehemanns. Für die Befragte selbst war es ein Desaster, da ihr Mann sie schlug und sich von ihr scheiden ließ, nachdem sie täglich Ohnmachtanfälle erlitten hatte. Ihre Rückkehr zur Familie galt in der »Ägypter«Gemeinschaft als ein Scheitern und Verlust ihrer weiblichen Ehre. Damit wurde sie - aber auch ihre Familie - von anderen gemieden, was deren soziales Kapital verminderte und sie damit auch von Unterstützungsleistungen einer solidarischen Gemeinschaft ausschloss. 
der Minderheit wiederum wurde ihnen oft diese fehlende Erfahrung als Defizit vorgeworfen. Oft wurden kosovarische Gleichaltrige von den Abgeschobenen als aggressiv und »kriegsgeschädigt" (Murat 1. Mai 2006) empfunden. "Man muss bei denen immer aufpassen, was man sagt, weil sie ganz plötzlich aggressiv werden können.« (Visar 2. Mai 2006).

Während den Mädchen ihre Andersartigkeit zum Vorwurf gemacht wurde, konnten die Jungen daraus auch einen Vorteil ziehen. Aufgrund ihres "Deutsch-seins « wurde ihnen auch Anerkennung von Gleichaltrigen entgegengebracht. Da Deutschland im Kosovo prinzipiell als bevorzugtes Migrationsziel gilt, wurde ihnen auch besonderes Interesse entgegengebracht. Oft galten sie als »Exemplare« der "modernen Welt», die es anzustreben galt.

Jedoch erschienen den abgeschobenen Jugendlichen aufgrund ihres »Deutsch-seins « kosovarische Arbeitsbedingungen und vor allem die Bezahlungen als unzureichend oder auch »unwürdig «: »Ich arbeite doch nicht über zehn Stunden für fünf Euro!« sagte Visar aus Pec/Peja (2. Mai 2006). Dies schien eine zusätzliche (anfängliche) Hürde bei der Suche nach Arbeit und gleichzeitig wurden sie dadurch von der eigenen Gruppe als "Snobs « und als »arrogant " stereotypisiert (»Die Deutschen sind sich zu gut für unsere Arbeiten«). Allerdings ist eine solche Einstellung gegenüber bestimmten Arbeiten im Kosovo nur dann aufrecht zu erhalten, solange das Überleben auf eine andere Art gesichert werden kann und Deutschland weiter als Bezugssystem gilt. Es war anzunehmen, dass eine solche Haltung nach einiger Zeit aufgegeben werden muss.

\section{Deutschlandorientierung}

Die ungünstigen sozialen und wirtschaftlichen Rahmenbedingungen im Kosovo, in die sie gegen ihren Willen hineingerieten, die Abwertung ihrer Erfahrungen und Kenntnisse aus Deutschland, das Bewusstwerden der Andersartigkeit und das Zurücknehmen der individuellen Bedürfnisse waren die Gründe dafür, dass alle interviewten Jugendlichen extrem unzufrieden mit ihrem Leben im Kosovo waren. Dies führte zu einer stark ausgeprägten Deutschlandorientierung. Eine solche 
Orientierung kann auch als Schutzmechanismus zur Wahrung ihres eigenen Selbstwertgefühls und als grundsätzliche Lebensperspektive verstanden werden. In der Befragung zeigte sich, dass die meisten ihre verlorene Heimat »Deutschland « stark idealisierten. Murat aus Vurshtri/Vucitrn meinte: »In Deutschland war der Himmel, im Kosovo ist die Hölle«. Da der Assimilationsgrad der Jugendlichen in Deutschland in der vorliegenden Untersuchung hoch war und Deutschland aufgrund des niedrigen Einreisealters als Bezugsobjekt übernommen wurde, wird ihre »Heimat« auch weiter Deutschland bleiben. ${ }^{29}$ Wenn es in den Haushalten Fernsehgeräte gab, liefen grundsätzlich nur deutsche Programme. Oftmals waren die Interviewten über Entwicklungen in Deutschland besser informiert als über aktuelle Ereignisse im Kosovo.

Die Kontakte nach Deutschland hatten neben einer emotionalen auch eine finanzielle Bedeutung. Alle Interviewten erhielten finanzielle Unterstützung von Verwandten und Bekannten aus Deutschland. Allerdings war der Betrag eher bescheiden, oftmals beliefen sich die finanziellen Unterstützungsleistungen auf 50 bis 100 Euro alle zwei bis drei Monate. Aber für die überwiegende Mehrzahl bedeutete diese Unterstützung die einzige Geldquelle im Kosovo. Die Pflege und Aufrechterhaltung dieser Beziehungen - und damit auch die Deutschlandorientierung - waren somit Teil einer ökonomischen Rationalität.

Ohne Ausnahme sahen alle Befragten ihre Zukunft in Deutschland. Als Rückkehrmöglichkeit nach Deutschland wurde vor allem bei den Mädchen, aber auch vereinzelt bei den Jungen, die Heirat mit einem/einer Deutschen oder mit einer Person mit deutschem Aufenthaltsrecht gesehen, auch Adoption wurde erwähnt. Insbesondere bei den jungen Mädchen birgt aber eine Heirat nach Deutschland, aufgrund ihrer verzweifelten Lage, auch die Gefahr der Ausbeutung. In zwei Fällen wurden von Bekannten in Deutschland Verlobungen vermittelt, ohne das auch nur einer in der Familie der Mädchen,

29 Obwohl Deutschkenntnisse im Kosovo überflüssig wurden, war es allen Befragten enorm wichtig, die Sprache nicht zu verlieren. Letztlich bedeutet die Sprache auch eine wichtige Ressource für eine Rückkehr. 
den zukünftigen Ehemann kennen gelernt hätte. Prinzipiell gilt aber für Abgeschobene eine fünfjährige Zutrittssperre für sämtliche Schengen-Staaten ${ }^{30}$. Eine legale Rückkehr ist daher meist nur ein fernes Ziel.

Solange aber Deutschland weiter als Bezugsrahmen behalten wird und die Hoffnung auf eine Rückkehr nach Deutschland besteht, scheint der Wille zur Integration im Kosovo kaum gegeben zu sein. Einer der Befragten brachte die Grundstimmung unter den Abgeschobenen auf den Punkt: »Ich kann und will das Kosovo nicht verstehen! Ich will einfach nur zurück!« (Murat 1. Mai 2006). Tatsächlich wirkten die meisten Abgeschobenen wie in einem Wartezustand. Langfristige Investitionen oder Bemühungen zum Überleben im Kosovo wurden nicht angestellt. Nur diejenigen, die unter besonders harten Bedingungen litten, mussten sich aktiver mit der Umwelt auseinandersetzen. Eine solche Verweigerungshaltung birgt aber die Gefahr, dass sich die Jugendlichen ihre Zukunftschancen verbauen und zwar insbesondere dann, wenn es ihnen nicht gelingt, das Kosovo wieder zu verlassen.

\section{Abschiebung als Sonderform der Migration}

Auch die Form der Migration hat einen Einfluss auf den Willen zur Integration. Im Falle einer Abschiebung handelt es sich nicht um eine eigene Entscheidung zur Rückkehr - sondern um eine erzwungene Migration.

Die Abschiebung wurde von der Mehrheit der Befragten als Trauma erlebt. Bei zwölf der Befragten wurde die Abschiebung unangemeldet in der Nacht durchgeführt. Sie erklärten, dass es sich um das schlimmste Erlebnis ihres Lebens gehandelt habe. In einer Familie stürzte sich die Schwester aus dem Fenster, in anderen fielen die Mütter in Ohnmacht oder bekamen einen Schwächeanfall. Als besonders erniedrigend wurde es empfunden, dass sie wie Verbrecher behandelt wurden, obwohl sie sich

30 Im Juni 2008 verabschiedete das Europaparlament die so genannte Rückführungsrichtlinie, in der das fünfjährige Wiedereinreiseverbot von Abgeschobenen für alle Schengenstaaten enthalten ist (vgl. www.europarl.europa.eu). 
nie etwas zu Schulden haben kommen lassen. Die Hälfte der Fälle wusste nach ihrer Ankunft im Kosovo nicht, wo sie hin sollten, da sie keine eigene Unterkunft hatte und irrte von einem Verwandten/Bekannten zum nächsten.

Es ist leicht nachzuvollziehen, dass diese Trauma-Erfahrung das Einleben in der neuen Heimat erschwert. Viele der Jugendlichen gaben an, dass sie nach ihrer Ankunft über einen längeren Zeitpunkt weder sprechen noch richtig essen konnten. Unter Umständen kann eine solch erzwungene Rückkehr lang anhaltende psychische Folgen haben. Auch bei den Jugendlichen konnte ein fehlender Lebensmut und mangelndes Selbstbewusstsein festgestellt werden. Zweimal kam die Äußerung, dass sie im Kosovo »keine Lust auf Leben« (Gyke 3. Mai 2006 und Visar 2. Mai 2006) hätten.

Im Unterschied zur freiwilligen Migration, die meist mit der Hoffnung und der Motivation unternommen wird, insbesondere den Kindern bessere Zukunftschancen zu ermöglichen, bedeutete hier die Abschiebung gerade im Gegenteil einen Verlust an Zukunftschancen. Ein damit zusammenhängender Umstand und Unterschied zur freiwilligen Migration war, dass die Mehrzahl der Eltern der befragten Jugendlichen den sozialen Abstieg aufgrund der Abschiebung nicht verkrafteten und ihnen die Kraft fehlte, den Schwierigkeiten im Kosovo zu begegnen. Resigniert und ratlos, oft an Depressionen oder anderen Krankheiten leidend, hielten die Eltern für ihre Kinder keine Lebensplanung mehr bereit und konnten ihnen damit keine Unterstützung zum Einleben in das Kosovo bieten. Zum Teil mussten die Kinder die Organisation des Überlebens im Kosovo übernehmen. Da freiwillige Migration meist in reiche und "moderne« OECD-Länder erfolgt, in denen die Gleichberechtigung der Geschlechter - zumindest vergleichsweise - weiter fortgeschritten ist, stellt schließlich die Abschiebung in eine eher traditionell patriarchiale Gesellschaft, besonders für die weiblichen Jugendlichen eine extrem schwierige Erfahrung des Freiheitsverlustes dar. Angesichts dieser Umstände ist anzunehmen, dass die "Heimatorientierung « im Fall einer Abschiebung wesentlich stärker ausgeprägt ist, als bei einer freiwilligen Migration und damit automatisch auch das Einleben in das Kosovo erschwert wird. 


\section{Fazit}

Aus der Feldforschung über abgeschobene Jugendliche aus Deutschland im Kosovo ergab sich das folgende Bild:

Die Abschiebung in das Kosovo bedeutete einen massiven sozialen Abstieg in eine verarmte Nachkriegsgesellschaft sowie eine Inkorporation in eine diskriminierte und bedrohte Minderheit. Von Albanern wurden abgeschobene Jugendliche den Roma zugeordnet, von Seiten der Roma-Gemeinschaften begegnete ihnen ein Anpassungsdruck, dem sie sich aufgrund ihrer Bedürftigkeit nach Schutz und Solidaritätsleistungen beugen mussten. Mit der Inkorporation in die Minderheitsgesellschaft wurden ihnen - wie auch umgekehrt den nicht Migrierten - Differenzen aufgrund ihrer in Deutschland erfolgten Sozialisierung bewusst. Wegen ihrer »anderen Art « begegnete man ihnen mit Vorurteilen und auch sie selbst fühlten sich fremd, orientierten sich weiter an Deutschland und warteten einzig auf eine Möglichkeit zur Rückkehr. Vor allem bei den Mädchen bedeutete die Abwertung der Normen aus Deutschland erhebliche Freiheitseinschränkungen, woraus sich unterschiedliche "Integrationsgeschichten « von Mädchen und Jungen ergaben.

Angesichts dieser Situation wäre sowohl für das Abschiebeland als auch für die UNMIK im Kosovo zu überlegen, ob die $\mathrm{Ab}$ schiebung - wenn überhaupt - nicht erst zu einem späteren Zeitpunkt durchgeführt werden sollte, wenn tatsächlich die allgemeinen Bedingungen für eine Rückkehr in das Kosovo gegeben sind. Die UNMIK selbst stellte vier Grundbedingungen für eine Rückkehr auf (UNMIK Revised Manual for Sustainable Return July 2006): Sicherheit und Bewegungsfreiheit; Zugang zu öffentlichen Einrichtungen/Diensten (Bildung, Gesundheit); Zugang zu Unterkunft und wirtschaftliche Überlebensfähigkeit sowie gleicher Zugang zu Arbeitsmöglichkeiten. Die Ergebnisse dieser Untersuchung ergaben, dass alle vier Grundbedingungen bisher nicht für die abgeschobenen Minderheitenangehörigen zutrafen.

Sowohl UNMIK als auch UNHCR warnen vor einer ungeregelten Massenrückkehr von Auslandsflüchtlingen aus Deutschland und Europa in den Kosovo, weil damit die längst noch nicht gelösten Inlandsprobleme vor allem in wirtschaftli- 
chen und sozialen Bereichen verstärkt und das Zusammenleben auch in den »Fortschrittsregionen " negativ belastet würden. Der Aufbau von Instrumenten und Strukturen im Kosovo, welche die mitgebrachten Potenziale (humankulturelles Kapital aus Deutschland) der Jugendlichen aus Deutschland auffangen würden, könnte für sie einen Integrationsanreiz darstellen und damit auch einen positiven Beitrag für das Kosovo leisten. Insbesondere Unterricht auf Deutsch würde den abgeschobenen Kindern (Kosovo-Albanern wie Roma-Angehörigen) einen Schulabschluss und damit bessere Zukunftsoptionen ermöglichen, zudem das Potenzial der Jugendlichen, wie ihre Deutschkenntnisse, nutzen und sie gleichzeitig aus der häuslichen und ethnischen Isolierung herausführen.

Für Deutschland aber gilt, die Abschiebepolitik im Falle der vorliegenden Untersuchungsgruppe zu überdenken. Deutschland sollte nicht die vereinbarten Standards unterlaufen und damit ein zusätzliches humanitäres Problem im Kosovo schaffen. Nach Informationen des »Internal Displacement Monitoring Centre« (IDMC) gibt es immer wieder Fälle von Abschiebung, die zu spät oder gar nicht der UNMIK gemeldet wurden, auch wurden Personen abgeschoben, obwohl die UNMIK fehlende Rückkehrbedingungen feststellte (IDMC 2006: 5).

Von Abschiebung und den Folgen sind nicht nur Menschen in Deutschland betroffen. Immer mehr westliche Staaten erklären sich nur noch bereit, zeitlich befristetes »Asyl« zu gewähren und beschränken generell den legalen Zutritt zu ihren Ländern gegenüber Drittstaatenangehörigen. In Europa lebten im Jahr 2005 zwischen 3 und 6 Millionen Menschen ohne legalen Aufenthaltsstatus (HWWI 2005), entweder weil sie bereits illegal eingereist sind oder ihre Aufenthaltserlaubnis im Laufe der Zeit verloren haben. Mit der neuen »europäischen Rückführungsrichtlinie", (im Juni 2008 vom Europaparlament verabschiedet), will man sich in Europa dem »Problem « verstärkt zuwenden indem Abschiebungen schneller und effektiver durchgeführt werden sollen. Dabei ist zu fragen, ob es sich bei diesen Menschen tatsächlich um ein "Problem « für Europa, und nicht vielmehr ein Problem für die Betroffenen selbst handelt, die als »illegal« kriminalisiert werden und von jeglichen Rechten ausgschlossen sind. Sicher ist aber, dass mit der Abschiebung vor allem für die Betroffenen ein zusätzliches und oft existen- 
tielles Problem ensteht, was die Ergebnisse dieser Arbeit zeigen.

\section{Literatur}

Arbeiterwohlfahrt AWO (Juli 2005): Aktuelle Bedingungen für Maßnahmen der freiwilligen Rückkehr und humanitären Reintegration von Flüchtlingen aus der Roma-Bevölkerung in den Kosovo. Einschätzungen, Ergebnisse und Schlussfolgerungen einer Informationsfahrt in den Kosovo vom 04. Juni 2005 bis zum 10. Juni 2005., Kreisverband Bremerhaven e.V. Heimatgarten: Situationsbericht, CD-ROM der AWO.

Barth, Frederik (1969): Ethnic Groups and Boundaries. The Social Organisation of Cultural Difference. Oslo: Scandinavian University Press

Bourdieu, Pierre (1983): »Der Habitus als Vermittlung zwischen Struktur und Praxis«. in: Ders.: Zur Soziologie der symbolischen Formen, 2. Aufl., Frankfurt/M: Suhrkamp Taschenbuch.

Elwert, Georg (1989): »Nationalismus und Ethnizität. Über die Bildung von Wir-Gruppen«. Kölner Zeitschrift für Soziologie und Sozialpsychologie, 41, S.440-464.

Esser, Hartmut (2004): »Welche Alternativen zur >Assimilation gibt es eigentlich?«. In: Klaus J. Bade/K.J. M. Bommes, (Hg.), Migration - Integration - Bildung. Grundfragen und Problembereiche, IMIS-Beiträge, Heft 23, Osnabrück: Eigenverlag IMIS, S. 41-59.

Gesellschaft für bedrohte Völker (GfbV)/Polansky (2005): Roma und Aschkali im Kosovo: Verfolgt, vertrieben, vergiftet. Ergebnisse einer Recherche vom Dezember 2004 bis Mai 2005.,http:/ / www.gfbv.de/inhaltsDok.php?id=477\&stayIns ideTree $=1 \&$ backlink=veroeffentlichungen_archiv_liste.php ?bereich $=2005,02.05 .2006$.

Helsinki Committee for Human Rights in Serbia/Biserko, Sonja (Hg.) (2003): Human Rights in the Shadow of Nationalism, Belgrade: Helsinki Committee for Human Rights.

HWWI (Hamburger Weltwirtschaftsinstitut) (2008): Database on irregular migration 2004-2006: Stocks of Irregular Foreign 
Residents in the EU25: http://irregular-migrationhwwi. net/2004-2006_Stocks_of. 5869.0.html, 02.07.2009.

Internal Displacement Monitoring Centre (IDMC) (30.06.2006):

Submission from the Internal Displacement Centre (IDMC) to the Human Rights Committee. Issues of concern and recommendations in relation to the report submitted by the United Nations Interim Administration Mission in Kosovo, (CCPR/C/UNK/1, 13 March 2006), http://www.ohchr. org/english/bodies/hrc/docs/ngos/IDMC.pdf, 10.07.2006.

Lindemann, M., (2006): Möglichkeiten zur Beseitigung von Rückführungshindernissen im Rahmen der Klärung der Identität der Zurückzuführenden und der Passersatzbeschaffung, Zentrale Ausländerbehörde Düsseldorf (unveröffentlichtes Dokument).

Nee, Victor/Sander, Jimy (2001): »Understanding the diversity of immigrant incorporation: A forms-of-Capital-Model «. Ethnic and Racial Studies, Vol. 24, Nr. 3, S. 386-411.

Portes, Alejandro/Zhou, Min (1993): »The New Second Generation: Segmented Assimilation and Its Variants«. Annals of the American Academy of Political and Social Science, Vol. 530, Interminority Affairs in the U. S.: Pluralism at the Crossroads (Nov., 1993), S. 74-96.

SFH (Schweizerische Flüchtlingshilfe)/Mattern, Reinhard (2006): Zur Lage der Roma in Kosovo, Gutachten der SFHLänderanalyse,http://www.fluechtlingshilfe.ch/herkunfts laender/europe/kosovo, 27.07.2009.

UNHCR (United Nation High Commissioner for Refugees) (Januar 2003): Update on the Situation of Roma, Ashkaelia, Bosniak and Gorani in Kosovo, UNHCR Kosovo. http:// www.unhcr.ch/cgibin/texis/vtx/rsd/rsddocview.pdf?CAT EGORY=RSDLEGAL\&id=3e2d52934, 24.05.2006.

UNHCR (2005): Strategy Paper, Operation in Serbia and Montenero, http://www.unhcr.org/cgibin/texis/vtx/publ/ opendoc.pdf?tbl=PUBL\&id=4371d1ac0, 02.04.2005.

UNMIK (UN Interim Administration Mission in Kosovo) 2006: Draft - Transition Paper (unveröffentlichtes Dokument).

UNMIK 2006: Revised Manual for Sustainable Return, http:// www.unmikonline.org/srsg/orc/documents/manual_ENG .pdf, S. 8, 06.07.2006. 


\section{Experteninterviews:}

Halley, David J. UNMIK Returns Coordinator Pec/Peja, Interview am 3. Mai 2006 in Pec/Peja.

Lüthke, Karsten UNMIK Repatriation Adviser Prishtina, Interview am 29. April 2006 in Prishtina. 



\section{Autorinnen und Autoren}

Katja Baltzer, geb. 1978, ist Sozialwissenschaftlerin und begleitete 2004 im Rahmen eines Forschungspraktikums die Flüchtlingsarbeit des UNHCR in der ecuadorianischen Stadt Ibarra. Nachdem sie im vergangenen Jahr für den deutschen Entwicklungsdienst DED in Honduras tätig war, lebt und arbeitet sie heute in Hamburg.

Didier Bigo ist Professor für Internationale Beziehungen an der Sciences-Po Paris, Forscher am CERI/FNSP und derzeit für drei Jahre Gastprofessor am King's College in London am Institute for War Studies. Er ist zudem Direktor des Center d'études sur les conflits - C\&C, Herausgeber der Zeitschrift »Alternatives« (Lynne Rienner Verlag) und Mitherausgeber der neuen ISA Zeitschrift »Internationale Politische Soziologie«(Blackwell Verlag). Didier Bigo arbeitet an kritischen Ansätzen zu Sicherheit in Europa und der Beziehung zwischen interner und externer Sicherheit, sowie zur Soziologie der Überwachung und Kontrolle. Er analysiert die Beziehungen und Spannungen zwischen Politik, Soziologie und internationale Beziehungen. Für das Libe Komitee des europäischen Parlaments ist er Experte zu Sicherheitsfragen. Zuletzt veröffentlichte er zusammen mit L. Bonelli und T. Deltombes Au nom du 11 Septembre, les démocraties à l'épreuve de l'antiterrorisme, (Paris, La découverte, 2008). 
Felix Gerdes, geb. 1975, ist Diplom-Politologe und Mitarbeiter der Forschungsstelle Kriege, Rüstung und Entwicklung der Universität Hamburg. Zu seinen Arbeitsschwerpunkten zählen Konflikte und Friedensbildung in Westafrika, Militarisierung von Flüchtlingen und afrikanische Migration.

Pénélope Larzillière lebt in Paris und arbeitet am Institut de Recherche pour le Développement (IRD) im Bereich Soziologie zum Thema politisches Engagement im Nahen Osten, wo sie jedes Jahr mehrere Monate zur Feldforschung verbringt. Sie veröffentlichte bereits ihre Dissertation »être jeune en Palestine" und schrieb mehrere Artikel zu den Themen Islamismus und Nationalismus in Palästina und Jordanien, Selbstmordattentäter in Palästina und in Tschetschenien sowie zu Ideologie und Engagement in Jordanien.

Kristofer Lengert, geb. 1977, ist Politologe und Mitarbeiter des Informationsbüros Nicaragua in Wuppertal. Er arbeitet zu politischen und sozio-ökonomischen Entwicklungen in Lateinamerika. Bis Ende 2008 war er im Rahmen eines einjährigen Arbeitseinsatzes für ein Menschenrechtsprojekt in Kolumbien und veröffentlichte eine Reihe journalistischer und sozialwissenschaftlicher Arbeiten zum Thema »Menschenrechte im Kontext des bewaffneten Konfliktes«.

Mahmood Mamdani, geb. 1947 in Uganda, lehrte an verschiedenen afrikanischen und amerikanischen Universitäten und ist derzeit Herbert Lehman Professor an der Fakultät für Anthropologie und Politikwissenschaft an der Columbia Universität in New York. Mamdani gilt als Experte für Afrikanische Geschichte, Politik und Internationale Beziehungen. Seine wohl bekanntesten Bücher sind »When victims become killers: Colonialism, Nativism and the Genocide in Rwanda " und "Good Muslim and Bad Muslim: America, the Cold War and the Roots of Terror«. Sein Buch »Citizen and Subject: Contemporary Africa and the Legacy of Late Colonialism « (1996) gilt als eines der besten, auf Englisch publizierten, wissenschaftlichen Arbeiten über Afrika und gewann dafür den renommierten Herskovits Award der African Studies Association in den USA (1998). 
Margarete Misselwitz, geb. 1977, ist Diplom Sozialwissenschaftlerin und absolvierte einen zusätzlichen Master of Peace and Security Studies am Institute für Friedensforschung und Sicherheitspolitik in Hamburg. Von 2003 bis 2005 studierte sie in Belgrad und drehte dort zusammen mit Anne Misselwitz den Film »Belgrad Backspin « (2005) über abgeschobene Roma aus Deutschland in Belgrad. Zurzeit lebt sie in Berlin und arbeitet sowohl wissenschaftlich als auch journalistisch und filmisch insbesondere zu den Themen Balkan, Migration, Abschiebung und EU-Außengrenzen.

Philipp Misselwitz, geb. 1974, ist Architekt und Stadtforscher und lebt derzeit in Istanbul. Er studierte an der Universität Cambridge und der Architectural Association in London und lehrte an der London Metropolitan University und der Universität der Künste Berlin. In zahlreichen Forschungsprojekten beschäftigte er sich mit der Wechselbeziehung von Formalität und Informalität in der Stadtplanung, sowie mit Konflikten im Stadtraum. Seit 2005 leitete er als Mitarbeiter der Universität Stuttgart ein Forschungsprojekt für die UN zu urbanisierten Flüchtlingslagern in Nahost und promovierte zum gleichen Thema (2009). Für die UN verfasste er ein Handbuch für partizipative Neuplanung von palästinensischen Flüchtlingslagern. Weitere Veröffentlichungen: "City of Collision - Jerusalem and the Principles of Conflict Urbanism« (mit Tim Rieniets (2006)).

Katrin Radtke, geb. 1975, lebt in Bonn und Berlin und arbeitet bei der Welthungerhilfe als Referentin für Entwicklungspolitik und Humanitäre Hilfe. Sie veröffentlichte bereits mehrere Arbeiten im Bereich Internationale Beziehungen und Entwicklungspolitik, insbesondere zu transnationaler Solidarität, Migration, Bürgerkriegsökonomien und der Mikropolitik bewaffneter Gruppen. Im Jahr 2009 erschien die Monographie »Mobilisierung der Diaspora - Die moralische Ökonomie der Bürgerkriege in Sri Lanka und Eritrea«.

Klaus Schlichte ist Professor für Politikwissenschaft an der Otto-von-Guericke-Universität Magdeburg. Zu Forschungs- und Lehraufenthalten war er in Frankreich, Senegal, Mali, Liberia, USA, Uganda, Serbien und Kirgistan. Zu seinen wichtigsten 
Veröffentlichungen zählen »In the Shadow of Violence. The politics of armed groups « (Chicago 2009); »Der Staat in der Weltgesellschaft. Politische Herrschaft in Afrika, Asien und Lateinamerika«, (Frankfurt a.M. 2005) und "Strukturgeschichte internationaler Beziehungen. Staat und internationales System nach dem Westfälischen Frieden« (Mit-Hg., Opladen 2000). 


\section{Global Studies}
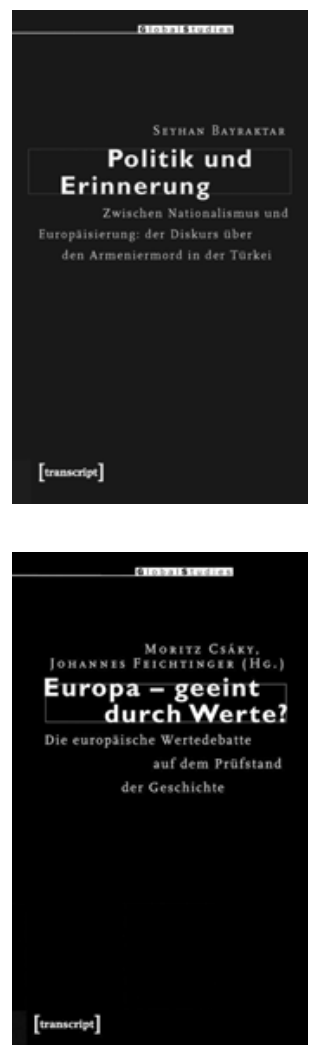

Satirin fatili |lip.|

Komplotte, Ketzer und Konspirationen

Lur Logik des

Verschwörungsdenkens

Inispite aแs

ten Heter Istu
Seyhan BAyraktar

Politik und Erinnerung

Zwischen Nationalismus und

Europäisierung: der Diskurs über den Armeniermord in der Türkei

Februar 20I0, ca. 316 Seiten, kart., ca. 29,80€, ISBN 978-3-8376-I312-4

Moritz CsÁKY, Johannes Feichtinger (Hg.) Europa - geeint durch Werte? Die europäische Wertedebatte auf dem Prüfstand der Geschichte

2007, 218 Seiten, kart., 24,80€, ISBN 978-3-89942-785-I

Schirin Fathi (Hg.)

Komplotte, Ketzer und Konspirationen Zur Logik des Verschwörungsdenkens Beispiele aus dem Nahen Osten

Februar 2010, ca. 360 Seiten,

kart., ca. $29,80 €$,

ISBN 978-3-8376-I34I-4 


\section{Global Studies}
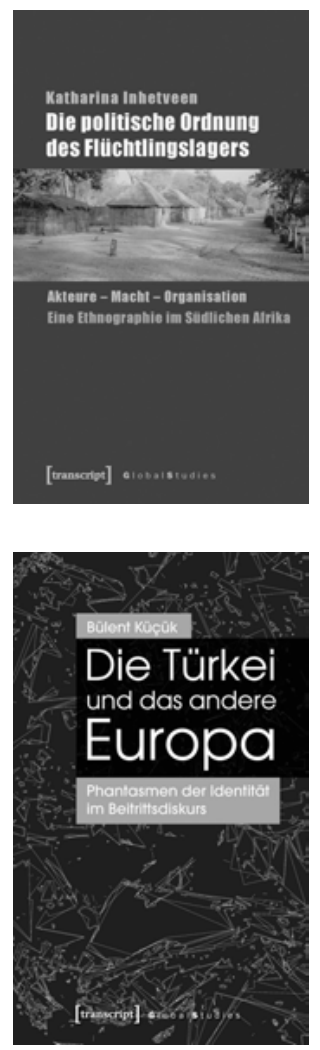

Stefan tuft.

Peter Sebinany (Hg.)

Integration

von Zuwanderern

Erfahrungen, Konzepte,

Perspektiven
Katharina In Hetveen

Die politische Ordnung des Flüchtlingslagers

Akteure - Macht - Organisation.

Eine Ethnographie im Südlichen Afrika

Mai 20IO, ca. 500 Seiten,

kart., zahlr. Abb., ca. $39,80 €$,

ISBN 978-3-8376-I378-0

\section{BÜLENT KÜÇÜK}

Die Türkei und das andere Europa

Phantasmen der Identität

im Beitrittsdiskurs

2008, 236 Seiten, kart., zahlr. Abb., 25,80€, ISBN 978-3-8376-IOI2-3

Stefan Luft, Peter Schimany (Hg.) Integration von Zuwanderern Erfahrungen, Konzepte, Perspektiven

April 2010, ca. 202 Seiten, kart., ca. $24,80 €$, ISBN 978-3-8376-I438-I 


\section{Global Studies}

Luise Althanns

\section{McLenin}

Die Konsumrevolution

in Russland

Dezember 2009, 296 Seiten, kart., zahlr. z.T. farb. Abb., 29,80€,

ISBN 978-3-8376-I254-7

Friedrich ARndT,

Carmen Dege,

Christian Ellermann,

MaXimilian Mayer,

David Teller,

Lisbeth Zimmermann (Hg.)

Ordnungen im Wandel

Globale und lokale

Wirklichkeiten im Spiegel

transdisziplinärer Analysen

2008, 386 Seiten, kart., 30,80€,

ISBN 978-3-89942-783-7

InES BRAUnE

Aneignungen des Globalen

Internet-Alltag in der

arabischen Welt.

Eine Fallstudie

in Marokko

2008, 262 Seiten, kart., 26,80€,

ISBN 978-3-89942-97I-8

Claas Christophersen

Kritik der transnationalen Gewalt

Souveränität, Menschenrechte und Demokratie im Übergang zur Weltgesellschaft

Oktober 2009, 282 Seiten,

kart., 29,80 €,

ISBN 978-3-8376-I288-2

Georg Glasze

\section{Politische Räume}

Die diskursive Konstitution

eines »geokulturellen Raums« -

die Frankophonie

Februar 2010, ca. 256 Seiten,

kart., ca. $27,80 €$,

ISBN 978-3-8376-I232-5
Anne KarRass

Die EU und der Rückzug

des Staates

Eine Genealogie der

Neoliberalisierung der

europäischen Integration

Januar 2009, 280 Seiten,

kart., $28,80 €$,

ISBN 978-3-8376-1067-3

WiebKe KeIM

Vermessene Disziplin

Zum konterhegemonialen

Potential afrikanischer und

lateinamerikanischer Soziologien

2008, 564 Seiten, kart., $35,80 €$,

ISBN 978-3-89942-838-4

Peter LindNeR

Der Kolchoz-Archipel im

Privatisierungsprozess

Wege und Umwege der russischen Landwirtschaft

in die globale Marktgesellschaft 2008, 282 Seiten, kart., 27,80€, ISBN 978-3-89942-784-4

BORIS MICHEL

Global City als Projekt

Neoliberale Urbanisierung

und Politiken der Exklusion

in Metro Manila

Februar 20Io, ca. 370 Seiten,

kart., zahlr. Abb., ca. 33,80 €,

ISBN 978-3-8376-I334-6

Jan Pospisil

Die Entwicklung von Sicherheit

Entwicklungspolitische

Programme der USA und

Deutschlands im Grenzbereich zur Sicherheitspolitik

Juli 2009, 442 Seiten, kart., zahlr. Abb., 39,80 €,

ISBN 978-3-8376--1077-2 
